\title{
RESPOSTAS DA ALFAFA (Medicago sativa L.) A FONTES DE FÓSFORO E MOMENTO DE CALAGEM
}

\author{
PATRÍCIA SARMENTO \\ Zootecnista
}

Orientador: Prof. Dr. MOACYR CORSI

\begin{abstract}
Dissertação apresentaaa a Escola superior de Agricultura "Luiz de Queiroz", Universidade de São Paulo, para obtenção do titulo de Mestre em Agronomia, Área de Concentração: Ciência Animal e Pastagens.
\end{abstract}

\section{PIRACICABA}

Estado de São Paulo - Brasil

Fevereiro - 2000 


\section{ERRATA}

1 - Na página 2, o penúltimo parágrafo não existe.

2 - Página 18, Quadro 2, onde se lê: "Resultados de análises de micronutrientes do solo usado nos vasos para o cultivo da alfafa usado nos vasos para o cultivo da alfafa", lê-se: "Resultados de análises de micronutrientes do solo usado nos vasos para o cultivo da alfafa".

3 - Página 22, quarto parágrafo, primeira linha, onde se lê: "Os adubos (calcário, superfosfato triplo...", lê-se "Os fertilizantes e corretivos (calcário, superfosfato triplo...".

4 - Página 23, segundo parágrafo, segunda linha, onde se lê: "Quando se utilizou de gesso junto ao fosfato, a dose de calcário foi $2 / 3$ do recomendado para elevar a saturação por bases a $80 \%$ ", lê-se: "Quando se utilizou de gesso junto ao fosfato, a dose de calcário foi $2 / 3$ da quantidade de $\mathrm{Ca}$ recomendada para elevar a saturação por bases a $80 \% "$.

5 - Página 46, quarto parágrafo, quarta linha, onde se lê: “... (ao redor de $11 \mathrm{mg} \mathrm{P} \mathrm{dm}^{-3 *}$ )

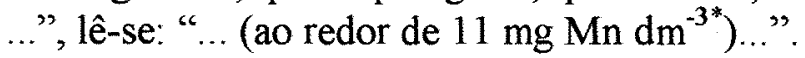

6 - Página 53, a quinta linha dessa página não existe.

7 - Página 58, segundo parágrafo, primeira linha, onde se lê: "Após a germinação, a primeira...", lê-se: "Após a emergência, a primeira ...".

8 - Página 60, Figura 9, onde se lê: "(A) Seqüência da germinação da semente da alfafa...", lê-se: "(A) Seqüência da germinação e emergência da semente da alfafa...". 


\title{
Dados Internacionas: de Catalogação na Publicação (CIP) DIVISĀo DE BIBLIOTECA E DOCUMENTAÇĀO - Campus "Luiz de Queiroz"/USP
}

\author{
Sarmento, Patricia \\ Respostas da alfafa (Medicago sativa L.) a fontes de fósforo e momento de \\ calagem / Patrícia Sarmento. - - Piracicaba, 2000. \\ $146 \mathrm{p}$. \\ Dissertação (mestrado) - Escola Superior de Agricultura Luiz de Queiroz, 2000. \\ Bibliografia. \\ 1. Adubação fosfatada 2. Alfafa 3. Calagem 4. Fertilizante fosfatado 5. Fósforo \\ 6. Leguminosa forrageira I. Titulo
}

CDD 633.31

"Permitida a cópia total ou parcial deste documento, desde que citada a fonte - 0 autor" 


\section{Dedico}

Ao meu pai Custódio Sarmento (in memorian),

à minha mãe Lourdes, ao meu irmão Rogério, à minha cunhada Renata e aos sobrinhos Ricardo e Raquel

Ao meu noivo e melhor amigo, Fábio Prudêncio de Campos, que enorme ajuda ofereceu-me nesse período de Pós graduação. 


\section{AGRADECIMENTOS}

- A Deus, sem o qual nada seria possível;

- A meu pai, a sua luta, dando-me todas as condições para que chegasse até aqui, sempre com seu exemplo de honestidade e perseverança;

- À minha mãe, o apoio e enorme paciência durante meus trabalhos de Mestrado;

- Ao meu noivo, Fábio Prudêncio de Campos, a paciência, amizade e carinho, os conselhos, as várias sugestões na elaboração do experimento, assim como na sua condução e discussão. Agradeço os momentos em que deixou seus afazeres para não me deixar trabalhando só nas noites frias em uma estufa. Obrigada por estar ao meu lado, com todo seu otimismo e equilibrio, nos momentos mais difíceis que passei até então. Agradeço por entrar em minha vida, pois foi a melhor coisa que me aconteceu nesse período;

- Ao Prof. Dr. Moacyr Corsi, a sua orientação, o seu incentivo, sua confiança e auxilio em dificuldades que encontrei durante o período de Pós-graduação;

- À CAPES, a bolsa de Mestrado, e à FAPESP o financiamento da presente pesquisa;

- Ao Prof. Dr. Joaquim Werner, a simpatia e sugestões oferecidas;

- Ao Prof. Dr. Godofredo Vitti, as sugestões sobre os tratamentos da minha pesquisa;

- Ao Prof. Dr. Oto Crocomo, chefe do CEBTEC, por ter cedido a estufa para a realização do experimento; e aos funcionários Ênio e Romeu o auxílio prestado;

- Ao Departamento de Produção Vegetal, a concessão da autoclava e o axílio no processo de esterilização do solo;

- Aos Professores Drs. Sila Carneiro da Silva e Carlos G. S. Pedreira, a concessão do Laboratório de Plantas Forrageiras e equipamentos;

- À Profa. Dra. Siu Tsai, Professora do CENA/USP, a importantes informações;

- Aos colegas de curso: Cláudia Sucupira, Soraia Vanessa, Isabel, Sônia, Michelle Costa, Tereza, Patrícia Pauletti, Moema Bueno, Andréia, Mônica, Oswaldo, Jailson, Carlinha, Aparecido, Alsester, Narcísio, Felipe, Vicente e Edson, a amizade durante o tempo de convivência;

- Aos colegas João Batista e Reinaldo, os esclarecimentos sobre a instalação do experimento;

- Aos colegas Adonês Moreira e Patrícia P. A. Oliveira (Morango), as valiosas informaçōes e sugestões para a realização do projeto;

- Ao Wladecir Oliveira, a doação das sementes de alfafa (P. XAI 32) e fornecimento do Rhizobium;

- À Empresa de sementes PIRAÍ Ltda., a doação das sementes de alfafa (cultivar Crioula);

- À Creide Martins, secretária do Dep. de Zootecnia, a simpatia e auxilio prestados em serviços burocráticos; 
- Ao laboratorista Carlos César Alves, o apoio nos trabalhos realizados no Laboratório;

- À Marise, da Clínica do Dep. de Fitopatologia, a boa vontade e serviços prestados;

- À Renata Maschietto, a grande amizade e principalmente o seu apoio num momento muito dificil de minha vida;

- À Roberta Carnevalli, a grande amizade, as longas conversas, as sugestões e informações importantes sobre o trabalho realizado;

- Ao estagiário Adriano Valentin, a amizade e a responsabilidade com que auxiliou-me na condução do experimento;

- Ao colega Carlos Giaveno, a amizade e o fornecimento de materiais de estudo;

- Ao Prof. Dr. Francisco Antônio Monteiro, a simpatia, atenção, boa vontade, empréstimo de literatura, os importantes ensinamentos e a possibilidade de realizar experimento adicional sobre efeito de Mn na alfafa, ampliando meus conhecimentos;

- Ao Prof. Dr. Quirino Carmelo, principalmente, a simpatia, como também o fornecimento dos micronutrientes utilizados no trabalho. Muitas vezes estamos mais necessitados de um sorriso ou de um gesto de consideração do que qualquer outra coisa...

- À Laura Bruno, Giselle A. M. Soares e Carlos I. A. Vildoso que considero verdadeiros amigos;

- Ao amigo Carlos I. A. Vildoso, as fotos de sintoma nutricional das plantas;

- Aos estagiários orientados pelo Prof. Dr. Francisco Antônio Monteiro: Renata Rodrigues Vidal, Israel Benetti, Pelerson Furlan, José Lavres Junior e Sérgio que participaram efetivamente do experimento com alfafa submetido a crescentes niveis de $\mathrm{Mn}$, mencionado na presente Dissertação. 


\section{- SUMÁRIO}

Página

LISTA DE ABREVIATURAS ....................................................... vii

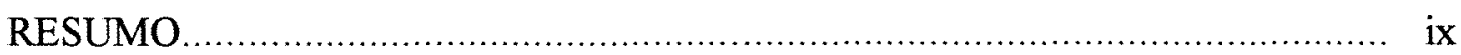

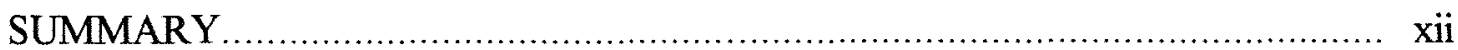

1 INTRODUÇÃO

2 REVISÃO DE LITERATURA..................................................... 3

2.1 Importância do fósforo para a alfafa............................................... 3

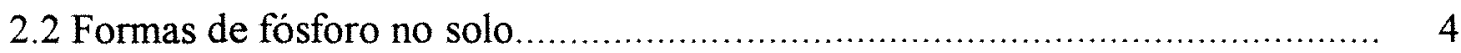

2.3 Métodos de aplicação e disponibilidade do fósforo no solo, utilizando fontes solúveis.

2.4 Métodos de aplicação e disponibilidade do fósforo no solo, utilizando fosfato de rocha.

2.5 Utilização do fosfato de Gafsa.................................................... 7

2.6 Disponibilidade do fosfato de Gafsa ............................................. 10

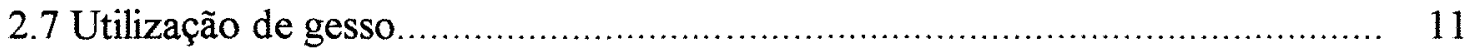

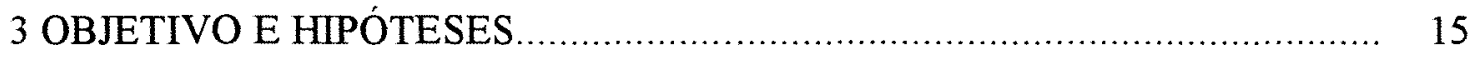

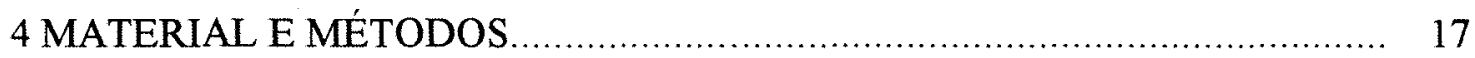

4.1 Local e características do solo ....................................................... 17

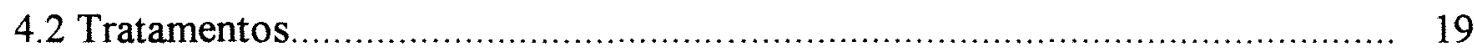

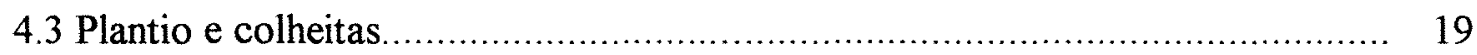

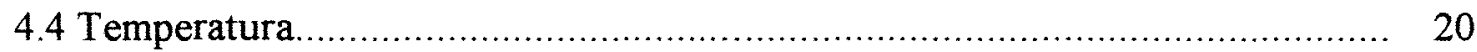

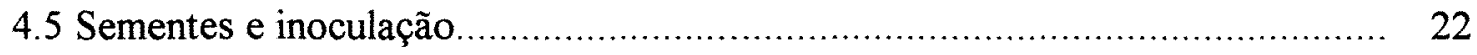

4.6 Irrigação e manutenção da umidade ................................................. 22

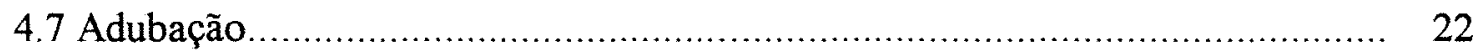

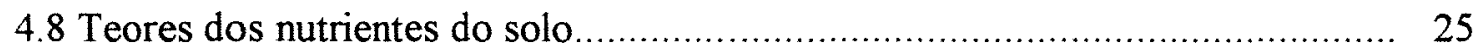

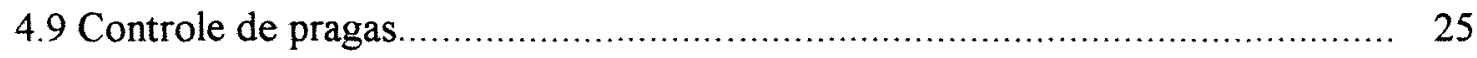

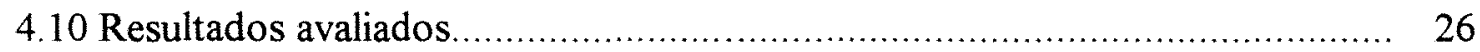


4.11 Determinação do teor de fósforo no solo de macronutrientes da planta......... 26

4.12 Índice de eficiência agronômica................................................... 27

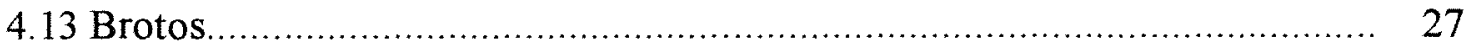

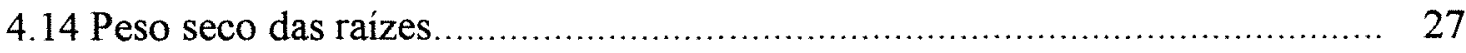

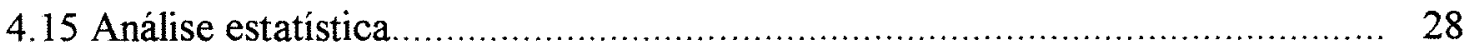

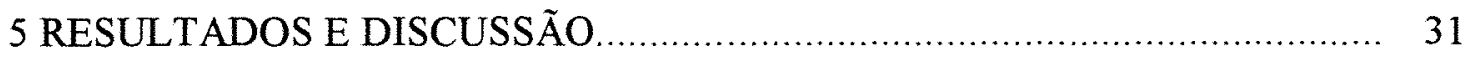

5.1 Produção de matéria seca da parte aérea da alfafa.............................. 31

5.2 Produção de matéria seca das raizes de alfafa...................................... 41

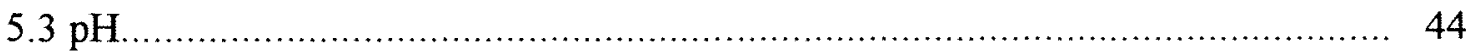

5.4 Concentração de fósforo no solo ................................................ 49

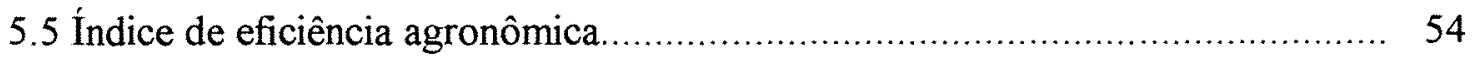

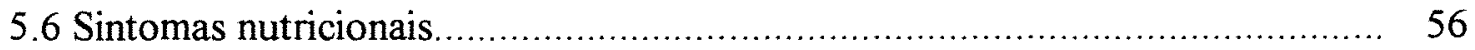

5.7 Dinâmica do surgimento de brotos................................................ 58

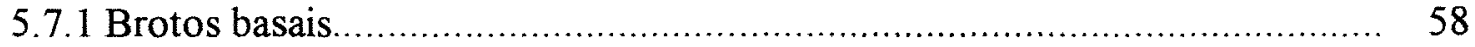

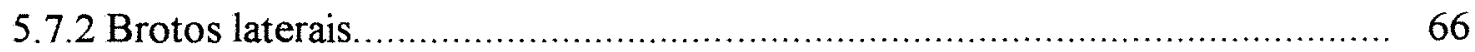

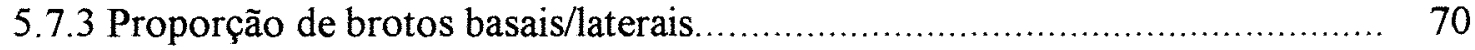

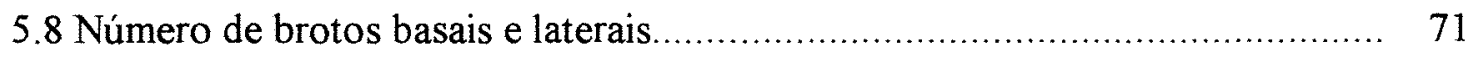

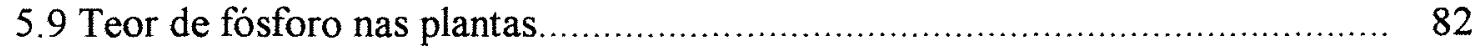

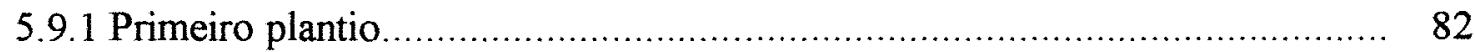

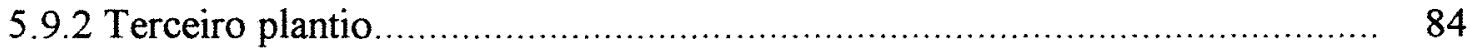

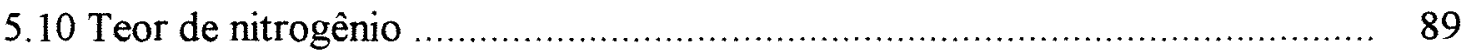

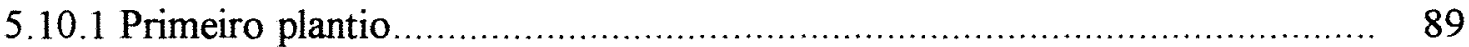

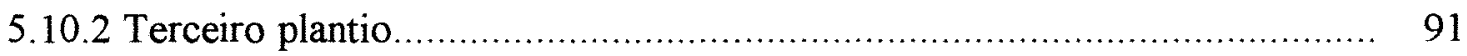

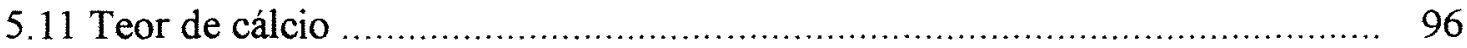

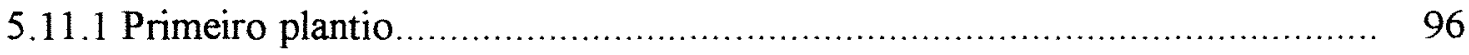

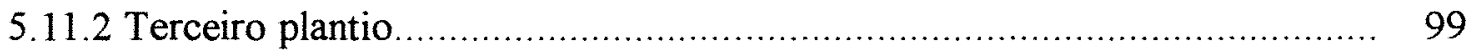

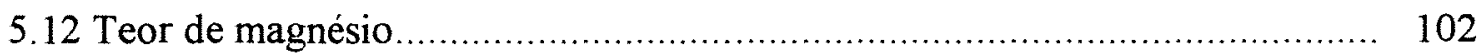

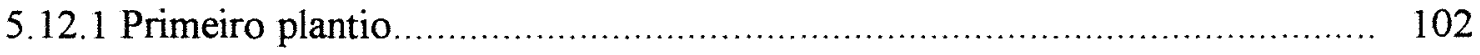




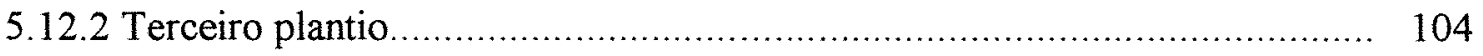

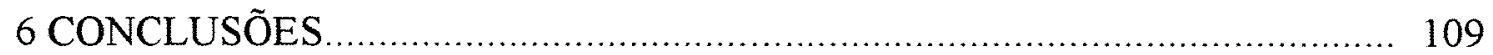

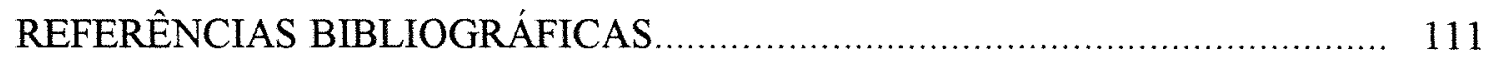




\section{LISTA DE ABREVIATURAS}

1 Supertriplo antes da calagem........................................................ STAC

2 Supertriplo depois da calagem. STDC

3 Fosfato de Gafsa antes da calagem. FGAC

4 Fosfato de Gafsa depois da calagem. FGDC

5 Fosfato de Gafsa antes da calagem + gesso FGACG

6 Fosfato de Gafsa depois da calagem + gesso FGDCG

7 Média dos tratamentos supertriplo antes da calagem e supertriplo depois da calagem.

8 Média dos tratamentos fosfato de Gafsa antes da calagem e fosfato de Gafsa depois da calagem. FG

9 Média dos tratamentos fosfato de Gafsa antes da calagem + gesso e fosfato de Gafsa depois da calagem + gesso $\mathrm{FG}+\mathrm{G}$ 10 Matéria seca 


\title{
RESPOSTAS DA ALFAFA (Medicago sativa L.) A FONTES DE FÓSFORO E MOMENTO DE CALAGEM
}

\author{
Autor: Patrícia Sarmento \\ Orientador: Prof. Dr. Moacyr Corsi
}

\section{RESUMO}

O fósforo (P) é um dos nutrientes mais importantes na produção de alfafa nos solos brasileiros e sua deficiência interfere na fixação biológica de nitrogênio. Diversas fontes de fósforo são disponíveis no mercado e o fosfato de Gafsa (FG) é considerado tão eficiente quanto o fosfato solúvel, devendo ser, portanto, a fonte de fósforo mais econômica na produção de alfafa. O FG necessita de acidez do solo para solubilizar-se, permitindo a aplicação de calcário antes ou após o FG. O uso do FG associado ao gesso pode ser uma alternativa para corrigir o perfil do solo em relação ao alumínio.

O trabalho foi realizado em estufa no Centro de Biotecnologia Agricola - ESALQ/USP e teve por objetivos avaliar a eficiência de adubos fosfatados associados ao momento de aplicação do calcário e a utilização de gesso associado ao FG sobre a produção de matéria seca (MS), o surgimento de brotos e a composição mineral da alfafa.

As plantas foram cultivadas em vasos contendo $6 \mathrm{~kg}$ de solo (Latossolo Vermelho Amarelo Álico) coletados no município de Nova Odessa, São Paulo. O delineamento experimental foi realizado em blocos completos casualizados, com 3 repetições. Foram utilizadas duas fontes de fósforo (superfosfato triplo - ST, e fosfato de Gafsa) e o fosfato de Gafsa associado ao gesso $(F G+G)$, sendo que esses foram adicionados antes ou depois da calagem, nas doses de $0,50,100$ e $200 \mathrm{mg} \mathrm{P} \mathrm{dm}^{-3}$.

Foram realizados três plantios devido ao ataque do fungo de solo Fusarium nas plantas. Porém, o segundo plantio não foi avaliado em função do curto periodo de crescimento (15 dias). As sementes do cultivar Crioula (primeiro plantio) e XAI 32 (terceiro plantio) foram inoculadas com Rhizobium meliloti SEMIA 116. Foram realizadas adubações uniformes de potássio e micronutrientes e elevou-se a saturação por bases a $85 \%$. Foram realizados um corte no primeiro plantio e três cortes no terceiro para fins de avaliações de produção de MS, do número e tipos de brotos e dos nutrientes minerais nas plantas. 
$\mathrm{O}$ aumento nos níveis de fósforo aplicados de 50 a $200 \mathrm{mg} \mathrm{P} \mathrm{dm}{ }^{-3}$ de solo provocou aumentos lineares na produção de matéria seca da alfafa durante o primeiro plantio. O ST aplicado antes ou depois da calagem proporcionou melhores produções de matéria seca ( $3,3 \mathrm{~g}$ MS/vaso) do que os tratamentos que utilizaram o FG (1,0 g MS/vaso). O ST aplicado depois da calagem (STDC) mostrou produção de MS superior (5,0 g MS/vaso) em relação à aplicação antes da calagem (STAC) (3,7 g MS/vaso) para os níveis de 100 e $200 \mathrm{mg} \mathrm{P} \mathrm{dm}{ }^{-3}$. Não houve efeito $(P>0,05)$ de momento de aplicação do FG associado ou não ao gesso, nem do uso de $F G+G$ em relação ao $F G(P>0,05)$.

No terceiro plantio o FG apresentou, em geral, maior produção de MS (6,0 g MS/vaso) da parte aérea em relação ao ST (2,4 g MS/vaso). A adição de ST, FG e FG + G depois da aplicação da calagem não apresentaram, freqüentemente, produções de MS superiores aos tratamentos em que a calagem precedeu a aplicação das fontes de fósforo. Observou-se, no terceiro plantio, efeito $(\mathrm{P}<0,05)$ do tratamento $\mathrm{FG}+\mathrm{G}(7,0 \mathrm{~g} \mathrm{MS} / \mathrm{vaso}) \mathrm{em}$ relação ao FG $\left(3,7 \mathrm{~g} \mathrm{MS} /\right.$ vaso) para o nível de $100 \mathrm{mg} \mathrm{P} \mathrm{dm}^{-3}$ no primeiro corte e de $50 \mathrm{mg} \mathrm{P}$ $\mathrm{dm}^{-3}$ no segundo e terceiro cortes.

A eficiência dos adubos fosfatados foi avaliada pelo índice de eficiência agronômica (IEA). No primeiro plantio, todas as combinações de aplicação do FG apresentaram-se IEA muito baixo $(29,4 \%)$. Porém, no terceiro plantio, os tratamentos com FG apresentaram valores elevados IEA $(111,4 \%)$.

No terceiro plantio, a dose de $100 \mathrm{mg} \mathrm{P} \mathrm{dm}^{-3}$ retardou o surgimento do segundo broto

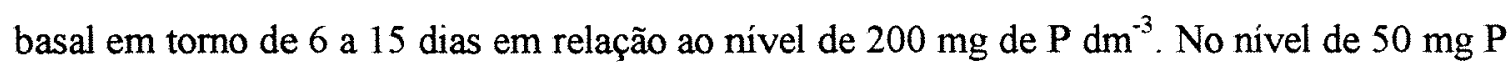
$\mathrm{drn}^{-3}$ o aparecimento do segundo broto basal ocorreu somente para o tratamento fosfato de Gafsa associado ao gesso e aplicado depois da calagem (FGDCG).

$O$ aumento da dose de fósforo de 50 para $200 \mathrm{mg} \mathrm{P} \mathrm{dm}^{-3}$ aumentou o número de brotos basais e laterais da alfafa de 1,5 e 0,5 broto/planta para 8,0 e 6,9 brotos/planta, respectivamente. Verificou-se maior número de hastes basais com a utilização do $F G(5,1$ brotos/planta) do que com ST (2,9 brotos/planta) para o nivel de $100 \mathrm{mg} \mathrm{P} \mathrm{dm}^{-3}$ no segundo e terceiro cortes e de $50 \mathrm{mg} \mathrm{P} \mathrm{dm}^{-3}$ no segundo corte do terceiro plantio. Não se observou efeito $(P>0,05)$ do tratamento $F G+G$ sobre o número de brotos axilares. No entanto, o 
tratamento $\mathrm{FG}+\mathrm{G}$ incrementou o número de brotos basais $(5,9$ brotos/planta) em relação ao tratamento FG (3,9 brotos/planta) para os níveis de 50 e $200 \mathrm{mg} \mathrm{P} \mathrm{dm}^{-3}$.

A adição de fósforo aumentou o teor de $P$ na alfafa de 0,7 e $1,0 \mathrm{~g} \mathrm{~kg}^{-1}$ para 1,8 e $1,4 \mathrm{~g}$ $\mathrm{kg}^{-1}$ nos tratamentos com FG aplicados antes e depois da calagem (FGAC e FGDC), respectivamente, no primeiro plantio, e de 1,2 para $1,8 \mathrm{~g} \mathrm{~kg}^{-1}$ em todos os tratamentos no terceiro plantio. Não se verificou efeito $(P>0,05)$ das doses de fósforo sobre a concentração de $\mathrm{N}$ na planta no primeiro plantio. Porém, observou-se redução do teor de $\mathrm{N}$ na alfafa de 50,7 para $32,1 \mathrm{~g} \mathrm{~kg}^{-1}$ com o aumento da dose de $\mathrm{P}$ de 50 para $200 \mathrm{mg} \mathrm{dm}^{-3}$ no terceiro plantio. $\mathrm{O}$ teor de Ca na parte aérea da alfafa subiu de 11,1 para $14,3 \mathrm{~g} \mathrm{~kg}^{-1}$ com o aumento da dose de fósforo de 50 para $200 \mathrm{mg} \mathrm{dm}^{-3}$ para os tratamentos STAC, FGAC, FGDC e FGACG, no primeiro plantio, e de 12,0 para $16,2 \mathrm{~g} \mathrm{~kg}^{-1}$ para os tratamentos STAC, STDC e FGAC, no terceiro plantio. O teor de $\mathrm{Mg}$ diminuiu de 7,3 para $5,8 \mathrm{~g} \mathrm{~kg}^{-1}$ com a adição de fósforo em todos os tratamentos no primeiro plantio e de 5,0 para $3,0 \mathrm{~g} \mathrm{~kg}^{-1}$ para os tratamentos FGDC, FGACG e FGDCG no terceiro plantio.

Concluiu-se que o ST é uma boa fonte de fósforo para respostas iniciais de produção de alfafa enquanto que o FG apresenta-se eficiente após 5 meses de incubação. $O$ uso da calagem antes ou após a aplicação do fosfato de Gafsa, associado ou não ao gesso, não interfere na produção de MS. O gesso associado ao fosfato de Gafsa tende a aumentar a produção da alfafa. 


\section{ALFALFA RESPONSE (Medicago sativa L.) TO PHOSPHORUS SOURCES AND TIME OF LIMING}

Author: Patricia Sarmento.

Adviser: Prof. Dr. Moacyr Corsi.

\section{SUMMARY}

Phosphorus $(\mathrm{P})$ is one of the most important nutrient in alfalfa production in Brazilian soil since its deficiency interferes with biological nitrogen fixation. Several phosphorus sources are available in the market and Gafsa phosphate (GP) being considered as efficient as soluble phosphate. This could indicate a more economical phosphorus source for alfalfa production. GP needs soil acidity to become more soluble and that would corresponds to an opportunity for applying lime either before or after GP. The use of GP associated to gypsum may be an alternative to correct soil profile concerned to aluminum.

The study was conducted in a glasshouse located at Centro de Biotecnologia Agricola at ESALQ/USP and aimed at evaluating the efficiency of phosphate fertilizers on alfalfa dry mater (DM) production, rate of shoot appearance and herbage mineral composition.

Plants were cultivated in pots containing $6 \mathrm{~kg}$ of a Typic Mapluolox soil collected in Nova Odessa, state of São Paulo. The experimental design was a complete randomized block with three replications. Two phosphorus sources were used (triple superphosphate - TS and Gafsa phosphate) at the rates of $0 ; 50 ; 100$ and $200 \mathrm{mg} \mathrm{P} \mathrm{dm}^{-3}$. TS and GP were applied before and after liming. GP was also applied with gypsum $(\mathrm{GP}+\mathrm{G})$. Treatments were than:

- TS before and after liming (TSBL; TSAL);

- GP before and after liming (GPBL; GPAL);

- GP before and after liming combined with gypsum (GPBLG; GPALG).

Three seedings were necessary due to the attack of Fusarium ssp. Results from the second seeding were not evaluated due the short growing period (15 days) before plants were killed by Fusarium. Crioula and XAI 32 cultivars were used in the first and third seeding, respectively. Seeds were inoculated with Rhizobium meliloti SEMIA 116. Potassium and 
micronutrients were applied and lime used to increase soil base saturation to $85 \%$. Plants were harvested only once in the first seeding and three times in the third seeding. Responses evaluated were DM production, shoot number and types, phosphorus fertilizer efficiency and plant mineral composition.

Dry matter production increased linearly with phosphorus rates from 50 to $200 \mathrm{mg} \mathrm{dm}^{-3}$ during the first seeding. TS applied before or after liming showed higher alfalfa dry mater production (3.3 g DM/pot) than GP ( $1.0 \mathrm{~g} \mathrm{DM} / \mathrm{pot})$. TS applied after liming (TSAL) resulted in higher dry matter production $(5.0 \mathrm{~g} \mathrm{DM} / \mathrm{pot})$ than TS applied before liming (TSBL) $(3.7 \mathrm{~g}$ $\mathrm{DM} / \mathrm{pot})$ for 100 and $200 \mathrm{mg} \mathrm{P} \mathrm{dm}^{-3}$. Time of lime application had no effect $(\mathrm{P}>0.05)$ on dry matter production when GP was either associated or not with gypsum. Gypsum combined with GP was not different $(P>0.05)$ than GP.

A higher dry matter production was obtained with GP (6.0 g DM/pot) than TS (2.4 g $\mathrm{DM} / \mathrm{pot}$ ) during the third seeding. There was no difference in alfalfa dry matter production when TS, GP and GP + G were applied before or after liming. It was observed, in the third seeding, a superiority $(P<0.05)$ of the treatment $\mathrm{GP}+\mathrm{G}(7.0 \mathrm{~g} \mathrm{DM} / \mathrm{pot})$ in relation to GP $(3.7$ $\mathrm{g} \mathrm{DM} / \mathrm{pot}$ ) at the level of $100 \mathrm{mg} \mathrm{P} \mathrm{dm}^{-3}$ in the first harvest and at $50 \mathrm{mg} \mathrm{P} \mathrm{dm}^{-3}$ in the second and third harvests.

The efficiency of the phosphate fertilizer was evaluated through an agronomic efficiency index (AEI). All GP combinations presented a very low AEI (29.4\%) during the first seeding, although during the third seeding, GP and GP + G showed high values of AEI (111.4\%) at the level of $200 \mathrm{mg} \mathrm{P} \mathrm{dm}^{-3}$.

Phosphorus applied at $100 \mathrm{mg} \mathrm{dm}^{-3}$ delayed second basal shoot appearance in 6 to 15 days compared to plants receiving $200 \mathrm{mg} \mathrm{P} \mathrm{dm}^{-3}$ in the third seeding. When phosphorus was applied at $50 \mathrm{mg} \mathrm{dm}^{-3}$, the appearance of the second basal shoot was observed only when Gafsa phosphate was associated with gypsum and applied after liming (GPALG).

Basal and axillary shoot numbers in alfalfa increased from 1.5 and 0.5 shoot/plant to 8.0 and 6.9 shoots/plant, respectively, with increasing phosphorus rates. Axillary shoots and shoots originated from the crown were produced in higher numbers with GP (5.1 shoots/plant) 
in comparison to TS (2.9 shoots/plant) at the level of $100 \mathrm{mg} \mathrm{P} \mathrm{dm}^{-3}$ in the second and third harvests, and at $50 \mathrm{mg} \mathrm{P} \mathrm{dm}^{-3}$ in the second harvest of the third seeding. There was no effect $(P<0.05)$ of treatment $\mathrm{GP}+\mathrm{G}$ in relation to $\mathrm{GP}$ on axillary shoot numbers. However, $\mathrm{GP}+\mathrm{G}$ resulted in higher basal shoot number ( 5.9 shoots/plant) than GP (3.9 shoots/plant) at the levels of 50 and $200 \mathrm{mg} \mathrm{P} \mathrm{dm}^{-3}$.

Dry matter phosphorus concentration increased from 0.7 and $1.0 \mathrm{~g} \mathrm{~kg}^{-1}$ to 1.8 and $1.4 \mathrm{~g} \mathrm{~kg}^{-1}$ when GP was applied before and after liming, respectively. All phosphorus sources increased $\mathrm{P}$ concentration in alfalfa from 1.2 to $1.8 \mathrm{~g} \mathrm{~kg}^{-1}$ during the third seeding. Phosphorus fertilizer did not affect $(\mathrm{P}>0.05) \mathrm{N}$ concentration during the first seeding. On the other hand, there was a reduction in plant $\mathrm{N}$ concentration from 50.7 to $32.1 \mathrm{~g} \mathrm{~kg}^{-1}$ when 50 and $200 \mathrm{mg} \mathrm{P} \mathrm{dm}^{-3}$ were applied in the third seeding. Plant $\mathrm{Ca}$ concentration increased from 11.1 to $14.3 \mathrm{~g} \mathrm{~kg}^{-1}$ with 50 and $200 \mathrm{mg} \mathrm{P} \mathrm{dm}^{-3}$ phosphorus fertilizer application in TSBL, GPBL, GPAL and GPBLG in the first seeding and from 12.0 to $16.2 \mathrm{~g} \mathrm{~kg}^{-1}$ in TSBL, TSAL and GPBL in third seeding. Plant Mg concentration decreased from 7.3 to $5.8 \mathrm{~g} \mathrm{~kg}^{-1}$ with the use of all phosphorus fertilizer sources in the first seeding and from 5.0 to $3.0 \mathrm{~g} \mathrm{~kg}^{-1}$ for treatments GPAL, GPBLG and GPALG in the third seeding.

It was concluded that TS increased alfalfa dry matter production more effectively than GP in initial growth (first seeding) but GP showed better results than TS after been incubated in the soil for 5 months. The use of liming either before or after GP application, associated or not to gypsum, had no effect on alfalfa dry matter production. However, gypsum combined with GP tended to increase alfalfa production. 


\section{INTRODUÇÃO}

Proveniente de diferentes fontes, o fósforo (P) é um nutriente mineral que se apresenta em várias formas químicas. Assim, diversos adubos fosfatados são encontrados no comércio, distinguindo-se na concentração de fósforo e na sua solubilidade (Malavolta, 1979 e Raij, 1991).

Devido ao baixo nível de fósforo nos solos brasileiros, a longevidade e a produção da alfafa (Medicago sativa L.) são dependentes da adubação fosfatada para o estabelecimento e manutenção. Dessa maneira, os altos preços dos adubos fosfatados e o requerido tempo de retorno dos custos impulsionam as pesquisas para se identifiquem maneiras mais eficientes e econômicas de se combinar a cultura de alfafa com as fontes fosfatadas disponiveis. Os fosfatos solúveis em água, como o superfosfato simples, superfosfato triplo, monoamônio fosfato e diamônio fosfato, são as melhores formas de adubos fosfatados, embora sejam os mais onerosos devido ao consumo elevado de energia para sua produção. Existem os fosfatos de rocha nacionais que são de menor preço, como o fosfato de Patos de Minas, Olinda, Araxá, Catalão, etc., mas por serem de baixa eficiência agronômica em relação às fontes de fosfatos solúveis são pouco aceitos pelos produtores. Por outro lado os fosfatos naturais importados, como o de Gafsa (Tunísia, $8 \%$ de $\mathrm{P}_{2} \mathrm{O}_{5}$ solúvel em ácido cítrico a $2 \%$ ), que possuem maior solubilidade que os nacionais têm apresentado eficiência semelhante a dos fosfatos solúveis, mostrando ser competitivos com os mesmos. Desse modo, o fosfato de Gafsa torna-se uma opção interessante como fonte de fósforo para produção de alfafa. 
Por outro lado, os fosfatos de rocha importados, assim como os nacionais, necessitam de acidez e contato com o solo para que ocorra a solubilização do mesmo. Dessa maneira estas fontes devem ser utilizadas com incorporação ao solo seguida de incubação. Em pH menor que 5,5 ocorre a fixação do fósforo pelo alumínio, sendo que a utilização de gesso junto à adubação fosfatada poderia ser uma alternativa para diminuir o teor de alumínio no perfil do solo, e consequentemente diminuir a fixação do fósforo oferecendo, também, condições para um enraizamento profundo da alfafa e mantendo a acidez do solo necessária a solubilização do fosfato de Gafsa. Além disso, o fosfato de Gafsa é deficiente em enxofre e uma forma de contornar isso é associar o fosfato ao gesso, uma vez que o gesso possui $15 \%$ desse nutriente. Assim, a adição de gesso combinado com o fosfato de Gafsa poderia aumentar a eficiência desse adubo.

Considerando que os fertilizantes fosfatados são essenciais no aumento da produtividade da alfafa e de outras culturas e devido à maior participação desses insumos nos custos de produção das explorações agrícolas nos últimos anos, torna-se necessário aprimorar técnicas e conhecimentos para aumentar a sua eficiência de utilização. A eficiência dos adubos fosfatados é afetada pela acidez do solo, assim a calagem é um fator que deve ser desconsiderado nas pesquisas envolvendo fontes de fósforo.

Considerando que os fertilizantes fosfatados são essenciais no aumento da produtividade da alfafa e de outras culturas e que seu uso está relacionado a maior participação desses insumos nos custos de produção das explorações agricolas, torna-se necessário aprimorar técnicas e conhecimentos para aumentar a eficiência de utilização desses fertilizantes. Já que a eficiência dos adubos fosfatados é afetada pela acidez do solo, o uso da calagem não deve ser desconsiderado nas pesquisas envolvendo fontes de fósforo. 


\section{REVISÃO DE LITERATURA}

\subsection{Importância do fósforo para a alfafa}

O fósforo é essencial para o crescimento da alfafa, onde seu valor crítico encontra-se ao redor de $3,5 \mathrm{~g} \mathrm{~kg}^{-1}$ de $\mathrm{P}$ na forragem no início do florescimento (Lanyon $\&$ Griffith, 1988). A alfafa é uma leguminosa que apresenta maior nível critico interno de fósforo quando comparada com as leguminosas tropicais (Lobato et al., 1985).

$O$ fósforo age na fotossintese, na síntese de carboidratos e proteínas, na formação e divisão celular e no metabolismo de gorduras, pelo fato de fazer parte dos ácidos nucleicos, fosfolipídios, ATP, e das coenzimas NAD e NADP (Rhykerd \& Overdahl, 1972). Esse nutriente ajuda as raizes a se desenvolverem-se mais rapidamente, melhorando a absorção de nutrientes pela planta, assim como a eficiência na utilização da água. Desta forma, o melhor desenvolvimento das raízes torna-se importante na tolerância à seca, contribuindo para uma melhor distribuição sazonal da produção. Sanderson \& Jones (1993) verificaram que na ausência da aplicação de fósforo as raizes da alfafa concentravam-se no solo a $20 \mathrm{~cm}$ de profundidade. Quando o solo apresentava quantidades adequadas de fósforo, no entanto estas encontravam-se distribuídas a uma profundidade de 40 a $50 \mathrm{~cm}$.

A adubação fosfatada aumenta a resistência da planta a invernos rigorosos, melhora a resistência a doenças, eleva o teor de fósforo na forragem e a sua produção (Honda \& Honda, 1990). 
Como o fósforo faz parte da adenosina trifosfato (ATP) e também está associado à atividade da nitrogenase, esse nutriente torna-se essencial no processo simbiótico pelo alto requerimento de ATP no processo de fixação de $\mathrm{N}_{2}$ (Lanyon \& Griffith, 1988). Yupanqui (1997) constatou que o efeito da deficiência de fósforo sobre a nodulação foi má formação e desenvolvimento dos nódulos. Collins et al. (1986) observaram aumento de $96 \%$ no número de nódulos e de $129 \%$ na fixação de $\mathrm{N}_{2}$ com o aumento de 0 para 56 $\mathrm{kg} \mathrm{P} \mathrm{ha}{ }^{-1}$.

As respostas da cultura à adubação com fósforo, variam em função da localização do adubo, da planta cultivada, do manejo, e da disponibilidade de fósforo no solo (Raij, 1991). Como nos solos do Brasil ocorre uma deficiência generalizada de fósforo, e sendo a alfafa uma planta muito exigente nesse elemento, fica clara a necessidade de incluir o fósforo nas adubações destas culturas.

Mailhi et al. (1992), em Lacome (solo Black Chernozem silt loam) localizado na região central de Alberta, no Canadá, verificaram aumento de produção de alfafa de 4,53 $\mathrm{t} \mathrm{ha}^{-1}$ para $7,50 \mathrm{t} \mathrm{ha}^{-1}$ com a aplicação de $20 \mathrm{~kg} \mathrm{P} \mathrm{ha}^{-1}$ ano ${ }^{-1}$, numa média de três anos com dois cortes por ano. Por outro lado o uso de doses acima de $20 \mathrm{~kg} \mathrm{P} \mathrm{ha}^{-1}$ proporcionou pequeno incremento de produção ao redor de $0,15 \mathrm{t} \mathrm{ha}^{-1}$.

Pinheiro et al. (1993) trabalhando com alfafa cultivar Crioula em solo Cambisolo distrófico álico verificou que a adubação de $0 ; 60 ; 120$ e $180 \quad \mathrm{~kg}_{2} \mathrm{P}_{2} \mathrm{O}_{5}$ ha $^{-1}$ no estabelecimento de alfafa proporcionou produções de 6,$2 ; 7,1 ; 7,0$ e $8,0 \mathrm{t} \mathrm{MS} \mathrm{ha}^{-1}$ respectivamente. As adubações de manutenção de $0 ; 50,100$ e $150 \mathrm{~kg} \mathrm{P}_{2} \mathrm{O}_{5} \mathrm{ha}^{-1}$, em média de seis anos, permitiram as produções de 7,$5 ; 11,0 ; 11,1 \mathrm{e} 11,6 \mathrm{t} \mathrm{MS} \mathrm{ha}{ }^{-1}$ ano $^{-1}$, respectivamente.

\subsection{Formas de fósforo no solo}

A concentração do fósforo na solução do solo, assim como a manutenção dessa concentração são importantes para a nutrição da planta. A movimentação do fósforo através da solução do solo para a raiz da planta se dá por difusão, a qual ocorre somente a curtas distâncias, dependendo da umidade do solo. Assim, uma pequena deficiência 
hídrica no solo causa drástica redução no fornecimento de fósforo às plantas mesmo que o fósforo esteja em elevados teores no solo, e de forma disponível (Novais et al., 1990). Outro aspecto que facilita o aproveitamento do fósforo disponível no solo, apesar de poder estar em baixos teores, é o sistema radicular bem desenvolvido (Raij, 1991).

A disponibilidade de fósforo para as plantas depende da forma em que o elemento se encontra no solo. As formas de fósforo encontradas no solo são: a) na solução do solo, disponível à planta; b) lábil, estando o fósforo adsorvido aos sítios de troca dos colóides argilo-orgânicos do solo ou precipitado. A forma lábil de fósforo está em equilíbrio com o P da solução do solo, e é considerada como disponivel para as plantas; c) não lábil, representado pelo fósforo precipitado em compostos insolúveis, ou adsorvido por sítios de troca de elevada energia, não estando, dessa maneira, disponível às plantas.

Teores de fósforo na solução do solo são baixos, geralmente, pelo fato dos compostos de fósforo serem de pouca solubilidade como, também, pela alta capacidade de adsorsão do elemento pelas partículas do solo. Já o fósforo não-lábil representa a maioria do fósforo inorgânico do solo, e só lentamente pode passar para a forma lábil (Raij, 1991).

Tem-se constado (Crocker et al. ${ }^{1}$, citado por Lanyon \& Griffith, 1988) que uma adequada aplicação de calcário eleva a disponibilidade do fósforo e aumenta o crescimento da raiz. Em solos ácidos predominam os fosfatos de ferro e alumínio que possuem baixa solubilidade em água sendo indisponíveis para a planta. Por outro lado, o excesso de calagem reduz a disponibilidade de fósforo pela precipitação desse com o $\mathrm{Ca}$ (Lanyon \& Griffith, 1988 e Honda \& Honda, 1990). Dessa maneira, a maior solubilidade de fósforo encontra-se em pH em torno de 6,0 (Raij, 1991).

Outro aspecto observado em relação a disponibilidade do fósforo é que em solos arenosos e de textura média, a difusão desse é maior do que em solos argilosos. Isso

\footnotetext{
1 - CROCKER, G.J.; SHERIDAN, K.P.; HOLFORD, I.C.R. Lucerne responses to lime and interactions other nutrients on granitic soils. Aust. J. Agric., v.25, p.337-346, 1985.
} 
pode explicar porque a soja, em solos menos férteis, tem produzido mais do que em solos argilosos e férteis (Novais et al., 1990).

\subsection{Métodos de aplicação e disponibilidade do fósforo no solo, utilizando fontes solúveis}

Os fosfatos solúveis em água são as principais fontes de fósforo. Por outro lado, quando aplicado a lanço e incorporados, sua eficiência é comprometida em razão de sua fixação ao solo (Raij, 1991). Esses adubos fosfatados passam rapidamente para a fase sólida (lábil) e com o passar do tempo vão adquirindo uma solubilização mais dificil (não lábil), tornando-se indisponivel para a planta. Consequentemente, a aplicação do fosfato solúvel no sulco, com o propósito de diminuir o volume de solo com o qual o adubo reage, é desejável para evitar a fixação. A aplicação do adubo no sulco, no entanto possui a desvantagem de limitar o desenvolvimento radicular, tornando a planta mais susceptível à seca, principalmente em regiões que apresentam estiagens freqüentes (Lobato et al., 1985).

Outro fato que concorre para o aumento da eficiência dos fosfatos solúveis é a elevação do $\mathrm{pH}$ para valores adequados $(5,5$ a 6,5$)$, uma vez que a calagem diminui o teor de $\mathrm{Al}$ trocável, diminuindo a capacidade de fixação do fósforo pelo $\mathrm{Al}^{3+}$ ( $\mathrm{P}$ não lábil). O aumento de $\mathrm{pH}$, também, serve para diminuir o "reservatório" de $\mathrm{P}$ não lábil, através da redução do número de sítios de troca no solo. Dessa maneira, tem-se uma diminuição da capacidade de adsorsão ou fixação de fósforo pelo solo (Goedert \& Sousa, 1984).

Smyth \& Sanchez (1980) ao estudarem, em laboratório, o efeito da aplicação de calcário antes da incorporação de fosfato solúvel ao solo, verificaram que a aplicação do calcário reduziu de 20 a $30 \%$ a adsorção do fósforo pelo solo.

Le Mare \& Goedert ${ }^{2}$ (citados por Goedert \& Sousa, 1984), ao adicionarem

\footnotetext{
2 - LE MARE, P.; GOEDERT, W.J. Effects of Liming on Sorption and Desorption of Phosphate by Some Acid Soil of Soouth America. Proceedings of the $3^{\text {rd }}$ International Congress on Phosphorus Compuns. IMPHOS. Marrocos, 1983.
} 
calcário no solo a fim de atingir $\mathrm{pH}$ em torno de 5,5 , observaram diminuição na quantidade de fósforo adsorvido na forma não tracável em cerca de $30 \%$, em solo Latossolo Vermelho Escuro, fase Cerrado.

\subsection{Métodos de aplicação e disponibilidade do fósforo no solo, utilizando fosfato de rocha}

Os fosfatos naturais brasileiros são de lenta dissolução, necessitando de maior contato das partículas do fosfato com as do solo e de maior acidez (ion $\mathrm{H}$ ) que favoreça a dissolução e eficiência dos mesmos. A dissolução do fosfato de rocha é reduzida pela atividade do $\mathrm{Ca}$, porém essa relação entre $\mathrm{Ca}$ e $\mathrm{P}$ difere entre as fontes de fosfato de rocha (Smyth \& Sanhez, 1982; Wilson \& Ellis, 1984). Dessa maneira, recomenda-se a aplicação de fosfato natural com incorporação no solo para promover maior contato entre as partículas e consequentemente reação mais intensa com as partículas do solo. Em culturas sensiveis ao baixo $\mathrm{pH}$ deve-se oferecer, primeiramente, certo periodo de incubação do adubo fosfatado a fim de iniciar a solubilização do fosfato de rocha antes que se efetue a calagem (Lobato et al., 1985).

Kochhann et al. (1982), em revisão sobre o uso de fosfatos naturais em adubação, concluíram que a eficiência desses fertilizantes é função da espécie vegetal, do tipo de solo, da dose utilizada, do pH e da duração da avaliação.

A eficiência dos fosfatos naturais brasileiros, que possuem tendência inversa dos fosfatos solúveis, aumentam com o passar do tempo devido ao acréscimo da solubilização do fosfato de rocha, que reflete em melhoria na produtividade (Goedert \& Sousa, 1984).

\subsection{Utilização do fosfato de Gafsa}

Estudando o estabelecimento de trevo branco (Trilolim repens L.) em solo Brunizem Hidromórfico Vértico (Argiaquoll) Macedo et al. (1985) observaram que a produção de matéria seca dessa leguminosa foi menor quando se empregou níveis de 0 , 50,100 e $150 \mathrm{~kg}$ de $\mathrm{P}_{2} \mathrm{O}_{5} \mathrm{ha}^{-1}$ na forma de fosfato de Gafsa, fosfato de Patos de Minas e 
de Araxá em relação a produção obtida com o superfosfato triplo. A equivalência agronômica* dos fosfatos naturais em relação ao fosfato super triplo (ao nível de $89 \mathrm{~kg}$ de $\mathrm{P}_{2} \mathrm{O}_{5} \mathrm{ha}^{-1}$ ) foi: $36 \%$ para o fosfato de Araxá, $42 \%$ para o fosfato de Patos de Minas e $69 \%$ para o fosfato de Gafsa.

Em Latossolo Vermelho-Escuro (Haplustox), onde se cultivou por dois anos o trigo (Triticum vulgare Vill), arroz (Orysa sativa L.), sorgo (Sorghum vulgare Pers.) e três anos o Capim Andropogon (Andropogon gayanus Hack.), Goedert \& Lobato (1984) constataram uma eficiência similar do termofosfato magnesiano (Yoorin) e do fosfato de Gafsa-Marrocos (hiperfosfato) em relação ao superfosfato triplo, desde o primeiro cultivo, utilizando os niveis de 88 e $350 \mathrm{~kg}$ de $\mathrm{P} \mathrm{ha}{ }^{-1}$. Os fosfatos foram aplicados somente antes do primeiro cultivo.

Trabalhando com diferentes fontes de fósforo nas culturas de trigo e soja em latossolo vermelho-escuro argiloso Ramos (1982) verificou que a escória de Thomas e termofosfatos (Yoorin), bem como os fosfatos de Gafsa $(8,9 \%$ de solubilidade em ácido cítrico a $2 \%$ ) apresentaram eficiência semelhante aos fosfatos solúveis quando empregou 150 e $120 \mathrm{~kg}$ de $\mathrm{P}_{2} \mathrm{O}_{5}$ para o trigo e soja, respectivamente. A adubação de fósforo foi realizada a lanço e incorporados com enxada rotativa.

O fosfato monocálcio, e os fosfatos de Patos, Bayovar e Gafsa (apresentam 5,5; 15,2 e $12,6 \%$ de $\mathrm{P}_{2} \mathrm{O}_{5}$ solúvel em ácido cítrico, respectivamente) foram estudados através do cultivo do sorgo em vasos por 32 dias em nove tipos de solos, utilizando dosagens equivalentes a zero e $250 \mu \mathrm{g}$ de $\mathrm{P}$ por grama de solo. As produções de biomassa e os teores de fósforo nas plantas evidenciaram elevada eficiência das rochas fosfatadas de Bayovar (Peru) e Gafsa (Tunísia), em comparação ao fosfato monocálcio e ao fosfato de Patos. A eficiência relativa de produção de massa seca total para os fosfatos de Bayovar, Gafsa e Patos foi de 143, 145 e $83,5 \%$, respectivamente, em relação ao fosfato monocálcio (Rosand \& Santana, 1986).

\footnotetext{
* Equivalência Agronômica $(\%)=\frac{Y_{1}}{Y_{2}} \times 100$;

$\mathrm{Y}_{1}=$ produção obtida com o fosfato de rocha na dose $n ; Y_{2}=$ produção obtida com a fonte solúvel na dose n.
} 
Em Latossolo Roxo distrófico fase cerrado foi avaliada a eficiência agronômica de oito fontes de fósforo, em culturas sucessivas de milho-trigo-soja-trigo, sem utilização de calagem (Oliveira et al., 1984). O superfosfato triplo foi utilizado como referência aplicando-se doses de $50,100,200,400$ e $800 \mathrm{~kg} \mathrm{ha}^{-1}$ de $\mathrm{P}_{2} \mathrm{O}_{5}$. O hiperfosfato, o termofosfato IPT e os fosfatos de Maranhão, Araxá, Alvorada e Catalão foram adicionados nas doses de 100 e $400 \mathrm{~kg} \mathrm{ha}^{-1}$ de $\mathrm{P}_{2} \mathrm{O}_{5}$. $\mathrm{O}$ índice de eficiência relativa (Dynia ${ }^{3}$, citado por Oliveira et al., 1984) foi de $115 \%$ para o hiperfosfato em relação ao superfosfato triplo quando o nivel de adubação foi de $400 \mathrm{~kg} \mathrm{P}_{2} \mathrm{O}_{5}$ ha $^{-1}$. O termofosfato apresentou índice de eficiência relativa de $86 \%$, enquanto que nos fosfatos naturais esse índice foi de 60,72, 51 e 51\% para os fosfatos de Maranhão, Alvorada, Araxá e Patos de Minas, respectivamente.

Léon et al. (1986) estudaram a produção de matéria seca de Panicum maximum Jacq. em casa de vegetação, utilizando solo da Colômbia (Tropeptic Haplustox) e níveis de $0,50,100,200$ e $400 \mathrm{mg}$ P/vaso (1,5 kg de solo), provenientes de 17 fontes de fósforo. De acordo com a eficiência agronômica dos fosfatos em relação ao fosfato supertriplo (400 mg P/vaso), os fosfatos de Jacupiranga, Catalão e Tapira apresentaram potencial agronômico muito baixo $(28,22$ e $12 \%$, respectivamente), dentro da escala de classificação, enquanto os fosfatos de Lobatera (Venezuela), Sardinata (Colômbia), Patos de Minas, Araxá e Abaete foram classificados como baixo $(67,59,58,48$ e 42\%, respectivamente). Os fosfatos que apresentaram potencial médio foram os da Flórida, Huila (Colômbia), Pesca (Colômbia) e Tennessee, enquanto que o Norte Carolina, Bayovar (Peru), Gafsa e Arad apresentaram alto potencial, com índice de eficiência agronômica em relação ao supertriplo de $99,96,96$ e $85 \%$, respectivamente.

Braga et al. (1991) testaram em Latossolo Vermelho Escuro (Typic Acrustox), textura média, nove fontes de fósforo em quatro cultivos de soja (Glycine max (L.) Merrill), empregando os níveis de 0, 100, 200 e $400 \mathrm{~kg} \mathrm{P}_{2} \mathrm{O}_{5} \mathrm{ha}^{-1}$. Dentre os fosfatos utilizados, os que proporcionaram maiores produções foram: termofosfato magnesiano

\footnotetext{
3 - DYNIA, J.F. Efeito do pH e da capacidade de retenção de fósforo dos solos na eficiência dos adubos fosfatados. Tese de Mestrado. Porto Alegre, RS, Faculdade de agronomia, Universidade Federal do Rio Grande do Sul, p.61, 1977.
} 
fundido e o fosfato de Gafsa, apresentando 117 e $111 \%$ de índice de eficiência agronômica em relação ao fosfato super triplo, com nível de adubação fosfatada de 400 $\mathrm{kg} \mathrm{P}_{2} \mathrm{O}_{5} \mathrm{ha}^{-1}$. Por outro lado, os fosfatos naturais de Araxá, Patos de Minas e Catalão não afetaram as produções de soja, apresentando índice de eficiência agronômica de 14, 15 e $9 \%$, respectivamente. Os fosfatos calcinados e o termofosfato IPT tiveram comportamento intermediário com 82 e 55\% de índice de eficiência agronômica.

Hanafi \& Syers (1994) estudaram o efeito do fosfato de Christmas Island e o fosfato de Gafsa na produção de Setaria splendida em solos da Malásia. Cinco solos foram incubados por duas semanas, após atingirem $\mathrm{pH}$ 5,5. O indice de eficiência agronômica do fosfato de Gafsa e do fosfato de Christmas Island foi de 90 e $72 \%$ respectivamente em relação ao superfosfato triplo na dose de $300 \mathrm{~kg} \mathrm{P} \mathrm{ha}^{-1}$.

\subsection{Disponibilidade do fosfato de Gafsa}

Kochhann et al. (1982) verificaram que entre os fosfatos naturais de Patos, Gafsa e Pirocauna, em pH acima de 5 ocorreu diminuição da eficiência dos dois primeiros fosfatos, enquanto o último foi pouco afetado. Isso mostra que mesmo possuindo maior solubilidade do que outros fosfatos naturais brasileiros, o fosfato de Gafsa necessita de certa acidez para solubilizar-se e apresentar melhor desempenho.

Albulquerque \& Marinho ${ }^{4}$ (citados por Rosand \& Santana, 1986) relataram que a eficiência do fosfato de Gafsa, mesmo sendo um fosfato de alta reatividade, é diminuída quando o adubo é aplicado em linhas e/ou na forma granulada, sendo, por isso, necessária a aplicação à lanço com incorporação no solo.

Os fosfatos de Gafsa e Patos, tiveram eficiência melhorada em 36\%, quando foram aplicados ao solo (de 100 a $300 \mu \mathrm{g} \mathrm{P} \mathrm{g}^{-1}$ de solo Laterífico Bruno Avermelhado Distrófico) quatro meses antes da calagem e seis meses antes da semeadura de trigo, quando comparados com a aplicação dos mesmos oito meses após a calagem (Kochhann et al., 1982).

\footnotetext{
${ }^{4}$ - ALBUQUERQUE, C.A.C.; MARINHO, M.L. Resposta da Cana-de-açúcar à combinação de DAP e hiperfosfato. In: Congresso Nacional da Sociedade dos Técnicos Açucareiros do Brasil, $1^{\circ}$, Maceió, Brasil. 1979. s.1., s.e. p.11, 1979.
} 
Hanafi et al. (1992b) testaram, em sistema fechado, a solubilização dos fosfatos de Gafsa e de Christmas Island em seis tipos de solo da Península da Malásia com pH em água entre 3,0 e 5,4. Os fosfatos foram adicionados aos vasos com $200 \mathrm{~g}$ de solo nos niveis de 0 e $500 \mathrm{mg} \mathrm{P} \mathrm{kg}^{-1}$, umedecidos até $90 \%$ da capacidade de campo e incubados por $0,3,5,10,20,35,55$ e 90 dias, à temperatura de $20 \pm 2{ }^{\circ} \mathrm{C}$. Os autores verificaram maior solubilização do fosfato de Gafsa (22-71\%) do que o Christmas Island (26-42\%), sendo que ambos aumentaram a solubilização no solo com o incremento do período de incubação. A maior solubilização esteve relacionada com a maior capacidade de retenção de fósforo pelo solo. A solubilização dos fosfatos foi completada dentro de 50 dias; acima desse período o incremento na dissolução foi insignificante.

Hanafi et al. (1992a) observaram decréscimo de 42,0 e $41,2 \%$ para 19,0 e $32,5 \%$ da dissolução do fosfato de Gafsa à medida que aumentaram o nivel de $\mathrm{CaCO}_{3}$ (aumento do $\mathrm{pH}$ entre 4,5 e 6,1) ou de $\mathrm{CaCl}_{2}$ (fornecimento de equivalente quantia de $\mathrm{Ca}$ ) sem causar variação no $\mathrm{pH}$ no solo, respectivamente. Foi observado, também, que maior dissolução do fosfato de Gafsa no solo, ocorreu quando esse foi incubado por 60 dias (23\%) comparado a incubação por 40 e 20 dias (18 e $11 \%$ respectivamente) antes da adição do carbonato de cálcio ou cloreto de cálcio .

Portanto, a dissolução do fosfato natural de Gafsa, assim como a dos fosfatos naturais brasileiros, é favorecida quando as condições de $\mathrm{pH}$, e as concentrações de $\mathrm{Ca}$ trocável e de $\mathrm{P}$ solúvel no solo são baixas (Bolan \& Hedley ${ }^{5}$, citado por Hanafi et al., 1992a e Robison \& Syers, 1990).

\subsection{Utilização de gesso}

A palavra "gesso" pode referir-se ao sulfato de cálcio gipso (sulfato de cálcio hidratado - $\mathrm{CaSO}_{4} 2 \mathrm{H}_{2} \mathrm{O}$ ), ou anidro, ou ainda ao fosfogesso (sulfato de cálcio obtido como subproduto na fabricação de superfosfato simples, superfosfato triplo, fosfato de amônio, MAP e DAP) (Malavolta et al., 1979).

\footnotetext{
5 - BOLAN. N.S.; HEDLEY, M.J. Dissolution of phosphate rocks in soils. I. Evaluation of extraction methods fos the measurement of phosphate rock dissoluation. Fert. Res., v.19, pg.65-75, 1989.
} 
A técnica de utilização do gesso teve origem no Brasil, em meados da década de 70. A descoberta foi feita no CPAC (EMBRAPA) por acaso, que na ocasião de um veranico percebeu-se que os canteiros de milho tratados com superfosfato simples, permaneciam túrgidas, em oposição aos canteiros com superfosfato triplo cujas plantas apresentavam-se murchas (Ritchey et al., 1980). Observou-se, também, que as plantas que se apresentavam túrgidas tinham raizes mais desenvolvidas, o que possibilitava aumento na absorção de água em camadas mais profundas no solo. Como a única diferença entre os dois fosfatos era a presença de gesso do super fosfato simples, os efeitos favoráveis do aprofundamento da raiz do milho foram atribuídos ao gesso (Raij, 1988).

A partir desse fato vêm sendo realizadas pesquisas sobre o uso do gesso, embora ainda persistam muitas dúvidas a respeito da quantidade a ser utilizada para cada cultura, época de aplicação, entre outras (Raij, 1988).

$\mathrm{O}$ gesso reduz o teor de alumínio no perfil do solo, sem elevar o $\mathrm{pH}$. Sabe-se que a alfafa sensivel tanto aos altos teores de alumínio no solo como à escassez de água. Assim, a correção do perfil do solo contribuiria para maior produção e longevidade da cultura (Honda \& Honda, 1990).

O maior desenvolvimento radicular em profundidade em solos ácidos com altos teores de alumínio não é só devido à diminuição do teor de $\mathrm{Al}^{3+}$ com a aplicação do gesso, mas principalmente ao aumento no teor de cálcio em profundidade causado pela lixiviação do Ca pelo $\mathrm{SO}_{4}{ }^{2-}$ (Borkert et al, 1987).

Outra contribuição importante do gesso é o fornecimento de enxofre para a alfafa, uma vez que o fosfato de Gafsa não contém enxofre e que $50 \%$ dos solos da América Tropical apresentam deficiência desse elemento (Sanchez \& Salinas, 1981). O enxofre é requerido para a conversão do nitrogênio não protéico em proteína, estimula a nodulação e a fixação do nitrogênio nas raizes e garante crescimento mais vigoroso da planta.

Andrew (1977) após estudar o efeito do enxofre em uma série de leguminosas, verificou que o maior nivel crítico na parte aérea era observado para a alfafa, estando em torno de $0,2 \%$ de $\mathrm{S}$. Colozza et alii. (1983) aplicaram níveis de gesso agrícola $(0,300 \mathrm{e}$ $600 \mathrm{~kg} \mathrm{ha}^{-1}$ ) em dois solos ácidos (Podzólico Vermelho-Amarelo variação Laras e 
Latossolo Vermelho-Amarelo fase cerrado) cultivados com soja perene. Os autores verificaram que o aumento da dose de gesso de 0 para $600 \mathrm{~kg} \mathrm{ha}^{-1}$ aumentou a produção de matéria seca da parte aérea do segundo corte de 11,3 para 13,0 g MS/vaso e a quantidade total de nitrogênio da parte aérea de 265 para $303 \mathrm{mg} \mathrm{N} / \mathrm{vaso}$, mas apenas quando se fez a devida correção da acidez do solo com o emprego do calcário dolomítico.

Sonn (1988) utilizou três solos moderadamente ácidos ( $\mathrm{pH}$ médio de 4,8) para testar, em casa de vegetação, o efeito do gesso ou calcário em cultura de alfafa e centeio. Observou que a quantidade de calcário adicionada ao solo elevou o $\mathrm{pH}$ para 6,0 a 6,7, e o gesso fornecido foi equivalente em $\mathrm{Ca}$ ao $\mathrm{CaCO}_{3}$ utilizado para atingir $\mathrm{pH} 6,7$. A produção de matéria seca de alfafa e de cevada aumentou de 86 e $230 \mathrm{~g} \mathrm{MS} \mathrm{m}^{-2}$ para 159 e $359 \mathrm{~g} \mathrm{MS} \mathrm{m}^{-2}$, respectivamente, somente quando se elevou o $\mathrm{pH}$ do solo de 4,8 para 6,7 com adição de $\mathrm{CaCO}_{3}$ e não com o uso do gesso. A adição de gesso não causou elevação do pH do solo $(4,5)$. Fica claro que a utilização de gesso em alfafa deve estar acompanhada de calagem, uma vez que a alfafa é extremamente sensivel ao baixo $\mathrm{pH}$.

Sumner et al. (1986) testaram em solo ácido do sudeste do USA (Typic Hapludults) o efeito da calagem profunda (incorporado a 1 metro) e do gesso misturado na superficie do solo na cultura de alfafa em niveis de 10 e $18 \mathrm{tha}^{-1}$ de gesso e calcário calcítico respectivamente. Foi também adicionado $3 \mathrm{t} \mathrm{ha}^{-1}$ de calcário calcítico finamente moido na superficie do solo em cada tratamento. $\mathrm{O}$ tratamento com calcário foi o que obteve maior produção de alfafa, com $12 \mathrm{t} \mathrm{ha}^{-1}$ contra $10 \mathrm{e} 8 \mathrm{tha}^{-1}$ para os tratamentos com gesso e controle, respectivamente. Nessa mesma pesquisa foi verificado que após um ano de experimento houve aumento no enraizamento da planta em relação ao controle quando utilizou-se gesso. Observou-se, também, diminuição da concentração de $\mathrm{Al}^{3+}$ de 6,26 para $5,43 \mathrm{cmol} \mathrm{kg}^{-1}$ e aumento de 430 para $2349 \mathrm{cmol} \mathrm{kg}^{-1}$ do nivel de Ca na solução do perfil do solo enquanto que o $\mathrm{pH}$ permaneceu inalterado com a aplicação do gesso. Pela dificuldade de incorporação do calcário em profundidade e pelos bons resultados obtidos com o gesso, os autores concluíram que a utilização do gesso poderia ser uma prática viável. 
Assim, como o gesso reduziria a atividade do ín $\mathrm{Al}^{3+}$ no perfil do solo, sem alterar o pH (Borkert et al, 1987), sua combinação com o fosfato de Gafsa poderia diminuir a fixação do fósforo pelo alumínio e, portanto, não limitaria a disponibilidade do fosfato de Gafsa no solo aumentando, consequentemente, sua eficiência.

Considerando que as respostas da cultura com fosfato de rocha variam em função da espécie vegetal utilizada e a escassez de trabalhos sobre a utilização do fosfato de Gafsa no cultivo de alfafa, tornou-se, assim, necessária a presente pesquisas sobre esse assunto. Entretanto o estudo do efeito do calcário sobre a eficiência do adubo fosfatado é fundamental por haver interferência do $\mathrm{pH}$ do solo sobre a disponibilidade de fósforo as plantas. 


\section{OBJETIVOS E HIPÓTESES}

\subsection{Objetivos}

Os objetivos desse trabalho foram:

- verificar a eficiência do fosfato de Gafsa (FG) como fonte de fósforo para alfafa (Medicago sativa L.), em relação ao fosfato super triplo, em função dos níveis de fósforo, momento de calagem (antes ou após a aplicação do fósforo) e utilização do gesso junto ao FG;

- estimar a dose de adubo fosfatado para a produção máxima da parte aérea da alfafa;

- verificar a disponibilidade de fósforo no solo para cada fonte, momento de calagem e utilização do gesso junto da fosfatagem;

- verificar a variação de pH do solo em função das fontes de fósforo;

- verificar o efeito da dosagem e da fonte de fósforo sobre a dinâmica de brotação da alfafa, assim como o número de brotos basais e laterais em cada ciclo de crescimento; - verificar o efeito da dosagem e fonte de fósforo sobre o teor de $\mathrm{P}, \mathrm{N}, \mathrm{Ca}$ e $\mathrm{Mg}$ na MS da parte aérea e raiz da alfafa.

\subsection{Hipóteses}

As hipóteses estabelecidas nesse trabalho foram:

- alfafa (Medicago sativa L.) é exigente em fósforo;

- as respostas da alfafa em função das fontes de fósforo, momento de calagem e a 
utilização de gesso são diferentes devido a maior solubilidade do superfosfato triplo comparado ao fosfato de Gafsa;

- inicialmente, com o uso do ST ocorre maior produção de MS que deve diminuir ao longo do tempo devido ao menor valor residual desse fertilizante, enquanto o fosfato de Gafsa tem menor produção inicial e esta aumenta nos cortes subseqüentes;

- a aplicação de calagem antes do fosfato supertriplo eleva a eficiência desse; enquanto que a calagem adicionada depois do fosfato de Gafsa tem o objetivo de permitir a solubilização do fósforo pela acidez do solo, aumentando a eficiência desse fertilizante;

- a utilização do gesso junto ao fosfato de Gafsa, contribui para diminuir a fixação do fósforo pelo alumínio e, consequentemente, aumentar a disponibilidade do fósforo e eficiência do adubo;

- a brotação da alfafa está altamente relacionada com fósforo disponível. 


\section{MATERIAL E MÉTODOS}

\subsection{Local e características do solo}

O experimento foi realizado em estufa do CEBTEC (Centro de Biotecnologia Agrícola - ESALQ), localizado no município de Piracicaba, Estado de São Paulo.

Foi coletado aproximadamente $550 \mathrm{~kg}$ de solo classificado como Latossolo Vermelho Amarelo Álico (Typic Mapluolox soil) no Instituto de Zootecnia (IZ), localizado no município de Nova Odessa - SP, para o plantio de alfafa em vasos.

As análises química e granulométrica do solo são apresentadas nos Quadros $1,2 \mathrm{e}$ 3.

Quadro 1 - Resultados de análises química em amostra do solo usado nos vasos para o cultivo da alfafa.

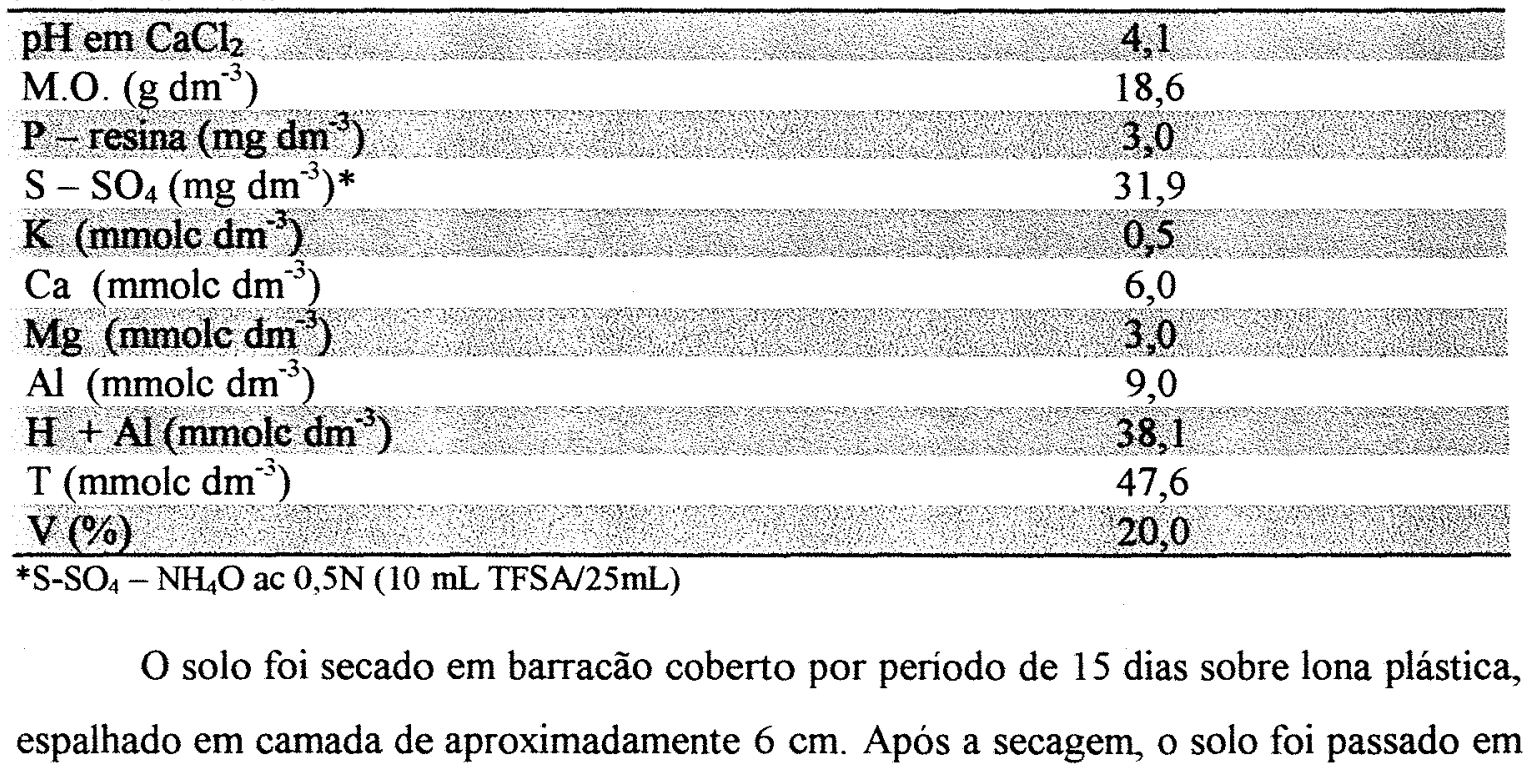


peneira (malha de $2 \mathrm{~mm}$ ) para destorroamento e uniformização. Posteriormente foram colocados $6 \mathrm{~kg}$ de solo por vaso plástico.

Quadro 2 - Resultados de análises de micronutrientes do solo usado nos vasos para o cultivo da alfafa usado nos vasos para o cultivo da alfafa.

\begin{tabular}{cccccc}
\hline $\mathrm{B}$ & $\mathrm{Cu}^{*}$ & $\mathrm{Fe}^{*}$ & $\mathrm{Mn}^{*}$ & $\mathrm{Zn}^{*}$ & $\mathrm{Na}$ \\
\hline \multicolumn{5}{c}{$\mathrm{mg} \mathrm{dm}^{-3}$} \\
\hline 0,02 & 0,6 & 32,0 & 1,2 & 0,2 & 2,3 \\
\hline
\end{tabular}

Método utilizado: * DTPA -TEA, pH 7,3.

B: $\mathrm{BaCl}_{2} \cdot 2 \mathrm{H}_{2} \mathrm{O} 0,125 \%$ microondas ( $10 \mathrm{~mL}$ TFSA $20 \mathrm{ml} \mathrm{BaCL}_{2} 0,124 \%$ ).

$\mathrm{Na}-\mathrm{HCl} 0,05 \mathrm{~N}+\mathrm{H}_{2} \mathrm{SO}_{4} 0,025 \mathrm{~N}(5 \mathrm{~g}$ TFSA$/ 50 \mathrm{~mL})$.

Quadro 3 - Resultados da análise granulométrica* do solo usado nos vasos para o cultivo da alfafa.

\begin{tabular}{ccccc}
\hline Areia & Limo & Argila & Floculação & Classe \\
\cline { 1 - 4 } & & $\%$ & & Textural \\
\hline 60 & 18 & 22 & 64 & Média arenosa \\
\hline
\end{tabular}

* Classes de diâmetro $(\mathrm{mm})$ :

areia: $2-0,05$

silte: $0,05-0,002$

argila: $<0,002$

Classe textural:

Solo médio arenoso: 15 a $24 \%$ de argila 


\subsection{Tratamentos}

Os tratamentos, usados, estão apresentados no Quadro 4.

Quadro 4 - Fontes e níveis de fosfatos combinados com calagem e fontes de enxofre aplicados em vasos para o cultivo da alfafa.

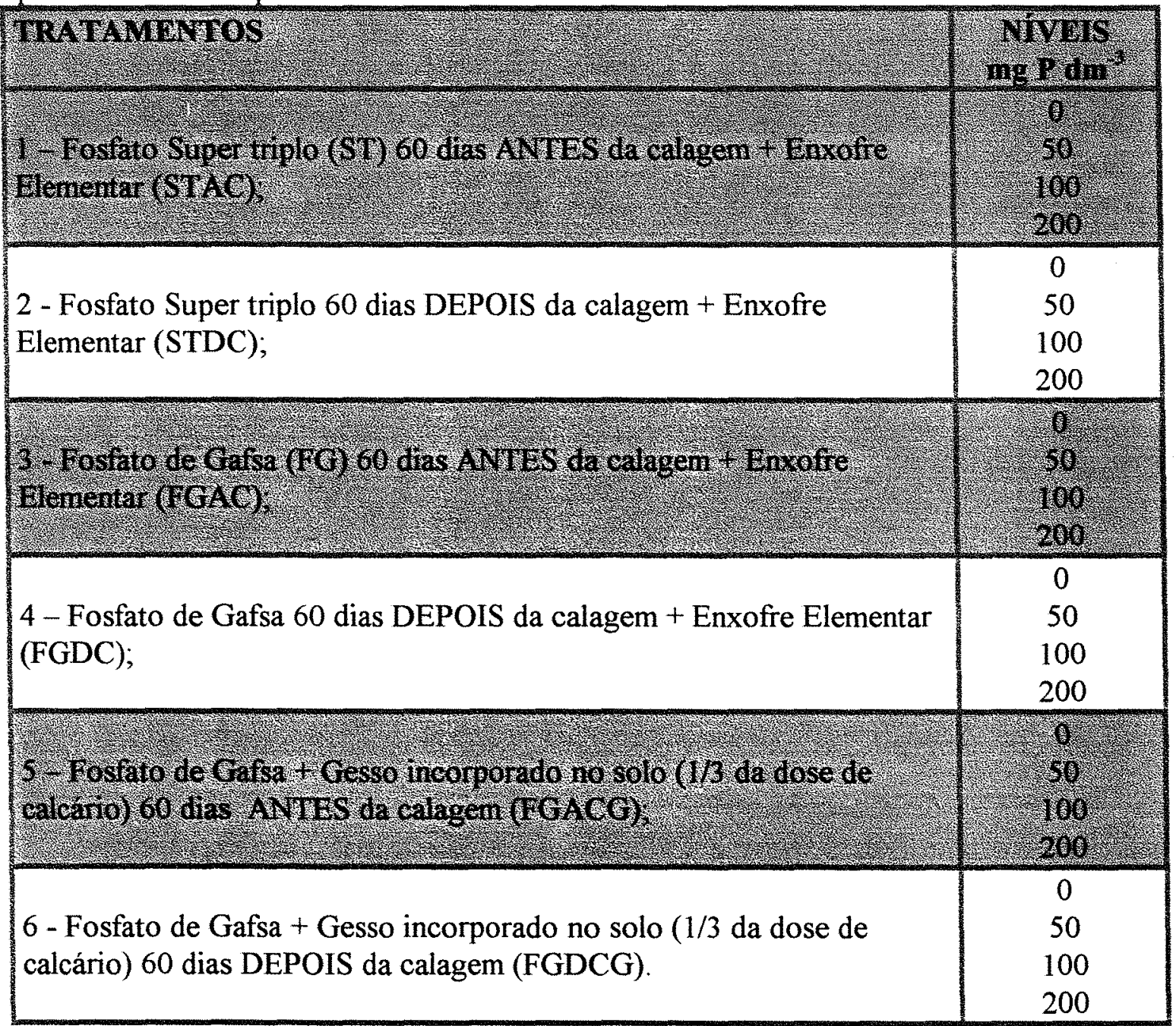

\subsection{Plantio e colheitas}

Durante a fase experimental constatou-se ataque de fungo de solo (Fusarium) nas raizes, por duas vezes consecutivas causando apodrecimento do sistema radicular e consequentemente morte das mesmas. Devido a esse fato o plantio foi realizado por três vezes, cultivando-se 5 plantas por vaso. No primeiro plantio (05/10/97) a alfafa foi colhida com 47 dias, quando ocorreram os primeiros sintomas de infecção fungíca. No 
segundo plantio (25/01/98) as plantas estavam com duas semanas de idade quando surgiram, novamente, os sintomas do ataque de Fusarium e, por estarem muito pequenas, não foi mensurada a produção de MS da parte aérea.

A solução encontrada para o problema do Fusarium foi esterelizar o solo por meio de autoclavagem $\left(120^{\circ} \mathrm{C}\right.$ a 1,5 atm, por três horas) eliminando os fungos e os clamidosporos.

As esterilizações do solo foram realizadas duas vezes junto às instalações do CEBTEC (Centro de Biotecnologia Agrícola - ESALQ). Finalizado cada processo de autoclavagem, foi necessário um mês de repouso do solo para novamente efetuar-se o plantio. Esse cuidado foi necessário para reduzir os riscos de liberação de substâncias tóxicas pelo processo de autoclavagem que poderiam afetar o Rhizobium.

A contaminação pelo fungo, no segundo plantio, pode ter ocorrido devido ao fato das sementes não terem sido tratadas, uma vez que constatou-se contaminação de Fusarium ao nível de $1 \%$ nesse material.

Já no terceiro plantio (12/04/98), o primeiro corte foi realizado quando as plantas estavam com 3 meses de idade (10/07/98), e os dois cortes restantes foram feitos a cada 30 dias (09/08/98 e 08/09/98, respectivamente), colhendo-se as plantas a 7,5 cm do solo.

\subsection{Temperatura}

Uma vez que a estufa não possuía equipamento para controle da temperatura, registrava-se até $50^{\circ} \mathrm{C}$ nas horas mais quentes do dia no mês de janeiro. A temperatura muito elevada é prejudicial à sobrevivência do Rhizobium antes de infectar a raiz da planta (Tsai, 1998) ${ }^{6}$. Por esse motivo tomou-se o cuidado de se remover os vasos para estufa coberta por tela sombrite durante os primeiros quinze dias após a semeadura. Acreditava-se que esse ambiente proporcionava melhores condições para a fixação do Rhizobium nas raizes das plantas. Os dados de temperatura ambiental, fora das estufas, durante os períodos experimentais podem ser vistos nas Figuras 1 e 2.

\footnotetext{
${ }^{6}$ Tsai. S.M. Comunicação pessoal, 1998.
} 


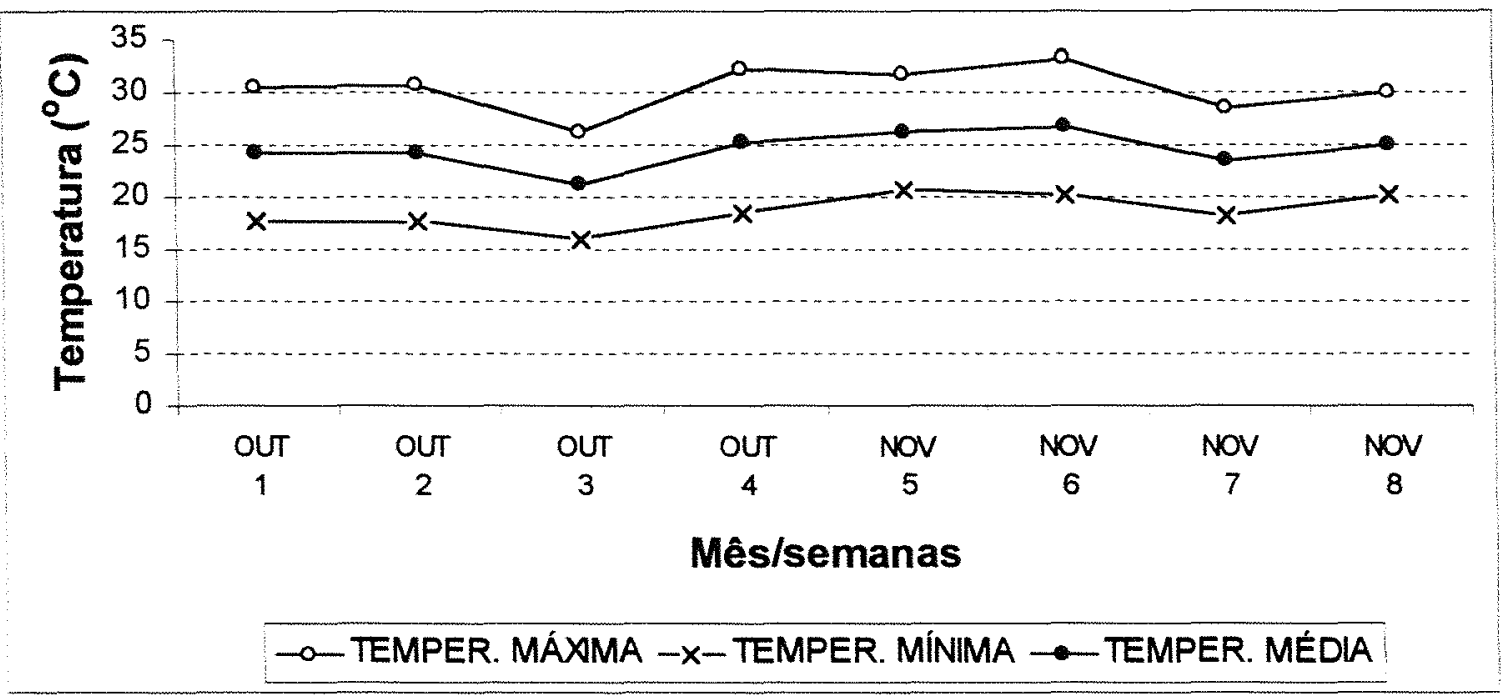

Figura 1 - Temperatura máximas, médias e mínimas (média semanal) durante o primeiro período experimental de 05 de outubro a 25 de novembro de 1997.

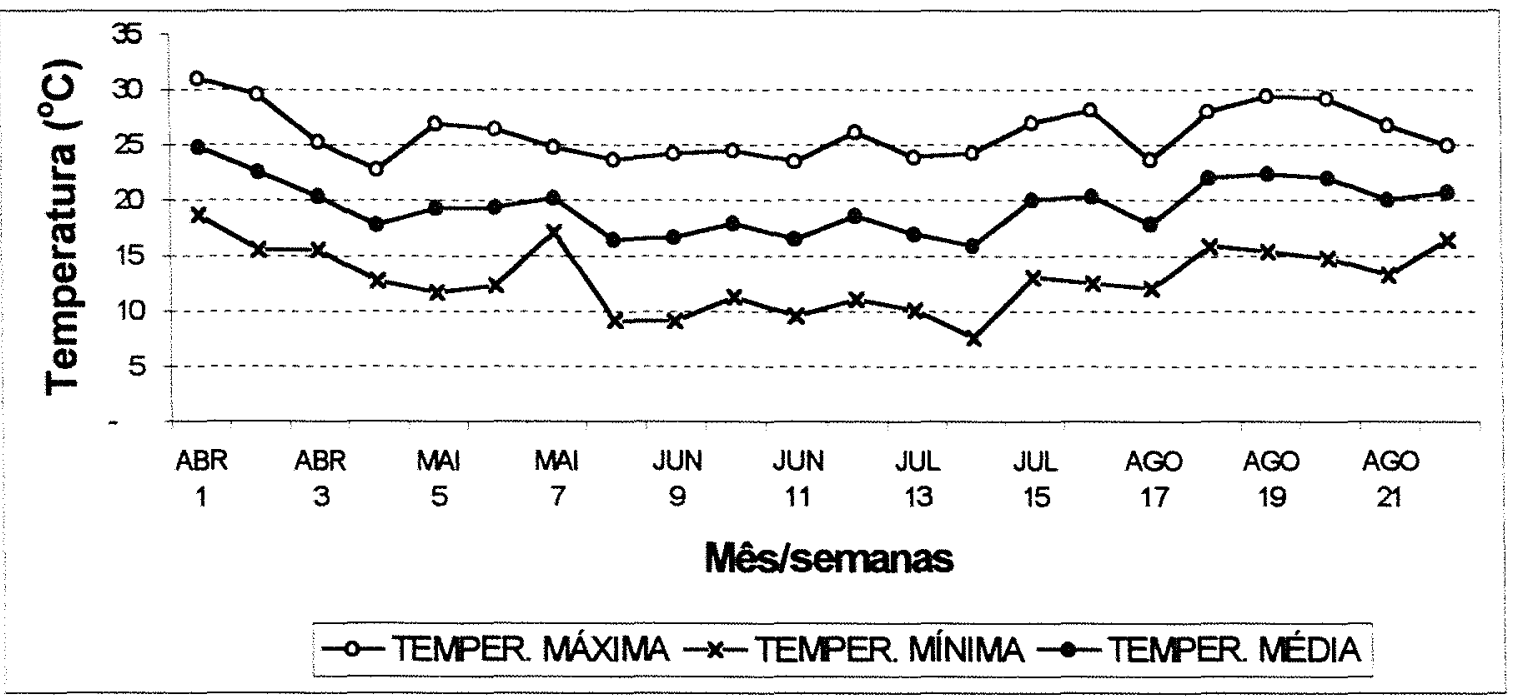

Figura 2 - Temperatura máximas, médias e mínimas (média semanal) durante o segundo período experimental (terceiro plantio) de 12 de abril a 08 de setembro de 1998. 


\subsection{Sementes e inoculação}

No primeiro e segundo plantios o cultivar de alfafa semeado foi Crioula cujas sementes não foram tratadas com fungicida. $O$ terceiro plantio foi feito com sementes do cultivar XAI 32 tratadas com fungicida.

As sementes de alfafa foram inoculadas com rizóbio específico (Rhizobium meliloti, SEMIA 116*), utilizando-se das proporções recomendadas por Sá e Keplin (1991); que são as seguintes:

- $10 \mathrm{~kg}$ de semente;

- $6 \mathrm{~kg}$ de calcário;

- 200 g de goma arábica;

- $600 \mathrm{~g}$ de inoculante;

- 1 litro de água

\subsection{Irrigação e manutenção da umidade}

A irrigação dos vasos foi realizada para manter a capacidade de campo do solo em $70 \%$. Para isso, os vasos foram pesados diariamente para completar a quantidade de água perdida por evaporação e/ou utilização pelas plantas.

\subsection{Adubação}

Os adubos (calcário, superfosfato triplo, fosfato de Gafsa, gesso e enxofre elementar) foram misturados uniformemente ao solo de acordo com os tratamentos. Após a primeira adubação os solos foram incubados por período de 2 meses, a fim de ocorrer a solubilização do fosfato de Gafsa e completa reação do calcário ao solo. Quando as fontes de fósforo foram aplicadas sem gesso foi fornecido enxofre elementar para manter o mesmo nível desse nutriente fornecido pelo gesso. O Quadro 5 indica a análise do gesso e enxofre utilizados na pesquisa.

Completados os dois meses de incubação inicial os solos de cada parcela foram colocados em sacos plásticos de 60 litros, durante uma semana em casa de vegetação a

\footnotetext{
* Doado pelo Cena (Centro de Energia Nuclear na Agricultura)
} 
fim de facilitar a secagem. A partir de então, realizou-se segunda etapa de adubação seguida de incubação por mais dois meses.

Quadro 5 - Resultados da análise do gesso e do enxofre elementar empregados no cultivo da alfafa em vasos.

\begin{tabular}{lcc}
\hline & $\mathrm{S}(\%)$ & $\mathrm{CaO}(\%)$ \\
\hline Gesso & 16,9 & 22,0 \\
\hline Enxofre elementar & 91,5 & 0,0 \\
\hline
\end{tabular}

Os fosfatos utilizados foram analisados (Quadro 6) objetivando conhecer as características químicas do produto.

Quadro 6 - Resultados de análises dos fertilizantes fosfatados empregados no cultivo da alfafa em vasos.

\begin{tabular}{lcc}
\hline Características & \multicolumn{2}{c}{ Fontes } \\
\cline { 2 - 3 }$\%$ & Superfosfato triplo & Fosf. de Gafsa \\
\hline $\mathbf{P}_{\mathbf{2}} \mathbf{O}_{\mathbf{5}}$ & & $\%$ \\
Total & 47,1 & \\
Solúvel em água & 38,8 & 27,4 \\
Solúvel em ácido cítrico & 40,0 & 0,2 \\
Solúvel em citrato + água & 43,8 & 11,1 \\
$\mathrm{Ca}$ & 14,5 & 2,7 \\
$\mathrm{Mg}$ & 0,0 & 35,5 \\
\hline
\end{tabular}

A calagem foi realizada visando elevar a saturação por bases a $80 \%$, utilizando calcário dolomítico (Quadro 7). Quando se utilizou de gesso junto ao fosfato, a dose de calcário foi $2 / 3$ do recomendado para elevar a saturação por bases a $80 \%$.

As adubações com micronutrientes e cloreto de potássio foram realizadas juntamente com o primeiro plantio, usando-se soluções preparadas conforme mostrado no Quadro 8.

As adubações de manutenção foram realizadas após cada corte que consistiram na aplicação de $\mathrm{KCl}$, de acordo com o teor de $\mathrm{K}$ na MS que foi considerado como sendo $3,6 \%$ de $\mathrm{K}$. Werner et al. (1996) indicaram os teores de 2,0 a $3,5 \%$ de potássio na 
matéria seca como sendo adequados para a alfafa. Assim, após a determinação da produção de matéria seca por tratamento calculou-se a adubação potássica.

Quadro 7 - Resultados de análises do calcário utilizado no cultivo da alfafa em vasos.

\begin{tabular}{lccc}
\hline Determinação & & $\%$ \\
\hline Óxido de cálcio & & & 29,7 \\
Óxido de magnésio & & & 19,4 \\
Carbonato de cálcio & & & 53,1 \\
Carbonato de magnésio & Tyler (Mesh) & abertura (mm) & 48,0 \\
\hline Granulometria & 10 & 2,0 & 100,0 \\
& 20 & 0,8 & 99,0 \\
& 50 & 0,3 & 81,2 \\
\hline PRNT & & & 89,0 \\
\hline
\end{tabular}

Quadro 8 - Composição das soluções usadas para fornecimento de micronutrientes as plantas de alfafa cultivadas em vasos.

\begin{tabular}{lccc} 
Produto & Elemento & $\mathrm{mg} \mathrm{dm}^{-3}$ & $\begin{array}{c}\text { Gramas do produto em } \\
1 \text { litro de água }\end{array}$ \\
\hline $\mathrm{KCl}$ & $\mathrm{K}$ & 171 & $17,4(1)$ \\
$\mathrm{H}_{3} \mathrm{BO}_{3}$ & $\mathrm{~B}$ & 1,0 & $1,00(2)$ \\
$\mathrm{CoCl}_{2} \cdot 2 \mathrm{H}_{2} \mathrm{O}$ & $\mathrm{Co}$ & 0,1 & $0,05(2)$ \\
$\mathrm{CuSO}_{4} \cdot 5 \mathrm{H}_{2} \mathrm{O}$ & $\mathrm{Cu}$ & 1,5 & $1,9(2)$ \\
$\mathrm{FeSO}_{4} \cdot 7 \mathrm{H}_{2} \mathrm{O}$ & $\mathrm{Fe}$ & 5 & $4,3(2)$ \\
$\mathrm{MnSO}_{4} \cdot \mathrm{H}_{2} \mathrm{O}$ & $\mathrm{Mn}$ & 5 & $3,1(2)$ \\
$\mathrm{NaMo}_{2 n \mathrm{ZO}_{4} \cdot 7 \mathrm{H}_{2} \mathrm{O}}$ & $\mathrm{Mo}$ & 0,1 & $0,04(2)$ \\
\hline
\end{tabular}

(1) Utilizou-se $100 \mathrm{~mL}$ de solução por vaso de $6 \mathrm{~kg}$ de solo

(2) Utilizou-se $30 \mathrm{~mL}$ de solução por vaso de $6 \mathrm{~kg}$ de solo

Antes de ser realizado o terceiro plantio constatou-se que o $\mathrm{pH}$ do solo se apresentava ao redor de $4,8\left(\mathrm{CaCl}_{2}\right)$ e a saturação de base em torno de $70,5 \%$. Assim, após a segunda autoclavagem, fez-se nova aplicação de calcário seguida de incubação por 38 dias a fim de elevar a saturação por bases a $85,0 \%$. 


\subsection{Teores dos nutrientes do solo}

Antes do terceiro plantio da alfafa foram coletadas amostras de solos e analisadas (Quadro 9).

Quadro 9 - Resultados das análises química em amostra do solo antes do terceiro plantio.

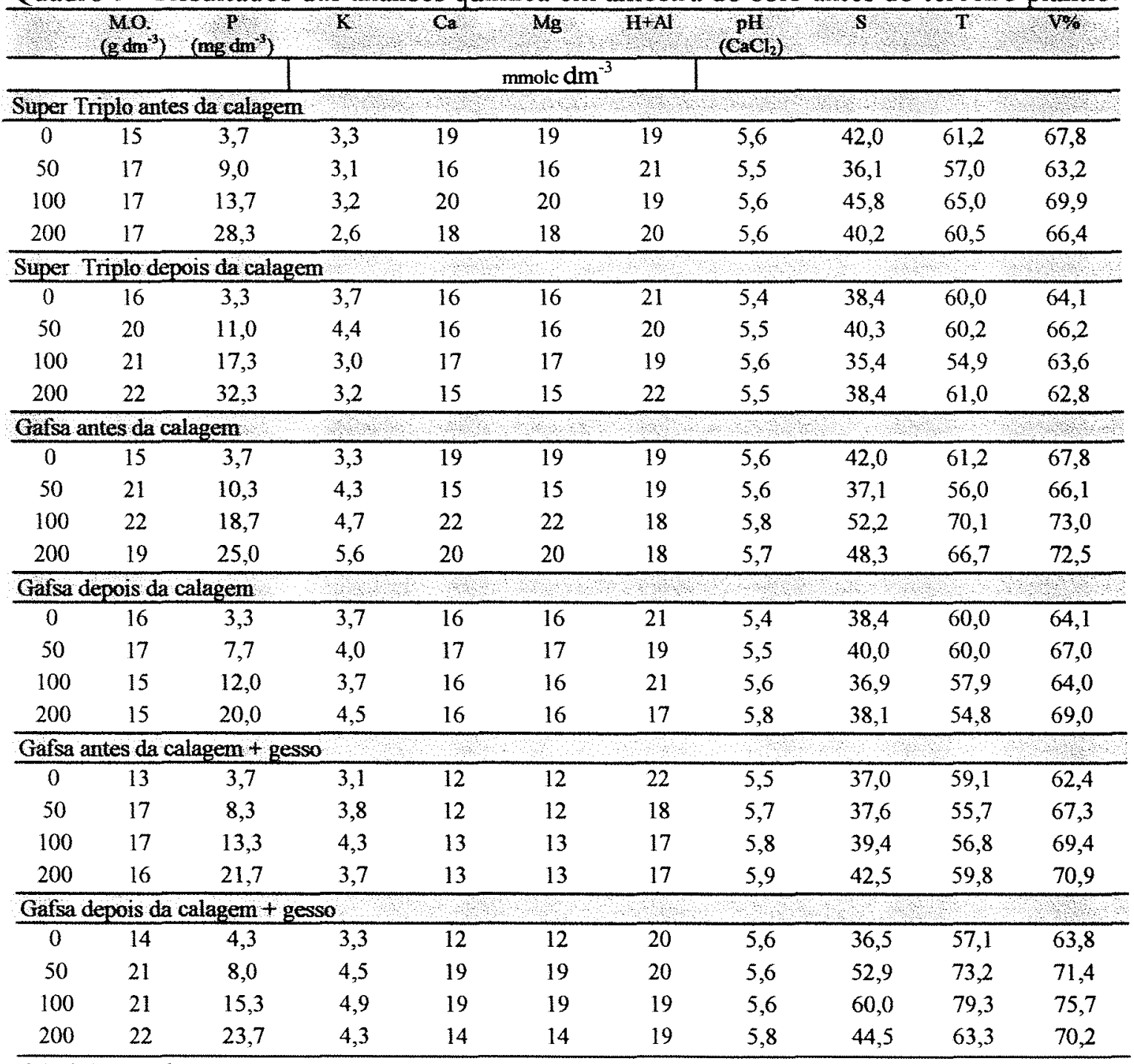

* Média de três repetiç̃̃es

\subsection{Controle de pragas}

O controle de pragas foi efetuado, quando necessário, mediante o uso dos inseticidas Decis (deltamethrine), Confidor 700 (imidacloprid) e o acaricida Vertimec 1.8 CE (abamectin). As pragas controladas durante a fase experimental foram tripes (Thrips 
tabaci), minador (Agromyza frontella Rondani), pulgão verde (Acyrthosiphon pisum Harris) e ácaro (Mononychus tanajoa).

As dosagens utilizadas para o controle específico de cada praga foram:

- $1 \mathrm{~mL}$ de Decis por litro de água - controle de tripes e minador;

- 0,3 mL de Vertimec por litro de água - controle de ácaro;

- $30 \mathrm{~g}$ de Confidor por litro de água - controle de pulgão.

\subsection{Resultados avaliados}

Os seguintes parâmetros avaliados nesse trabalho foram:

- produção de matéria seca da parte aérea em cada corte;

- peso seco das raízes;

- disponibilidade de fósforo no solo antes do terceiro plantio e após a última colheita;

- $\mathrm{pH}$ no solo antes do terceiro plantio e após a última colheita;

- eficiência agronômica do fosfato de Gafsa;

- sintomas nutricionais;

- macronutrientes na parte aérea e raiz da alfafa;

- dinâmica de surgimento de brotos e número de brotos.

\subsection{Determinação do teor de fósforo no solo e macronutrientes da planta}

A disponibilidade de fósforo no solo foi avaliada no laboratório de Nutrição Mineral de Plantas da ESALQ/USP através do método de resina trocadora de íons (Raij et al., 1986).

Após a colheita as plantas de alfafa foram lavadas com detergente neutro diluído, ácido clorídrico diluído (20\%) e água deonizada, secadas ao ar e colocadas em sacos de papel para secagem em estufa a $65^{\circ} \mathrm{C}$ até peso constante. Esse método foi usado para eliminar o provável efeito das aplicações dos inseticidas sobre a composição mineral das plantas (Monteiro, 1998) ${ }^{7}$.

\footnotetext{
Monteiro. F.A. Comunicação pessoal, 1998.
} 
As determinações dos teores de macronutrientes no tecido das plantas foram realizadas pelo Laboratório de Nutrição Mineral de Plantas da ESALQ/USP, seguindo os métodos descritos por Sarruge \& Haag (1974).

\subsection{2 Índice de eficiência agronômica}

Foi utilizado para avaliação dos fosfatos, o índice de eficiência agronômica (IEA), descrito por Goedert \& Sousa (1984), calculado como:

$$
\begin{aligned}
\text { IEA }(\%)= & \underline{Y}_{2}-Y_{1} \times 100 \\
& Y_{3}-Y_{1}
\end{aligned}
$$

Sendo:

$\mathrm{Y}_{1}=$ produção obtida pela parcela onde não houve aplicação de fósforo (zero para primeiro plantio e segundo e terceiro cortes do terceiro plantio e $50 \mathrm{mg} \mathrm{MS} / \mathrm{vaso}$ no primeiro corte do terceiro plantio);

$\mathrm{Y}_{2}=$ produção obtida pela fonte que está sendo testada, com a dose $\mathrm{X} 2$;

$\mathrm{Y}_{3}=$ produção obtida pela fonte de referência (Super triplo aplicado depois da calagem) na mesma dose $(\mathrm{X} 2)$ de fósforo total aplicado.

$\mathrm{X} 2=$ doses em estudo $\left(50,100 \mathrm{e} 200 \mathrm{mg} \mathrm{P} \mathrm{dm}^{-3}\right)$

\subsection{Brotos}

A dinâmica de aparecimento de brotos foi avaliada mediante a marcação do aparecimento de novos brotos basais e axilares através da colocação de fios coloridos, e contagem de brotos que morriam. Estas observações foram efetuadas a cada dois dias durante todos os períodos de crescimento do terceiro plantio.

\subsection{Peso seco das raízes}

Após o último corte do terceiro plantio as raízes das plantas foram recuperadas mediante lavagem com água corrente sobre duas peneiras com malhas de 5 e $2 \mathrm{~mm}$, para evitar perda de material. As raizes lavadas foram colocadas em bandejas e secas em estufa de circulação de ar a temperatura de $65^{\circ} \mathrm{C}$ até peso constante. 


\subsection{Análise estatística}

Embora tenha-se planejado a utilização do nível zero de fósforo nos tratamentos, esse nível não fez parte da análise estatística. Isso foi devido à morte das plantas, uma vez que, no primeiro plantio, na ausência do adubo, as plantas apresentaram-se mais sensiveis ao ataque do fungo Fusarium. Por outro lado, no terceiro plantio, nos tratamentos sem a aplicação de fósforo, as plantas morreram após o primeiro corte.

Dessa maneira, tanto para o primeiro plantio como para a produção de matéria seca e nutrientes da raiz da alfafa no terceiro plantio, foram adotados 6 fontes de fósforo e 3 doses, em esquema fatorial. O delineamento estatístico foi em blocos ao acaso com 3 repetições, sendo o modelo matemático:

$$
Y_{i j k}=m+T_{i}+D_{1}+(T D)_{i 1}+b_{j}+e_{i j j}
$$

onde:

$\mathrm{Y}_{\mathrm{ijk}}=$ valor observado referente ao i-ésimo tratamento no j-ésimo bloco;

$\mathrm{m}=$ fator fixo, estimado pela média geral;

$\mathrm{T}_{\mathbf{i}}=$ efeito da i-ésima fonte;

$\mathrm{D}_{1}=$ efeito da l-ésima dose;

$(\mathrm{TD})_{\mathrm{il}}=$ efeito da interação da i-ésima fonte com a l-ésima dose;

$b_{\mathrm{j}}=$ efeito do j-ésimo bloco;

$\mathrm{e}_{\mathrm{ij}}=$ erro aleatório, suposto independente e normalmente distribuído.

Para o terceiro plantio, o delineamento foi em blocos ao acaso com parcelas subdivididas no tempo. Foram utilizados 6 fontes de fósforo, 3 doses e 3 cortes, e o modelo matemático adotado foi:

$$
\mathrm{Y}=\mathrm{m}+\mathrm{T}_{\mathrm{i}}+\mathrm{D}_{\mathrm{l}}+(\mathrm{TD})_{\mathrm{il}}+\mathrm{b}_{\mathrm{j}}+\mathrm{e}_{\mathrm{ijl}}+\mathrm{C}_{\mathrm{k}}+(\mathrm{CT})_{\mathrm{ki}}+(\mathrm{CD})_{\mathrm{kl}}+(\mathrm{CTD})_{\mathrm{kil}}+\varepsilon_{\mathrm{ijkl}}
$$

sendo:

$Y_{\mathrm{ij}}=$ valor observado referente ao i-ésimo tratamento no j-ésimo bloco;

$\mathrm{m}$ = fator fixo, estimado pela média geral;

$T_{\mathrm{i}}=$ efeito da i-ésima fonte;

$D_{1}=$ efeito da l-ésima dose;

$(T D)_{i l}=$ efeito da interação da i-ésima fonte com a l-ésima dose; 
$b_{j}=$ efeito do j-ésimo bloco;

$\mathrm{e}_{\mathrm{ij}}=$ erro aleatório correspondente às parcelas (variação do acaso sobre as observações da i-ésima fonte e da l-ésima dose no j-ésimo bloco), suposto independente e normalmente distribuído.

$\mathrm{C}_{\mathrm{k}}=$ efeito do k-ésimo corte;

(CT) = efeito da interação do k-ésimo corte com a i-ésima fonte;

$(C D)_{\mathrm{kl}}=$ efeito da interação do k-ésimo corte com a l-ésima dose;

$(\mathrm{CTD})_{\mathrm{kil}}=$ efeito do k-ésimo corte com a i-ésima fonte e a l-esima dose;

$\varepsilon_{i \mathrm{jk}}=$ erro aleatório correspondente às parcelas (variação do acaso sobre as observações da i-ésima fonte, l-ésima dose, k-ésimo corte, no j-ésimo bloco), supostamente independente e normalmente distribuído.

Algumas variáveis não apresentaram distribuição normal ou homogeneidade de variância e precisaram ser transformadas para ajustar o modelo:

- produção de MS da parte aérea $\left(3^{\circ}\right.$ plantio $) \rightarrow$ raiz $(X+0)$;

- produção de MS da raiz $\left(3^{\circ}\right.$ plantio $) \rightarrow \operatorname{raiz}(X+0)$;

- teor de $\mathrm{P}$ no solo $\rightarrow \log (\mathrm{X}+0)$;

- número de brotos basais $\rightarrow$ raiz $(X+0)$;

- número de brotos laterais $\rightarrow$ raiz $(X+0)$.

- teor de $\mathrm{Mg}$ na parte aérea $\left(1^{\circ}\right.$ plantio $) \rightarrow 1 /\left(\mathrm{X}^{1 / 2}\right)$;

- teor de $\mathrm{P}$ na raiz $\left(3^{\circ}\right.$ plantio $) \rightarrow 1 /\left(X^{1 / 2}\right)$;

- teor de $\mathrm{Mg}$ na raiz $\left(3^{\circ}\right.$ plantio $) \rightarrow \log (\mathrm{X}+0)$.

Para a discussão do índice de eficiência agronômica do FG, da dinâmica de surgimento de brotos, do número percentual de brotos basais aos 15 dias após o corte, bem como dos teores de nutrientes da parte aérea da alfafa no terceiro plantio utilizou-se análise descritiva. Em relação aos nutrientes da parte aérea no terceiro plantio, a análise descritiva foi realizada devido à necessidade de juntar as produções de MS das três repetições de alguns tratamentos (Apêndice 26) a fim de se conseguir realizar as análises laboratoriais tornando assim, o delineamento incompleto e desbalanceado o que impossibilitou a utilização do modelo de análise de variância com parcelas subdivididas. 
Os dados foram submetidos à análise de variância através do SANEST/USP (Sarries et al., 1993). Para comparação entre as fontes de fósforo de todas as variáveis analisadas, com exceção daquelas onde realizou-se a análise descritiva, foi utilizado o teste $\mathrm{t}$ para contrastes ortogonais. Os resultados de $\mathrm{pH}$ do solo foram comparados pelo teste de Tukey. $\mathrm{O}$ efeito de doses de fósforo sobre as variáveis foi estudado através da análise de regressão polinomial, enquanto que utilizou-se o teste de Tukey para verificar o efeito dos cortes sobre as variáveis estudadas. 


\section{RESULTADOS E DISCUSSÃO}

\subsection{Produção de matéria seca da parte aérea de alfafa}

As produções médias de matéria seca da parte aérea da alfafa em decorrência das fontes e níveis de fósforo, obtidas no primeiro e terceiro plantio, estão apresentadas nas Tabelas 1 e 7 e Apêndice 1. Os quadros de análise de variância encontram-se nos Apêndices 2 e 3, onde foram detectados as interações $(P<0,05)$ entre fontes e doses, no primeiro plantio e, entre cortes, fontes e doses, no terceiro plantio respectivamente.

Tabela 1 - Produção de matéria seca da parte aérea (g MS/vaso) de alfafa durante o primeiro plantio.

\begin{tabular}{lcccccc}
\hline & & & Fontes de fósforo & & \\
\hline Niveis de P & STAC & STDC & FGAC & FGDC & FGACG & FGDCG \\
(mg d m $\left.\mathbf{m}^{-3}\right)$ & & & & & & \\
\hline 50 & 0,90 & 1,35 & 0,35 & 0,34 & 0,45 & 0,44 \\
100 & 2,75 & 4,29 & 1,45 & 1,23 & 0,86 & 0,60 \\
200 & 4,71 & 5,71 & 1,92 & 1,91 & 1,24 & 1,64 \\
\hline
\end{tabular}

(STAC: super triplo antes da calagem; STDC: super triplo depois da calagem; FGAC: Fosfato de Gafsa antes da calagem; FGDC: Fosfato de Gafsa depois da calagem; FGACG: Fosfato de Gafsa antes da calagem mais gesso; FGDCG: Fosfato de Gafsa depois da calagem mais gesso).

$\mathrm{CV}=24,6 \%$.

A alfafa respondeu $(\mathrm{P}<0,05)$ à adubação fosfatada em relação à produção de MS da parte aérea no primeiro plantio (Tabela 1 e 2). O melhor ajuste no modelo matemático para a produção de matéria seca em função das doses de fósforo aplicadas foi quadrática para o tratamento STDC e linear para as demais fontes (Tabela 2). A resposta linear a 
adubação fosfatada deve-se, provavelmente, à antecipação do corte (47 dias) por causa do ataque do fungo Fusarium, o que ocasionou, consequentemente, baixa produção de MS. A observação de equações de modelo linear, impediu a obtenção de respostas às doses de adubos fosfatados que garantissem a produção máxima esperada da alfafa.

Os dados observados mostram o efeito favorável da adubação fosfatada na produção da matéria seca de alfafa, confirmando os resultados obtidos por Sanderson (1993), Sanderson \& Jones (1993), Pinheiro et al. (1993), Yupanqui (1997) e Moreira (1997).

Tabela 2 - Equações de regressão ajustadas entre produção de matéria seca da parte aérea da alfafa $(\mathrm{Y})$, como variável dependente de dose de fósforo $\left(\mathrm{mg} \mathrm{dm}^{-3}\right)(\mathrm{X})$ para os três cortes e os níveis de fósforo calculados para máxima produção.

\begin{tabular}{|c|c|c|c|c|}
\hline $\begin{array}{l}\text { Fontes de } \\
\text { fósforo }\end{array}$ & Equações & $\mathbf{R}^{2}$ & $\begin{array}{c}\text { Nivel de P } \\
\left(\mathrm{mg}^{1} \mathrm{dm}^{-3}\right)\end{array}$ & $\begin{array}{l}\text { Produção }^{(2)} \\
\text { (g MS/vaso) }\end{array}$ \\
\hline STAC & $Y=0,012937+0,024873 X$ & $0,98^{*}$ & - & - \\
\hline STDC & $Y=-2,25955+0,092080 X-0,00025 X^{2}$ & $1,00^{*}$ & 184,16 & 6,22 \\
\hline FGAC & $Y=0,194175+0,0093692 X$ & $0,80^{*}$ & - & - \\
\hline FGDC & $Y=0,075981+0,0095881 X$ & $0,95 *$ & - & - \\
\hline FGACG & $Y=0,278385+0,0050783 X$ & $0,93^{*}$ & - & - \\
\hline FGDCG & $Y=-0,047515+0,0083403 X$ & $0,97^{*}$ & - & - \\
\hline
\end{tabular}

(STAC: super triplo antes da calagem; STDC: super triplo depois da calagem; FGAC: Fosfato de Gafsa antes da calagem; FGDC: Fosfato de Gafsa depois da calagem; FGACG: Fosfato de Gafsa antes da calagem mais gesso; FGDCG: Fosfato de Gafsa depois da calagem mais gesso).

(I) Nível de fósforo para produção máxima de MS estimada pela equação de regressão.

${ }^{\text {(2) }}$ Produção máxima de MS estimada pela equação de regressão.

* significativo a $5 \%$ de probabilidade.

No primeiro plantio, observou-se melhor resposta da alfafa $(\mathrm{P}<0,05)$ à adubação com ST (Figura 3 e contraste 1 da Tabela 3) do que com FG, em todas as doses de fósforo aplicadas. Isso deve-se ao fato da maior disponibilidade de fósforo proveniente da fonte solúvel, colaborando, assim, para o rápido crescimento da cultura e cobertura do solo em curto espaço de tempo. Honda \& Honda (1990) relataram que o rápido estabelecimento do alfafal é de vital importância para que não haja comprometimento, de modo irreversível, na formação e produtividade econômica da cultura pela competição com ervas daninhas. 


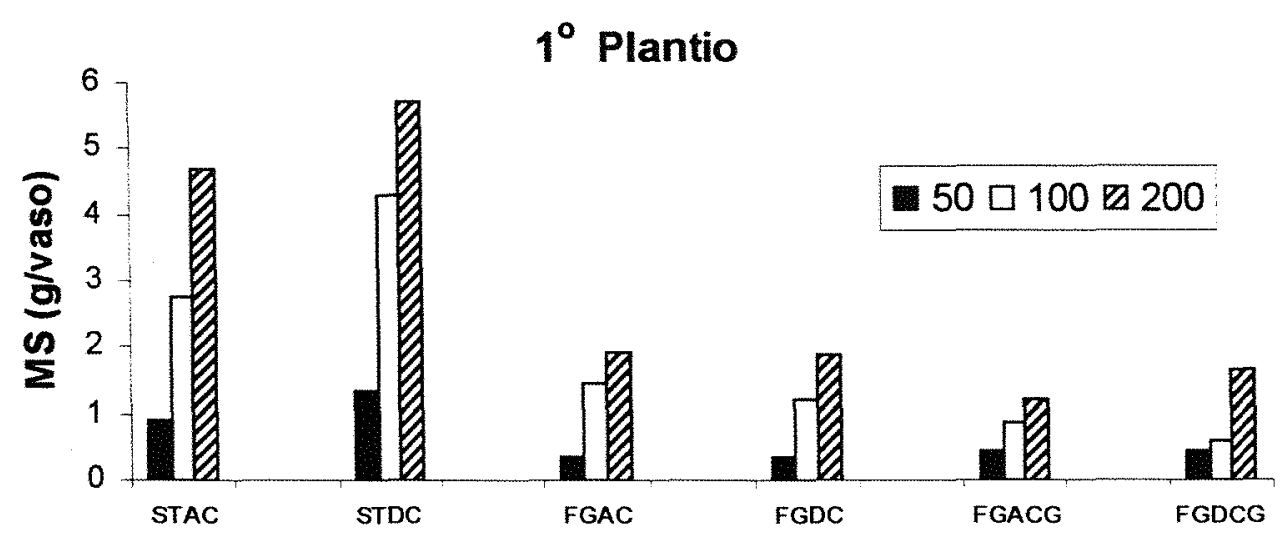

Fontes de fósforo

Figura 3 - Produção de matéria seca da parte aérea da alfafa (g MS/vaso) conforme diferentes fontes e doses de fósforo $\left(50,100\right.$ e $\left.200 \mathrm{mg} \mathrm{dm}^{-3}\right)$ no primeiro plantio da alfafa.

(STAC: super triplo antes da calagem; STDC: super triplo depois da calagem; FGAC: Fosfato de Gafsa antes da calagem; FGDC: Fosfato de Gafsa depois da calagem; FGACG: Fosfato de Gafsa antes da calagem mais gesso; FGDCG: Fosfato de Gafsa depois da calagem mais gesso).

Tabela 3 - Contrastes ortogonais para comparação das médias de produção de MS entre os tratamentos com fonte de fósforo dentro de cada dose de fósforo ( $\left.\mathrm{mg} \mathrm{dm}^{-3}\right)$ no primeiro plantio.

\begin{tabular}{|c|c|c|c|c|}
\hline \multirow[b]{3}{*}{$\mathrm{N}^{\circ}$} & \multirow[b]{3}{*}{ Contrastes } & \multicolumn{3}{|c|}{ Valor do contraste } \\
\hline & & \multicolumn{3}{|c|}{ Niveis de $\mathrm{P}\left(\mathrm{mg} \mathrm{dm}^{-3}\right)$} \\
\hline & & 50 & 100 & 200 \\
\hline 1 & $2 \mathrm{STAC}+2 \mathrm{STDC}-\mathrm{FGAC}-\mathrm{FGDC}-\mathrm{FGACG}-\mathrm{FGDCG}$ & $3,88^{*}$ & $10,07^{*}$ & $15,28^{*}$ \\
\hline 2 & STAC - STDC & $-0,63^{\mathrm{ns}}$ & $-1,68 *$ & $-1,23^{*}$ \\
\hline 3 & $\mathrm{FGAC}+\mathrm{FGDC}-\mathrm{FGACG}-\mathrm{FGDCG}$ & $-0,01^{\mathrm{ns}}$ & $1,22^{\text {ns }}$ & $0,94^{\mathrm{ns}}$ \\
\hline 4 & FGAC - FGDC & $-0,04^{\mathrm{ns}}$ & $0,31^{\text {ns }}$ & $0,003^{\mathrm{ns}}$ \\
\hline 5 & FGACG - FGDCG & $-0,01^{\mathrm{ns}}$ & $0,26^{\mathrm{ns}}$ & $-0,41^{\text {ns }}$ \\
\hline
\end{tabular}

(STAC: super triplo antes da calagem; STDC: super triplo depois da calagem; FGAC: Fosfato de Gafsa antes da calagem; FGDC: Fosfato de Gafsa depois da calagem; FGACG: Fosfato de Gafsa antes da calagem mais gesso; FGDCG: Fosfato de Gafsa depois da calagem mais gesso).

* significativo a $5 \%$ de probabilidade.

${ }^{\mathrm{ns}}$ não significativo a $5 \%$ de probabilidade.

A produção inferior de alfafa devido ao uso do fosfato de Gafsa (Figura 3 e contraste 1 da Tabela 3), no primeiro plantio deve-se ao fato do fosfato natural apresentar baixa solubilidade e, consequentemente, lenta liberação de fósforo para as 
plantas (Novais et al., 1990) colaborando para um lento estabelecimento do alfafal. Os resultados menos expressivos na produção de matéria seca no início do processo produtivo com a utilização do fosfato natural em relação ST confirmam as observações realizadas por Braga et al. (1991) e Moreira (1997).

A calagem realizada antes da aplicação do superfosfato triplo beneficiou $(P<0,05)$ a eficiência desse fertilizante em relação à utilização da calagem depois a aplicação do superfosfato triplo, nos níveis de $100 \mathrm{e} 200 \mathrm{mg} \mathrm{P} \mathrm{dm}^{-3}$, o que é caracterizado pela maior produção de MS da planta (Figura 3 e contraste 2 da Tabela 3). Isso se deve à redução do teor de Al tracável e redução da fixação do fósforo devido ao decréscimo dos sítios de troca do solo (Goedert \& Sousa, 1984; Honda \& Honda, 1990 e Lopes \& Guilherme, 1989).

Não foi observada diferença $(P>0,05)$ entre os métodos de aplicação da calagem para o FG associado ou não ao gesso, no primeiro plantio (Figura 3 e contrastes 4 e 5 da Tabela 3). A aplicação do gesso em associação com o FG não apresentou beneficios quanto à produção de matéria seca das plantas de alfafa (Figura 3 e contraste 3 da Tabela 3).

As plantas de alfafa resultantes do terceiro plantio morreram após o primeiro corte quando não receberam adubação fosfatada $\left(0 \mathrm{mg} \mathrm{P} \mathrm{dm}^{-3}\right)$. A produção de MS no primeiro corte foi somente cerca de mg/vaso. A morte das plantas foi atribuída ao baixo teor de $\mathbf{P}$ no solo (3,0 $\mathrm{mg} \mathrm{dm}^{-3}$, resina - Quadro 3). Observações semelhantes foram feitas por Yupanqui (1997), onde as plantas de alfafa morreram após o segundo e terceiro cortes em solos que apresentavam teor de P de 2,5 $\mathrm{mg} \mathrm{dm}^{-3}($ Mehlich - 1).

A aplicação de $\mathrm{P}$, independente da fonte, alterou $(\mathrm{P}<0,05)$ a resposta da alfafa em relação a produção de matéria seca no terceiro plantio sendo observado que as equações de regressão quadráticas explicaram, com maior freqüência, as respostas da alfafa a níveis de fontes de fósforo (Tabela 4). 
Tabela 4 - Equações de regressão ajustadas entre produção de MS da parte aérea da alfafa $(\mathrm{Y})$, como variável dependente de dose de fósforo $\left(\mathrm{mg} \mathrm{dm}^{-3}\right)(\mathrm{X})$ para os três cortes e os níveis de fósforo calculados para máxima produção.

\begin{tabular}{|c|c|c|c|c|}
\hline $\begin{array}{l}\text { Fontes de } \\
\text { fosforo }\end{array}$ & Equações & $\mathbf{R}^{2}$ & $\begin{array}{l}\text { Nivel de } \mathrm{P}^{(1)} \\
\left(\mathrm{mg} \mathrm{dm}^{-3}\right)\end{array}$ & $\begin{array}{l}\text { Produção } \\
\text { (g MS/vaso) }\end{array}$ \\
\hline \multicolumn{5}{|c|}{ CORTE 1} \\
\hline STAC & $Y=-5,74620+0,08435 X$ & $0,90^{*}$ & - & - \\
\hline STDC & $Y=-6,31012+0,10049 X$ & $0,95^{*}$ & - & - \\
\hline FGAC & $Y=-3,38083+0,06527 X$ & $0,99^{*}$ & - & - \\
\hline FGDC & $Y=-4,67057+0,10487 X-0,00017 X^{2}$ & $1,00^{*}$ & 313,03 & 11,49 \\
\hline FGACG & $Y=-6,87560+0,11898 X$ & $0,98^{*}$ & - & - \\
\hline FGDCG & $Y=-8,46624+0,20821 X-0,00042 X^{2}$ & $1,00^{*}$ & 247,90 & 17,34 \\
\hline \multicolumn{5}{|c|}{ CORTE 2} \\
\hline STAC & $Y=-5,82378+0,08865 X$ & $0,93^{*}$ & - & - \\
\hline STDC & $Y=-4,52983+0,08439 X$ & $0,99^{*}$ & - & - \\
\hline FGAC & $Y=-11,26883+0,26430 X-0,00074 X^{2}$ & $1,00^{*}$ & 178,65 & 12,33 \\
\hline FGDC & $Y=-12,0046+0,30228 X-0,00087 X^{2}$ & $1,00^{*}$ & 173,78 & 14,25 \\
\hline FGACG & $Y=-11,99208+0,28551 X-0,00075 X^{2}$ & $1,00^{*}$ & 189,35 & 15,18 \\
\hline FGDCG & $Y=-7,91558+0,25703 X-0,000682 X^{2}$ & $1,00^{*}$ & 190,23 & 16,31 \\
\hline \multicolumn{5}{|c|}{ CORTE 3} \\
\hline STAC & $\mathrm{Y}=-3,50767+0,05805 \mathrm{X}$ & $0,96^{*}$ & - & - \\
\hline STDC & $Y=-4,60289+0,10109 X-0,00017 X^{2}$ & $1,00^{*}$ & 294,56 & 10,42 \\
\hline FGAC & $Y=-10,25889+0,23807 X-0,00063 X^{2}$ & $1,00^{*}$ & 190,24 & 12,23 \\
\hline FGDC & $Y=-7,95333+0,22900 X-0,00064 X^{2}$ & $1,00^{*}$ & 178,90 & 12,53 \\
\hline FGACG & $Y=-10,3009+0,26440 X-0,00080 X^{2}$ & $1,00^{*}$ & 164,55 & 11,54 \\
\hline FGDCG & $Y=1,71667+0,05181 X$ & $0,94^{*}$ & - & - \\
\hline
\end{tabular}

(STAC: super triplo antes da calagem: STDC: super triplo depois da calagem; FGAC: Fosfato de Gafsa antes da calagem; FGDC: Fosfato de Gafsa depois da calagem; FGACG: Fosfato de Gafsa antes da calagem mais gesso; FGDCG: Fosfato de Gafsa depois da calagem mais gesso).

(1) Nível de fósforo para máxima produção de MS estimada pela equação de regressão.

(2) Produção máxima de MS estimada pela equação de regressão.

* significativo a $5 \%$ de probabilidade.

Em geral, o fosfato solúvel apresentou melhor ajuste através da regressão linear, provavelmente, em conseqüência da fixação do fósforo no solo em decorrência dos atrasos para realizar esse plantio. Yupanqui (1997) afirma que as doses de fósforo recomendáveis para proporcionar produção máxima refletem as características químicas dos solos, principalmente a capacidade tampão dos fosfatos e a disponibilidade de fósforo dos solos. Nesse plantio foi possivel estabelecer, através das equações de regressão, as 
doses de adubo fosfatado capazes de permitirem a máxima produção de matéria seca (Tabela 4).

A produção de matéria seca da parte aérea da alfafa, no terceiro plantio, foi maior $(\mathrm{P}<0,05)$ com o uso do fosfato natural em relação à utilização da fonte solúvel, em todos os cortes (Figura 4 e contrastes 1,6 e 11 da Tabela 5). No entanto, as exceções ocorreram nos níveis de $50 \mathrm{mg} \mathrm{P} \mathrm{dm}^{-3}$, no primeiro corte, e $200 \mathrm{mg} \mathrm{P} \mathrm{dm}^{-3}$, no primeiro e segundo cortes, que não apresentaram diferenças $(\mathrm{P}>0,05)$ entre essas fontes de fósforo (Figura 4 e contrastes 1 e 6 da Tabela 5). Essa menor eficiência observada do ST foi devido, possivelmente, à rápida formação do fósforo não lábil na fonte solúvel, que não é disponivel à planta, o que está de acordo com as observações de Novais et al. (1990).

$\mathrm{O}$ atraso na semeadura do terceiro plantio devido à contaminação das plantas pelo fungo Fusarium foi de aproximadamente 5 meses a partir da data em que se aplicou os fertilizantes e corretivos no solo. Isso teve efeito negativo sobre a disponibilidade de fósforo da fonte solúvel, logo no primeiro corte.

Apesar do primeiro e terceiro plantio serem considerados experimentos diferentes e, assim, não permitirem a comparação entre eles houve a redução na disponibilidade do fósforo do superfosfato triplo em relação ao tempo de incubação desse fertilizante no solo. A disponibilidade do fósforo no solo é refletida pela produção de matéria seca da alfafa quando se comparam os resultados do $1^{0}$ corte nos experimentos relativos ao $1^{\underline{0}} \mathrm{e}$ $3^{0}$ plantios (Tabela 6 ). Observa-se que o atraso de 5 meses aproximadamente para a semeadura relativa ao $3^{0}$ plantio pode promover efeito prejudicial na resposta da adubação com fonte solúvel de fósforo na forma de superfosfato triplo. 


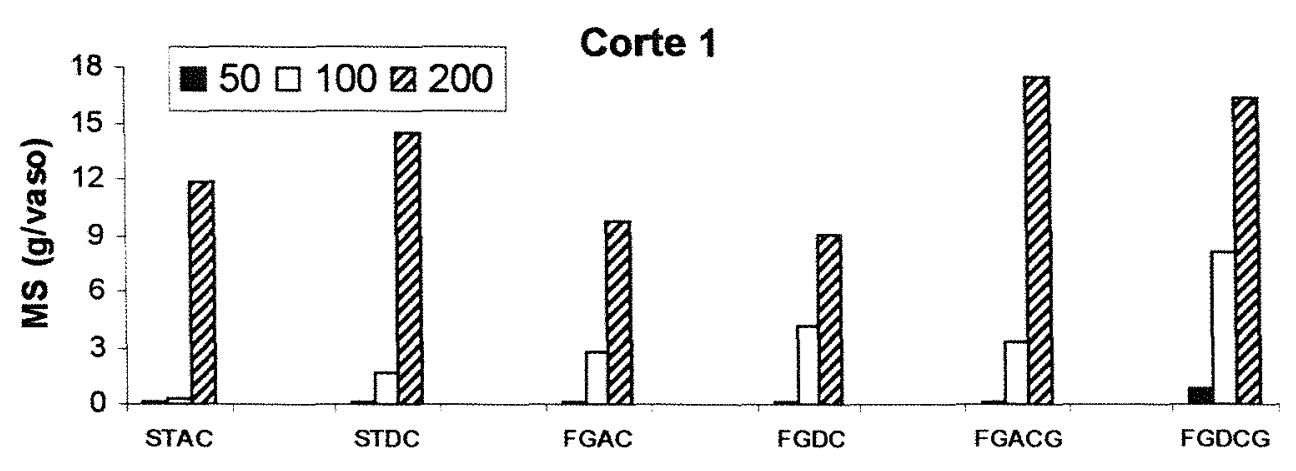

Fontes de fósforo

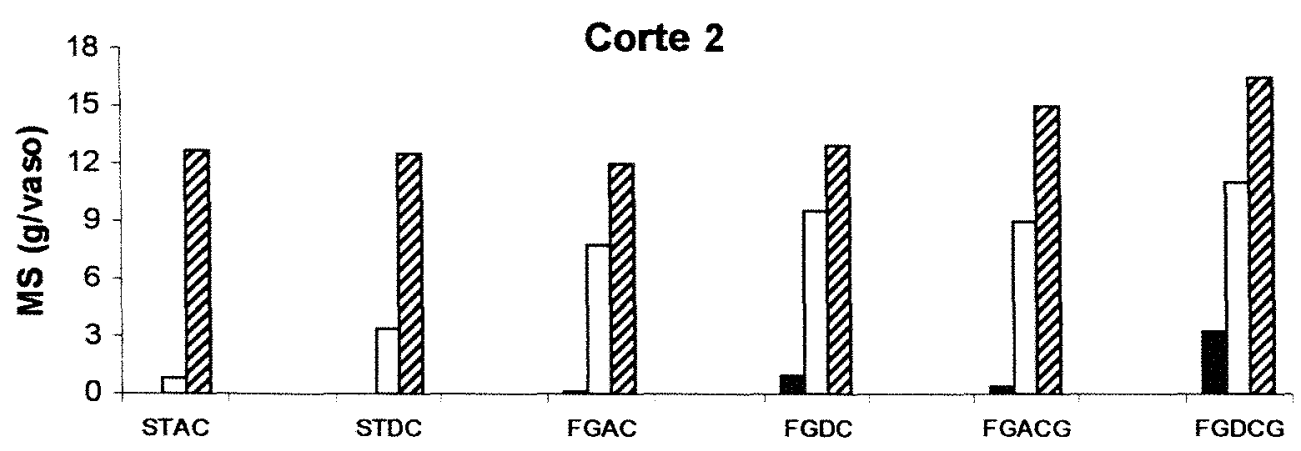

Fontes de fósforo

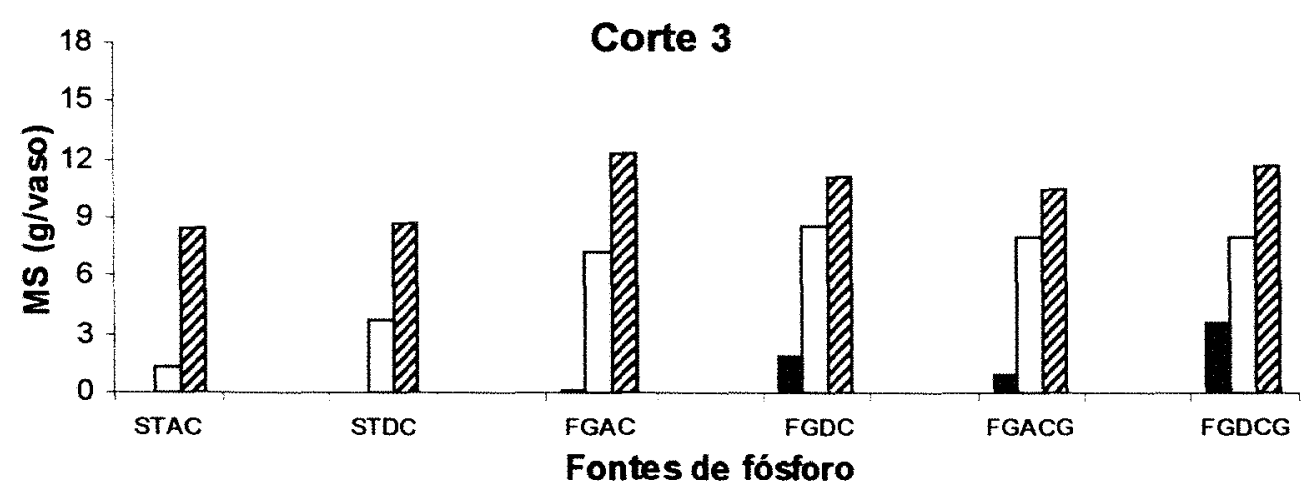

Figura 4 - Produção de matéria seca da parte aérea da alfafa (g MS/vaso) conforme diferentes fontes de fósforo, nas doses de $50,100 \mathrm{e} 200 \mathrm{mg} \mathrm{P} \mathrm{dm}^{-3}$ referente aos três cortes do terceiro plantio.

(STAC: super triplo antes da calagem; STDC: super triplo depois da calagem; FGAC: Fosfato de Gafsa antes da calagem: FGDC: Fosfato de Gafsa depois da calagem; FGACG: Fosfato de Gafsa antes da calagem mais gesso; FGDCG: Fosfato de Gafsa depois da calagem mais gesso). 
Tabela 5 - Contrastes ortogonais para comparação de produção de MS da parte aérea da alfafa entre os tratamentos dentro de cada dose de fósforo $\left(\mathrm{mg} \mathrm{dm}^{-3}\right)$ em cada corte do terceiro plantio.

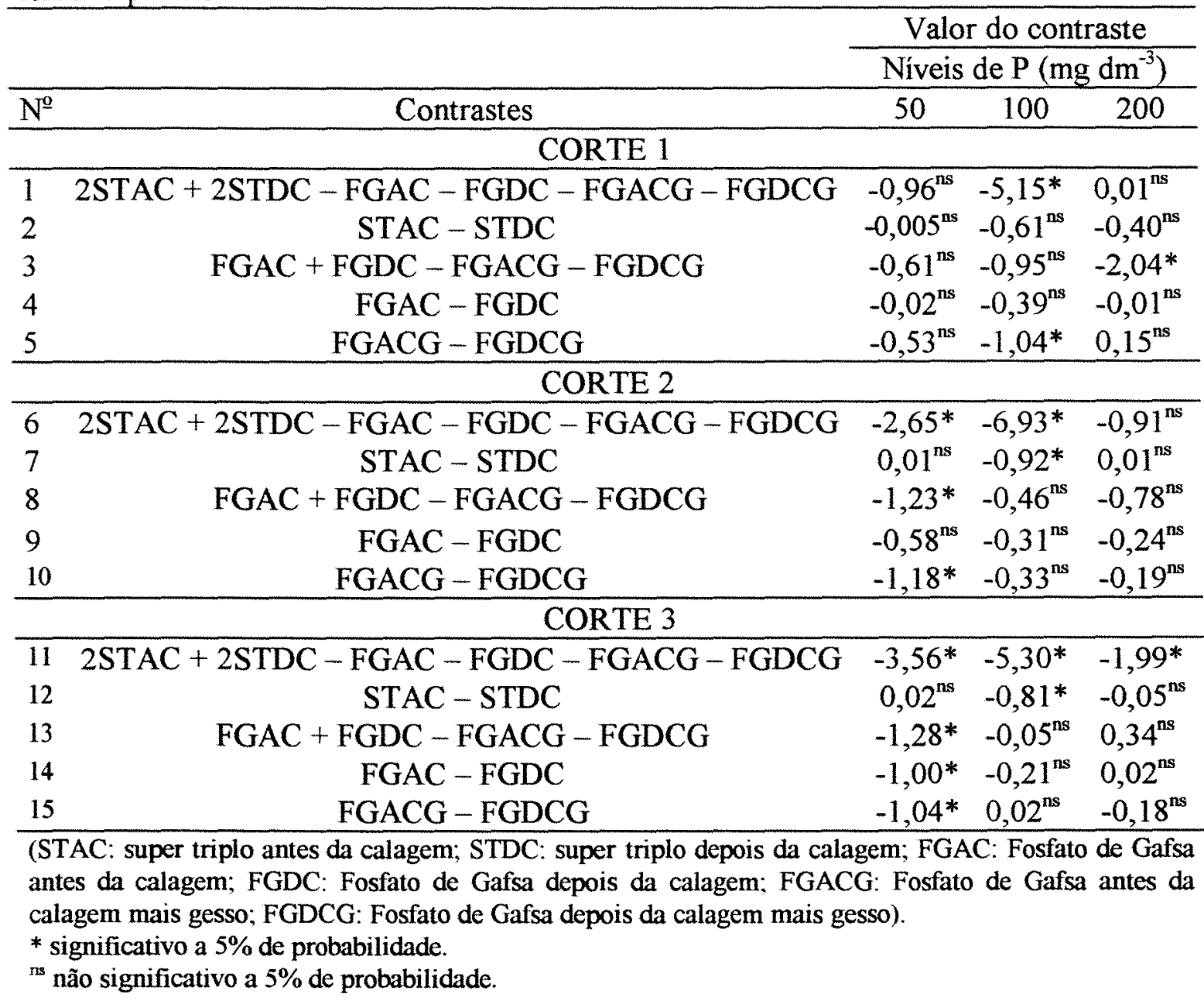

Tabela 6 - Produção de matéria seca da parte aérea (g de MS/vaso) obtida com o superfosfato triplo aplicado ao nível de $100 \mathrm{mg} \mathrm{P} \mathrm{dm}^{-3}$, no primeiro e terceiro plantio ( $1^{\text {은 }}$ corte).

Nivel de $\mathbf{P}$ Superfosfato triplo $\left(\mathrm{mg} \mathrm{dm}^{-3}\right)$ Antes da calagem Depois da calagem

\begin{tabular}{ccccc} 
& $1^{0}$ plantio & $3^{\circ}$ plantio & $1^{0}$ plantio & $3^{\circ}$ plantio \\
\hline 100 & 2,75 & 0,27 & 4,29 & 1,69 \\
\hline
\end{tabular}

A produção de matéria seca da parte aéra foi superior $(\mathrm{P}<0,05)$ no primeiro corte com o uso de $200 \mathrm{mg} \mathrm{P} \mathrm{dm}^{-3}$ da fonte FG aplicados antes e depois da calagem com gesso (FGACG e FGDCG) (Figura 4 e contraste 3 da Tabela 5) em relação ao FG adicionado 
antes e depois da calagem sem o gesso. Isso foi observado com maior evidência quando se empregou $50 \mathrm{mg} \mathrm{P} \mathrm{dm}^{-3}$ no segundo e terceiro cortes (Figura 4 e contrastse 8 e $13 \mathrm{da}$ Tabela 5). Esses resultados, possivelmente, não podem ser atribuídos ao nível de fósforo disponível já que esse é semelhante para o FG aplicado com e sem gesso (Figura 8 contraste 3 da Tabela 14). Entretanto pode-se especular sobre o efeito benéfico do $\mathrm{pH}$ que tendeu ser um pouco mais elevado (0,18 unidades - Apêndice 5) com o uso do gesso (Tabela 9) do que sem o gesso, permitindo um melhor desenvolvimento radicular da planta quando se usa o fosfato de Gafsa antes e depois da calagem com gesso (Figura 5 e contraste 3 da Tabela 10).

Resultados de aumento da produção de MS da alfafa com a elevação do $\mathrm{pH}$ do solo têm sido relatados por vários autores (Kornelius, 1972; Doerge et al., 1985; Culot, 1986; Rando, 1992 e Otsubo, 1993). A calagem aplicada antes da adubação com superfosfato triplo melhorou $(P<0,05)$ a eficiência agronômica desse fertilizante no segundo e terceiro cortes empregando-se $100 \mathrm{mg} \mathrm{P} \mathrm{dm}^{-3}$ (Figura 4 e contrastes 7 e $12 \mathrm{da}$ Tabela 5). Esses resultados devem-se ao fato da aplicação da calagem antes da adubação fosfatada diminuir a capacidade de adsorção ou fixação do fósforo pelo solo, segundo Goedert \& Sousa (1984) e Raij et al. (1982).

Por outro lado não houve efeito $(P>0,05)$ da aplicação do fosfatado natural antes da calagem na eficiência do uso do FG associado ou não ao gesso em todos os cortes e níveis de fósforo (Figura 4 e contrastes 4, 5, 9, 10, 14 e 15 da Tabela 5). Ao contrário, no nível de $50 \mathrm{mg} \mathrm{P} \mathrm{dm}^{-3}$, houve efeito negativo $(\mathrm{P}<0,05)$ do $\mathrm{FG}$ com gesso antes da calagem (FGACG) comparado ao FGDCG, no segundo corte (contraste 10 da Tabela 5). A produção de MS foi menor $(P<0,05)$ quando se usou o FG associado ou não ao gesso antes da aplicação do calcário (FGAC e FGACG) em relação ao FGDC e ao FGDCG no terceiro corte empregando-se $50 \mathrm{mg} \mathrm{P} \mathrm{dm}^{-3}$ (Figura 4 e contrastes 14 e 15 da Tabela 5). $O$ efeito negativo $(P<0,05)$ da utilização do fosfato natural com gesso antes da calagem (FGACG) em relação ao FGDCG foi também identificado no nível de $100 \mathrm{mg} \mathrm{P} \mathrm{dm}^{-3}$ no primeiro corte (Figura 5 e contraste 5 da Tabela 5) provavelmente devido à fixação do fósforo ao solo. Isso não condiz, no entanto, com as determinações apresentadas na 
Figura 6 e Tabela 14 (contraste 4) onde as concentrações de fósforo favoreceram o tratamento de FG aplicado antes da calagem (FGAC) em relação à adição do FG depois da calagem (FGDC) em amostragem do solo realizadas antes do terceiro plantio. Hanafi et al. (1992a) verificaram ocorrência de 46\%, em média, da dissolução do fosfato de Gafsa incubado em solo ácido $(\mathrm{pH} 4,4)$ pelo período de 50 dias. Embora, Chu et al. (1962) afirmem que a solubilização de fosfato de rocha em certos solos ácidos depende da quantia de $\mathrm{Al}^{+}$e $\mathrm{Fe}^{+}$no sistema do solo. A produção de matéria seca para o terceiro corte empregando $200 \mathrm{mg} \mathrm{P} \mathrm{dm}^{-3}$ na forma de superfosfato triplo apresentou queda $(\mathrm{P}<0,05)$ (Tabela 7). Isso deve ter ocorrido, provavelmente, devido à exaustão de nutrientes do solo.

As produções de matéria seca aumentaram $(\mathrm{P}<0,05)$ após o primeiro corte utilizando-se $100 \mathrm{mg} \mathrm{P} \mathrm{dm}^{-3}$ na forma de fosfato de Gafsa antes e depois da calagem (FGAC e FGDC) e fosfato de Gafsa antes da calagem associado ao gesso (FGACG) Tabela 7. Isso se repetiu $(\mathrm{P}<0,05)$ com o uso do FGDC, no nível de $50 \mathrm{mg} \mathrm{P} \mathrm{dm}{ }^{-3}$. Apesar do resultado não ser significativo, com $200 \mathrm{mg} \mathrm{P} \mathrm{dm}^{-3}$ houve tendência de elevação da produção de matéria seca do primeiro para o segundo corte, nos tratamentos FGAC e FGDC (Tabela 7). As tendências dos aumentos de produção de matéria seca devem-se, provavelmente, ao acréscimo da solubilização do fosfato de rocha, o que suportaria as afirmações de Novais et al., 1990. Os resultados obtidos confirmam as observações realizadas por Goedert \& Sousa (1984) Braga et al. (1991) e Moreira (1997) que trabalhando com fosfatos naturais, observaram aumento na eficiência dos fosfatos com o passar do tempo.

Contrariando uma expectativa inicial, ocorreu diminuição $(\mathrm{P}<0,05)$ na produção de matéria seca no terceiro corte empregando-se $200 \mathrm{mg} \mathrm{P} \mathrm{dm}^{-3}$ na forma de fosfato de Gafsa associado ao gesso (Tabela 7). A causa disso pode ter sido exaustão de nutrientes do solo uma vez que esse tratamento tendeu a apresentar maior produção de MS em relação aos demais no terceiro plantio (Figura 4). 
Tabela 7 - Produção de matéria seca da parte aérea (g MS/vaso) de plantas de alfafa obtida durante o cultivo referente a terceira semeadura.

\begin{tabular}{|c|c|c|c|}
\hline $\begin{array}{l}\text { Níveis de P } \\
\left(\mathrm{mg} \mathrm{dm}^{-3}\right)\end{array}$ & CORTE 1 & CORTE 2 & CORTE 3 \\
\hline \multicolumn{4}{|c|}{ Fontes de fósforo } \\
\hline \multicolumn{4}{|c|}{ Super triplo antes da calagem } \\
\hline 50 & $0,08 \mathrm{a}$ & $0,06 a$ & $0,03 a$ \\
\hline 100 & $0,27 \mathrm{~b}$ & $0,86 a b$ & $1,35 \mathrm{a}$ \\
\hline 200 & $11,93 \mathrm{ab}$ & $12,63 a$ & $8,42 \mathrm{~b}$ \\
\hline \multicolumn{4}{|c|}{ Super triplo depois da calagem } \\
\hline 50 & $0,08 \mathrm{a}$ & $0,05 a$ & $0,02 a$ \\
\hline 100 & $1,69 b$ & $3,36 \mathrm{a}$ & $3,79 \mathrm{a}$ \\
\hline 200 & $14,47 \mathrm{a}$ & $12,53 \mathrm{ab}$ & $8,75 \mathrm{~b}$ \\
\hline \multicolumn{4}{|c|}{ Fosf. Gafsa antes da calagem } \\
\hline 50 & $0,13 a$ & $0,10 \mathrm{a}$ & $0,08 \mathrm{a}$ \\
\hline 100 & $2,77 \mathrm{~b}$ & $7,76 \mathrm{a}$ & $7,29 a$ \\
\hline 200 & $9,80 \mathrm{a}$ & $12,00 \mathrm{a}$ & $12,32 \mathrm{a}$ \\
\hline \multicolumn{4}{|c|}{ Fosf Gafsa depois da calagem } \\
\hline 50 & $0,15 b$ & $0,93 a b$ & $1,90 \mathbf{a}$ \\
\hline 100 & $4,14 \mathrm{~b}$ & $9,53 \mathbf{a}$ & $8,58 \mathrm{a}$ \\
\hline 200 & $9,09 \mathrm{a}$ & $12,91 \mathrm{a}$ & $11,21 \mathrm{a}$ \\
\hline \multicolumn{4}{|c|}{ Fosf Gafsa antes da calagem + gesso } \\
\hline 50 & $0,17 \mathrm{a}$ & $0,40 \mathrm{a}$ & $0,91 \mathrm{a}$ \\
\hline 100 & $3,38 b$ & $9,02 \mathrm{a}$ & $8,11 \mathrm{a}$ \\
\hline 200 & $17,47 \mathrm{a}$ & $14,95 \mathrm{a}$ & $10,46 \mathrm{~b}$ \\
\hline \multicolumn{4}{|c|}{ Fosf Gafsa depois da calagem + gesso } \\
\hline 50 & $0,89 \mathrm{~b}$ & $3,25 \mathrm{a}$ & $3,57 \mathrm{a}$ \\
\hline 100 & $8,15 \mathrm{a}$ & $11,03 \mathrm{a}$ & $8,00 \mathrm{a}$ \\
\hline 200 & $16,38 \mathrm{a}$ & $16,47 \mathrm{a}$ & $11,71 \mathrm{~b}$ \\
\hline
\end{tabular}

*médias seguidas por letras distintas, numa mesma linha, diferem entre si a $5 \%$ de probabilidade pelo teste de Tukey.

$\mathrm{CV}$ (parcelas) $=13,0 \%$;

$\mathrm{CV}$ (subparcela) $=14,7 \%$.

\subsection{Produção de matéria seca de raízes de alfafa}

As produções de matéria seca da raiz (g/vaso), no terceiro plantio, coletadas após o terceiro corte são apresentadas na Tabela 8 e Figura 5. Ocorreu interação $(P<0,05)$ entre fontes e doses de fósforo (Apêndice 4).

A produção de raiz da alfafa em resposta à adubação fosfatada foi acentuada (Tabela 8 e 9) o que está de acordo com Singh \& Sale (1997) e Singh \& Sale (1998) que 
trabalharam com trevo branco (Trifolium repens L.), Fageria \& Baligar (1989), Martins et al. (1990), Mugwira \& Haque (1993) e Drevon \& Hartwing (1997) que trabalharam com alfafa. Segundo Rhykerd e Overdahl (1972) o fósforo ajuda no desenvolvimento das raízes contribuindo para a melhora da absorção de nutrientes pela planta e, consequentemente, elevando a produção da cultura.

Tabela 8 - Produção de matéria seca das raízes (g MS/vaso) obtida após três cortes.

\begin{tabular}{lcccccc}
\hline $\begin{array}{l}\text { Niveis de P } \\
\left(\mathbf{m g ~ d m}^{-3}\right)\end{array}$ & STAC & STDC & FGAC & FGDC & FGACG & FGDCG \\
\hline 50 & & & & & & \\
100 & 0,24 & 0,20 & 0,83 & 5,69 & 2,98 & 15,66 \\
200 & 5,70 & 13,58 & 25,08 & 30,07 & 29,27 & 40,29 \\
\hline
\end{tabular}

(STAC: super triplo antes da calagem; STDC: super triplo depois da calagem; FGAC: Fosfato de Gafsa antes da calagem; FGDC: Fosfato de Gafsa depois da calagem; FGACG: Fosfato de Gafsa antes da calagem mais gesso; FGDCG: Fosfato de Gafsa depois da calagem mais gesso).

*Média de três repetições

$\mathrm{CV}=16,9 \%$.

Tabela 9 - Equações de regressão ajustadas entre produção de MS da raiz da alfafa (Y), como variável dependente da dose de fósforo $\left(\mathrm{mg} \mathrm{dm}^{-3}\right)$ aplicada $(\mathrm{X})$ no solo.

\begin{tabular}{lcc}
\hline Fontes de fósforo & \multicolumn{1}{c}{ Equaçōes } & $\mathbf{R}^{2}$ \\
\hline STAC & $\mathrm{Y}=-15,65000+0,25818 \mathrm{X}$ & $0,96^{*}$ \\
STDC & $\mathrm{Y}=-13,10333+0,26652 \mathrm{X}$ & $\mathbf{1 , 0 0 ^ { * }}$ \\
FGAC & $\mathrm{Y}=-4,19833+0,21038 \mathrm{X}$ & $0,83^{*}$ \\
FGDC & $\mathrm{Y}=3,10333+0,17629 \mathrm{X}$ & $\mathbf{0 , 7 3 ^ { * }}$ \\
FGACG & $\mathrm{Y}=-10,65167+0,34492 \mathrm{X}$ & $0,97^{*}$ \\
FGDCG & $\mathrm{Y}=10,59500+0,21313 \mathrm{X}$ & $0,83^{*}$ \\
\hline
\end{tabular}

(STAC: super triplo antes da calagem; STDC: super triplo depois da calagem; FGAC: Fosfato de Gafsa antes da calagem; FGDC: Fosfato de Gafsa depois da calagem; FGACG: Fosfato de Gafsa antes da calagem mais gesso; FGDCG: Fosfato de Gafsa depois da calagem mais gesso).

*significativo a $5 \%$ de probabilidade.

Os tratamentos com ST, nas doses de 50 e $100 \mathrm{mg} \mathrm{P} \mathrm{dm}^{-3}$, apresentaram produções inferiores $(\mathrm{P}<0,05)$ de matéria seca de raizes em relação ao fosfato de Gafsa (Figura 5 e contraste 1 da Tabela 10). Isso deve-se, provavelmente, à solubilização do FG com o tempo e aumento da disponibilidade do fósforo à planta (Tabela 15) refletindo 
em maior peso das raízes. Outro fator a considerar é o efeito do $\mathrm{pH}$ do solo que foi maior quando utilizou-se o FG comparado com o ST após o último corte (Tabela 11).

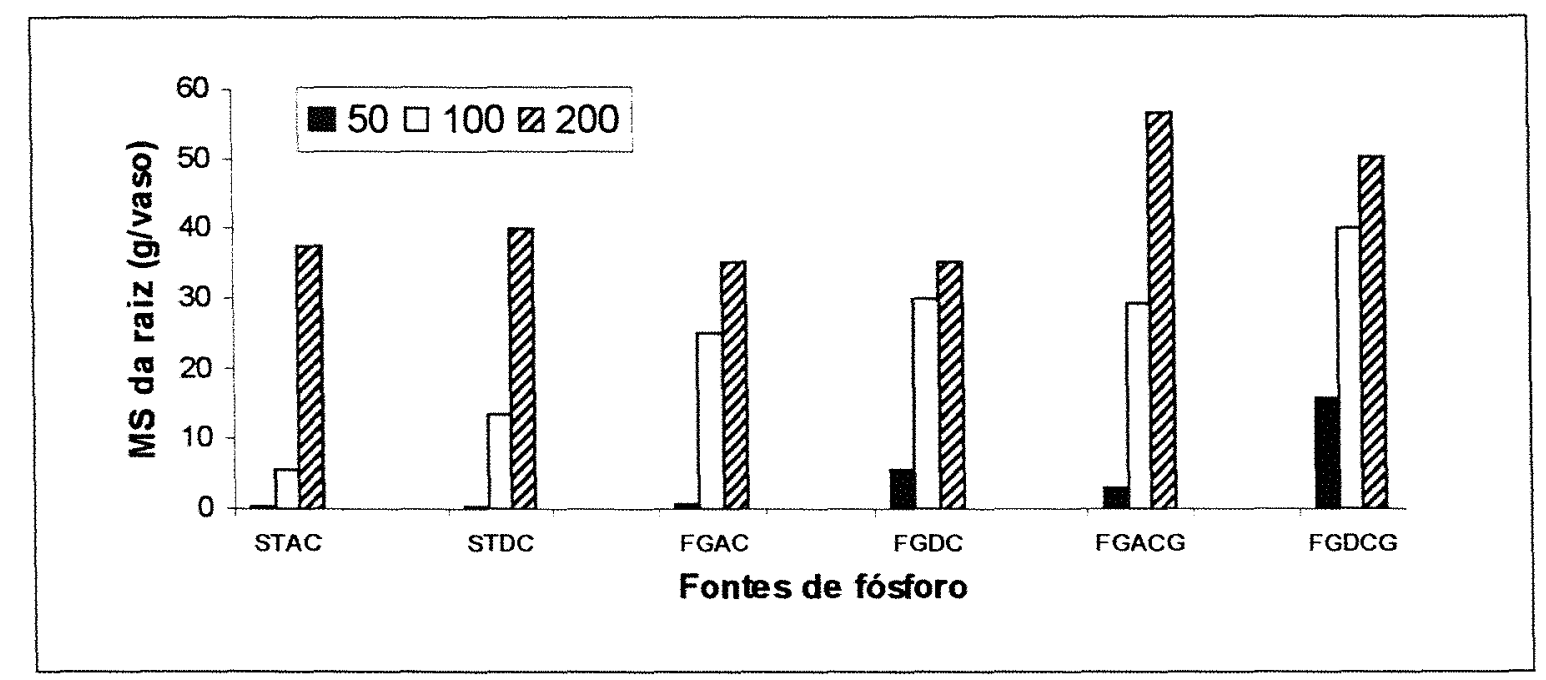

Figura - 5 Produção de matéria seca da raiz da alfafa (g/vaso) conforme diferentes fontes e doses de fósforo $\left(50,100\right.$ e $\left.200 \mathrm{mg} \mathrm{dm}^{-3}\right)$ referente ao terceiro plantio da alfafa.

(STAC: super triplo antes da calagem; STDC: super triplo depois da calagem; FGAC: Fosfato de Gafsa antes da calagem; FGDC: Fosfato de Gafsa depois da calagem; FGACG: Fosfato de Gafsa antes da calagem mais gesso; FGDCG: Fosfato de Gafsa depois da calagem mais gesso).

Tabela 10 - Contrastes ortogonais para comparação de produção de matéria seca da raiz entre os tratamentos dentro de cada dose de fósforo $\left(\mathrm{mg} \mathrm{dm}^{-3}\right)$ referente ao terceiro plantio.

\begin{tabular}{lcccc} 
& & \multicolumn{3}{c}{ Valor do contraste } \\
\cline { 3 - 5 }$N^{\mathrm{o}}$ & Contrastes & 50 & 100 & 200 \\
\cline { 3 - 5 } & Niveis de P $\left(\mathrm{mg} \mathrm{dm}^{-3}\right)$ \\
2 & 2 STAC + 2STDC - FGAC - FGDC - FGACG - FGDCG & $-6,62^{*}$ & $-10,26^{*}$ & $-1,62^{\text {ns }}$ \\
3 & STAC - STDC & $0,04^{\text {ns }}$ & $-1,38^{*}$ & $-0,24^{\text {ns }}$ \\
4 & FGAC + FGDC - FGACG - FGDCG & $-2,75^{*}$ & $-1,27^{\text {ns }}$ & $-2,82^{*}$ \\
5 & FGAC - FGDC & $-1,38^{*}$ & $-0,49^{\text {ns }}$ & $-0,07^{\text {ns }}$ \\
\hline
\end{tabular}

(STAC: super triplo antes da calagem; STDC: super triplo depois da calagem: FGAC: Fosfato de Gafsa antes da calagem; FGDC: Fosfato de Gafsa depois da calagem; FGACG: Fosfato de Gafsa antes da calagem mais gesso; FGDCG: Fosfato de Gafsa depois da calagem mais gesso).

* significativo a $5 \%$ de probabilidade.

${ }^{n s}$ não significativo a $5 \%$ de probabilidade. 
A produção de matéria seca de raízes foi aumentada $(P<0,05)$ quando se utilizou fosfato de Gafsa associado ao gesso comparado ao uso exclusivo do fosfato empregando-se 50 e $200 \mathrm{mg} \mathrm{P} \mathrm{dm}$ (Figura 5 e contraste 3 da Tabela 10). O efeito benéfico do gesso sobre o sistema radicular parece não estar associado à disponibilidade de fósforo uma vez que a Figura 8 e a Tabela 14 (contraste 3 ) indica valores semelhantes para esse nutriente nos tratamentos de FG com ou sem gesso antes do terceiro plantio e menor teor de fósforo no solo em amostragem após o último corte com o uso fosfato de Gafsa associado ao gesso.

Analisando-se os efeitos dos tratamentos com gesso foi observado que esse elemento proporcionou aumento $(3,0 \%$ - média de todos os níveis de $\mathrm{P})$ do $\mathrm{pH}$ do solo em relação aos tratamentos com FG somente (Apêndice 5). Mugwira \& Haque (1993) verificaram aumento no peso das raízes de alfafa em função da adição de calcário, e consequentemente a elevação do $\mathrm{pH}$ do solo. Sabe-se que o alumínio é o principal elemento tóxico associado à acidez do solo e sua ação se faz sentir principalmente nas raízes das plantas prejudicando o seu crescimento (Raij, 1988). Por outro lado, o manganês é outro elemento tóxico associado ao baixo $\mathrm{pH}$ afetando a raiz de forma indireta através do resultado da inibição no crescimento da parte aérea (Adams \& Pearson, 1967 e Smith et ali., 1983).

$\mathrm{O}$ efeito positivo $(\mathrm{P}<0,05)$ da calagem antecedendo a aplicação da fonte solúvel de fósforo sobre o peso seco da raiz foi observado unicamente no nível de $100 \mathrm{mg} \mathrm{Pdm}^{-3}$ (Figura 5 e contraste 2 da Tabela 10). A calagem antes da adubação fosfatada beneficiou $(\mathbf{P}<0,05)$ a utilização do $\mathrm{FG}$ associado ou não ao gesso no nível de $50 \mathrm{mg} \mathrm{P} \mathrm{dm}^{-3}$ (Figura 5 e contrastes 4 e 5 da Tabela 10 ).

\section{$5.3 \mathrm{pH}$}

Foram encontradas interações $(\mathrm{P}<0,05)$ entre momentos de amostragens do solo $\mathrm{e}$ fontes de fósforo e, entre momentos de amostragens e doses de fósforo (Apêndice 6) para pH do solo (Tabelas 11 e 12 , Figura 6 e Apêndice 4). 
O uso do fosfato de Gafsa associado ou não ao gesso (FG e FG+G) foram os tratamentos que apresentaram maior $(\mathrm{P}<0,05)$ ação neutralizante no solo para os dois momentos de amostragem (Tabela 11). Isso está de acordo com as observações de Goedert \& Lobato (1984) que verificaram maior pH no solo quando foi utilizado o FG comparado ao ST.

Tabela $11-\mathrm{pH}\left(\mathrm{CaCl}_{2}\right)$ no solo antes do plantio e depois da última colheita de alfafa, nos diferentes tratamentos.

\begin{tabular}{lccc}
\hline & & Fontes de fósforo & \\
\hline Período de amostragem & $\mathbf{S T}$ & $\mathbf{F G}$ & FG+ \\
\hline Antes do terceiro plantio & $5,56 \mathrm{Ab}$ & $5,67 \mathrm{Aa}$ & $5,74 \mathrm{Ba}$ \\
Após o último corte & $5,28 \mathrm{Bc}$ & $5,78 \mathrm{Ab}$ & $6,06 \mathrm{Aa}$ \\
\hline
\end{tabular}

(ST: média de todos os níveis de fósforo do super triplo aplicados antes e após a calagem; FG: média de todos os níveis de fósforo do Fosfato de Gafsa antes e após a calagem; FG+G: média de todos os níveis de fósforo do Fosfato de Gafsa mais gesso antes e após a calagem).

$\mathrm{CV}$ (parcela) $=1,5 \%$.

$\mathrm{CV}$ (subparcela) $=2,6 \%$

* médias seguidas por letras maiúsculas distintas, numa mesma coluna e por letras minúsculas distintas, numa mesma linha, diferem entre si a $5 \%$ de probabilidade pelo teste de Tukey.

$\mathrm{O} \mathrm{pH}$ do solo que recebeu o tratamento $\mathrm{FG}+\mathrm{G}$ se manteve semelhante $(\mathrm{P}>0,05)$ ao tratamento com FG antes do terceiro plantio (Tabela 11). Porém, na amostragem do solo, após o último corte, o $\mathrm{pH}$ do solo com o uso do $\mathrm{FG}+\mathrm{G}$ foi superior $(\mathrm{P}<0,05)$ ao FG. Malavolta et al. (1979), Borkert et al. (1987) e Rechcigl et al. (1988) afirmaram que os íons cálcio $\left(\mathrm{Ca}^{2+}\right)$ e o sulfato $\left(\mathrm{SO}_{4}{ }^{2-}\right)$ resultantes da hidrólise do gesso não são neutralizantes e, consequentemente, não diminuem a acidez do solo. Entretanto, em experimentos com gesso, em solos da região dos cerrados, foi constatado aumento do $\mathrm{pH}$ do solo com a aplicação de gesso (Sousa et al., 1985). Esses resultados contrastantes parecem estar relacionados com as características químicas e mineralógicas dos solos. Segundo Sousa \& Ritchey (1985) o aumento de pH do solo, com o uso do gesso, tem sido atribuído ao domínio da reação de troca do sulfato pela hidroxila $\left(\mathrm{OH}^{-}\right)$das superficies dos óxidos de ferro e alumínio.

Dentre as leguminosas, a alfafa talvez seja a mais exigente em $\mathrm{pH}$ do solo sendo sua faixa ótima de 6,5 a 7,5 (Honda \& Honda, 1990; Lanyon \& Griffith, 1988). Em 
1984, McLean \& Brown ${ }^{8}$ (citado por Lanyon \& Griffith, 1988) observaram que 93\% da produção máxima de alfafa era conseguida em pH 6,0 e 100\% no pH 6,6.

Robson e Loneragan', (citados por Howieson e Ewing, 1989) consideraram que a alta concentração de íons hidrogênio na solução do solo foi o fator que mais afetou a simbiose do Rizobium melilot com a alfafa prejudicando o crescimento e sobrevivência do rizóbio. Segundo Vance et al. (1988) o prejuízo no desenvolvimento do rizóbio reflete numa depreciação geral do crescimento da planta.

Solos apresentando altos niveis de manganês e com $\mathrm{pH}$ igual ou menor que 5,5 podem induzir toxidez desse elemento na planta (Kabata-Pendias \& Pendias, 1985), uma vez que a cada incremento de 0,1 unidade de $\mathrm{pH}$ há uma redução de 10 vezes na atividade do íon manganês na solução do solo (Bataglia ${ }^{10}$, citado por Rando, 1992).

Rechcigl et al. (1988) trabalhando com alfafa em casa de vegetação observaram produções mais elevadas de matéria seca com o aumento do $\mathrm{pH}$ estando essas respostas relacionadas com a redução dos teores de manganês no tecido da planta. Elevados teores de Mn podem, também, afetar estirpes sensíveis de Rhizobium (Franco \& Dobereiner, 1988).

Dessa maneira é possível que os tratamentos com $\mathrm{FG}$, onde o $\mathrm{pH}$ do solo apresentou-se maior em 0,15 unidades (Apêndice 5) em relação aos tratamentos com ST, antes do terceiro plantio, tenham diminuído o efeito tóxico do Mn que estava alto no solo (ao redor de $11 \mathrm{mg} \mathrm{P} \mathrm{dm}^{-3^{*}}$ ) devido à liberação de manganês pelo processo de autoclavagem. O manganês foi mais absorvido pelas plantas adubadas com fosfatos solúveis onde se observou no tecido em torno de 376 ppm e aproximadamente 200 ppm

\footnotetext{
${ }^{8}$ MCLEAN; BROWN, J.R. Crop response to lime in the midwestern United States. In: F. Adams (ed.) Soil acidity and liming. 2nd ed. Agronomy 12:267-303, 1984.

${ }^{9}$ ROBSON, A.D.; LONERAGAN, J.F. (1970). Nodulation and growth of Medicago sativa on acid soils. II. Colonization of acid soils by Rhizobium meliloti. Australian Journal of Agricultural Research, v.21, p.435-445, 1970.

10 BATAGLIA, O.C. Micronutrientes: disponibilidade e interações. In: BORKERT, C.M.; LANTMANN, A.F., ed. Enxofre e micronutrientes na agricultura brasileira. Londrina: EMBRAPACNPSo/IAPAR/SBCS, 1988. cap. 6, p.121-132.

*Amostra composta por amostragens realizadas em todos os vasos antes do $3^{\circ}$ plantio.
} 
com o uso do FG (média dos tratamentos FG e FG + G aplicados antes e após a calagem) no primeiro corte do terceiro plantio com $200 \mathrm{mg} \mathrm{P} \mathrm{dm}^{-3}$.

A alfafa apresenta menor tolerância ao excesso de manganês comparada à outras leguminosas (Andrew \& Hutron ${ }^{11}$, citado por Rando, 1992), sendo possível ocorrerem diferenças de tolerâncias dentro de cultivares (Marschner, 1988 e Mascarenhas et al., 1990). Desse modo as diferenças nos níveis tóxicos de manganês na MS da alfafa variam: 175 ppm (Quellette \& Dessureaux ${ }^{12}$ citados por Helyar, 1978); 380 ppm (Andrew \& Hegarty, 1969); 300-400 ppm (Siman et al., 1974); 250 ppm (Jones ${ }^{13}$ citado por Lombin \& Bates, 1982) e 340 ppm (Smith et ali., 1983).

Em relação às épocas de amostragens do solo, antes do terceiro plantio e depois do último corte, somente o ST apresentou redução $(\mathrm{P}<0,05)$ do $\mathrm{pH}$ do solo (Tabela 11). Isso, provavelmente, se deve à dissociação do $\mathrm{CO}_{2}$ liberado pela respiração das raízes e nódulos da alfafa (Heichel et al., 1988). Novais (1990) afirma que a acidificação da rizosfera pela planta é benéfica à solubilização do fosfato natural. No entanto a diminuição do $\mathrm{pH}$ não foi observada no presente trabalho quando se utilizou o fosfato de Gafsa associado ou não ao gesso. Ao contrário, houve elevação do pH do solo após o último corte com o uso do gesso, por causa, talvez, à continuidade da reação do gesso e da fonte de fósforo no solo.

Houve queda $(\mathrm{P}<0,5)$ do $\mathrm{pH}$ após o último corte para o tratamento que empregou $50 \mathrm{mg} \mathrm{P} \mathrm{dm}^{-3}$ (Tabela 12). Isso também se deve, provavelmente, à dissociação do $\mathrm{CO}_{2}$ liberado pela respiração das raízes e nódulos da alfafa (Heichel et al., 1988). O mesmo não ocorreu entretanto nos outros níveis de fósforo devido, possivelmente, ao maior poder neutralizante presente nos elevados níveis de adubos fosfatados impedindo o abaixamento do $\mathrm{pH}$ nesse período.

\footnotetext{
1 ANDREW, C.S.; HUTTON, E.M. Effect of $\mathrm{pH}$ and calcium on the growth of tropical pasture legumes. In: INTERNATIONAL GRASSLAND CONGRESS, 12, Moscou, 1974. Proceedings. s. n.t. p.23-28.

12 QUELLETTE, G.J.; DESSUREAUX, L. Quimical composition of alfalfa as related to degree of tolerance to manganese and aluminium. Canadian Journal Plant of Science. v. 38, p. 206-214, 1958.

${ }^{13}$ JONES, J.B.Jr. Interpretation of plant analysis for several agronomic crops. Pages 49-58 In: G.W. Hardy, ed. Soil testing end plant analysis, Part II. Soil Sci. Soc. Amer. Spec. Publ. No. 2. Soil Sci. Soc. Am. Madison. 1967.
} 
Tabela $12-\mathrm{pH}\left(\mathrm{CaCl}_{2}\right)$ no solo antes do plantio e depois da última colheita de alfafa, conforme os niveis de fósforo.

\begin{tabular}{lccc}
\hline & Niveis de $\mathbf{P}\left(\mathrm{mg} \mathrm{dm}^{-3}\right)$ & & \\
\hline Periodo de amostragem & 50 & 100 & 200 \\
\hline Antes do terceiro plantio & $5,58 \mathrm{a}$ & $5,66 \mathrm{~b}$ & $5,77 \mathrm{a}$ \\
Após o último corte & $5,41 \mathrm{~b}$ & $5,93 \mathrm{a}$ & $5,73 \mathrm{a}$ \\
\hline
\end{tabular}

(ST: média do super triplo aplicados antes e após a calagem; FG: média do Fosfato de Gafsa antes e após a calagem; FG+G: média do Fosfato de Gafsa mais gesso antes e após a calagem).

$\mathrm{CV}$ (subparcela) $=2,6 \%$

* médias seguidas por letras distintas, numa mesma coluna diferem entre si a $5 \%$ de probabilidade pelo teste de Tukey.

Houve aumento $(\mathrm{P}<0,05)$ no $\mathrm{pH}$ do solo em função dos níveis de fósforo (Tabela 12 e Figura 6). $\mathrm{O}$ incremento do $\mathrm{pH}$ do solo com a adição de superfosfato foi, também, verificado por Helyar \& Anderson (1970) e Smyth \& Sanchez (1980), sendo que esses últimos atribuíram o resultado à liberação do $\mathrm{OH}$ durante o processo de adsorção do $\mathrm{P}$. Goedert \& Lobato (1984), Sanzonowicz et al. (1987) e Moreira (1997) não constataram aumento do $\mathrm{pH}$ do solo em função das doses de fósforo aplicadas utilizando fontes solúveis de P. Por outro lado, Goedert \& Lobato (1984), utilizando o FG como fonte de fósforo verificaram aumento do $\mathrm{pH}\left(\mathrm{H}_{2} \mathrm{O}\right)$ do solo de 4,9 na testemunha para 5,2 com a aplicação de $88 \mathrm{~kg} \mathrm{P}^{-1} \mathrm{~h}^{-1}$ e 5,5 com o uso de $350 \mathrm{~kg} \mathrm{P} \mathrm{ha}{ }^{-1}$. Já Sanzonowicz et al. (1987) observaram elevação do $\mathrm{pH}$ de $4,5\left(\mathrm{H}_{2} \mathrm{O}\right)$ com adição de $38 \mathrm{~kg} \mathrm{P}^{-1}$ para $4,8 \mathrm{com}$ o aplicação de $600 \mathrm{~kg} \mathrm{P}^{-1}$ com a utilização do fosfato de Gafsa. 


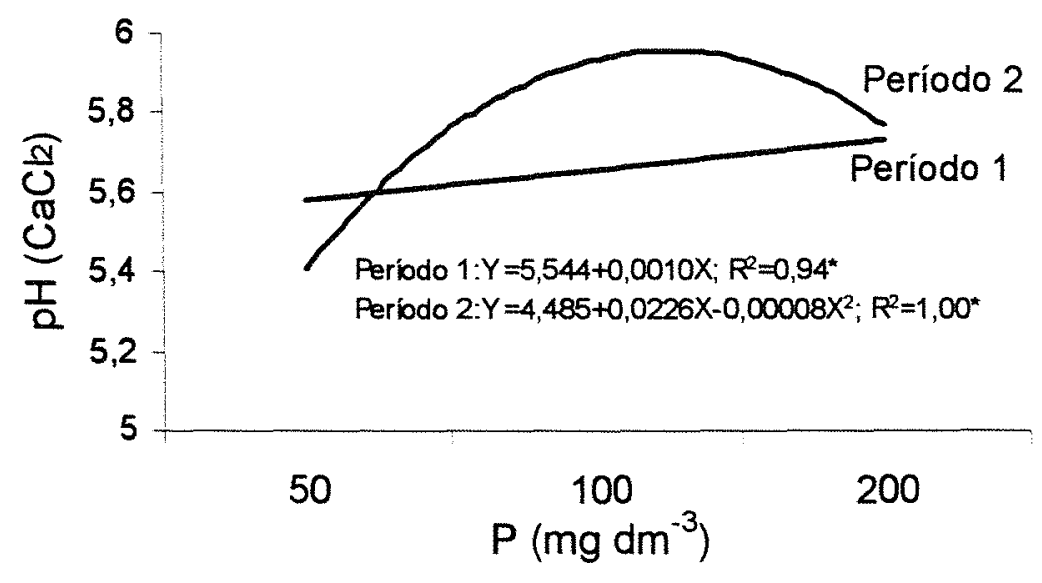

Figura 6 - pH no solo $\left(\mathrm{CaCl}_{2}\right)$ de acordo com o momento de amostragem do solo. (Período 1: amostragem do solo antes do terceiro plantio; Período 2: amostragem do solo após o último corte).

* significativo a $5 \%$ de probabilidade.

\subsection{Concentração de fósforo do solo}

As concentrações de fósforo no solo antes do terceiro plantio e depois do último corte são apresentadas no Apêndice 7, Figura 8 e Tabela 14 . Houve efeito $(P<0,05)$ das doses de fósforo, bem como das interações entre momento de amostragem do solo e fontes de fósforo sobre o teor de $P$ no solo (Apêndice 8).

A concentração de fósforo no solo aumentou $(\mathrm{P}<0,05)$ com as doses de $\mathrm{P}$ aplicadas de diferentes fontes (Figura 7). Resultados semelhantes foram encontrados por Goedert \& Lobato (1984), Rosand \& Santana (1986), Macedo (1985) e Braga et al. (1991).

As concentrações médias de fósforo no solo antes do terceiro plantio foram maiores $(\mathrm{P}<0,05)$ quando se utilizou a fonte solúvel em comparação com o emprego de fosfato de Gafsa (Figura 8 e contraste 1 da Tabela 13). Esse resultado concorda com os obtidos por Goedert \& Lobato (1984). As produções de matéria seca no entanto foram mais elevadas (Figura 4 e contrastes 1, 6 e 11 da Tabela 5), quando foi utilizado o fosfato de Gafsa. Isso pode estar relacionado ao aumento do $\mathrm{pH}$ do solo com a utilização do fosfato de Gafsa em relação ao ST (Tabela 11). 


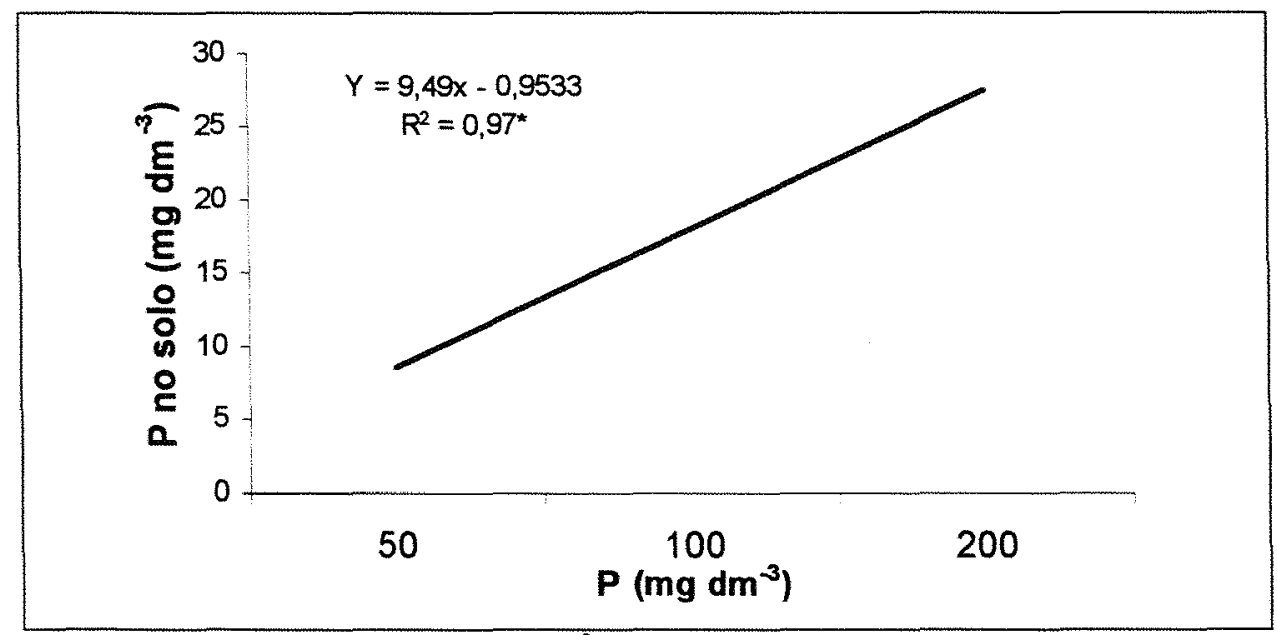

Figura 7 - Teor de $\mathrm{P}$ no solo $\left(\mathrm{mg} \mathrm{dm}^{-3}\right)$ em função dos níveis de fósforo aplicados (média de todas fontes e dos dois momentos de amostragem).

* significativo a $5 \%$ de probabilidade.

$\mathrm{Na}$ amostragem do solo após o último corte, os tratamentos com FG apresentaram teores mais elevados de fósforo no solo $(\mathrm{P}<0,05)$ que a fonte solúvel (Figura 8 e contraste 1 da Tabela 13). Isso é atribuído ao aumento $(\mathrm{P}<0,05)$ do fósforo no solo (Tabela 14), devido à solubilização com o tempo do $\mathrm{P}$ do fosfato natural, confirmando as afirmações de Goedert \& Sousa (1984). Por outro lado não foi verificado efeito $(P>0,05)$ do momento de amostragem sobre a concentração de fósforo no solo utilizando-se fonte solúvel de fósforo (Tabela 14).

Apesar de não se verificar efeito $(P>0,05)$ da aplicação da calagem antes da adubação com fonte solúvel de fósforo (contraste 2 da Tabela 13), observou-se tendência para que o teor de fósforo no solo com o tratamento STDC fosse superior ao tratamento STAC (Figura 8). Isso se deve, conforme Goedert \& Sousa (1984), à elevação do pH do solo que provoca redução no "reservatório" de P-não lábil por meio da diminuição do número de sítios de troca no solo. Por outro lado, a fixação do fósforo pode também ter sido reduzida com a aplicação da calagem antes da fonte solúvel devida à neutralização do alumínio trocável (Goedert \& Sousa, 1984).

Analisando-se o efeito do momento de calagem sobre o FG associado ou não ao gesso verificou-se maior $(P<0,05)$ concentração de fósforo no solo no tratamento FGAC 
do que no FGDC na amostragem do solo antes do terceiro plantio (Figura 8 e contraste 4 da Tabela 13). Esse resultado não refletiu em maior produção $(P>0,05)$ de MS da parte aérea (Figura 4 e contrastes 4,9 el4 da Tabela 5) ao contrário, houve maior $(\mathrm{P}<0,05)$ produção de MS com o uso do FGDC comparado ao FGAC, no nível de $50 \mathrm{mg} \mathrm{P} \mathrm{dm}^{-3}$ do terceiro corte (Figura 4 e contraste 19 da Tabela 5).

A adição do gesso juntamente com o FG não teve efeito ( $P>0,05)$ sobre a concentração de fósforo no solo amostrado antes do terceiro plantio (Figura 8 e contraste 3 da Tabela 13). Dessa maneira pode-se concluir que o teor de fósforo no solo, com a utilização do gesso associado ao $\mathrm{FG}$, não foi o responsável por maiores $(\mathrm{P}<0,05)$ produções de MS da parte aérea nos tratamentos FGACG e FGDCG em relação aos tratamentos sem gesso no nível de $200 \mathrm{mg} \mathrm{P} \mathrm{dm}^{-3}$, no primeiro corte do terceiro plantio (Figura 4 e contraste 3 da Tabela 5). Assim, pode-se concluir que o gesso não teve efeito sobre a solubilização do FG e é possível inferir que o aumento do $\mathrm{pH}$ do solo em 0,13 unidades (nivel de $200 \mathrm{mg} \mathrm{P} \mathrm{dm}^{-3}$, antes do terceiro plantio - Apêndice 5) pela utilização do gesso associado ao fosfato de Gafsa (FGACG e FGDCG), possivelmente, proporcionou maiores produções de matéria seca da parte aérea em relação ao uso do FG sem o gesso, considerando o efeito do $\mathrm{pH}$ sobre a absorção de manganês pela planta como descrito anteriormente. 


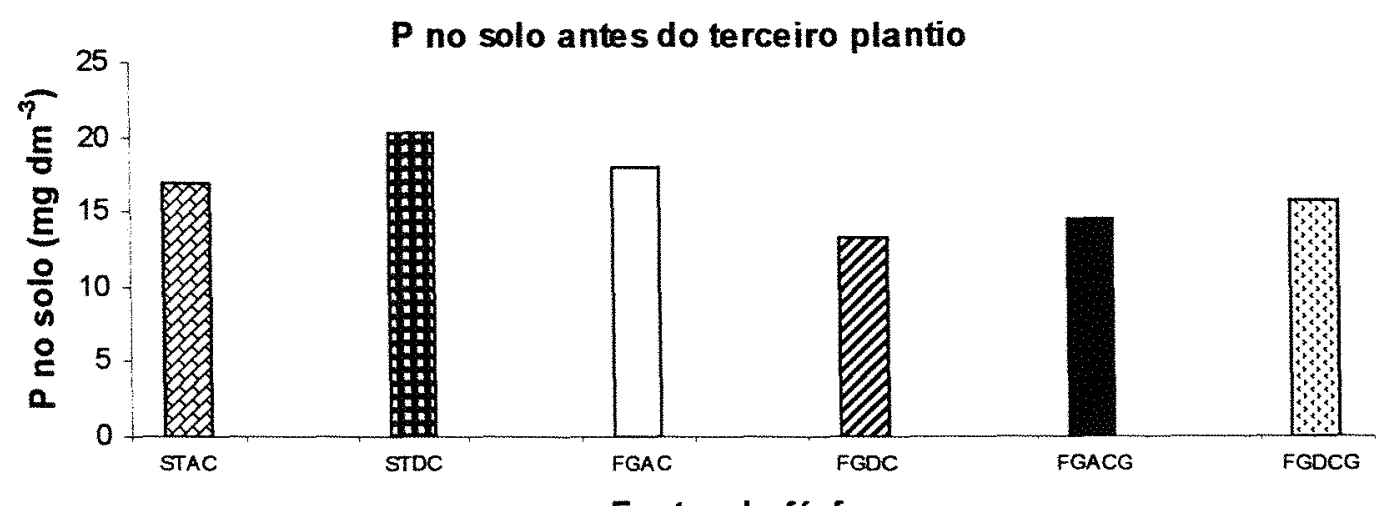

Fontes de fósforo

P no solo após o último corte

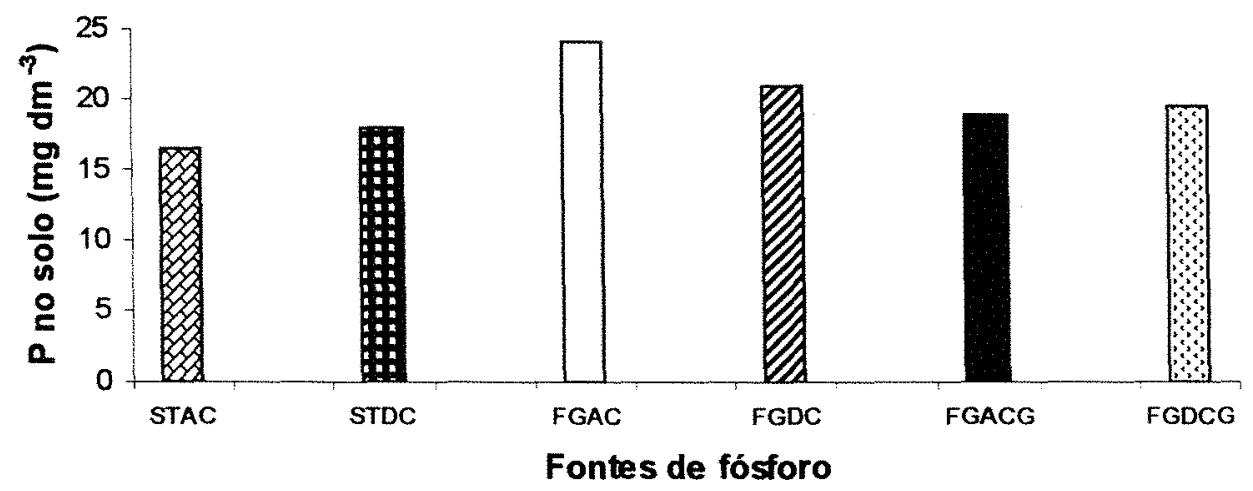

Figura 8 - Teor de $\mathrm{P}$ no solo $\left(\mathrm{mg} \mathrm{dm}^{-3}\right)$ conforme diferentes fontes de fósforo, antes do terceiro plantio e após o último corte da alfafa (médias dos três níveis de fósforo).

(STAC: super triplo antes da calagem; STDC: super triplo depois da calagem; FGAC: Fosfato de Gafsa antes da calagem; FGDC: Fosfato de Gafsa depois da calagem; FGACG: Fosfato de Gafsa antes da calagem mais gesso; FGDCG: Fosfato de Gafsa depois da calagem mais gesso).

$\mathrm{O}$ teor de fósforo no solo foi maior $(\mathrm{P}<0,05)$ sem o uso do gesso (FGAC e FGDC) do que com a aplicação dele (FGACG e FGDCG), depois do último corte (Figura 8 e contraste 3 da Tabela 13). Isso pode ser devido à maior retirada do fósforo do solo nos tratamentos FGACG e FGDCG, uma vez que esses tratamentos tenderam apresentar maiores produções de MS do que o FGAC e o FGDC, no terceiro plantio 
(Figuras 4). Constatações semelhantes foram encontradas por Siqueira ${ }^{14}$ e Pons ${ }^{15}$ (citados por Macedo, 1985), que trabalharam com trevo vermelho (Trifollium pratense L.) e alfafa, respectivamente. Por outro lado pode-se inferir que níveis de fósforo no solo acima de $30 \mathrm{mg} \mathrm{P} \mathrm{dm}^{-3}$ poderiam ser considerados adequados para produção da planta enquanto que esses poderiam ser considerados adequados para produção da planta enquanto que esses valores abaixo de $15 \mathrm{mg} \mathrm{P} \mathrm{dm}^{-3}$ poderiam ser deficientes.

Tabela 13 - Contrastes ortogonais para comparação do teor de $\mathrm{P}$ no solo entre os tratamentos com fósforo dentro de cada momento de amostragem do solo.

\begin{tabular}{|c|c|c|c|}
\hline \multirow[b]{3}{*}{$\mathrm{N}^{\mathrm{o}}$} & \multirow[b]{3}{*}{ Contrastes } & \multicolumn{2}{|c|}{ Valor do contraste } \\
\hline & & \multicolumn{2}{|c|}{ Momento de amostragem } \\
\hline & & $\begin{array}{l}\text { Antes do } \\
3^{\circ} \text { plantio }\end{array}$ & $\begin{array}{l}\text { Após o úl- } \\
\text { timo corte }\end{array}$ \\
\hline 1 & $2 S T A C+2 S T D C-F G A C-F G D C-F G A C G-F G D C G$ & $0,64^{*}$ & $-0,51^{*}$ \\
\hline 2 & STAC - STDC & $-0,17^{\mathrm{ns}}$ & $-0,10^{\mathrm{ns}}$ \\
\hline 3 & FGAC + FGDC - FGACG - FGDCG & $0,08^{\text {ns }}$ & $0,30^{*}$ \\
\hline 4 & FGAC - FGDC & $0,32 *$ & $0,05^{\mathrm{ns}}$ \\
\hline 5 & FGACG - FGDCG & $-0,06^{\mathrm{ns}}$ & $-0,07^{\mathrm{ns}}$ \\
\hline
\end{tabular}

(STAC: super triplo antes da calagem; STDC: super triplo depois da calagem; FGAC: Fosfato de Gafsa antes da calagem; FGDC: Fosfato de Gafsa depois da calagem; FGACG: Fosfato de Gafsa antes da calagem mais gesso; FGDCG: Fosfato de Gafsa depois da calagem mais gesso).

* significativo a $5 \%$ de probabilidade.

${ }^{\text {ns }}$ não significativo a $5 \%$ de probabilidade.

Tabela 14 - Teor de $\mathrm{P}\left(\mathrm{mg} \mathrm{dm}^{-3}\right)$ no solo antes do terceiro plantio e após o último corte da alfafa, em função das fontes de fósforo (média dos três níveis de fósforo).

\begin{tabular}{|c|c|c|c|c|c|c|}
\hline \multicolumn{7}{|c|}{ Fontes de fósforo } \\
\hline Período de amostragem & STAC & STDC & $\mathrm{FGAC}$ & FGDC & FGACG & FGDCG \\
\hline Antes do terceiro plantio & $17,00 \mathrm{a}$ & $20,22 a$ & $18,00 \mathrm{~b}$ & $13,22 b$ & $14,44 b$ & $15,67 \mathrm{~b}$ \\
\hline Após o último corte & $16,45 \mathrm{a}$ & $18,00 \mathbf{a}$ & $24,00 \mathrm{a}$ & $21,00 \mathrm{a}$ & $18,89 \mathrm{a}$ & $19,44 a$ \\
\hline
\end{tabular}

(STAC: super triplo antes da calagem; STDC: super triplo depois da calagem; FGAC: Fosfato de Gafsa antes da calagem; FGDC: Fosfato de Gafsa depois da calagem; FGACG: Fosfato de Gafsa antes da calagem mais gesso; FGDCG: Fosfato de Gafsa depois da calagem mais gesso).

* médias seguidas por letras distintas, numa mesma coluna, diferem entre si a $5 \%$ de probabilidade pelo teste de Tukey. $\mathrm{CV}=5,1 \%$

${ }^{14}$ SIQUEIRA, O.J.F. Resposta do trevo-vermelho (Trifolium pratense L.) à calagem e à adubação fosfatada e suas relações com a disponibilidade de fósforo em solos ácidos do Rio Grande do Sul. Porto Alegre, UFRS, 1972. Tese de Mestrado.

${ }^{15}$ PONS, A.L. Efeito residual da calagem e da adubação fosfatada na produção de alfafa (Medicago sativa L.) num Latossolo Bruno Distrófico de Rio Grande do Sul. Anuário Técnico IPZFO, Porto Alegre, v.3, p 540-592, 1976. 


\section{5 Índice de eficiência agronômica}

Todas as combinações da aplicação do fosfato de Gafsa nas três dosagens, no primeiro plantio, apresentaram muito baixo IEA (Tabela 15). Isso ocorreu, provavelmente, à menor solubilidade inicial do fosfato de rocha em relação ao fosfato solúvel e, também, ao curto período de implantação (47 dias) da alfafa por causa do surgimento de Fusarium. Esses resultados são bem inferiores aos encontrados por Braga et al. (1991) que determinaram o IEA do FG (dose de $400 \mathrm{~kg} \mathrm{P}_{2} \mathrm{O}_{5}$ ha $^{-1}$ ) como $70 \% \mathrm{em}$ relação ao ST no primeiro cultivo de soja em Latossolo vermelho-escuro (Typic Acrustox). Por outro lado, Goedert \& Lobato (1984) e Rosand \& Santana (1986) observaram IEA do FG semelhante ou superior ao supertriplo, desde o primeiro cultivo do sorgo (doses de 88 e $350 \mathrm{~kg} \mathrm{P} \mathrm{ha}^{-1}$ ) e do trigo (dose de $250 \mu \mathrm{g} \mathrm{P} \mathrm{g}$ de solo), em Latossolo vermelho-escuro (Haplustox) e em solos do sul da Bahia (Umbriorthox, Haplorthox, Tropodult e Tropudalf), respectivamente.

Tabela 15 - Índice de eficiência agronômica (IEA) em função das fontes de fósforo, momento de calagem e utilização do gesso, no primeiro plantio*

\begin{tabular}{lcccc}
\hline & \multicolumn{4}{c}{ Fontes de fósforo } \\
\hline $\left.\begin{array}{l}\text { Niveis de } \\
\text { (mg d d }\end{array}{ }^{3}\right)$ & FGAC & FGDC & FGACG & FGDCG \\
\hline 50 & & & & \\
100 & 25,93 & 25,19 & 33,33 & 32,59 \\
200 & 33,80 & 28,67 & 20,05 & 13,99 \\
\hline
\end{tabular}

(FGAC: Fosfato de Gafsa antes da calagem; FGDC: Fosfato de Gafsa depois da calagem; FGACG: Fosfato de Gafsa antes da calagem mais gesso; FGDCG: Fosfato de Gafsa depois da calagem mais gesso). *Média de três repetições.

A produção de matéria seca testemunha no terceiro plantio foi, em média, $50 \mathrm{mg}$ MS/vaso. Após essa colheita as plantas morreram.

No primeiro corte do terceiro plantio, os niveis de 50 e $100 \mathrm{mg} \mathrm{P} \mathrm{dm}$ apresentaram altos IEA, principalmente o fosfato de Gafsa associado ao gesso (Tabela 16). Esse resultado deve-se, provavelmente, à fixação do fosfato solúvel pelo solo provocado pelo atraso ocorrido para se efetuar o terceiro plantio. Essa fixação do fósforo provocou menor produção da alfafa quando se utilizou o fósforo solúvel. Admite-se que, 
em condições de maior contato solo-fertilizante, haja maior imobilização da fonte solúvel, devido à liberação mais rápida do fósforo que dos fosfatos naturais reativos (Rosand \& Wild, 1982). No entanto, em relação ao nível de $200 \mathrm{mg} \mathrm{P} \mathrm{dm}^{-3}$ no primeiro corte (Tabela 16), o FGACG e o FGDCG apresentaram IEA superior ao STDC, enquanto que o FGAC e o FGDC apresentaram baixos índices.

Tabela 16 - Índice de eficiência agronômica (IEA) em função das fontes de fósforo, momento de calagem e utilização do gesso junto da calagem para os três cortes do terceiro plantio*.

\begin{tabular}{lccc}
\hline $\begin{array}{l}\text { Níveis de P } \\
\left(\mathrm{mg} \mathrm{dm}^{-3}\right)\end{array}$ & CORTE 1 & CORTE 2 & CORTE 3 \\
\hline Fontes de fósforo & & & \\
\hline Fosf Gafsa antes da calagem & 266,67 & 200,00 & 400,00 \\
\hline 50 & 165,85 & 230,95 & 192,35 \\
100 & 67,61 & 95,77 & 140,80 \\
\hline 200 & & & \\
\hline Fosf. Gafsa depois da calagem & 333,33 & 1860,00 & 9500,00 \\
\hline 50 & 249,39 & 283,63 & 226,39 \\
100 & 62,76 & 103,03 & 128,11 \\
200 & & & \\
\hline Fosf. Gafsa antes da calagem + gesso & 400,00 & 800,00 & 4550,00 \\
\hline 50 & 203,05 & 268,45 & 213,98 \\
100 & 120,80 & 119,31 & 119,54 \\
200 & 2800,00 & 6500,00 & 17850,00 \\
\hline Fosf Gafsa depois da calagem + gesso & 493,90 & 328,27 & 211,08 \\
\hline 50 & 113,25 & 131,44 & 133,83 \\
\hline 100 & & &
\end{tabular}

* Média de três repetições.

Por outro lado, todos os tratamentos citados, elevaram os IEA em relação à época de corte no nível de $200 \mathrm{mg} \mathrm{P} \mathrm{dm}^{-3}$ com exceção do FGACG que manteve o IEA (Tabela 16). Isso deve-se as respostas medidas de aumento da produção de MS com o uso do FGAC e FGDC e a diminuição da produção com a utilização do STDC em função das épocas de corte (Tabela 7). 
Os valores de IEA nos níveis de 50 e $100 \mathrm{mg} \mathrm{P} \mathrm{dm}^{-3}$ aumentaram em função das épocas de corte, e de maneira acentuada no nível de $50 \mathrm{mg} \mathrm{P} \mathrm{dm}^{-3}$ (Tabela 16). Isso foi devido, provavelmente, ao efeito residual do fosfato de Gafsa que possibilitou o incremento na produção de MS nos cortes subsequente e também associado à baixa produção mantida com o uso do STDC no nível de $50 \mathrm{mg} \mathrm{P} \mathrm{dm}^{-3}$ (Tabela 7). A exceção foi para o FGDCG no nível de $100 \mathrm{mg} \mathrm{P} \mathrm{dm}^{-3}$, onde o IEA diminuiu nos cortes subsequentes (Tabela 16), devido ao aumento de produção de MS com o uso do STDC no segundo e terceiro corte, nesse mesmo nível (Tabela 7).

$\mathrm{O}$ aumento da eficiência do fosfato de rocha reativo com o passar do tempo foi relatado por Macedo et al. (1985), Braga et al. (1991) e Moreira (1997). Dessa maneira, percebe-se a importância de levar em consideração o efeito residual do fosfato de Gafsa na produção agricola. A elevada eficiência do fosfato de Gafsa em relação à uma fonte solúvel tem sido encontrada por vários autores como Macedo et al. (1985), Rosand \& Santana (1986), Léon et al. (1986) e Braga et al. (1991).

\subsection{Sintomas nutricionais}

No primeiro plantio foi constado como sintoma de deficiência de fósforo somente crescimento reduzido da planta. No entanto, no primeiro período de crescimento do terceiro plantio, os sintomas de deficiência de fósforo já se apresentavam bem evidentes após, aproximadamente, 47 dias da semeadura.

Os sintomas de deficiência de fósforo foram:

1 crescimento reduzido (Apêndice 9a);

2 hastes e pecíolos arroxeados;

3 folíolos muito pequenos (3,9 $\mathrm{mm}$ de largura e 4,2 $\mathrm{mm}$ de comprimento) (Apêndice $9 \mathrm{~b}$ ); 4 amarelecimento das folhas mais velhas que posteriormente morriam (Apêndice 9a) nas testemunhas e no nivel de $50 \mathrm{mg} \mathrm{P} \mathrm{dm}^{-3}$ em todas as fontes; 5 amarelecimento e morte das folhas mais velhas nos tratamentos STAC e FGAC no nível de $100 \mathrm{mg} \mathrm{P} \mathrm{dm}^{-3}$; 6 morte das plantas após o primeiro corte nos tratamentos que não recebiam fósforo. 
Estas observações estão de acordo com os sintomas de deficiência de fósforo em alfafa descritos por Kelling (1990).

Suspeitou-se que alguns sintomas que apareceram nas folhas mais velhas da alfafa durante o terceiro plantio no primeiro corte fossem o de toxidez por Mn que apresentaram as seguintes características:

1 amarelecimento nos bordos dos folíolos com pequenos pontos necróticos;

2 amarelecimento nos bordos dos folíolos (Apêndice 9c), seguido de necrose, com ou sem arroxeamento intenso dos bordos da lâmina inferior;

3 arroxeamento intenso nas bordas inferiores dos folíolos, que transparecia de maneira opaca nas bordas superiores (Apêndice 9d), ou de cor amarelo amarronzado;

4 amarelecimento entre nervuras e bordas dos folíolos, seguida de necrose, também, nos bordos (Apêndice 9e);

5 intensificados os sintomas de amarelecimento e arroxeamento nos bordos, as folhas ficavam totalmente amareladas e caiam.

Os sintomas apareceram quando as plantas tinham, aproximadamente 54 dias de idade e apresentaram-se de maneira mais intensa nos tratamentos com superfosfato triplo do que com a utilização do fosfato de Gafsa. Os tratamentos que apresentaram esses sintomas foram:

- STAC - nível de $200 \mathrm{mg} \mathrm{P} \mathrm{dm}^{-3}$;

- STDC, FGAC, FGDC, FGACG - níveis de 100 e $200 \mathrm{mg} \mathrm{P} \mathrm{dm}^{-3}$;

- FGDCG - niveis de 50, 100 e $200 \mathrm{mg} \mathrm{P} \mathrm{dm}^{-3}$.

Esses sintomas foram confirmados como sendo devido a toxidez por manganês em outro experimento complementar realizado junto ao Departamento de Nutrição de Plantas da ESALQ/USP, em casa de vegetação (Apêndice 10). Esse experimento constituiu-se de dois cultivares de alfafa (Crioula e XAI 32) e cinco doses crescentes de manganês $\left(0,5 ; 2,5 ; 5,0 ; 15,0\right.$ e $\left.30,0 \mathrm{mg} \mathrm{Mn} \mathrm{L}^{-1}\right)$ em solução nutritiva, com três repetições. Nesse trabalho observou-se os mesmos sintomas descritos acima, com exceção do sintoma apresentado no Apêndice 9e. 
Quellette \& Dessureaux ${ }^{16}$ (citados por Helyar, 1978), Siman el at. (1974), Kelling (1990), Sale et al. (1992) e De Marco et al. (1995) descreveram os sintomas de toxidez de Mn nas folhas mais velhas da alfafa como clorose nas margens dos foliolos para toxidez suave e necrose para toxidez severa. Quellette \& Dessureaux ${ }^{16}$ (citados por Robson \& Loneragan, 1970), Smith et al. (1983) e Kelling (1990) também apontaram como sintoma de toxidez o aparecimento de pequenos pontos necróticos nas margens dos folíolos. Entretanto somente Siman et al. (1974) apontam os sintomas de toxidez pelo Mn como apresentado no Apêndice $9 \mathrm{~d}$. No trabalho complementar realizado junto ao Departamento de Nutrição Mineral de Plantas (Apêndice 10), utilizando crescentes niveis de $\mathrm{Mn}$, confirmou-se os sintomas observados nesse trabalho. A exceção foi o sintoma de amarelecimento entre nervuras (Apêndice 9e) devido à toxidez por Mn que não foi encontrado na literatura consultada ou no trabalho complementar.

\subsection{Dinâmica do surgimento de brotos}

\subsubsection{Brotos basais}

Após a germinação, a primeira folha da alfafa é simples, unifoliolada e com pecíolo delgado. As folhas subsequentes produzidas na haste primária são trifolioladas. A haste primária continua a se elongar e desenvolver folhas dispostas alternadamente. $\mathrm{O}$ broto da primeira folha unifoliolada desenvolve-se na primeira haste secundária. As hastes subsequentes que surgem de gemas na base da planta (hastes secundárias) formam a coroa primária (Teuber \& Brick, 1988). A coroa consiste de porções perenes do caule mas não é uma estrutura simples ou única e sim uma área incluindo algumas estruturas separadas, como a parte superior da raiz (Grove \& Carlson, 1972). Quando as plantas do primeiro crescimento não são cortadas, produzem hastes secundárias adicionais originadas das gemas axilares das folhas trifolioladas da haste primária e, eventualmente, podem surgir hastes terciárias das gemas axilares das folhas da haste secundária (Figura

\footnotetext{
${ }^{16}$ QUELLETTE, G.J; DESSUREAUX, L. Quimical composition of alfalfa as related to degree of tolerance to manganese and aluminium. Canadian Journal Plant of Science, v. 38, p. 206-214, 1958.
} 
9) (Teuber \& Brick, 1988). Nas rebrotas os brotos originam-se de gemas da coroa, formando as hastes da coroa, $\mathrm{e}$ as gemas axilares das hastes remanescentes darão origem aos brotos axilares (Romero et al., 1995).

No presente trabalho, tanto as hastes primárias como as hastes secundárias originadas da base da planta, e os brotos surgidos da coroa na rebrota foram considerados como brotos basais ou da coroa. Por outro lado, tanto os brotos surgidos das folhas trifolioladas da haste primária e das hastes secundárias, como os brotos originados das hastes remanescentes depois do corte, foram considerados como brotos laterais ou axilares.

Nas testemunhas, as plantas apresentaram somente um broto basal, que foi a haste principal ou primária, e não apresentaram brotação lateral durante o crescimento do primeiro corte do terceiro plantio. Após o primeiro corte, todas as plantas do nível zero de fósforo morreram em decorrência da deficiência nutricional.

O segundo broto basal surgiu da primeira folha unifoliolada quando as plantas tinham em média 41 dias de idade para todas as fontes de fósforo ao nivel de $200 \mathrm{mg} \mathrm{P}$ $\mathrm{dm}^{-3}$ (Figuras 10, 11 e 12). O número de brotos basais aumentou até os 90 dias de idade quando foi feito o primeiro corte. Essas brotações basais devem ser preservadas durante o corte para auxiliarem no vigor da rebrota da planta (Monteiro, 1989 e Honda \& Honda, 1990).

O segundo broto basal da alfafa no tratamento que recebeu $100 \mathrm{mg} \mathrm{P} \mathrm{dm}^{-3}$ teve o aparecimento retardado entre 6 a 15 dias em relação ao nível de $200 \mathrm{mg} \mathrm{P} \mathrm{dm}^{-3}$ (Figuras 10,11 e 12). Nos tratamentos FGDC e FGDCG (Figuras 11 e 12), no entanto, o aparecimento dos brotos basais no nível de $100 \mathrm{mg} \mathrm{P} \mathrm{dm}^{-3}$ foi iniciado no mesmo período que os tratamentos que receberam $200 \mathrm{mg} \mathrm{P} \mathrm{dm}^{-3}$. Em todos os tratamentos no nível de 100 e $200 \mathrm{mg} \mathrm{P} \mathrm{dm}^{-3}$, verificou-se elevação no número de brotos basilares até os 90 dias de idade. A única exceção foi o tratamento STAC que apresentou aumento pouco expressivo (Figura 10), devido, provavelmente, à fixação do fósforo proveniente da fonte solúvel aplicado antes da calagem (Tabela 6), tornando-o pouco disponível à planta. 

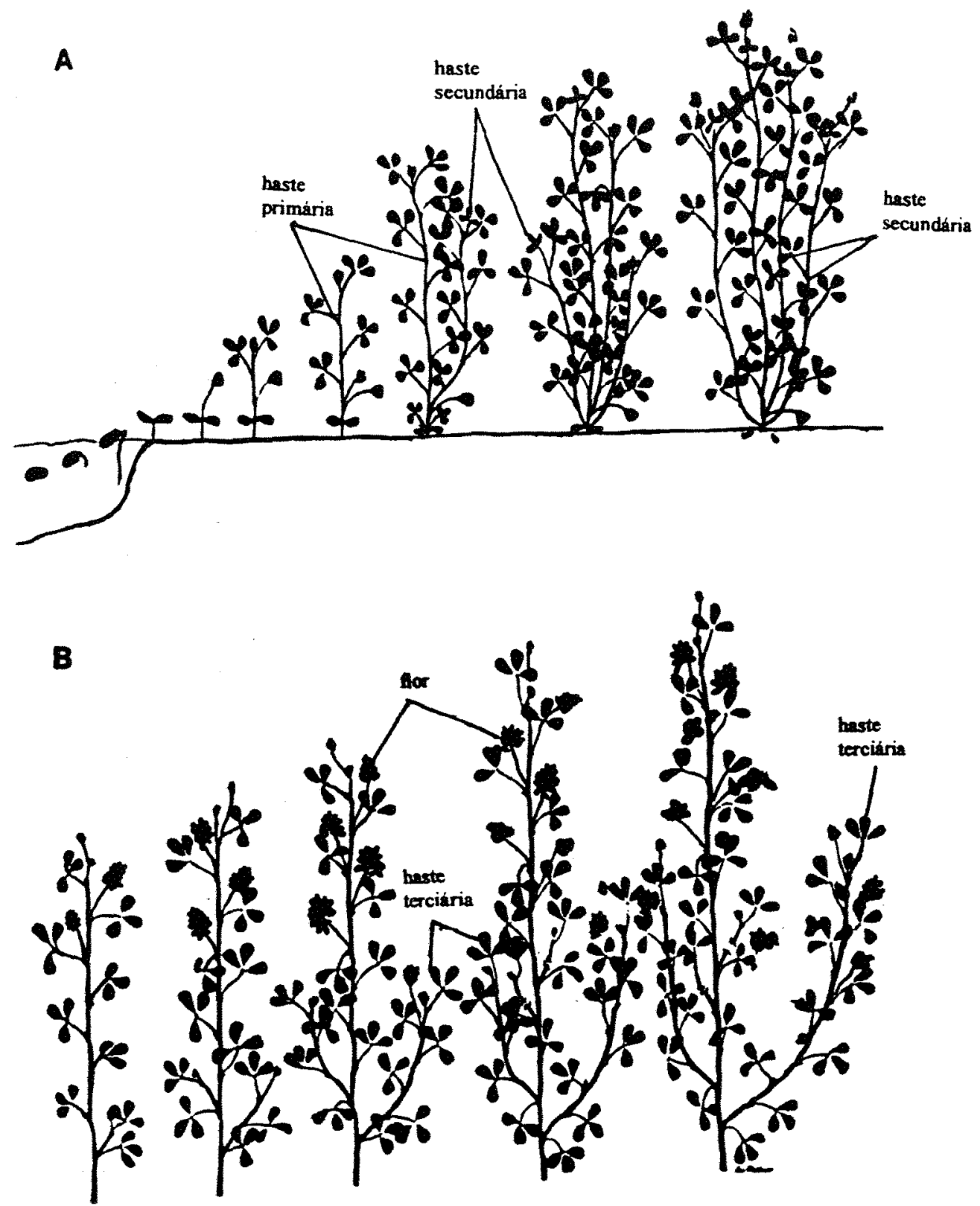

Figura 9 - (A) Sequência da germinação da semente da alfafa e subsequente desenvolvimento da haste primária e hastes secundárias, estas últimas surgindo de gemas na base da planta. (B) Ramificações subsequêntes da alfafa, no primeiro crescimento, com o surgimento de hastes terciárias. (Adaptado de Teuber \& Brick. 1988) 
$O$ surgimento do segundo broto basal no tratamento que recebeu $50 \mathrm{mg} \mathrm{P} \mathrm{dm}^{-3}$ ocorreu com o uso do FGDCG quando as plantas tinham em torno de 50 dias de idade (Figura 12).

Observou-se grande redução no número de perfilhos basais da alfafa logo em seguida aos cortes (Figuras 10, 11 e 12). Segundo Monteiro \& Moraes (1996), isso é devido à alfafa apresentar hábito de crescimento ereto que ocorre o alongamento do colmo, expondo muito seus pontos de crescimento (meristemas apicais) e portanto deixando-os mais susceptiveis à decaptação pelo corte, o que causa redução drástica da área foliar.

Posteriormente aos cortes, o número de brotos basilares aumentou com a idade, nos níveis de 50,100 e $200 \mathrm{mg} \mathrm{P} \mathrm{dm}^{-3}$, em todas as fontes de fósforo (Figuras 10, $11 \mathrm{e}$ 12). Esses resultados estão de acordo com os encontrados por Belesky \& Fedders (1997) e Juan ${ }^{17}$, citado por Romero et al. (1995), que verificou aumento dos brotos originados da coroa em observações realizadas até 42 dias de rebrota. As subsequentes brotações da coroa são conseqüência da quebra de dominância apical provocada pela decaptação do meristema apical com o corte.

A rebrota das hastes da coroa foi mais rápida nos níveis mais elevados de fósforo, porém o FG associado ou não ao gesso, no nível de $100 \mathrm{mg} \mathrm{P} \mathrm{dm}^{-3}$, apresentou comportamento próximo ao nível mais alto de fósforo (Figuras 10, 11 e 12), exceto para o FGACG.

Em relação ao período de rebrota nos tratamentos com 100 e $200 \mathrm{mg} \mathrm{P} \mathrm{dm}^{-3}$ observou-se que o aparecimento de brotos basais foi mais rápido na segunda rebrota do que na primeira. Na segunda rebrota ocorreu aumento acentuado no número de brotos até, aproximadamente, 9 dias após segundo corte, enquanto que na primeira rebrota observou-se aumento do número de brotos basilares de maneira mais acentuada até, aproximadamente, 15 dias depois do primeiro corte (Figuras 10, 11 e 12). Isso pode ter ocorrido em consequência do aumento da temperatura ambiental durante o crescimento após o segundo corte, onde as temperaturas máxima, mínima e média semanal a partir

\footnotetext{
17 JUAN, N.A. Growth of alfalfa germplasms differing in dormancy cut at two maturity stages. M.S. Thesis. University of Minnesota. USA. 1989.
} 
$-x-50-100-200$

STAC

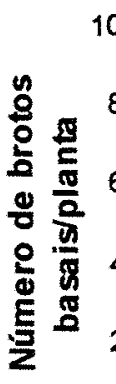

10

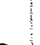

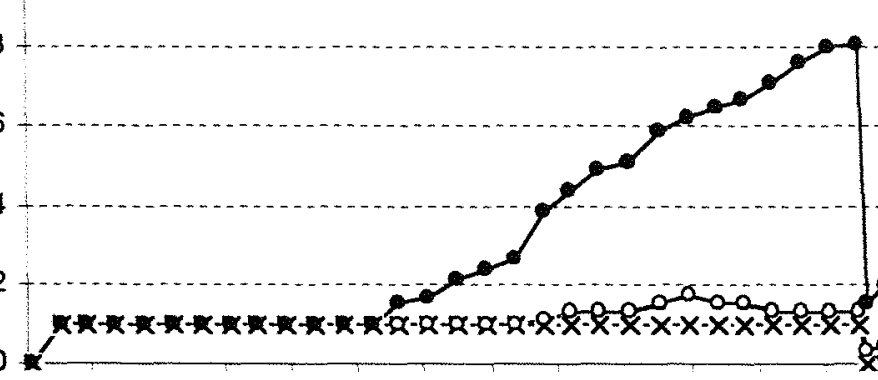

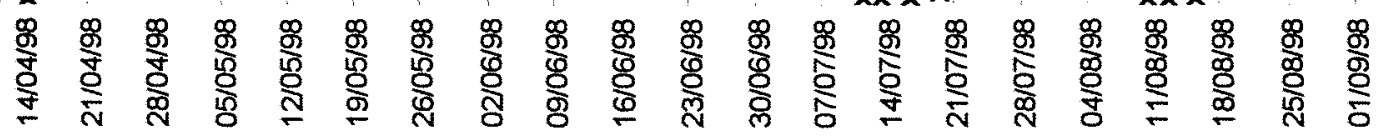

Dias das avaliações

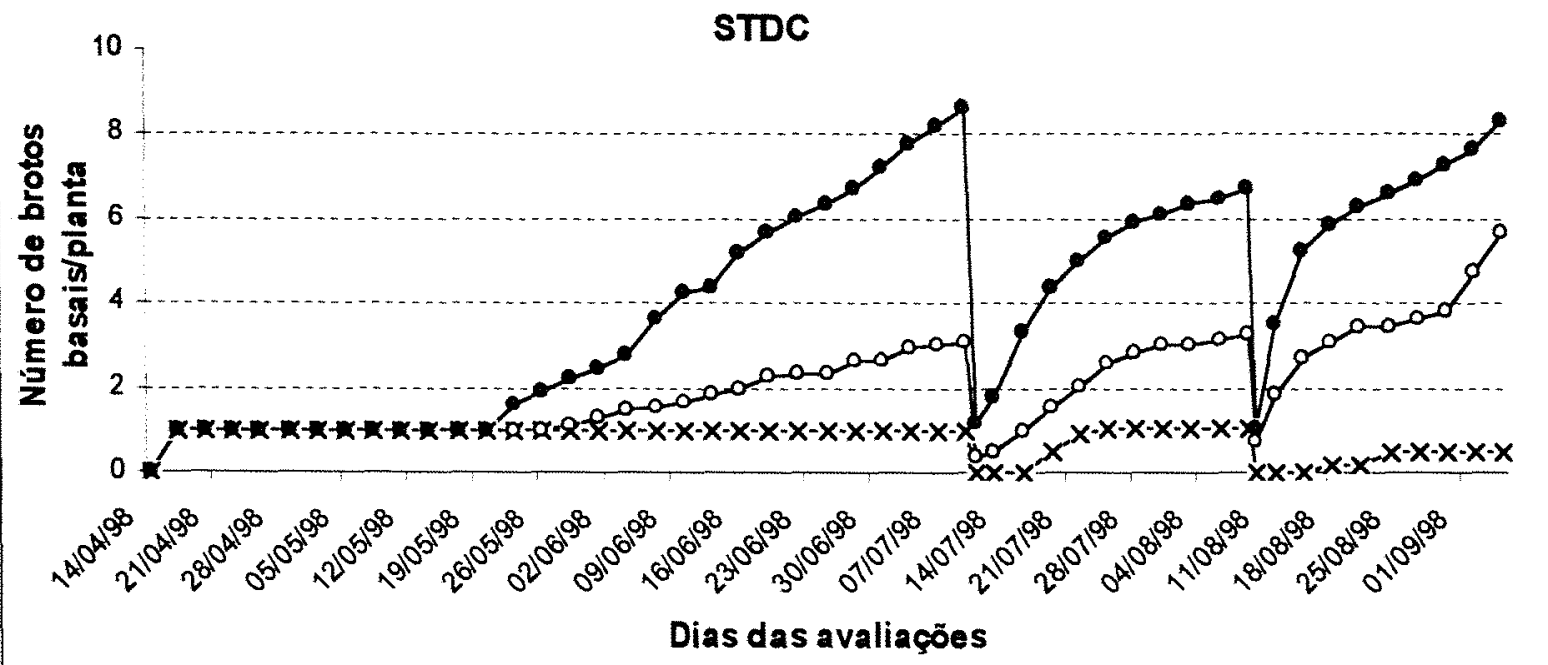

Figura 10 - Evolução do número de brotos basais por planta em função dos níveis de fósforo $\left(50,100\right.$ e $\left.200 \mathrm{mg} \mathrm{P} \mathrm{dm}^{-3}\right)$ com o uso do STAC e do STDC, no terceiro plantio.

(STAC: super triplo aplicado antes da calagem; STDC: super triplo aplicado depois da calagem). 


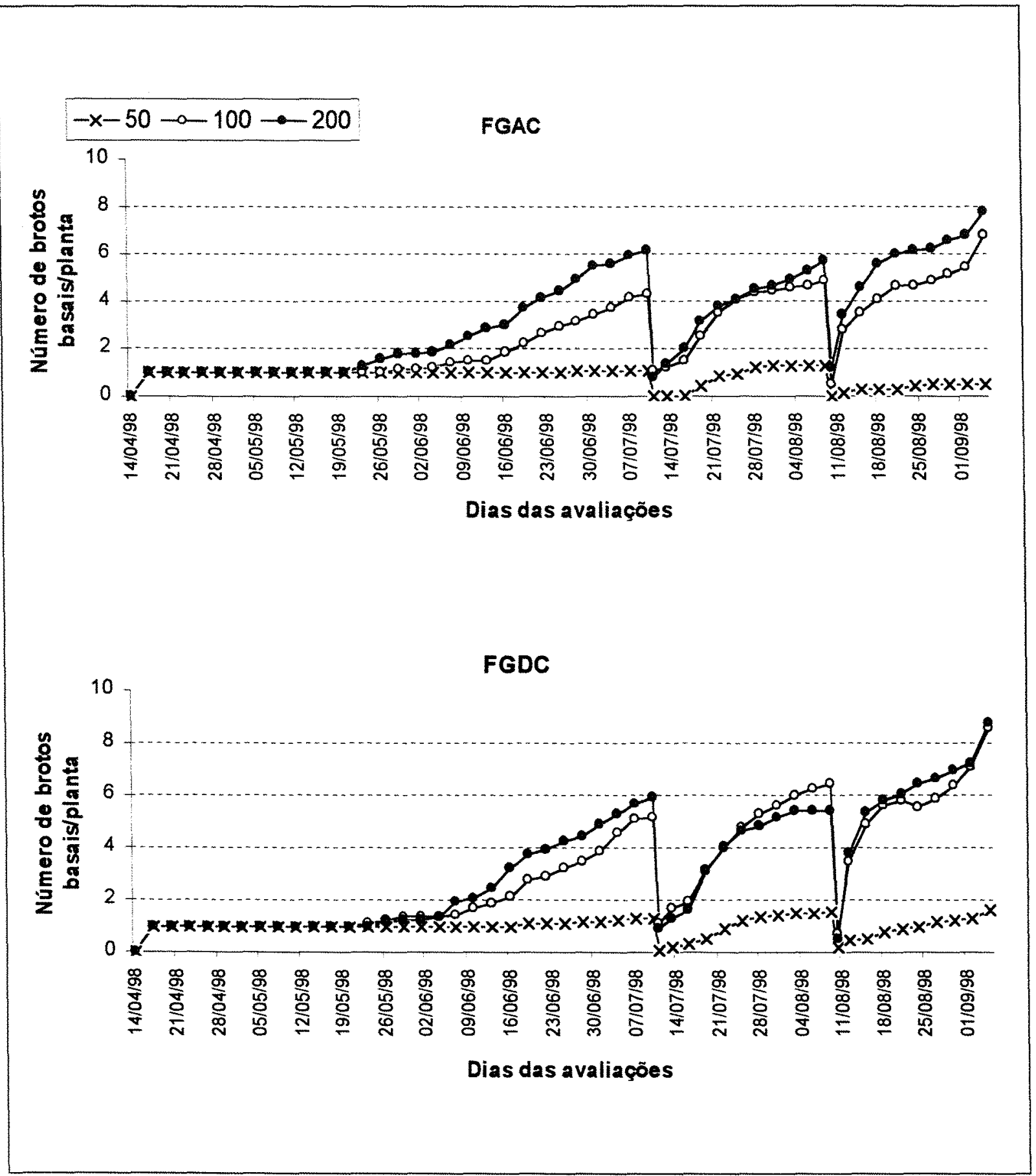

Figura 11 - Evolução do número de brotos basais por planta em função dos níveis de fósforo $\left(50,100\right.$ e $\left.200 \mathrm{mg} \mathrm{P} \mathrm{dm}^{-3}\right)$ com o uso do FGAC e do FGDC, no terceiro plantio.

(FGAC: Fosfato de Gafsa aplicado antes da calagem; FGDC: Fosfato de Gafsa aplicado depois da calagem). 


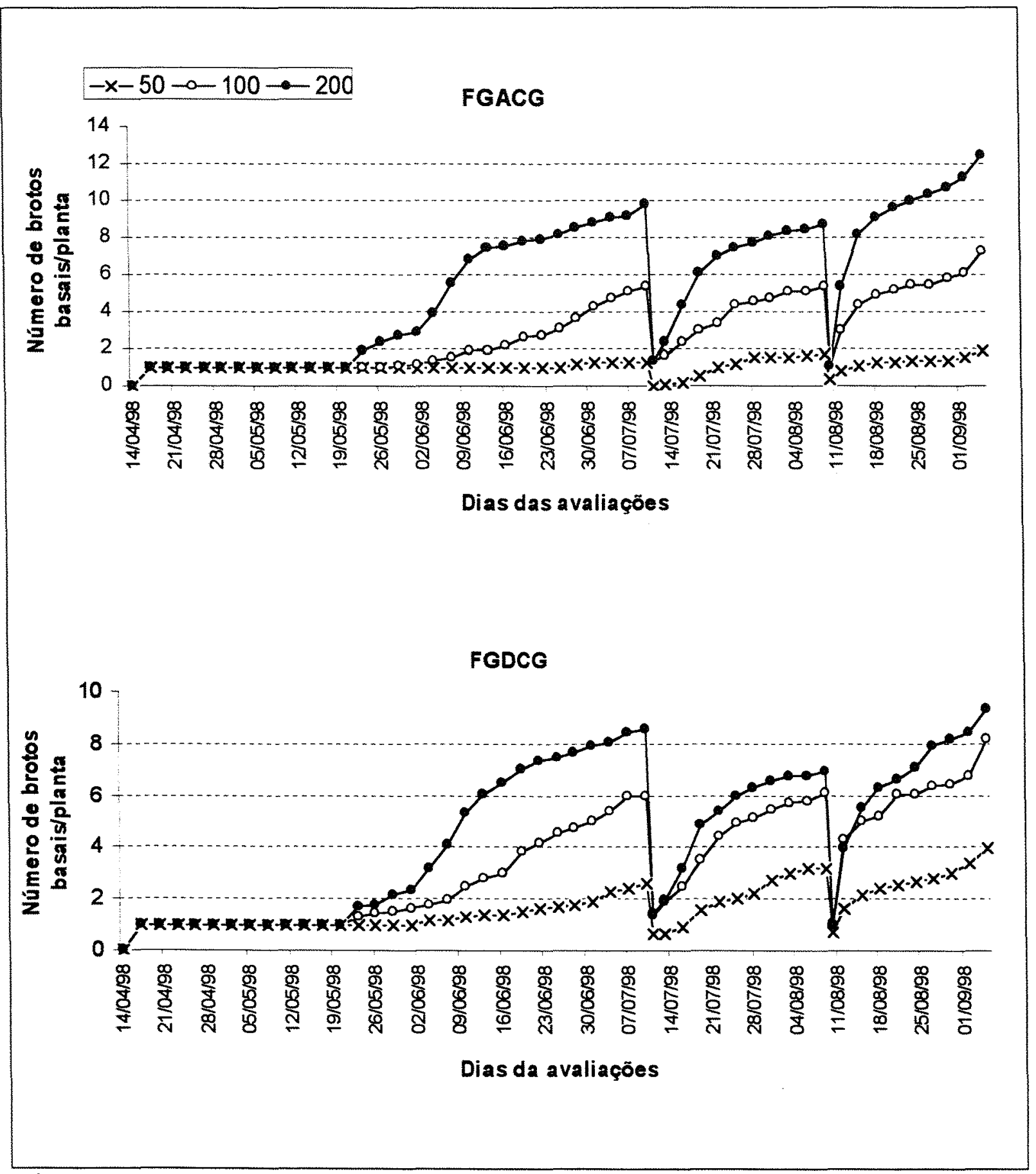

Figura 12 - Evolução do número de brotos basais por planta em função dos níveis de fósforo $\left(50,100\right.$ e $200 \mathrm{mg} \mathrm{P} \mathrm{dm}^{-3}$ ) com o uso do FGACG e do FGDCG, no terceiro plantio.

(FGACG: Fosfato de Gafsa associado ao gesso aplicado antes da calagem; FGDCG: Fosfato de Gafsa associado ao gesso aplicado depois da calagem). 
do primeiro corte foram de 22,8 e $15^{\circ} \mathrm{C}$, respectivamente, enquanto que na semana a partir da segundo corte essas temperaturas foram de 28,16 e $22^{\circ} \mathrm{C}$, respectivamente. Esse resultado corrobora os obtidos por Leach (1971) que estudando o efeito da temperatura $\left(15,21,27\right.$ e $\left.33^{\circ} \mathrm{C}\right)$ no crescimento dos brotos de alfafa, observou rebrota inicial mais rápida e maior número final de brotos em plantas crescidas no ambiente com maior temperatura. Desde 1968 Leach afirmava que a morfogênese pode ser mais prejudicada do que o crescimento pelo ambiente menos favorável, confirmando o fato que o processo de formação dos brotos pode sofrer reduções marcantes com a diminuição da temperatura.

Na primeira e principalmente na segunda rebrotas, próximo ao segundo e terceiro corte, respectivamente, verificaram-se novos aumentos no número de brotos basais nos níveis de 100 e $200 \mathrm{mg} \mathrm{P} \mathrm{dm}^{-3}$ (Figuras 10, 11 e 12). Esses resultados estão de acordo com os encontrados por Leach (1969), Janson ${ }^{18}$ (1975), citado por Christian (1977) e Monteiro (1989), que observaram no final do ciclo de crescimento o surgimento de brotações na base das plantas quando os primeiros botões florais tornavam-se visíveis. As novas brotações basilares são consideradas como sinal de maturidade da forragem, sendo esta utilizada como referência para a realização dos cortes da alfafa no inverno, uma vez que não há florescimento nesse período.

O estabelecimento das novas populações de brotos foi realizada, praticamente, até o $15^{\circ}$ dia de rebrota, independente do tratamento (Tabela 17). Esses resultados confirmam as observações de Leach (1968), Skrzyniarz (1984) e Monteiro (1989). O número de perfilhos que iniciaram crescimento até 15 dias após o corte tendeu a ser maior maior nos tratamentos que receberam $200 \mathrm{mg} \mathrm{P} \mathrm{dm}^{-3}$ em relação aos de $100 \mathrm{mg} P$ $\mathrm{dm}^{-3}$, com exceção do tratamento FGAC na primeira rebrota (Tabela 17). Isso mostra que a menor fertilização de fósforo retardou a reposição de brotos basais da alfafa. No entanto, isso não ocorreu em todas as fontes no nível de $50 \mathrm{mg} \mathrm{P} \mathrm{dm}^{-3}$, provavelmente devido ao baixo número de brotos nos tratamentos com $50 \mathrm{mg} \mathrm{P} \mathrm{dm}^{-3}$.

\footnotetext{
${ }^{18}$ JANSON, C.G. New Zeland Journal Experimental Agriculture, v.3, p. 63-69, 1975.
} 
Tabela 17 - Números percentuais de brotos basais aos 15 dias após o corte, em relação ao número de hastes totais da coroa no final do respectivo período de crescimento.

\begin{tabular}{|c|c|c|c|c|c|c|}
\hline 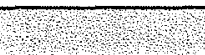 & 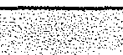 & \% & es de fó & & & . \\
\hline $\begin{array}{l}\text { Niveis de } \\
\text { p(mg dm }\end{array}$ & STAC & STDC & $\mathrm{FGAC}$ & FGDC & FGACG & $\mathrm{FGDCG}$ \\
\hline & X & brotos & $\operatorname{aos} 15$ & la $1^{\circ} \mathrm{rel}$ & & \\
\hline 50 & 88 & 100 & 71 & 78 & 69 & 63 \\
\hline 100 & 57 & 80 & 84 & 74 & 81 & 78 \\
\hline 200 & 73 & 82 & 72 & 87 & 86 & 87 \\
\hline 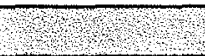 & & brotos & $\operatorname{aos} 15$ & a $2^{\mathrm{a}} \mathrm{rel}$ & & \\
\hline 50 & 100 & 100 & 75 & 63 & 71 & 68 \\
\hline 100 & 75 & 61 & 69 & 64 & 75 & 74 \\
\hline 200 & 84 & 79 & 78 & 74 & 80 & 76 \\
\hline
\end{tabular}

(STAC: super triplo antes da calagem; STDC: super triplo depois da calagem; FGAC: Fosfato de Gafsa antes da calagem; FGDC: Fosfato de Gafsa depois da calagem; FGACG: Fosfato de Gafsa antes da calagem mais gesso; FGDCG: Fosfato de Gafsa depois da calagem mais gesso).

$\mathrm{A}=$ (número de brotos aos 15 dias de rebrota/número de brotos no final do respectivo período de crescimento) $\times 100$.

*Média de três repetições.

\subsubsection{Brotos laterais}

No primeiro período de crescimento o primeiro broto lateral apareceu, aproximadamente, aos 65 dias após o plantio quando surgiram os primeiros botões florais na alfafa, nos tratamentos que receberam $200 \mathrm{mg} \mathrm{P} \mathrm{dm}^{-3}$ independente da fonte de fósforo (Figura 13, 14 e 15). A exceção foi para o tratamento FGDCG, no nível de 100 $\mathrm{mg} \mathrm{P} \mathrm{dm}{ }^{-3}$, que também apresentou brotação lateral no primeiro periodo de crescimento (Figura 15) quando surgiram os botões florais no mesmo momento que ao nível de 200 $\mathrm{mg} \mathrm{P} \mathrm{dm}{ }^{-3}$. Esses brotos laterais aumentaram até o momento do primeiro corte realizado aos 90 dias de idade.

Nas rebrotas, observou-se que os brotos laterais originados logo após o corte surgiam de gemas axilares de hastes remanescentes, enquanto que aqueles que apareciam nos últimos 10 dias do ciclo eram originados, em sua maioria, de gemas de folhas trifolioladas de brotos laterais ou dos brotos basais. Esses últimos surgiam com o aparecimento dos botões florais, nos níveis de 100 e $200 \mathrm{mg} \mathrm{P} \mathrm{dm}^{-3}$, e apresentavam, aparentemente, menor peso do que os brotos basais ou brotos laterais originados de hastes remanescentes. Leach (1970) observou que $90 \%$ da produção de matéria seca 


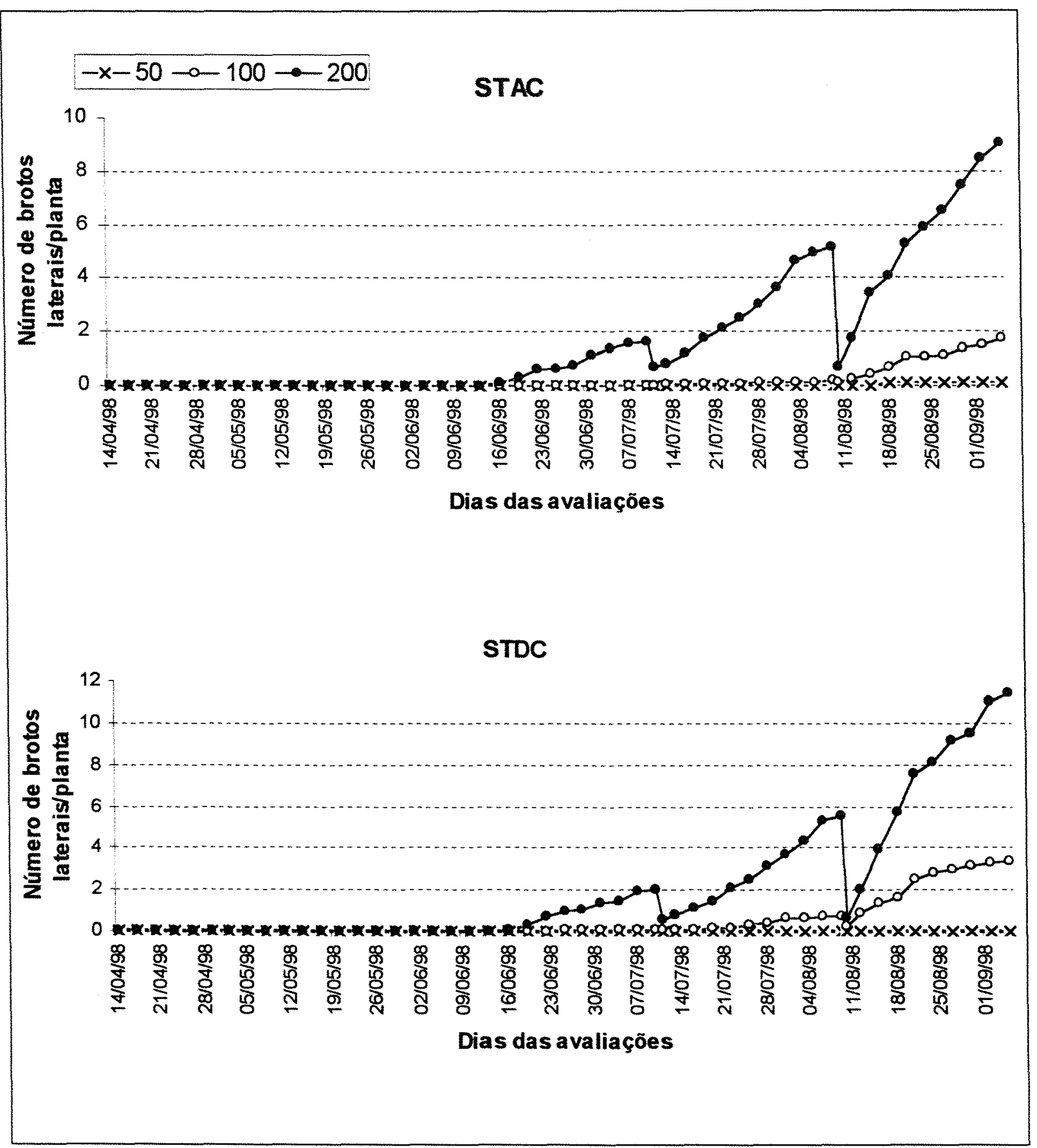

Figura 13 - Evolução do número de brotos laterais por planta em função dos níveis de fósforo $\left(50,100\right.$ e $200 \mathrm{mg} \mathrm{P} \mathrm{dm}^{-3}$ ) com o uso do STAC e do STDC, no terceiro plantio.

(STAC: super triplo aplicado antes da calagem; STDC: super triplo aplicado depois da calagem). 


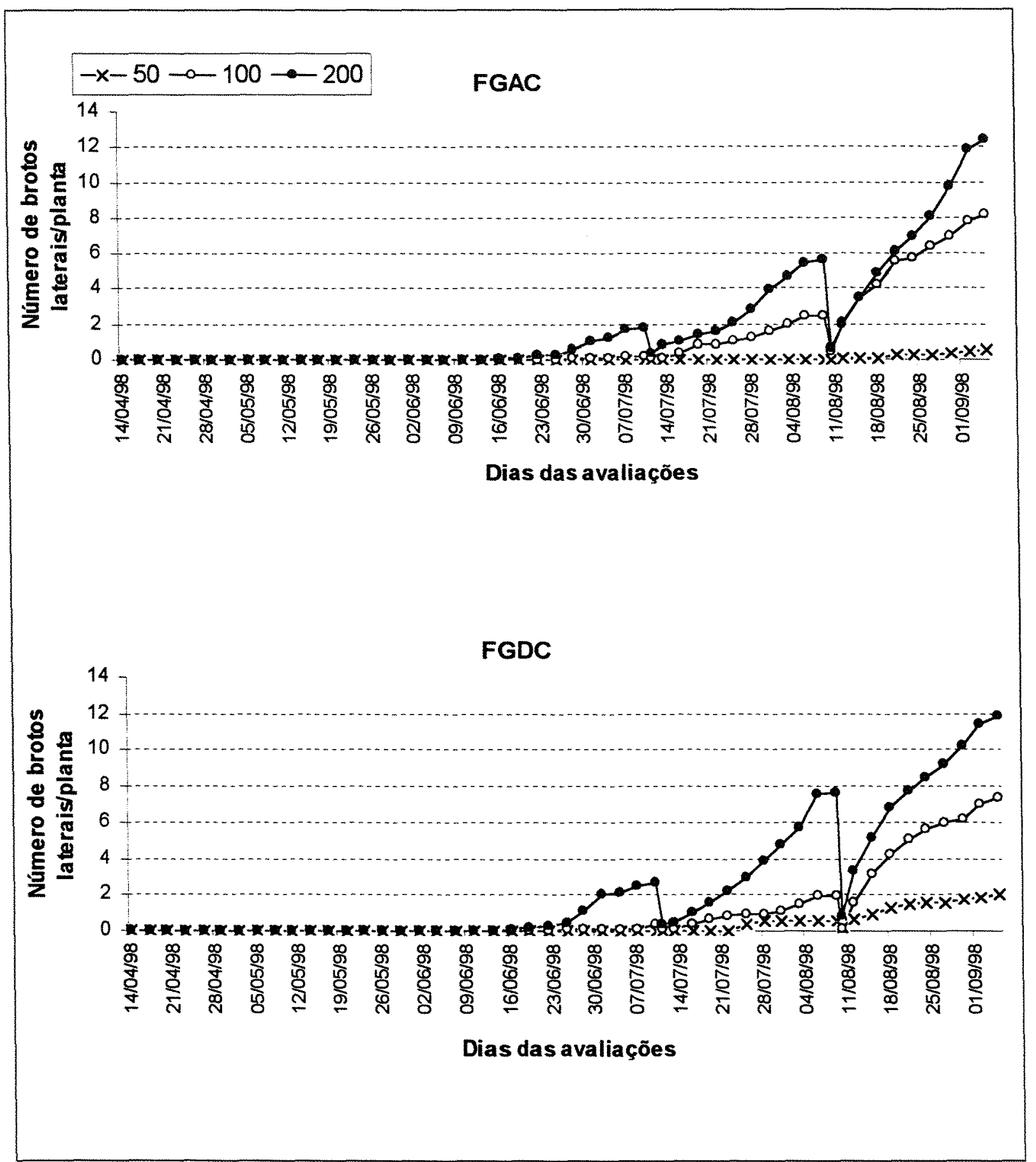

Figura 14 - Evolução do número de brotos laterais por planta em função dos níveis de fósforo $\left(50,100\right.$ e $\left.200 \mathrm{mg} \mathrm{P} \mathrm{dm}^{-3}\right)$ com o uso do FGAC e do FGDC, no terceiro plantio.

(FGAC: Fosfato de Gafsa aplicado antes da calagem; FGDC: Fosfato de Gafsa aplicado depois da calagem). 


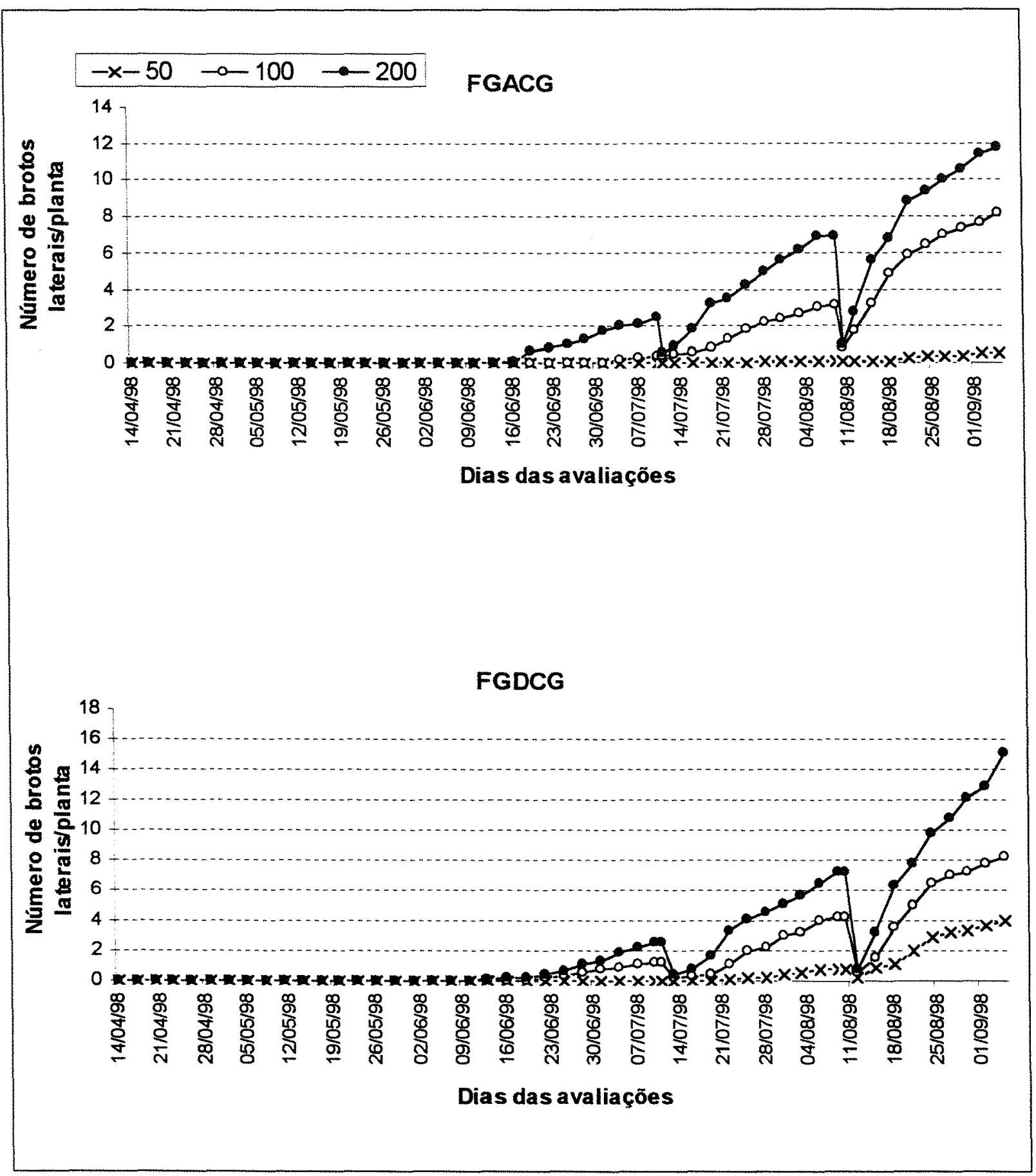

Figura 15 - Evolução do número de brotos laterais por planta em função dos níveis de fósforo $\left(50,100\right.$ e $\left.200 \mathrm{mg} \mathrm{P} \mathrm{dm}^{-3}\right)$ com o uso do FGACG e do FGDCG, no terceiro plantio.

(FGACG: Fosfato de Gafsa associado ao gesso aplicado antes da calagem; FGDCG: Fosfato de Gafsa associado ao gesso aplicado depois da calagem). 
poderia ser atribuída a perfilhos que iniciaram crescimento na coroa ou até $2 \mathrm{~cm}$ acima dela.

Nelson \& Smith (1968) observaram decréscimo de 500 para 360 hastes laterais por $8,5 \mathrm{dm}^{2}$ a partir de, aproximadamente, um mês e meio de rebrota da alfafa devido à competição por luz e, depois por causa do corte, aos três meses de rebrota. No presente trabalho, não foi observada diminuição do número de brotos axilares uma vez que não houve tempo de ocorrer a competição por luz que provocasse a senescência dos brotos. A diminuição drástica do número de brotos laterais foi devida, unicamente, ao corte aos trinta dias de rebrota da alfafa.

$\mathrm{Na}$ segunda rebrota o aumento do número de brotos laterais foi mais acentuado do que na primeira, à semelhança do que ocorreu para os brotos basais (Figuras 13, $14 \mathrm{e}$ 15), devido, provavelmente, ao aumento de temperatura no período do segundo corte e, também, à solubilização do fósforo do fosfato de Gafsa (Tabela 14).

\subsubsection{Proporção de brotos basais/brotos laterais}

Houve aumento na proporção de brotos laterais em relação aos basais no decorrer dos períodos de crescimento e com o aumento do nível de fósforo aplicado (Apêndices $11,12,13,14,15$ e 16). Assim, verifica-se que a proporção de brotos basais e axilares não depende somente do momento do corte anterior (Juan ${ }^{19}, 1989$, citado por Romero et al.,1995), da altura ou da freqüência de corte (Monteiro, 1989, Belesky \& Fedders, 1997), mas também da nutrição mineral da planta.

No primeiro período de crescimento a proporção de brotos basais em relação aos laterais foi elevada (Apêndices 11, 12, 13, 14, 15 e 16), e que está de acordo com as observações de Singh \& Winch (1974) e Belesky \& Fedders (1997). Logo após o corte, o rebrote originou-se, em sua maioria, de gemas da coroa, sendo essas observações coincidentes com as obtidas por Monteiro (1989) quando efetuou os cortes nos cultivares CUF 101 e Crioula a $7 \mathrm{~cm}$ da base. No entanto, isso não está de acordo com os resultados obtidos por Leach (1968), Leach (1971) e Singh \& Winch (1974), que

\footnotetext{
${ }^{19}$ JUAN, N.A. Growth of alfalfa germplasms differing in dormancy cut at two maturity stages. M.S. Thesis. University of Minnesota. USA. 1989.
} 
observaram o rebrote originando-se, em geral, de gemas axilares de hastes remanescentes, quando realizaram os cortes a 5,5 e $7,5 \mathrm{~cm}$ da base, respectivamente. Belesky \& Fedders (1997) observaram que quando as plantas de alfafa foram cortadas a baixas alturas $(<2 \mathrm{~cm})$ a maioria dos brotos originou-se da coroa. No presente experimento, todavia, os cortes foram feitos a $7,5 \mathrm{~cm}$ da base. Dessa maneira, a maior proporção de brotos basais em relação aos laterais, encontradas no presente trabalho, pode ser devido o cultivar da alfafa como explicou Monteiro (1989) trabalhando com os cultivares CUF 101 e Crioula.

A maior proporção de brotos basais em relação aos brotos laterais decresceu no decorrer dos períodos de crescimento. No nível de $200 \mathrm{mg} \mathrm{P} \mathrm{dm}^{-3}$, na segunda rebrota, a proporção de hastes axilares superou a de hastes basais no momento do corte nos tratamentos STDC, FGAC, FGDC e FGDCG (Apêndices 12, 13, 14 e 16). Esses resultados corroboram os obtidos por Belesky \& Fedders (1997), quando realizaram os cortes da alfafa a 5 e $10 \mathrm{~cm}$ da base.

\subsection{Número de brotos basais e laterais}

Houve interações $(\mathrm{P}<0,05)$ entre fontes e doses de $\mathrm{P}$, cortes e fontes e, cortes $\mathrm{e}$ doses (Apêndice 19) no número de brotos basais por planta. Para o número de brotos laterais por planta, foi detectado interação tripla $(\mathrm{P}<0,05)$ entre cortes, fontes e doses de fósforo (Apêndice 20).

A adição de $\mathrm{P}$ aumentou linearmente $(\mathrm{P}<0,05)$ o número de brotos laterais em todas as fontes de fósforo, nos três períodos de crescimento (Tabela 18).

$\mathrm{O}$ aumentou nos níveis de fósforo aplicados de 50 a $200 \mathrm{mg} \mathrm{dm}^{-3}(\mathrm{P}<0,05)$ provocou respostas lineares no número de brotos basais em todas as fontes de fósforo (Tabela 19). Esses resultados confirmam o efeito do fósforo como nutriente que estimula o aumento do número de brotos em leguminosas e corrabora os resultados obtidos por Nie et al. (1997), Singh \& Sale (1997) e Singh \& Sale (1998), trabalhando com trevo branco (Trifolium repens L.), e os de Petit et al. (1992) e Sanderson \& Jones (1993), em observações com alfafa. 
Tabela 18 - Equações de regressão ajustadas entre o número de brotos laterais da alfafa $(\mathrm{Y})$, como variável dependente da dose de fósforo $\left(\mathrm{mg} \mathrm{dm}^{-3}\right)$ aplicada $(\mathrm{X})$ no solo, em função das épocas de corte.

\begin{tabular}{|c|c|c|}
\hline Fontes de fósforo & - Equações & $\mathbf{R}^{2}$ \\
\hline$\sqrt{10}$ & CORTE 1 & 50 \\
\hline STAC & $Y=-0,835+0,0119 X$ & $0,89^{*}$ \\
\hline STDC & $Y=-0,465+0,0142 X$ & $0,91^{*}$ \\
\hline FGAC & $Y=-0,800+0,0126 X$ & $0,95^{*}$ \\
\hline FGDC & $Y=-1,140+0,0186 X$ & $0,96^{*}$ \\
\hline FGACG & $Y=-1,035+0,017 X$ & $0,97^{*}$ \\
\hline FGDCG & $Y=-0,630+0,0163 X$ & $0,96^{*}$ \\
\hline 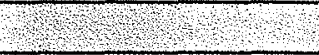 & CORTE 2 & +10 \\
\hline STAC & $Y=-2,465+0,0364 X$ & $0,91^{*}$ \\
\hline STDC & $Y=-2,400+0,0385 X$ & $0,96^{*}$ \\
\hline FGAC & $Y=-1,565+0,0365 X$ & $0,99^{*}$ \\
\hline FGDC & $Y=-2,330+0,0489 X$ & $0,98^{*}$ \\
\hline FGACG & $Y=-1,770+0,0443 X$ & $0,99^{*}$ \\
\hline FGDCG & $Y=-0,770+0,0417 X$ & $0,94^{*}$ \\
\hline 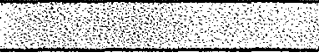 & CORTE 3 & 58 \\
\hline STAC & $Y=-3,540+0,0616 X$ & $0,97^{*}$ \\
\hline STDC & $Y=-4,000+0,0766 X$ & $1,00^{*}$ \\
\hline FGAC & $Y=-1,535+0,0735 X$ & $0,88 *$ \\
\hline FGDC & $Y=-0,260+0,0627 X$ & $0,94^{*}$ \\
\hline FGACG & $Y=-1,270+0,0695 X$ & $0,85^{*}$ \\
\hline FGDCG & $Y=0,535+0,0764 X$ & $1,00^{*}$ \\
\hline
\end{tabular}

(STAC: super triplo antes da calagem; STDC: super triplo depois da calagem; FGAC: Fosfato de Gafsa antes da calagem; FGDC: Fosfato de Gafsa depois da calagem; FGACG: Fosfato de Gafsa antes da calagem mais gesso; FGDCG: Fosfato de Gafsa depois da calagem mais gesso).

* significativo a $5 \%$ de probabilidade.

Tabela 19 - Equações de regressão ajustadas entre o número de brotos basais da alfafa $(Y)$, como variável dependente da dose de fósforo $\left(\mathrm{mg} \mathrm{dm}^{-3}\right)$ aplicada $(\mathrm{X})$ no solo.

\begin{tabular}{lcc} 
Fontes de fósforo & \multicolumn{1}{c}{ Equacões } & $\mathbf{R}^{2}$ \\
\hline STAC & $\mathrm{Y}=-1,98889+0,05000 \mathrm{X}$ & $0,98^{*}$ \\
STDC & $\mathrm{Y}=-1,11111+0,04597 \mathrm{X}$ & $0,98^{*}$ \\
FGAC & $\mathrm{Y}=0,33333+0,03378 \mathrm{X}$ & $0,77^{*}$ \\
FGDC & $\mathrm{Y}=1,47778+0,02993 \mathrm{X}$ & $0,57^{*}$ \\
FGACG & $\mathrm{Y}=-0,55555+0,05600 \mathrm{X}$ & $0,96^{*}$ \\
FGDCG & $\mathrm{Y}=2,48889+0,03098 \mathrm{X}$ & $0,84^{*}$ \\
\hline
\end{tabular}

(STAC: super triplo antes da calagem; STDC: super triplo depois da calagem; FGAC: Fosfato de Gafsa antes da calagem; FGDC: Fosfato de Gafsa depois da calagem; FGACG: Fosfato de Gafsa antes da calagem mais gesso; FGDCG: Fosfato de Gafsa depois da calagem mais gesso).

*significativo a $5 \%$ de probabilidade. 
Analisando-se as doses de fósforo dentro de cada corte, houve aumentos $(\mathrm{P}<0,05)$ no número de brotos originados da coroa, em todos os cortes, em função das doses de $\mathrm{P}$ aplicadas (Figura 16). Esse efeito foi constatado pelo fato de que a adição de $200 \mathrm{mg} \mathrm{P} \mathrm{dm}^{-3}$ aumentou em torno de 590, 430 e $770 \%$ o número de brotos basais por planta, em relação à utilização de $50 \mathrm{mg} \mathrm{P} \mathrm{dm}^{-3}$, no primeiro, segundo e terceiro corte, respectivamente.

Figura 16 - Número de brotos basais da alfafa em função dos níveis de fósforo (mg $\left.\mathrm{dm}^{-3}\right)$, em cada corte.

* significativo à $5 \%$ de probabilidade

Segundo Fick et al. (1988) o número de brotos por planta da alfafa é considerado como um dos componentes da produção de forragem, fato que foi comprovado nesse trabalho, onde foi encontrada correlação positiva $(P<0,05)$ entre número de brotos totais e produção de MS (Apêndice 21), em todas as fontes de $P$.

$\mathrm{O}$ número de brotos laterais foi maior $(\mathrm{P}<0,05)$ com a utilização do $\mathrm{FG}$ quando comparado ao ST, no nível de $100 \mathrm{mg} \mathrm{P} \mathrm{dm}^{-3}$ do segundo ciclo de crescimento (Figura 17 e contraste 6 da Tabela 20), e nos níveis de 50 e $100 \mathrm{mg} \mathrm{P} \mathrm{dm}^{-3}$ do terceiro ciclo (Figura 17 e contraste 11 da Tabela 20). 

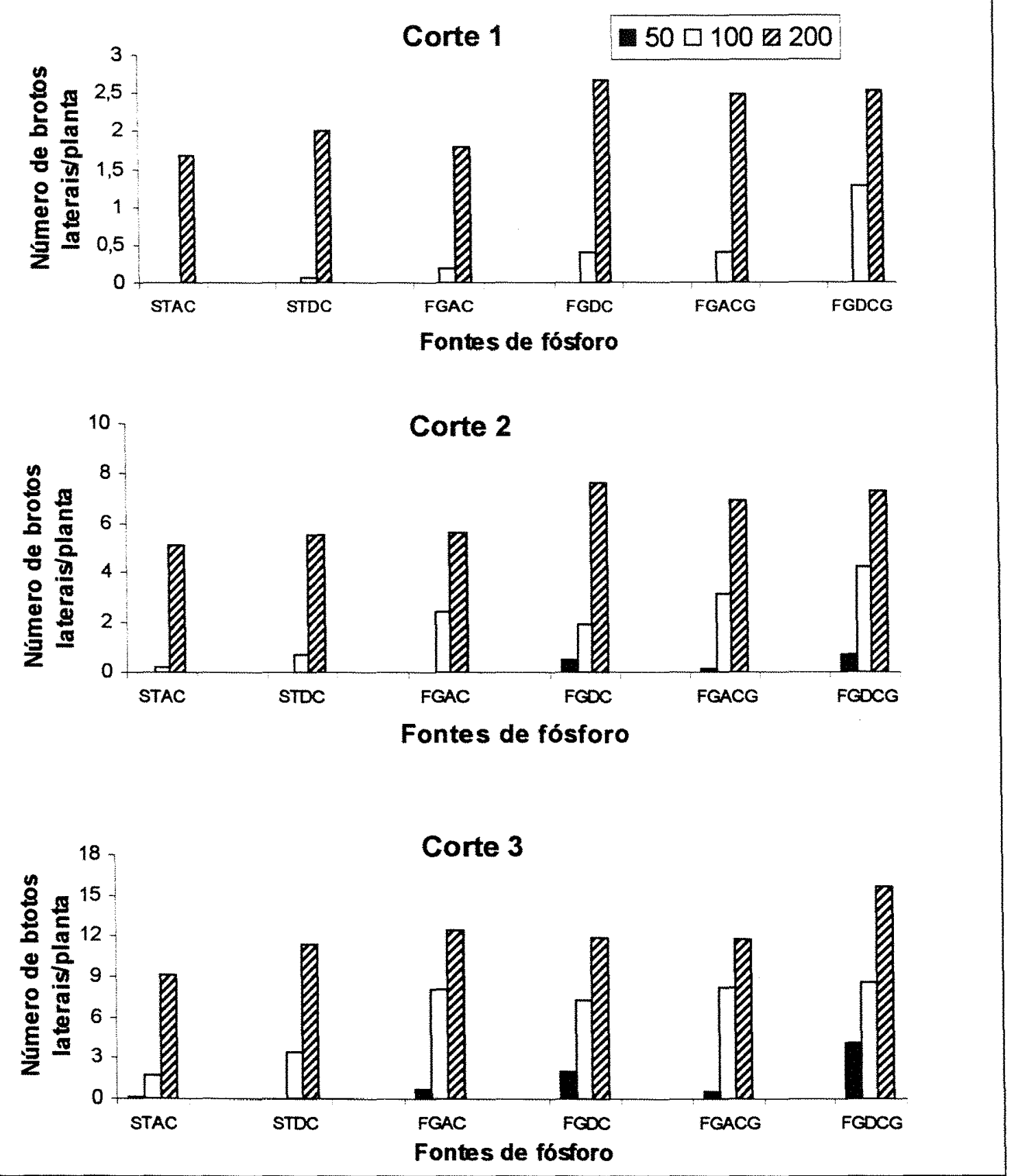

Figura 17 - Número de brotos laterais por planta obtidas em todas as fontes e doses de fósforo $\left(50,100 \mathrm{e} 200 \mathrm{mg} \mathrm{dm}^{-3}\right)$ nos três cortes do terceiro plantio.

(STAC: super triplo antes da calagem; STDC: super triplo depois da calagem; FGAC: Fosfato de Gafsa antes da calagem; FGDC: Fosfato de Gafsa depois da calagem; FGACG: Fosfato de Gafsa antes da calagem mais gesso; FGDCG: Fosfato de Gafsa depois da calagem mais gesso). 
Tabela 20 - Contrastes ortogonais para comparação do número de brotos laterais entre os tratamentos dentro de cada dose de fósforo $\left(\mathrm{mg} \mathrm{dm}^{-3}\right)$ em cada corte do terceiro plantio.

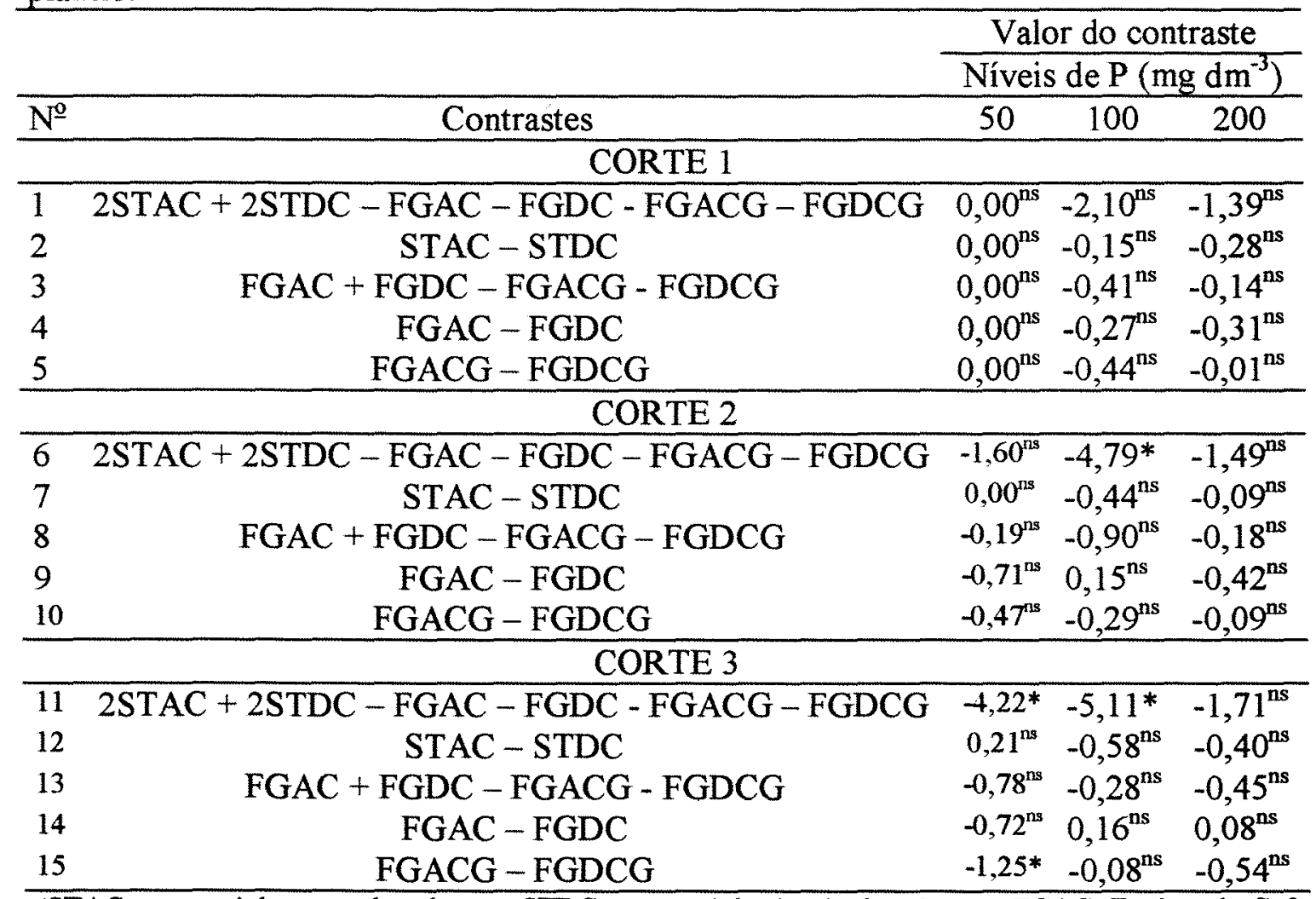

(STAC: super triplo antes da calagem; STDC: super triplo depois da calagem; FGAC: Fosfato de Gafsa antes da calagem; FGDC: Fosfato de Gafsa depois da calagem; FGACG: Fosfato de Gafsa antes da calagem mais gesso; FGDCG: Fosfato de Gafsa depois da calagem mais gesso).

* significativo a $5 \%$ de probabilidade.

${ }^{\text {ns }}$ não significativo a $5 \%$ de probabilidade.

Analisando as fontes de fósforo dentro de cada dose, observou-se maior $(\mathrm{P}<0,05)$ número de hastes originadas da coroa com a utilização do FG do que com o uso do ST, nos niveis de 50 e $100 \mathrm{mg} \mathrm{P} \mathrm{dm}^{-3}$ (Figura 18 e contraste 1 da Tabela 21). Isso foi, também, observado com o desdobramento da interação entre fontes e cortes, em todos períodos de crescimento (Figura 19 e contraste 1 da Tabela 22).

Esses resultados devem-se, provavelmente, à fixação do fósforo proveniente da fonte solúvel por causa do atraso que ocorreu para realizar terceiro plantio e ao aumento solubilização do fosfato de rocha com o tempo (Tabela 14).

Não houve efeito $(P>0,05)$ da utilização de gesso associado ao FG sobre 0 número de brotos axilares da alfafa (Figura 17 e contrastes 3, 8 e 13 da Tabela 20). Para 
os brotos basais, no entanto, analisando as fontes dentro de cada dose de $\mathrm{P}$, a adição de gesso ao FG aumentou $(\mathrm{P}<0,05)$ o número de brotos basais, nos níveis de 50 e $200 \mathrm{mg} P$ $\mathrm{dm}^{-3}$ (Figura 18 e contraste 3 da Tabela 21). Também foi observado aumento do número de brotos basais com o uso do FG associado ao gesso do que sem gesso, em todos os cortes $(\mathrm{P}<0,05)$ (Figura 19 e contraste 3 da Tabela 22). $\mathrm{O}$ aumento do número de hastes basais com o adição do gesso ao FG comparado ao uso do FG somente foi devido, possivelmente, ao aumento do $\mathrm{pH}$ do solo (Apêndice 5), mesmo que esse aumento não tenha se mostrado significativo antes do plantio (Tabela 11).

Rando (1992) verificou elevação no número de brotos totais por planta de 11,3 para 20,8, quando o $\mathrm{pH}\left(\mathrm{H}_{2} \mathrm{O}\right)$ do solo passou de 5,8 para 6,8, enquanto Petit et al. (1992) observaram incremento no número de brotos de 5 para 6,8 quando o $\mathrm{pH}$ (em $\mathrm{H}_{2} \mathrm{O}$ ) passou de 5,4 para 7,5 em trabalhos realizados com alfafa em casa de vegetação.

Não houve diferença $(P>0,05)$ entre a aplicação do superfosfato triplo antes ou depois da calagem sobre o número de brotos axilares da alfafa nos três períodos de crescimento (Figura 17 e contrastes 2,7 e 12 da Tabela 20).

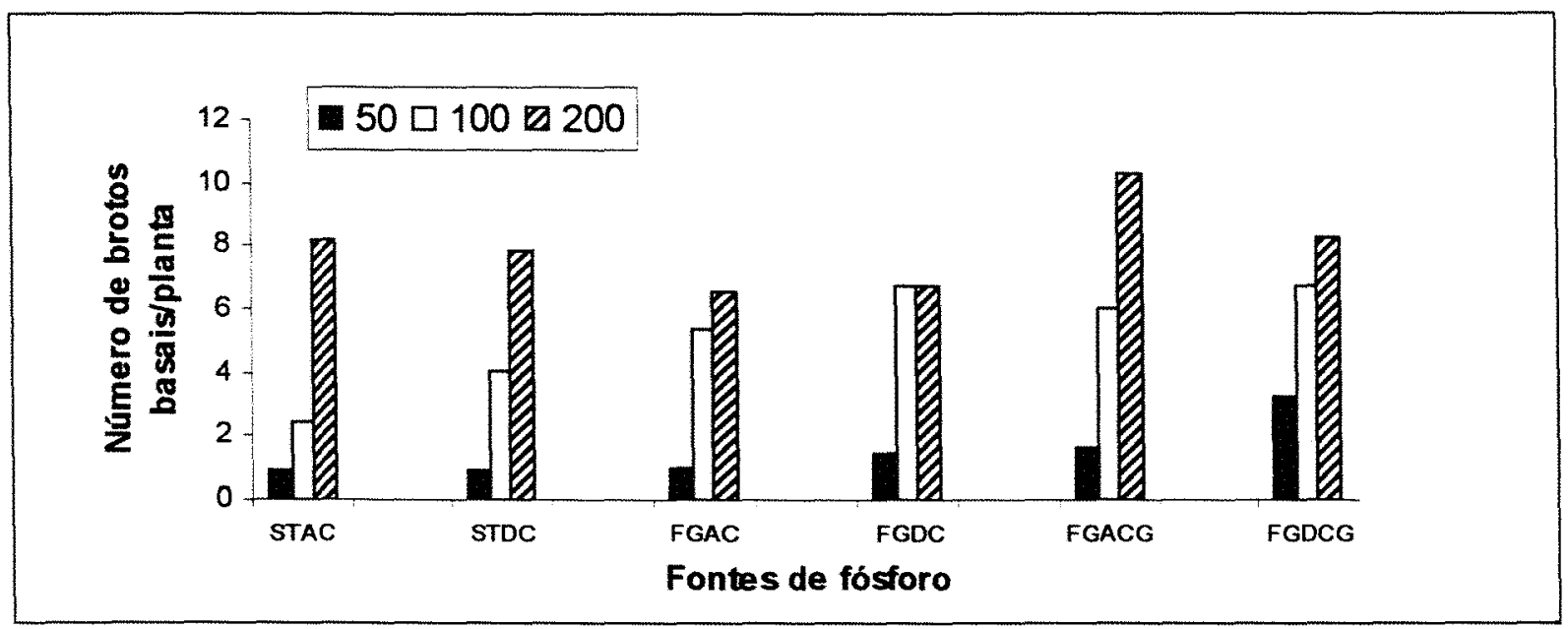

Figura - 18 Número de brotos basais por planta obtidas em todas as fontes e doses de fósforo (50, 100 e $200 \mathrm{mg} \mathrm{dm}^{-3}$ ) no terceiro plantio (média dos três cortes). (STAC: super triplo antes da calagem; STDC: super triplo depois da calagem; FGAC: Fosfato de Gafsa antes da calagem; FGDC: Fosfato de Gafsa depois da calagem; FGACG: Fosfato de Gafsa antes da calagem mais gesso: FGDCG: Fosfato de Gafsa depois da calagem mais gesso). 
Tabela 21 - Contrastes ortogonais para comparação do número de brotos basais entre os tratamentos dentro de cada dose de fósforo $\left(\mathrm{mg} \mathrm{dm}^{-3}\right)$ referente ao terceiro plantio (interação fontes e doses).

\begin{tabular}{lcccc}
\hline & & \multicolumn{3}{c}{ Valor do contraste } \\
\cline { 3 - 5 } & & \multicolumn{3}{c}{ Niveis de P $\left(\mathrm{mg} \mathrm{dm}^{-3}\right)$} \\
\hline $\mathrm{N}^{\mathrm{o}}$ & Contrastes & 50 & 100 & 200 \\
\hline 1 & 2STAC + 2STDC - FGAC - FGDC - FGACG - FGDCG & $-1,50^{*}$ & $-2,93^{*}$ & $0,13^{\text {ns }}$ \\
2 & STAC - STDC & $0,03^{\text {ns }}$ & $-0,43^{*}$ & $0,05^{\text {ns }}$ \\
3 & FGAC + FGDC - FGACG - FGDCG & $-0,94^{*}$ & $-0,15^{\text {ns }}$ & $-0,96^{*}$ \\
4 & FGAC - FGDC & $-0,27^{\text {ns }}$ & $-0,29^{\text {ns }}$ & $-0,03^{\text {ns }}$ \\
5 & FGACG - FGDCG & $-0,52^{*}$ & $-0,16^{\text {ns }}$ & $0,32^{\text {ns }}$ \\
\hline
\end{tabular}

(STAC: super triplo antes da calagem; STDC: super triplo depois da calagem; FGAC: Fosfato de Gafsa antes da calagem; FGDC: Fosfato de Gafsa depois da calagem; FGACG: Fosfato de Gafsa antes da calagem mais gesso; FGDCG: Fosfato de Gafsa depois da calagem mais gesso).

* significativo a $5 \%$ de probabilidade.

ns não significativo a $5 \%$ de probabilidade.

$\mathrm{O}$ número de brotos basais não diferiu $(\mathrm{P}>0,05)$ entre os tratamentos STAC e STDC nos três cortes (Figura 19 e contraste 2 da Tabela 22). Isso foi também verdadeiro para o número de brotos basais nas doses de 50 e $200 \mathrm{mg} \mathrm{P} \mathrm{dm}^{-3}$, (Figura 18 e contraste 2 da Tabela 21). A exceção foi para o nível $100 \mathrm{mg} \mathrm{P} \mathrm{dm}^{-3}$, onde o número de brotos basais foi maior $(\mathrm{P}<0,05)$ com a aplicação da calagem antes do $\mathrm{ST}$ em relação a aplicação da calagem depois do ST (Figura 18 e contraste 2 da Tabela 21).

Da mesma maneira, não se observou ( $P>0,05)$ na aplicação do $F G$, com ou sem gesso, antes da calagem em relação à sua aplicação depois da calagem para os brotos laterais (Figura 17 e Tabela 20). A única exceção foi o nivel de $50 \mathrm{mg} \mathrm{Pdm}^{-3}$ do terceiro corte em que apareceram mais brotos laterais $(P<0,05)$ com a utilização do FG com gesso aplicado depois da calagem (FGDCG) em relação ao FG com gesso aplicado antes da calagem (FGACG) (Figura 17 e contraste 15 da Tabela 20).

Para os brotos basais não se observou diferença $(P>0,05)$ com a aplicação do $F G$, com ou sem gesso, antes da calagem em relação a sua aplicação depois da calagem nos níveis de 50,100 e $200 \mathrm{mg} \mathrm{P} \mathrm{dm}^{-3}$ (Figura 18 e contrastes 4 e 5 da Tabela 21). A única exceção foi o nível de $50 \mathrm{mg} \mathrm{P} \mathrm{dm}^{-3}$ no tratamento FGDCG que apresentou maior $(\mathrm{P}<0,05)$ número de brotos basais em relação ao FGACG (Figura 18 e contraste 5 da Tabela 21). 


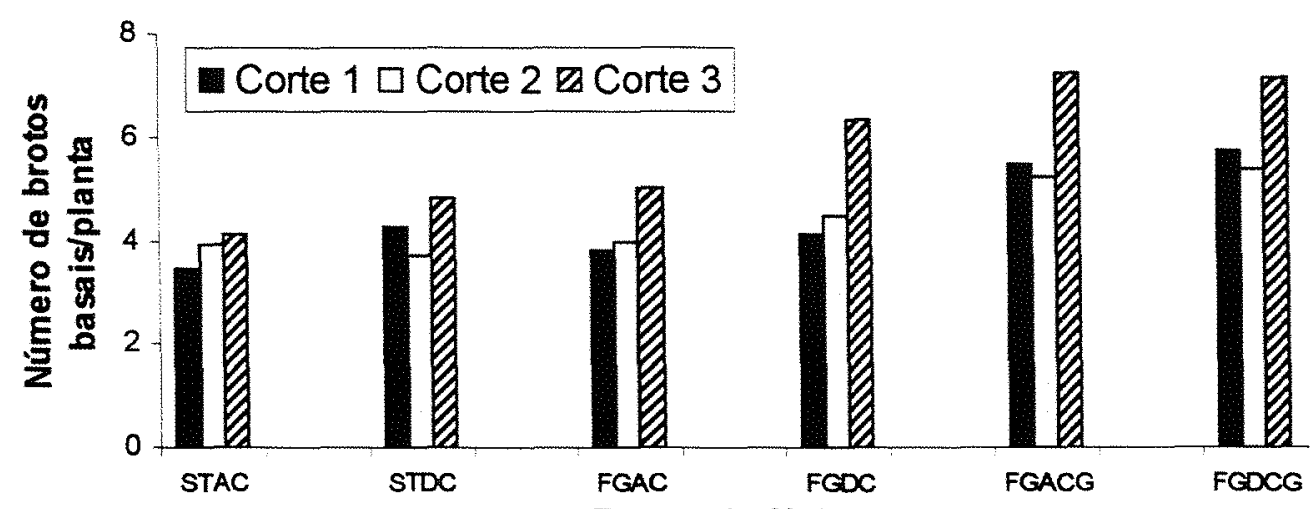

Fontes de fósforo

Figura - 19 Número de brotos basais por planta obtidas em todas as fontes nos três cortes do terceiro plantio (média das três doses de fósforo).

(STAC: super triplo antes da calagem; STDC: super triplo depois da calagem; FGAC: Fosfato de Gafsa antes da calagem; FGDC: Fosfato de Gafsa depois da calagem; FGACG: Fosfato de Gafsa antes da calagem mais gesso; FGDCG: Fosfato de Gafsa depois da calagem mais gesso).

Tabela 22 - Contrastes ortogonais para comparação do número de brotos basais entre os tratamentos dentro de cada corte do terceiro plantio (interação entre fontes e cortes).

\begin{tabular}{|c|c|c|c|c|}
\hline \multirow[b]{2}{*}{$\mathrm{N}^{2}$} & \multirow[b]{2}{*}{ Contrastes } & \multicolumn{3}{|c|}{$\begin{array}{c}\text { Valor do contraste } \\
\text { CORTES }\end{array}$} \\
\hline & & 1 & 2 & 3 \\
\hline 1 & $2 \mathrm{STAC}+2 \mathrm{STDC}-\mathrm{FGAC}-\mathrm{FGDC}-\mathrm{FGACG}-\mathrm{FGDCG}$ & $-1,19^{*}$ & $-1,13^{*}$ & $-1,98 *$ \\
\hline 2 & STAC - STDC & $-0,24^{\mathrm{ns}}$ & $0,04^{\mathrm{ns}}$ & $-0,15^{\mathrm{ns}}$ \\
\hline 3 & $\mathrm{FGAC}+\mathrm{FGDC}-\mathrm{FGACG}-\mathrm{FGDCG}$ & $-0,72 *$ & $-0,55^{*}$ & $-0,78^{*}$ \\
\hline 4 & FGAC - FGDC & $-0,09^{\mathrm{ns}}$ & $-0,13^{\mathrm{ns}}$ & $-0,37^{\mathrm{ns}}$ \\
\hline 5 & FGACG - FGDCG & $-0,14^{\mathrm{ns}}$ & $-0,10^{\mathrm{ns}}$ & $-0,12^{\text {ns }}$ \\
\hline \multicolumn{5}{|c|}{$\begin{array}{l}\text { (STAC: super triplo antes da calagem; STDC: super triplo depois da calagem; FGAC: Fosfato de Gafsa } \\
\text { antes da calagem; FGDC: Fosfato de Gafsa depois da calagem; FGACG: Fosfato de Gafsa antes da } \\
\text { calagem mais gesso; FGDCG: Fosfato de Gafsa depois da calagem mais gesso). } \\
\text { * significativo a } 5 \% \text { de probabilidade. } \\
\text { ns não significativo a } 5 \% \text { de probabilidade. }\end{array}$} \\
\hline
\end{tabular}

Analisando as respostas às fontes de fósforo dentro de cada corte, também, não foi constatado $(P>0,05)$ beneficio do uso da calagem após a aplicação do $F G$, associado ou não ao gesso, para os brotos basais em todos os períodos de crescimento (Figura $19 \mathrm{e}$ contrastes 4 e 5 da Tabela 22).

Analisando os ciclos de crescimento, observa-se que, em geral, o número de brotos laterais no primeiro período de crescimento foi menor $(\mathrm{P}<0,05)$ que nos outros períodos (Tabela 23). A diminuição ocorreu devido às hastes laterais originarem-se, 
unicamente, das folhas trifolioladas, no primeiro ciclo de crescimento, e não das hastes remanescentes, confirmando o relato de Teuber \& Brick (1988). Porém, nos níveis de 50 mg P dm ${ }^{-3}$, os tratamentos STAC e STDC não apresentaram elevação do número de brotos laterais $(\mathrm{P}>0,05)$ em função dos ciclos de crescimento (Tabela 23).

Em relação aos brotos basais, analisando os cortes dentro de cada fonte de $\mathrm{P}$, houve aumento significativo $(\mathrm{P}<0,05)$ no terceiro corte para os tratamentos FGDC, FGACG e FGDCG (Figura 20), enquanto que os demais tratamentos permaneceram inalterados.

Esses resultados, tanto em relação à variação no número dos brotos basais como nos laterais foram devidos, provavelmente, à elevação da temperatura e ao aumento da solubilidade do fosfato de Gafsa com o passar do tempo, refletindo no aumento do número de brotos da alfafa no terceiro corte. Leach (1971) estudanto o efeito da temperatura sobre o crescimento de brotos da alfafa, cultivar Rhizoma, constatou elevação no número de brotos por planta de 38 , a $15^{\circ} \mathrm{C}$, para 50 , a $33^{\circ} \mathrm{C}$.

Desdobrando a interação entre cortes e doses de fósforo, nota-se que nos níveis de 100 e $200 \mathrm{mg} \mathrm{P} \mathrm{dm}^{-3}$, o número de brotos da coroa aumentou $(\mathrm{P}<0,05)$ no terceiro corte (Figura 21). No entanto, isso não se repetiu com o nível de $50 \mathrm{mg} \mathrm{P} \mathrm{dm}^{-3}$, e ao contrário, houve menor $(\mathrm{P}<0,05)$ número de brotos no terceiro corte (Figura 21). Dessa maneira, o aumento do número de brotos no decorrer dos ciclos de crescimento da alfafa foi dependente, também, do estado nutricional em que encontra-se a planta. Segundo Silva \& Pedreira (1997) o número de brotos ou perfilhos por planta é utilizado como indicador de vigor e persistência de pastagens, portanto, a redução na quantidade de brotos da planta devido a deficiência de nutrientes pode proporcionar menor longevidade da cultura. 
Tabela 23 - Número de brotos laterais por planta obtidas em todas as fontes e doses de fósforo $\left(\mathrm{mg} \mathrm{dm}^{-3}\right)$ nos três cortes do terceiro plantio de alfafa.

\section{CORTES}

\begin{tabular}{|c|c|c|c|}
\hline Niveis de $\mathrm{P}\left(\mathrm{mg} \mathrm{dm}^{-3}\right)$ & 1 & 2 & 3 \\
\hline \multicolumn{4}{|l|}{ Fontes de fósforo } \\
\hline \multicolumn{4}{|c|}{ Super triplo antes da calagem } \\
\hline 50 & $0,00 \mathrm{a}$ & $0,00 a$ & $0,13 a$ \\
\hline 100 & $0,00 \mathrm{~b}$ & $0,20 \mathrm{~b}$ & $1,73 \mathrm{a}$ \\
\hline 200 & $1,67 \mathrm{c}$ & $5,13 \mathrm{~b}$ & $9,07 \mathrm{a}$ \\
\hline \multicolumn{4}{|c|}{ Super triplo depois da calagem } \\
\hline 50 & $0,00 \mathrm{a}$ & $0,00 \mathrm{a}$ & $0,00 \mathbf{a}$ \\
\hline 100 & $0,07 \mathrm{~b}$ & $0,73 b$ & $3,40 \mathrm{a}$ \\
\hline 200 & $2,00 \mathrm{c}$ & $5,53 \mathrm{~b}$ & $11,40 \mathrm{a}$ \\
\hline \multicolumn{4}{|c|}{ Fosf. Gafsa antes da calagem } \\
\hline 50 & $0,00 \mathrm{~b}$ & $0,00 \mathrm{~b}$ & $0,60 \mathbf{a}$ \\
\hline 100 & $0,20 \mathrm{c}$ & $2,47 \mathrm{~b}$ & $8,13 a$ \\
\hline 200 & $1,80 \mathrm{c}$ & $5,60 \mathrm{~b}$ & $12,40 \mathrm{a}$ \\
\hline \multicolumn{4}{|c|}{ Fosf. Gafsa depois da calagem } \\
\hline 50 & $0,00 \mathrm{c}$ & $0,53 \mathrm{~b}$ & $2,00 \mathrm{a}$ \\
\hline 100 & $0,40 \mathrm{c}$ & $1,93 \mathrm{~b}$ & $7,33 \mathbf{a}$ \\
\hline 200 & $2,68 \mathrm{c}$ & $7,65 \mathrm{~b}$ & $11,85 \mathrm{a}$ \\
\hline \multicolumn{4}{|c|}{ Fosf Gafsa antes da calagem + gesso } \\
\hline 50 & $0,00 \mathrm{~b}$ & $0,13 \mathrm{ab}$ & $0,53 a$ \\
\hline 100 & $0,40 \mathrm{c}$ & $3,13 \mathrm{~b}$ & $8,20 \mathrm{a}$ \\
\hline 200 & $2,47 \mathrm{c}$ & $6,93 \mathrm{~b}$ & $11,80 \mathrm{a}$ \\
\hline \multicolumn{4}{|c|}{ Fosf. Gafsa depois da calagem + gesso } \\
\hline 50 & $0,00 \mathrm{c}$ & $0,73 b$ & $4,07 a$ \\
\hline $\begin{array}{l}100 \\
200\end{array}$ & $\begin{array}{l}1,27 \mathrm{c} \\
253 \mathrm{c}\end{array}$ & $4,27 \mathrm{~b}$ & $8,60 \mathrm{a}$ \\
\hline & $2,53 \mathrm{c}$ & $7,27 \mathrm{~b}$ & $15,67 \mathrm{a}$ \\
\hline
\end{tabular}

*médias seguidas por letras distintas, numa mesma linha, diferem entre si a $5 \%$ de probabilidade pelo teste de Tukey.

$\mathrm{CV}$ (parcelas) $=24,6 \%$.

$\mathrm{CV}($ subparcela $)=20,9 \%$. 


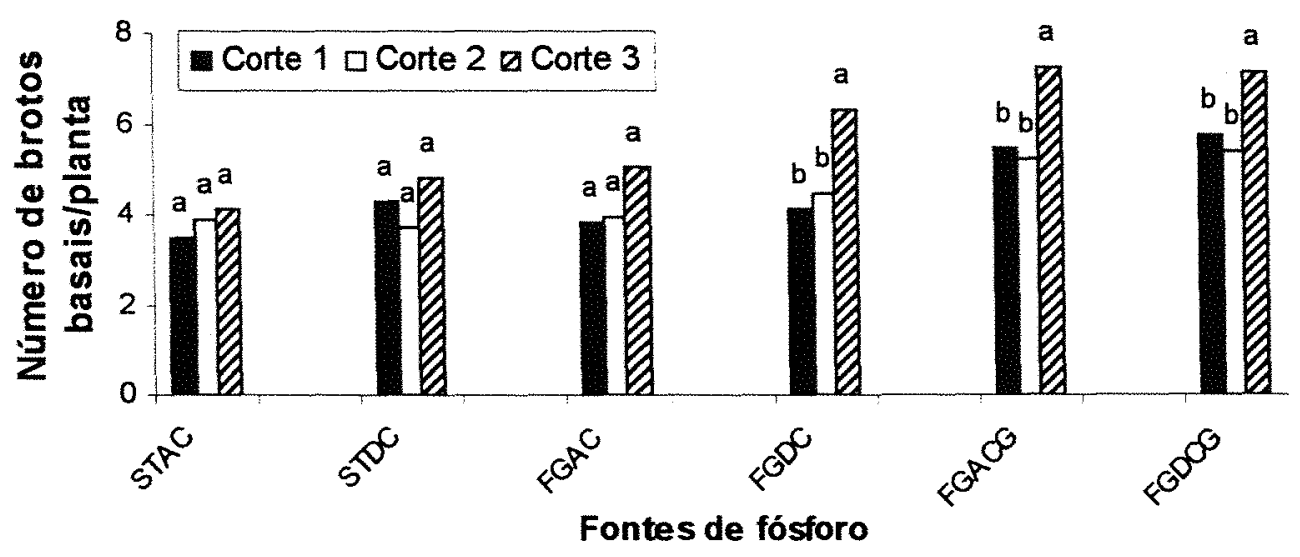

Figura -20 Número de brotos basais por planta nas diferentes fontes de fósforo em função dos cortes.

(STAC: super triplo antes da calagem; STDC: super triplo depois da calagem; FGAC: Fosfato de Gafsa antes da calagem; FGDC: Fosfato de Gafsa depois da calagem; FGACG: Fosfato de Gafsa antes da calagem mais gesso; FGDCG: Fosfato de Gafsa depois da calagem mais gesso).

*médias seguidas por letras distintas, numa mesma fonte, diferem entre si a $5 \%$ de probabilidade pelo teste de Tukey.

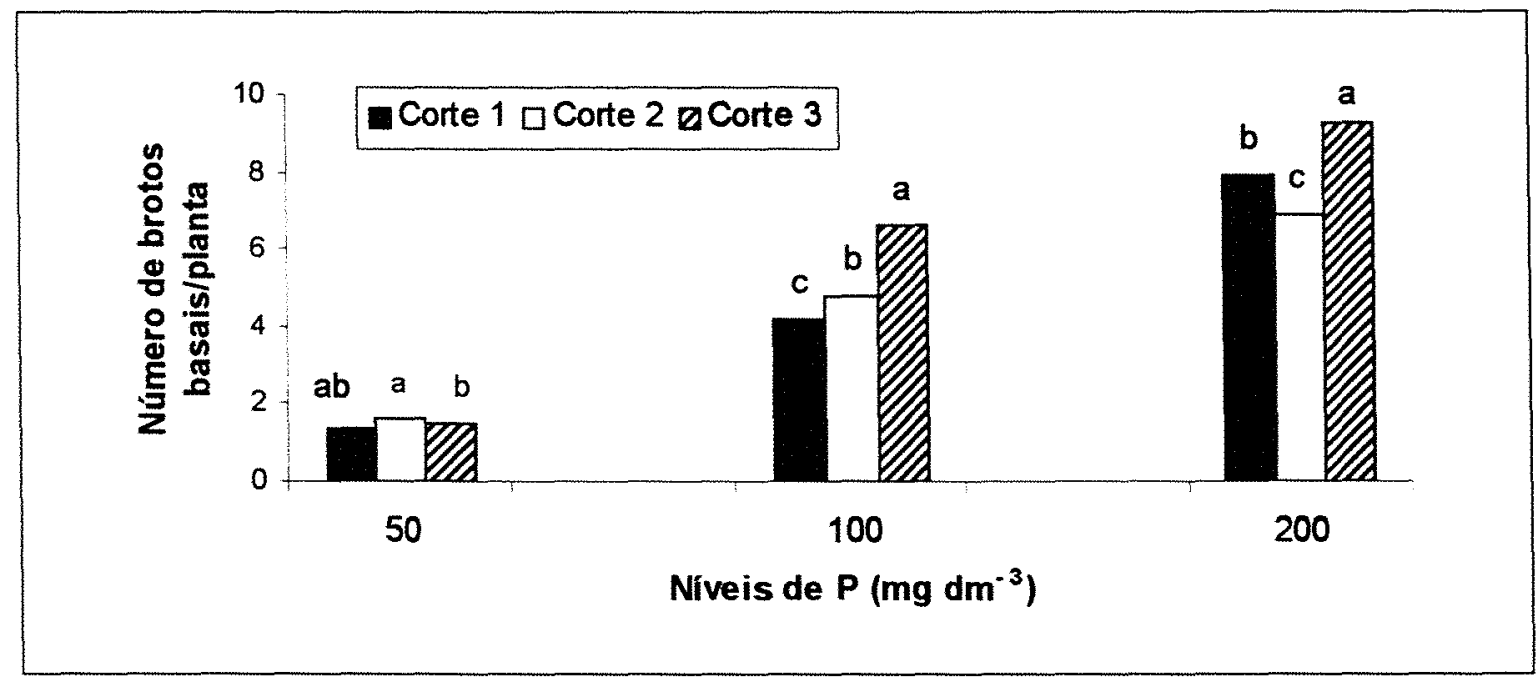

Figura -21 Número de brotos basais por planta em função dos momentos de cortes, nos níveis de 50,100 e $200 \mathrm{mg} \mathrm{P} \mathrm{dm}^{-3}$.

(STAC: super triplo antes da calagem; STDC: super triplo depois da calagem; FGAC: Fosfato de Gafsa antes da calagem; FGDC: Fosfato de Gafsa depois da calagem; FGACG: Fosfato de Gafsa antes da calagem mais gesso; FGDCG: Fosfato de Gafsa depois da calagem mais gesso).

*médias seguidas por letras distintas, num mesmo corte, diferem entre si a $5 \%$ de probabilidade pelo teste de Tukey. 


\subsection{Teor de fósforo nas plantas}

\subsubsection{Primeiro plantio}

Foi encontrada interação $(\mathrm{P}<0,05)$ entre fontes e doses de fósforo para o teor de $\mathrm{P}$ na matéria seca da alfafa (Apêndice 22).

Ocorreu elevação $(\mathrm{P}<0,05)$ no teor de $\mathrm{P}$ na parte aérea da alfafa em função das doses de fósforo para os tratamentos com FG não associados ao gesso (FGAC e FGDC) (Figura 22). Diversos autores têm observado elevação nas concentrações de $P$ na alfafa com adição de fósforo (Fageria \& Baligar, 1989; Walworth \& Sumner, 1990; James et al., 1995 e Moreira, 1997). No presente trabalho o teor médio de fósforo na parte aérea foi de $1,4 \mathrm{~g} \mathrm{~kg}^{-1}$ (Apêndice 25), valor que está abaixo dos encontrados pelos autores citados que variam de 1,5 a $3,5 \mathrm{~g} \mathrm{~kg}^{-1}$. Isso pode ser devido ao curto período de desenvolvimento da planta (47 dias), ou devido ao efeito de cultivar. Diferenças de concentração de fósforo entre cultivares de alfafa tem sido relatadas por vários autores, como Heinrichs et al. (1969), Hill \& Lanyon (1983) e James et al. (1995).

Por meio do teste de correlação entre o teor de fósforo na MS da parte aérea com a produção de MS no primeiro plantio não se observou correlação significativa $(P>0,05)$ entre essas duas variáveis (Apêndice 23), resultados esses que foram semelhantes aos encontrados por Moreira (1997) em experimento com centrosema. No entanto, a única exceção foi o tratamento FGAC, onde a elevação na concentração de fósforo na MS resultou em idêntico aumento na produtividade $(\mathrm{P}<0,05)$ no primeiro plantio (Apêndice 23).

Comparando as fontes de fósforo $(\mathrm{ST}$ e FG) observou-se maior $(\mathrm{P}<0,05)$ teor de $P$ na parte aérea da alfafa nos tratamento que utilizaram ST em relação ao uso do FG para as doses de 50 e $100 \mathrm{mg} \mathrm{P} \mathrm{dm}^{-3}$ (Figura 23 e contraste 1 da Tabela 24), devido, provavelmente, a maior disponibilidade de fósforo proveniente da fonte solúvel. Resultado semelhante foi encontrado por Moreira (1997) que utilizou o ST, como fonte solúvel, e o fosfato Carolina do Norte e Arad, como fosfato de rocha, no primeiro corte de alfafa. 


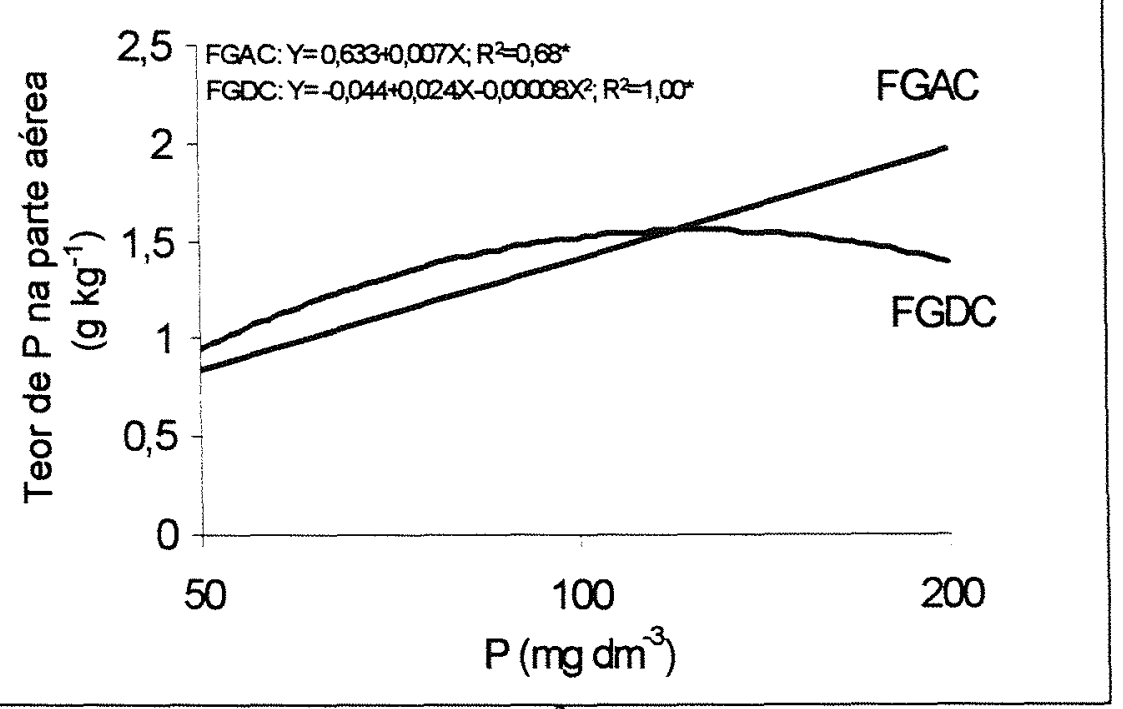

Figura 22 - Efeito dos níveis de fósforo $\left(\mathrm{mg} \mathrm{dm}^{-3}\right)$ sobre os teores de $\mathrm{P}$ na MS da parte aérea da alfafa, para os tratamentos FGAC e FGDC, no primeiro plantio. * significativo a $5 \%$ de probabilidade.

(FGAC: Fosfato de Gafsa antes da calagem; FGDC: Fosfato de Gafsa depois da calagem)

A adição de gesso juntamente com a adubação fosfatada promoveu elevação $(\mathbf{P}<0,05)$ na concentração de fósforo da parte aérea dos tratamentos com $\mathrm{FG}$, para o nível de $50 \mathrm{mg} \mathrm{P} \mathrm{dm}^{-3}$ somente, não havendo diferença quando se aplicou 100 e $200 \mathrm{mg}$ $\mathrm{P} \mathrm{dm}^{-3}$ (Figura 23 e contraste 3 da Tabela 24). Como já discutido anteriormente, a adição de gesso associado ao FG tendeu a elevar o pH do solo (0,07 unidades) (Apêndice 5), e segundo Mahler (1983), pode proporcionar diferenças na absorção de fósforo pela alfafa devido: (1) ao incremento do crescimento da raiz sob elevado $\mathrm{pH}$ do solo possibilitando maior exploração do solo e, portanto, maior disponibilidade de fósforo à planta; (2) a menor quantidade de $\mathrm{Al}$ presente em solo deixando o fósforo mais disponivel.

A calagem não afetou $(P>0,05)$ o teor de $P$ na parte aérea da planta dentro das fontes de fósforo (Figura 23 e contrastes 2,4 e 5 da Tabela 24). A exceção foi para o fosfato de Gafsa sem gesso aplicado antes da calagem que resultou em maior $(\mathrm{P}<0,05)$ teor de fósforo na MS em comparação ao fosfato de Gafsa sem gesso adicionado ao solo depois da calagem (Figura 23 e contraste 4 da Tabela 24). 


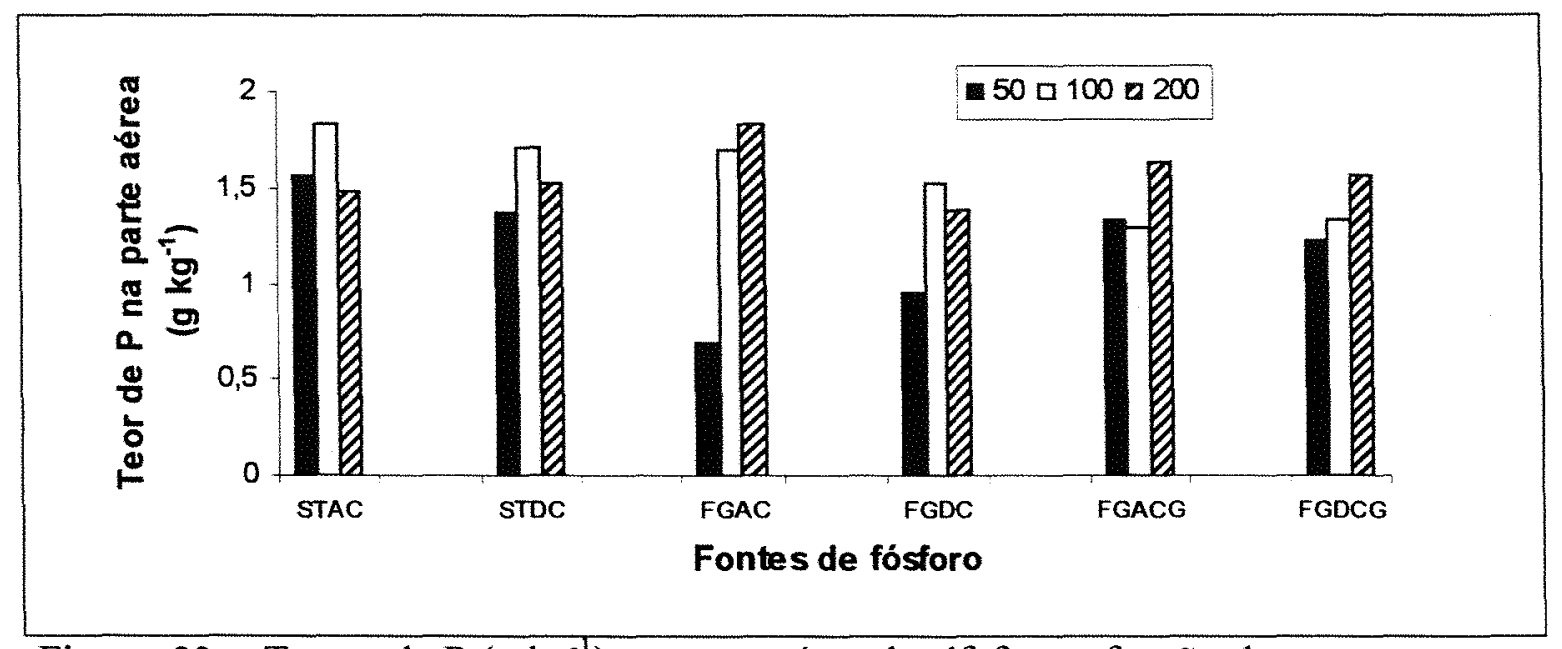

Figura 23 - Teores de $\mathrm{P}\left(\mathrm{g} \mathrm{kg}^{-1}\right)$ na parte aérea da alfafa em função dos tratamentos e doses de fósforo $\left(50,100 \mathrm{e} 200 \mathrm{mg} \mathrm{dm}^{-3}\right)$ referentes a primeira semeadura. (STAC: super triplo antes da calagem; STDC: super triplo depois da calagem; FGAC: Fosfato de Gafsa antes da calagem; FGDC: Fosfato de Gafsa depois da calagem; FGACG: Fosfato de Gafsa antes da calagem mais gesso; FGDCG: Fosfato de Gafsa depois da calagem mais gesso).

Tabela 24 - Contrastes ortogonais para comparação do teor de P na MS da parte aérea da alfafa entre os tratamentos com fonte de fósforo dentro de cada dose de fósforo referente ao primeiro plantio.

\begin{tabular}{|c|c|c|c|c|}
\hline \multirow[b]{2}{*}{ № } & \multirow[b]{2}{*}{ Contrastes } & \multicolumn{3}{|c|}{$\frac{\text { Valor do contraste }}{\text { Niveis de } \mathrm{P}\left(\mathrm{mg} \mathrm{dm}^{-3}\right)}$} \\
\hline & & 50 & 100 & 200 \\
\hline 1 & $2 \mathrm{STAC}+2 \mathrm{STDC}-\mathrm{FGAC}-\mathrm{FGDC}-\mathrm{FGACG}-\mathrm{FGDCG}$ & $169^{*}$ & $1,26^{*}$ & $-0,39^{\text {ns }}$ \\
\hline 2 & STAC - STDC & $0,18^{\text {ns }}$ & $0,10^{\mathrm{ns}}$ & $-0,05^{\text {ns }}$ \\
\hline 3 & FGAC + FGDC - FGACG - FGDCG & $-0,92 *$ & $0,59^{\text {ns }}$ & $0,03^{\mathrm{ns}}$ \\
\hline 4 & FGAC - FGDC & $-0,25^{\mathrm{ns}}$ & $0,18^{\mathrm{ns}}$ & $0,44^{*}$ \\
\hline 5 & FGACG - FGDCG & $0,12^{\text {ns }}$ & $-0,04^{\mathrm{ns}}$ & $0,07^{\mathrm{ns}}$ \\
\hline
\end{tabular}

(STAC: super triplo antes da calagem; STDC: super triplo depois da calagem; FGAC: Fosfato de Gafsa antes da calagem; FGDC: Fosfato de Gafsa depois da calagem; FGACG: Fosfato de Gafsa antes da calagem mais gesso; FGDCG: Fosfato de Gafsa depois da calagem mais gesso).

* significativo a $5 \%$ de probabilidade.

${ }^{\text {ns }}$ não significativo a $5 \%$ de probabilidade.

\subsubsection{Terceiro plantio}

Ocorreu interação $(\mathrm{P}<0,05)$ entre fontes e doses para o teor de $\mathrm{P}$ na MS da raiz (Apêndice 24).

Os teores de P na MS da parte aérea aumentaram em função das doses de fósforo (Figuras 24 e 25). Resultados semelhantes foram observados por Martins et al. (1990), Moreira (1997) e Yupanqui (1997). Esses resultados repetiram-se $(\mathbf{P}<0,05)$ para a 
produção de raiz (Figuras 24 e 25 e Tabela 25), com exceção para o tratamento STDC, onde não houve efeito $(\mathrm{P}>0,05)$ das doses de fósforo. A elevação no teor de $\mathrm{P}$ da raiz da alfafa com a adição de fósforo foi também observada por Drevon \& Hartwing (1997) e Volenec et al. (1998).

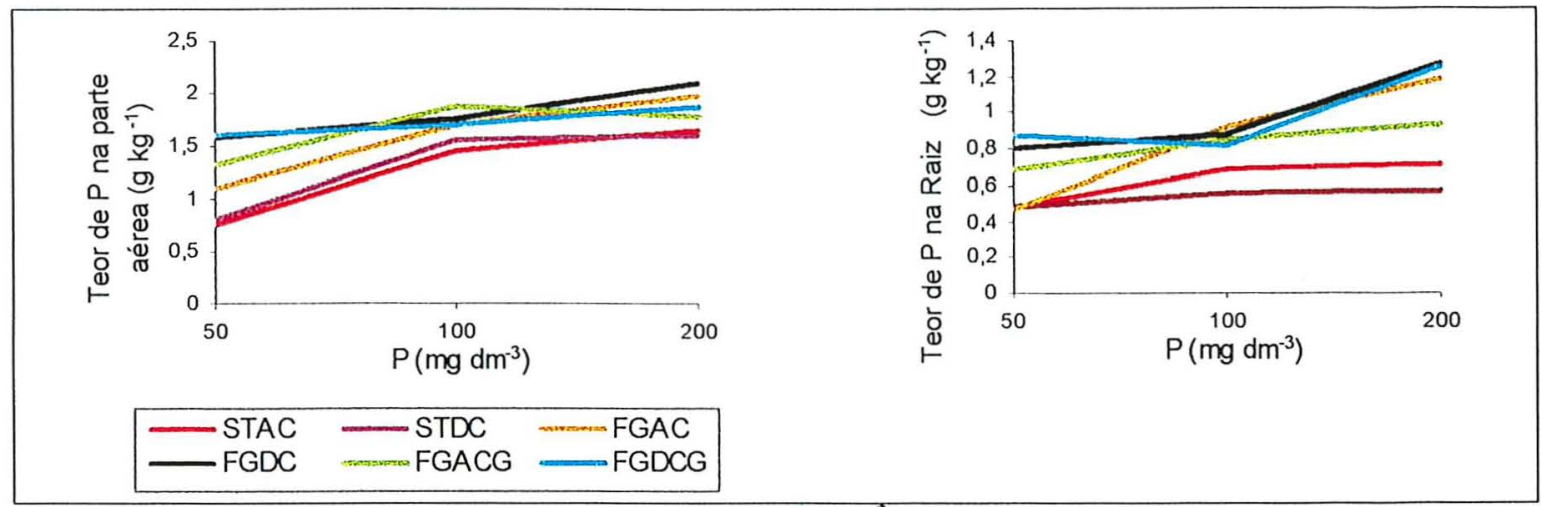

Figura 24 - Efeito das doses de fósforo $\left(\mathrm{mg} \mathrm{dm}^{-3}\right)$ sobre os teores de P na MS da parte aérea e raiz da alfafa, em decorrência dos diferentes tratamentos (média dos três cortes), no terceiro plantio.

(STAC: super triplo antes da calagem; STDC: super triplo depois da calagem; FGAC: Fosfato de Gafsa antes da calagem; FGDC: Fosfato de Gafsa depois da calagem; FGACG: Fosfato de Gafsa antes da calagem mais gesso; FGDCG: Fosfato de Gafsa depois da calagem mais gesso).

Tabela 25 - Equações que expressam a relação entre a concentração de $P\left(\mathrm{~g} \mathrm{~kg}^{-1}\right)$ na raiz das plantas em função das doses de fósforo $\left(\mathrm{mg} \mathrm{dm}^{-3}\right)$ obtida em decorrência dos diferentes tratamentos referente ao terceiro plantio.

\begin{tabular}{lll}
\hline Fontes de fósforo & Equação & $\mathrm{R}^{2}$ \\
\hline STAC & $\mathrm{Y}=0,390+0,120 \mathrm{X}$ & $0,84^{*}$ \\
STDC & $\mathrm{Y}=0,447+0,045 \mathrm{X}$ & $0,63^{\text {ns }}$ \\
FGAC & $\mathrm{Y}=0,133+0,360 \mathrm{X}$ & $0,97^{*}$ \\
FGDC & $\mathrm{Y}=0,513+0,235 \mathrm{X}$ & $0,87^{*}$ \\
FGACG & $\mathrm{Y}=0,570+0,125 \mathrm{X}$ & $0,95^{*}$ \\
FGDCG & $\mathrm{Y}=0,613+0,185 \mathrm{X}$ & $0,83^{*}$ \\
\hline
\end{tabular}

(STAC: super triplo antes da calagem; STDC: super triplo depois da calagem; FGAC: Fosfato de Gafsa antes da calagem; FGDC: Fosfato de Gafsa depois da calagem; FGACG: Fosfato de Gafsa antes da calagem mais gesso; FGDCG: Fosfato de Gafsa depois da calagem mais gesso)

* significativo a $5 \%$ de probabilidade.

"ns não significativo.

O teor médio de fósforo na raiz obtido nesse trabalho $\left(0,8 \mathrm{~g} \mathrm{~kg}^{-1}\right.$ - Apêndice 27) está abaixo daqueles obtidos por Martins et al. (1990), Suzuki (1991), Drevon \& Hartwing (1997) e Volenec et al. (1998), que obtiveram, em média, 1,8; 2,7; 1,8 e 2,0 g 
$\mathrm{kg}^{-1}$, respectivamente. Por outro lado, a concentração média de fósforo na parte aérea da alfafa no nível de $200 \mathrm{mg} \mathrm{P} \mathrm{dm}$ (1,8 $\mathrm{g} \mathrm{kg}^{-1}$ - Apêndice 26), no terceiro plantio, aumentou pouco $\left(0,26 \mathrm{~g} \mathrm{~kg}^{-1}\right)$ em relação ao primeiro plantio $\left(1,6 \mathrm{~g} \mathrm{~kg}^{-1}\right.$ - média do nível de $200 \mathrm{mg} \mathrm{P} \mathrm{dm}^{-3}$ - Apêndice 25), mas ainda está abaixo dos valores obtidos por Gallo et alii (1974) e Oliveira (1986), que foram em torno de 3,9 e $3,0 \mathrm{~g} \mathrm{~kg}^{-1}$, respectivamente; e abaixo do teor considerado adequado para a alfafa, que é de 2,5 a 5,0 $\mathrm{g} \mathrm{kg}^{-1}$ (Werner et al., 1996).

O teor de $\mathrm{P}$ na parte aérea foi maior com o uso do FG em relação a utilização da fonte solúvel, em todas as doses de fósforo (Figura 25). Esses resultados se repetiram $(\mathrm{P}<0,05)$ paras as raizes, nos três níveis de fósforo (Figura 25 e contraste 1 da Tabela 26). Esse fato está de acordo com as maiores concentrações de fósforo no solo com a utilização do FG após o último corte (Figura 8 e contraste 1 da Tabela13). A exceção foi para o FGAC que apresentou teor de fósforo na parte aérea da alfafa semelhante ao ST aplicado antes e após a calagem ao nível de $100 \mathrm{mg} \mathrm{P} \mathrm{dm}^{-3}$ (Figura 25).

Como ocorrido no primeiro plantio, o teor de fósforo na MS da raiz foi maior $(\mathrm{P}<0,05)$ com o uso do $\mathrm{FG}+\mathrm{G}$ em relação ao $\mathrm{FG}$ sem gesso ao nível de $50 \mathrm{mg} \mathrm{P} \mathrm{dm}^{-3}$ (Figura 25 e contraste 3 da Tabela 26). Na parte aérea da alfafa, o teor de fósforo foi maior com a utilização do gesso associado ao FG aplicado antes e depois da calagem (FGACG e FGDCG) em relação ao uso do FG aplicado antes da calagem sem gesso (FGAC) referente ao nivel de $50 \mathrm{mg} \mathrm{P} \mathrm{dm}^{-3}$ (Figura 25).

As respostas descritas podem estar relacionados com o maior desenvolvimento das raízes com a utilização do FG em relação ao ST ao nível de 50 e $100 \mathrm{mg} \mathrm{P} \mathrm{dm}^{-3}$ (Figura 5 e contraste 1 da Tabela 10), e com o uso do FG $+\mathrm{G}$ do que com $50 \mathrm{mg} \mathrm{P} \mathrm{dm}^{-3}$ de FG (Figura 5 e contraste 3 da Tabela 10) que possuem papel importante na absorção de fósforo do solo pela planta (Andrews \& Jones, 1978).

O teor de fósforo na parte aérea com a adição de gesso junto ao FG (FGACG e FGDCG) foi menor do que a utilização do FG isolado (FGAC e FGDC), na dose de 200 $\mathrm{mg} \mathrm{P} \mathrm{dm}{ }^{-3}$ (Figura 25). A diminuição do teor de fósforo pode ter ocorrido por causa do efeito diluição, pois o $\mathrm{FG}+\mathrm{G}$ tendeu a produzir maior quantidade de MS da parte aérea da alfafa comparado ao FG sem gesso ao nível de $200 \mathrm{mg} \mathrm{P} \mathrm{dm}^{-3}$ (Figura 4). 

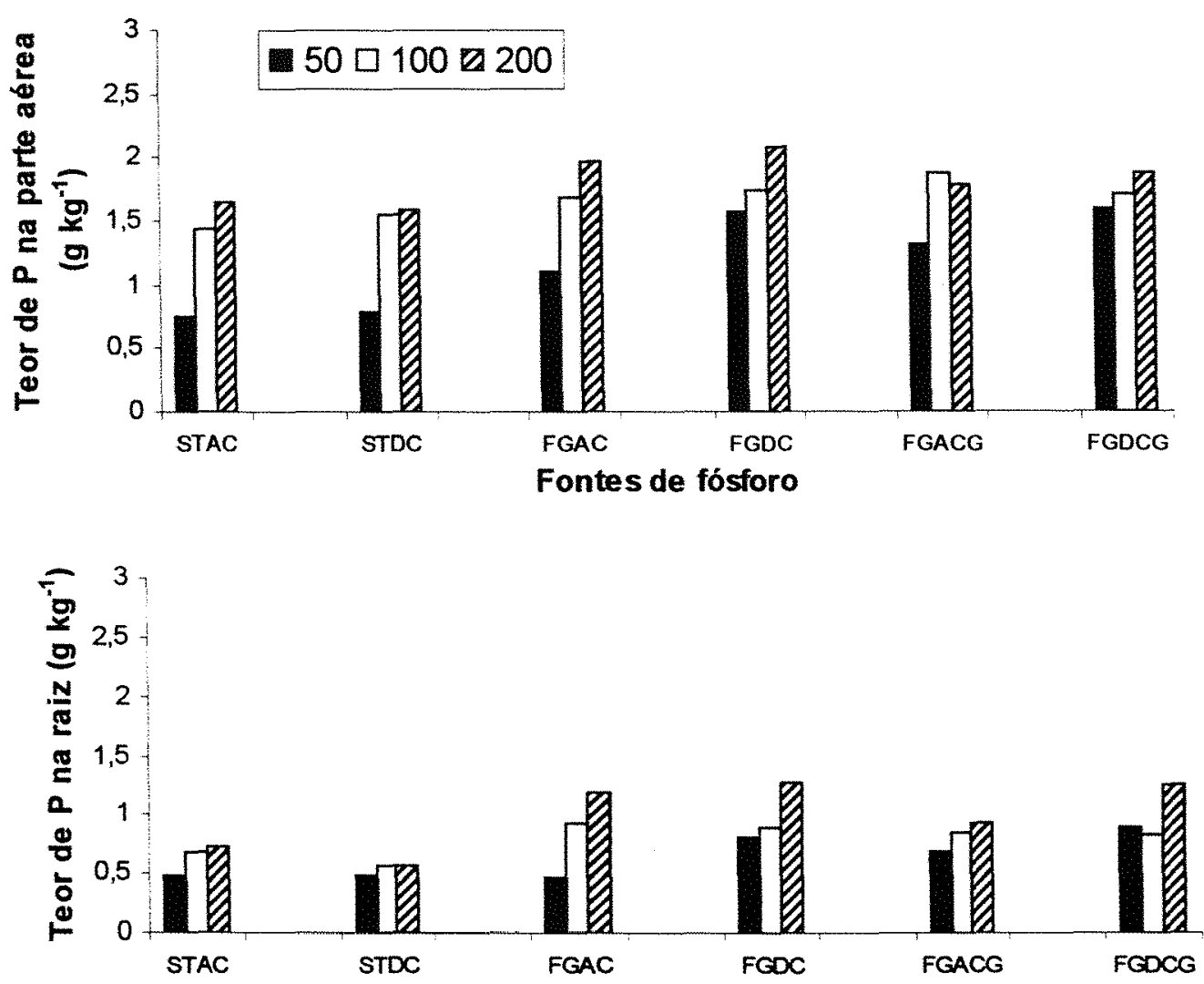

Fontes de fósforo

Figura 25 - Teores de $\mathrm{P}\left(\mathrm{g} \mathrm{kg}^{-1}\right)$ na MS da parte aérea e raiz obtidos em decorrência dos diferentes tratamentos e doses de fósforo $\left(50,100\right.$ e $200 \mathrm{mg} \mathrm{dm}^{-3}$ ) referente ao terceiro plantio (média dos três cortes).

(STAC: super triplo antes da calagem; STDC: super triplo depois da calagem; FGAC: Fosfato de Gafsa antes da calagem; FGDC: Fosfato de Gafsa depois da calagem; FGACG: Fosfato de Gafsa antes da calagem mais gesso; FGDCG: Fosfato de Gafsa depois da calagem mais gesso).

Em relação ao momento de calagem, não houve diferença no teor de fósforo na parte aérea e na raiz $(\mathrm{P}>0,05)$ de alfafa com a aplicação do ST depois da calagem em relação à adição do superfosfato triplo antes da calagem (Figura 25 e contraste 2 da Tabela 26). Também não foi encontrado efeito do momento de calagem para o FG associado ou não ao gesso sobre o teor de fósforo na parte aérea e na raiz $(P>0,05)$ (Figura 25 e contrastes 4 e 5 da Tabela 26). As exceções foram para o nível de $50 \mathrm{mg} \mathrm{P}$ $\mathrm{dm}^{-3}$ na raiz $(\mathrm{P}<0,05)$ (Figura 25 e contraste 4 da Tabela 26) e na parte aérea (Figura 25), onde os tratamentos FGDC mostraram teores mais elevados de fósforo na MS em 
relação ao FGAC e, para o tratamento FGDCG o teor de $\mathrm{P}$ na parte aérea foi superior ao FGACG (Figura 20).

Tabela 26 - Contrastes ortogonais para comparação do teor de P na MS da raiz da alfafa entre os tratamentos com fonte de fósforo dentro de cada dose de $\mathrm{P}$, no terceiro plantio.

\begin{tabular}{|c|c|c|c|c|}
\hline \multirow[b]{3}{*}{ № } & \multirow[b]{3}{*}{ Contrastes } & \multicolumn{3}{|c|}{ Valor do contraste } \\
\hline & & \multicolumn{3}{|c|}{ Niveis de $P\left(\mathrm{mg} \mathrm{dm}^{-3}\right)$} \\
\hline & & 50 & 100 & 200 \\
\hline 1 & $2 \mathrm{STAC}+2 \mathrm{STDC}-\mathrm{FGAC}-\mathrm{FGDC}-\mathrm{FGACG}-\mathrm{FGDCG}$ & $-0,85^{*}$ & $-0,79^{*}$ & $-1,26^{*}$ \\
\hline 2 & STAC - STDC & $0,00^{\mathrm{ns}}$ & $0,11^{\mathrm{ns}}$ & $0,14^{\mathrm{ns}}$ \\
\hline 3 & FGAC + FGDC - FGACG - FGDCG & $-0,31^{*}$ & $0,07^{\text {ns }}$ & $0,11^{\text {ns }}$ \\
\hline 4 & FGAC - FGDC & $-0,33^{*}$ & $0,01^{\mathrm{ns}}$ & $-0,01^{\mathrm{ns}}$ \\
\hline 5 & FGACG - FGDCG & $-0,13^{\text {ns }}$ & $0,03^{\mathrm{ns}}$ & $-0,15^{\mathrm{ns}}$ \\
\hline
\end{tabular}

(STAC: super triplo antes da calagem; STDC: super triplo depois da calagem; FGAC: Fosfato de Gafsa antes da calagem; FGDC: Fosfato de Gafsa depois da calagem; FGACG: Fosfato de Gafsa antes da calagem mais gesso; FGDCG: Fosfato de Gafsa depois da calagem mais gesso).

* significativo a $5 \%$ de probabilidade.

${ }^{\text {ns }}$ não significativo a $5 \%$ de probabilidade.

Houve queda no teor de fósforo da parte áerea da alfafa em função dos momentos de corte em todos os tratamentos (Figura 26).

O aumento da temperatura acelera a maturidade da alfafa (Lee \& Smith, 1972), e a concentração de fósforo na planta diminui com a idade da planta (Rominger et al., 1975). Assim, as maiores temperaturas máxima e mínima durante o terceiro período de crescimento $\left(29,3\right.$ e $15,4^{\circ} \mathrm{C}$, respectivamente) em relação ao primeiro e segundo periodos $\left(25,9\right.$ e $12,8^{\circ} \mathrm{C}$ e 26,2 e $11,8^{\circ} \mathrm{C}$, respectivamente), provocaram elevação na temperatura do interior da estufa (atingindo ao redor dos $42^{\circ} \mathrm{C}$ ) durante o dia, e deve ter colaborado para acelerar a maturidade da planta provocando a queda no teor de fósforo na parte aérea (Figura 26). 


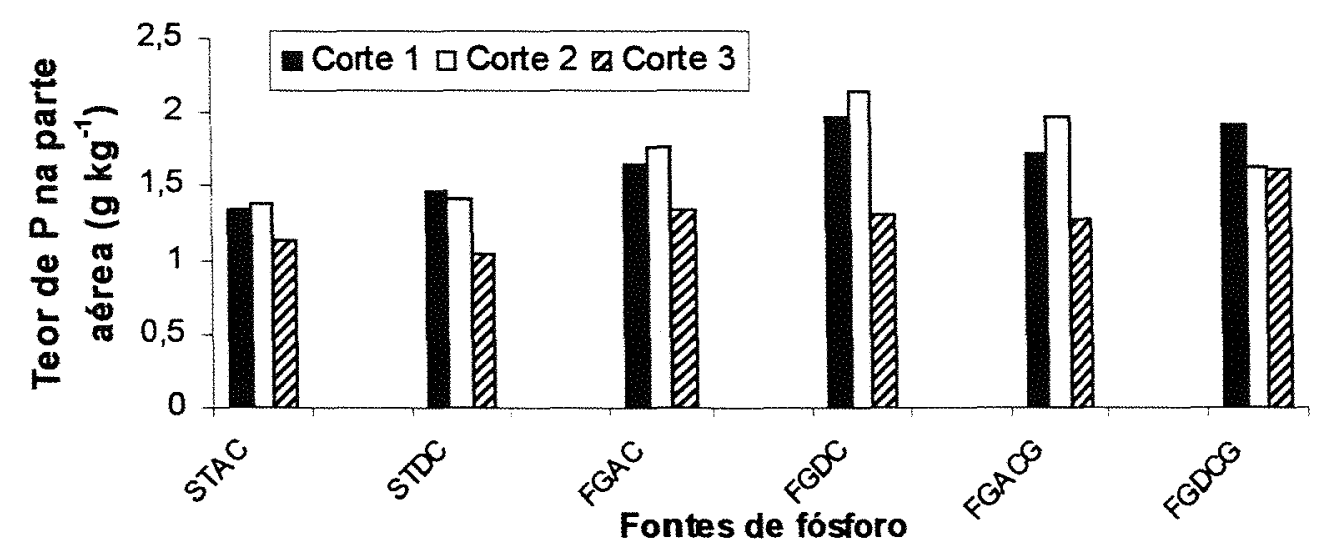

Figura 26 - Teores de $\mathrm{P}\left(\mathrm{g} \mathrm{kg}^{-1}\right)$ na MS da parte aérea da alfafa em respostas as épocas de corte, obtidos em decorrência dos diferentes tratamentos, no terceiro plantio (médias dos três níveis de fósforo).

(STAC: super triplo antes da calagem; STDC: super triplo depois da calagem; FGAC: Fosfato de Gafsa antes da calagem; FGDC: Fosfato de Gafsa depois da calagem; FGACG: Fosfato de Gafsa antes da calagem mais gesso; FGDCG: Fosfato de Gafsa depois da calagem mais gesso).

\subsection{Teor de Nitrogênio}

\subsubsection{Primeiro plantio}

Não ocorreu interação $(P>0,05)$ entre fontes e doses de fósforo para o teor de $\mathrm{N}$ na parte aérea, portanto, apenas os efeitos principais foram analisados (Apêndice 22).

Não houve efeito $(P>0,05)$ das doses de fósforo sobre o teor de $\mathrm{N}$ na MS da parte aérea (Apêndice 22). Isso contraria a expectativa inicial, pois na fixação simbiótica, o fósforo tem a capacidade de aumentar o número, o tamanho dos nódulos e a quantidade de $\mathrm{N}_{2}$ fixado pela alfafa (Lanyon \& Grifftih, 1988). Yupanqui (1997) concluiu que o processo de formação e desenvolvimento dos nódulos da alfafa são influenciados pelo teor de fósforo no solo. Em experimento de omissão de macronutrientes, Jones et al. (1970), observaram queda significativa de 38,1 para $30,8 \mathrm{~g} \mathrm{~kg}^{-1}$ de $\mathrm{N}$ na alfafa quando se omitiu o fósforo da adubação. No presente trabalho, todavia, devido ao curto periodo de desenvolvimento a que foram submetidas as plantas (47 dias), provavelmente, não houve 
tempo suficiente para a formação completa dos nódulos. Viands et al. ${ }^{1}$, citado por Moreira (1997), consideram que no início da simbiose a bactéria prioriza seu metabolismo na formação de nódulos em detrimento da simbiose com a planta.

Outro fator que pode ter afetado o teor de $\mathrm{N}$ na MS da planta, no primeiro plantio, foi o $\mathrm{pH}$ do solo que estava em torno de $4,8^{*}\left(\mathrm{CaCl}_{2}\right)$. A acidez do solo, provavelmente, afetou o crescimento da planta e a fixação simbiótica de nitrogênio através da redução na formação e eficiência dos nódulos. Doerge et al (1985) e Walworth \& Sumner (1990) verificaram elevação do teor de N na alfafa com a adição de calcário. Munns (1978) considera que para maximizar a relação simbiótica o pH do solo deve estar acima de 6,0, enquanto Honda \& Honda (1990) sugerem uma amplitude de $\mathrm{pH}$ variando de 6,8 a 7,0 .

Em relação às fontes de fósforo, houve maior $(\mathrm{P}<0,05)$ teor de $\mathrm{N}$ na MS da parte aérea das plantas nos tratamentos que utilizavam o FG associado ou não ao gesso do que com o uso do ST (Apêndice 25, Figura 27 e contraste 1 da Tabela 27). Isso deve-se ao efeito de concentração, uma vez que os tratamentos com FG produziram quantidade muito pequena de matéria seca, no primeiro plantio (Figura 3).

Não houve efeito de momento de aplicação de calagem $(P>0,05)$ sobre o teor de $\mathrm{N}$ da planta, bem como adição de gesso juntamente ao FG (Figura 27 e contrastes 2,4 e 5 da Tabela 27).

\footnotetext{
' VIANDS, D.R.: BARNES. D.K.; HEICHEL, G.H. Nitrogen fixation in alfafa; responses to bidirectional selection for associated characteristics. Washington: USDA, 1981, 24p.

" média da amostragem de todos os tratamentos, niveis e repetições.
} 


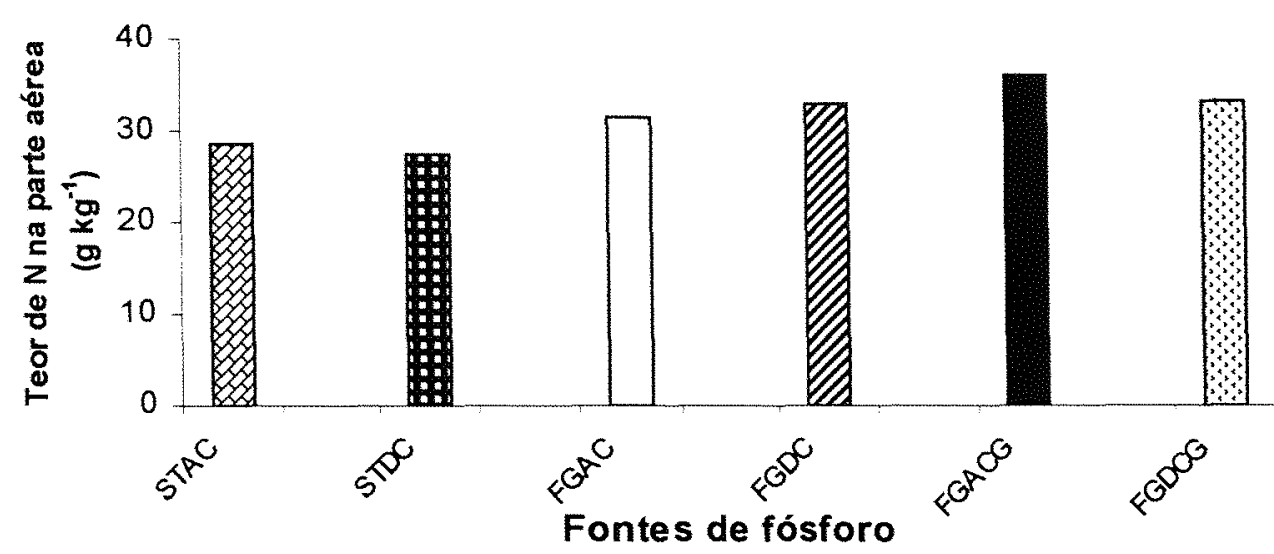

Figura 27 - Teores de $\mathrm{N}\left(\mathrm{g} \mathrm{kg}^{-1}\right)$ na parte aérea da alfafa em função dos tratamentos e doses de fósforo $\left(50,100 \mathrm{e} 200 \mathrm{mg} \mathrm{dm}^{-3}\right)$ no primeiro plantio.

(STAC: super triplo antes da calagem; STDC: super triplo depois da calagem; FGAC: Fosfato de Gafsa antes da calagem; FGDC: Fosfato de Gafsa depois da calagem; FGACG: Fosfato de Gafsa antes da calagem mais gesso; FGDCG: Fosfato de Gafsa depois da calagem mais gesso).

Tabela 27 - Contrastes ortogonais para comparação do teor de $\mathrm{N}$ na MS da parte aérea da alfafa entre os tratamentos com fonte de fósforo, no primeiro plantio.

\begin{tabular}{lcc}
\hline$N^{\mathrm{o}}$ & Contrastes & Valor do contraste \\
\hline 1 & $2 \mathrm{STAC}+$ 2STDC - FGAC - FGDC - FGACG - FGDCG & $-21,48^{*}$ \\
2 & STAC - STDC & $1,23^{\text {ns }}$ \\
3 & FGAC + FGDC - FGACG - FGDCG & $-5,11^{\text {ns }}$ \\
4 & FGAC - FGDC & $-1,54^{\text {ns }}$ \\
5 & FGACG - FGDCG & $2,82^{\text {ns }}$ \\
\hline
\end{tabular}

(STAC: super triplo antes da calagem; STDC: super triplo depois da calagem; FGAC: Fosfato de Gafsa antes da calagem; FGDC: Fosfato de Gafsa depois da calagem; FGACG: Fosfato de Gafsa antes da calagem mais gesso; FGDCG: Fosfato de Gafsa depois da calagem mais gesso).

* significativo a $5 \%$ de probabilidade.

${ }^{\text {ns }}$ não significativo a $5 \%$ de probabilidade.

\subsubsection{Terceiro plantio}

Foi encontrada interação $(\mathrm{P}<0,05)$ entre fontes e doses de fósforo para o teor de $\mathrm{N}$ na MS da raiz (Apêndice 24).

Houve diminuição no teor de $\mathrm{N}$ na MS da raiz $(\mathrm{P}<0,05)$ (Figura 28 e Tabela 28 ) e parte aérea da alfafa (Figura 28) quando o nível de fósforo no solo aumentou de $50 \mathrm{mg}$ $\mathrm{P} \mathrm{dm}^{-3}$ para 100 ou $200 \mathrm{mg} \mathrm{P} \mathrm{dm}^{-3}$. A diminuição deve-se, provavelmente, ao efeito de concentração relatado por Malavolta (1980) uma vez que a produção de MS foi muito 
pequena no nível de $50 \mathrm{mg} \mathrm{P} \mathrm{dm}^{-3}$ (Figura 4 e Figura 5). A exceção foi o tratamento FGDCG, tanto na parte aérea como na raiz, que não apresentaram alterações no teor de $\mathrm{N}$ da MS com a adição de P (Figura 28 e Tabela 28). Martins et al. (1990) em experimento com alfafa, utilizando a técnica de subtração de nutrientes verificaram que o tratamento em que omitiu-se o fósforo foi o que apresentou maior teor de $\mathrm{N}$ tanto na parte aérea como na raiz em razão, também, do efeito de concentração.

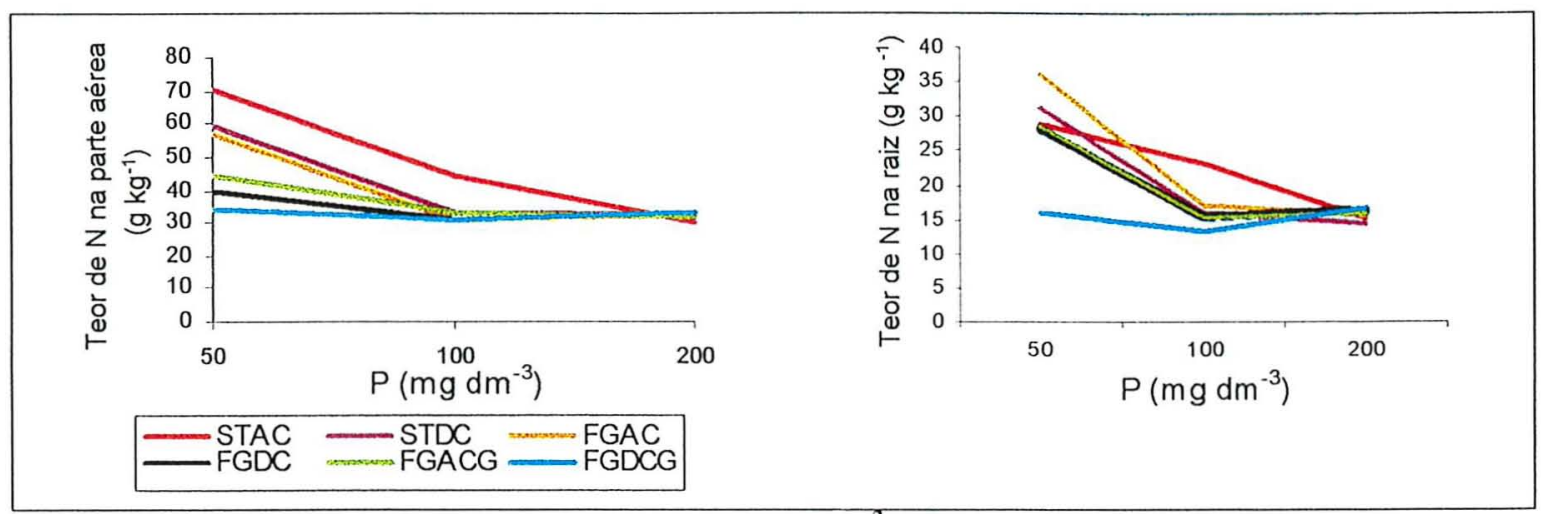

Figura 28 - Efeito das doses de fósforo $\left(\mathrm{mg} \mathrm{dm}^{-3}\right)$ sobre os teores de $\mathrm{N}$ na MS da parte aérea e raiz da alfafa, em decorrência dos diferentes tratamentos, no terceiro plantio (média dos três cortes).

(STAC: super triplo antes da calagem; STDC: super triplo depois da calagem; FGAC: Fosfato de Gafsa antes da calagem; FGDC: Fosfato de Gafsa depois da calagem; FGACG: Fosfato de Gafsa antes da calagem mais gesso; FGDCG: Fosfato de Gafsa depois da calagem mais gesso).

Tabela 28 - Equações que expressam a relação entre a concentração de $\mathrm{N}\left(\mathrm{g} \mathrm{kg}^{-1}\right)$ na raiz das plantas em função das doses $\left(\mathrm{mg} \mathrm{dm}^{-3}\right)$ de fósforo obtida em decorrência dos diferentes tratamentos referente ao terceiro plantio.

\begin{tabular}{lll}
\hline Fontes de fósforo & Equação & $\mathrm{R}^{2}$ \\
\hline STAC & $\mathrm{Y}=32,877-0,0893 \mathrm{X}$ & $0,99^{*}$ \\
STDC & $\mathrm{Y}=31,968-0,0979 \mathrm{X}$ & $0,65^{*}$ \\
FGAC & $\mathrm{Y}=37,100-0,1205 \mathrm{X}$ & $0,64^{*}$ \\
FGDC & $\mathrm{Y}=27,813-0,0673 \mathrm{X}$ & $0,50^{*}$ \\
FGACG & $\mathrm{Y}=28,328-0,0719 \mathrm{X}$ & $0,54^{*}$ \\
FGDCG & $\mathrm{Y}=14,163+0,0098 \mathrm{X}$ & $0,17^{\text {ns }}$ \\
\hline
\end{tabular}

(STAC: super triplo antes da calagem; STDC: super triplo depois da calagem; FGAC: Fosfato de Gafsa antes da calagem; FGDC: Fosfato de Gafsa depois da calagem; FGACG: Fosfato de Gafsa antes da calagem mais gesso; FGDCG: Fosfato de Gafsa depois da calagem mais gesso)

* significativo a $5 \%$ de probabilidade.

"ns não significativo. 
Portanto, os resultados encontrados no presente trabalho no terceiro plantio contrariam, novamente, as espectativas de encontrar efeito sinérgico na planta entre fósforo e nitrogênio (Mays et al., 1980 e Malavolta, 1980).

$\mathrm{O}$ teor médio de $\mathrm{N}$ na raiz $\left(20,2 \mathrm{~g} \mathrm{~kg}^{-1}\right.$, Apêndice 27), no presente trabalho, apresentou-se maior que o teor médio encontrado por Martins et al. (1990) $\left(11,4 \mathrm{~g} \mathrm{~kg}^{-1}\right)$, e menor que o observado por Volenec et al. (1998) $\left(30,8 \mathrm{~g} \mathrm{~kg}^{-1}\right)$, mas semelhante ao encontrado por Volenec et al. (1997) (19,2 $\left.\mathrm{g} \mathrm{kg}^{-1}\right)$. Na parte aérea da alfafa a concentração média de $\mathrm{N}$ na MS no terceiro plantio $\left(38,8 \mathrm{~g} \mathrm{~kg}^{-1}\right.$ - média de todos os niveis de fósforo e dos três cortes realizados, Apêndice 26) foi superior a concentração de $\mathrm{N}$ encontrada por Oliveira (1986) que foi ao redor de $33,0 \mathrm{~g} \mathrm{~kg}^{-1}$. No entanto, o teor de $\mathrm{N}$ encontra-se na faixa considerada adequada para a parte aérea da alfafa, que é de 34 a $56 \mathrm{~g} \mathrm{~kg}^{-1}$ (Werner et al., 1996).

Os tratamentos com ST apresentaram teores de $\mathrm{N}$ na parte aérea superiores ao FG nas doses de 50 e $100 \mathrm{mg} \mathrm{P} \mathrm{dm}^{-3}$, no terceiro plantio (Figura 29). Esses resultados repetiram-se para a raiz $(\mathrm{P}<0,05)$ ao nível de $100 \mathrm{mg} \mathrm{P} \mathrm{dm}^{-3}$ (Figura 29 e contraste 1 da Tabela 29). Os resultados obtidos devem-se ao efeito de concentração do $\mathrm{N}$ contido nas plantas que receberam o ST uma vez que a produção de MS da parte aérea e raiz foram muito inferiores em relação ao $\mathrm{FG}$ nas doses de 50 e $100 \mathrm{mg} \mathrm{P} \mathrm{dm}^{-3}$, no terceiro pantio (Figura 4 e contrastes 1, 6 e 11 da Tabela 5; Figura 5 e contraste 1 da Tabela 10). A exceção foi o STDC ao nível de $100 \mathrm{mg} \mathrm{P} \mathrm{dm}^{-3}$, cujo teor de $\mathrm{N}$ na parte aérea parece ser semelhante aos outros tratamentos utilizando o FG.

A adição de gesso ao fosfato de Gafsa $(\mathrm{FG}+\mathrm{G})$ proporcionou menor teor de $\mathrm{N}$ na raiz $(P<0,05)$ (Figura 29 e contraste 3 da Tabela 29) e na parte aérea da alfafa do que o uso do FG (Figura 29), no nível de $50 \mathrm{mg} \mathrm{P} \mathrm{dm}^{-3}$.

Quanto ao momento de aplicação de calagem, houve menor teor de $\mathrm{N}$ na parte aérea da planta com a aplicação dos fosfatos, tanto o solúvel como o de rocha, depois da calagem (STDC, FGDC e FGDCG) do que antes da calagem (STAC, FGAC e FGACG), no nível de $50 \mathrm{mg} \mathrm{P} \mathrm{dm}^{-3}$ (Figura 29). Para a raiz, no nível de $50 \mathrm{mg} \mathrm{P} \mathrm{dm}^{-3}$, os tratamentos FGDC e FGDCG apresentaram menores $(P<0,05)$ teores de $\mathrm{N}$ na MS comparado ao FGAC e FGACG, respectivamente (Figura 29 e contrastes 4 e 5 da Tabela 
29). No nível de $100 \mathrm{mg} \mathrm{P} \mathrm{dm}^{-3}$ os teores de $\mathrm{N}$ da raiz $(\mathrm{P}<0,05)$ e parte aérea foram inferiores quando utilizou-se o STDC comparado ao STAC (Figura 29 e contraste 2 da Tabela 29).

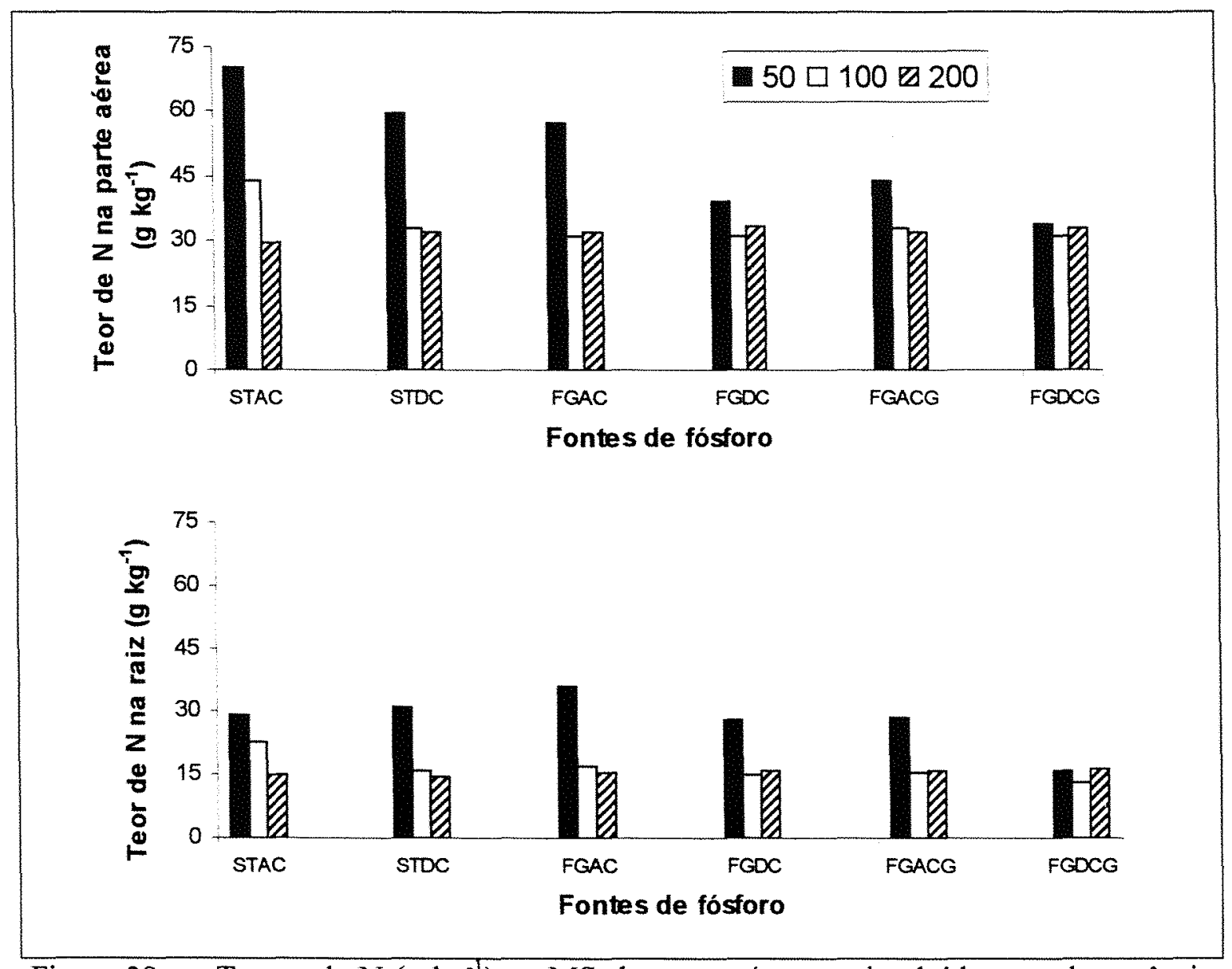

Figura 29 - Teores de $\mathrm{N}\left(\mathrm{g} \mathrm{kg}^{-1}\right)$ na MS da parte aérea e raiz obtidos em decorrência dos diferentes tratamentos e doses de fósforo $\left(\mathrm{mg} \mathrm{dm}^{-3}\right)$, no terceiro plantio (média dos três cortes).

(STAC: super triplo antes da calagem; STDC: super triplo depois da calagem; FGAC: Fosfato de Gafsa antes da calagem; FGDC: Fosfato de Gafsa depois da calagem; FGACG: Fosfato de Gafsa antes da calagem mais gesso; FGDCG: Fosfato de Gafsa depois da calagem mais gesso). 
Tabela 29 - Contrastes ortogonais para comparação do teor de N na MS da raiz da alfafa entre os tratamentos com fonte de fósforo dentro de cada dose de $\mathrm{P}\left(\mathrm{mg} \mathrm{dm}^{-3}\right)$ no terceiro plantio.

\begin{tabular}{lcccc} 
& & \multicolumn{3}{c}{ Valor do contraste } \\
\cline { 3 - 5 } & No & \multicolumn{3}{c}{ Niveis de P $\left(\mathrm{mg} \mathrm{dm}^{-3}\right)$} \\
\cline { 3 - 5 } & Contrastes & 50 & 100 & 200 \\
\hline 1 & 2STAC + 2STDC - FGAC - FGDC - FGACG - FGDCG & $11,34^{\text {ns }}$ & $16,94^{*}$ & $-4,95^{\text {ns }}$ \\
2 & STAC - STDC & $-2,24^{\text {ns }}$ & $7,14^{*}$ & $0,84^{\text {ns }}$ \\
3 & FGAC + FGDC - FGACG - FGDCG & $20,11^{*}$ & $3,87^{\text {ns }}$ & $-0,75^{\text {ns }}$ \\
4 & FGAC - FGDC & $7,93^{*}$ & $2,01^{\text {ns }}$ & $-0,70^{\text {ns }}$ \\
5 & FGACG - FGDCG & $12,65^{*}$ & $2,15^{\text {ns }}$ & $-0,89^{\text {ns }}$ \\
\hline (STAC: super triplo antes da calagem; STDC: super triplo depois da calagem; FGAC: Fosfato de Gafsa
\end{tabular}

super triplo antes da calagem; STDC: super triplo depois da calagem; FGAC: Fosfato de Gafsa antes da calagem; FGDC: Fosfato de Gafsa depois da calagem; FGACG: Fosfato de Gafsa antes da calagem mais gesso; FGDCG: Fosfato de Gafsa depois da calagem mais gesso).

* significativo a $5 \%$ de probabilidade.

${ }^{\text {ns }}$ não significativo a $5 \%$ de probabilidade.

Os resultados, provavelmente, se devem ao efeito diluição descrito por Malavolta (1980), uma vez que os menores teores de $\mathrm{N}$ na MS estavam relacionados com uma tendência a maior produção de MS da parte aérea da alfafa nos tratamentos utilizando FG com gesso e sem gesso adicionados depois da calagem (FGDC e FGDCG) em relação ao FG associado ou não ao gesso aplicado antes da calagem (FGAC e FGACG) ao nivel de $50 \mathrm{mg} \mathrm{P} \mathrm{dm}^{-3}$ (Figuras 4 e Tabela 7). Da mesma maneira, foram verificados menores teores de $\mathrm{N}$ da raiz nos tratamentos FGDC e FGDCG ao nível de $50 \mathrm{mg} \mathrm{P} \mathrm{dm}^{-3}$ em relação ao FGAC e FGACG respectivamente, estavam relacionados com maior $(\mathbf{P}<0,05)$ produção de MS da raiz (Figura 5 e contrastes 4 e 5 da Tabela 10); assim como a menor concentração de $\mathrm{N}$ na raiz com a utilização do STDC ao nível de $100 \mathrm{mg} \mathrm{P} \mathrm{dm}^{-3}$ estava relacionada com a maior $(\mathrm{P}<0,05)$ produção de MS comparada ao uso do STAC (Figura 5 e contraste 2 da Tabela 10 ).

Ocorreu decréscimo no teor de $\mathrm{N}$ na parte aérea da planta no ultimo corte, em todos os tratamentos, quando comparado ao primeiro corte, com exceção do FGDCG que manteve o mesmo teor de $\mathrm{N}$ da planta nos três cortes (Figura 30). A diminuição do teor de $\mathrm{N}$ ocorreu, possivelmente, por causa do efeito diluição devido ao aumento, em geral, da produção de MS da parte aérea com o tempo (Tabela 7), como também a aceleração da maturidade da alfafa pela elevação da temperatura no terceiro período de crescimento. 


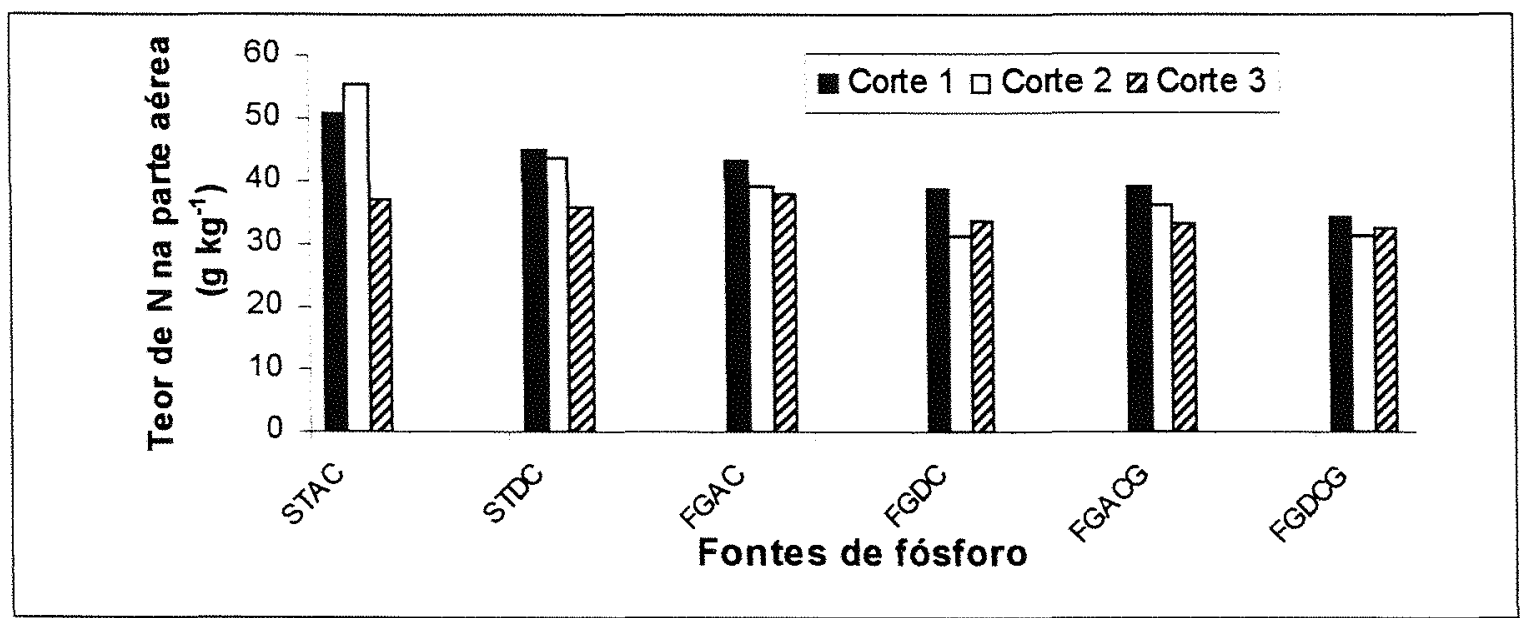

Figura 30 - Teores de $\mathrm{N}\left(\mathrm{g} \mathrm{kg}^{-1}\right)$ na MS da parte aérea da alfafa em resposta as épocas de corte, obtidos em decorrência dos diferentes tratamentos, no terceiro plantio (médias dos três níveis de $\mathrm{P}$ ).

(STAC: super triplo antes da calagem; STDC: super triplo depois da calagem; FGAC: Fosfato de Gafsa antes da calagem; FGDC: Fosfato de Gafsa depois da calagem; FGACG: Fosfato de Gafsa antes da calagem mais gesso; FGDCG: Fosfato de Gafsa depois da calagem mais gesso).

Foi constatado, por avaliação visual, que no momento do terceiro corte as plantas estavam com, aproximadamente, 30 a $40 \%$ de florescimento, enquanto que no momento do primeiro e segundo cortes as plantas apresentavam-se com, aproximadamente, $10 \%$ de florescimento. Segundo Rominger et al. (1975) o teor $N$ na alfafa diminui com a maturidade da planta.

\subsection{Teor de Cálcio}

\subsubsection{Primeiro plantio}

Foi encontrada interação $(P<0,05)$ entre fontes e doses de fósforo sobre teor de Ca na MS da parte aérea da planta (Apêndice 22).

$\mathrm{O}$ aumento da dose de 50 para $200 \mathrm{mg} \mathrm{P} \mathrm{dm}^{-3}$ provocou aumentos lineares $(\mathrm{P}<0,05)$ na concentração de Ca na MS da parte aérea da alfafa em função das doses de $P$, nos tratamentos STAC, FGAC, FGDC e FGACG (Figura 31). Esse resultado é devido ao cálcio existente tanto no ST como no FG. Elevação no teor de cálcio na alfafa foi, também, encontrado por Walworth \& Sumner (1990) e Moreira (1997), devido à adição de superfosfato triplo; e por Moreira (1997) devido à aplicação de fosfato de rocha. A 
não alteração na concentrão de Ca na parte aérea da planta em função dos níveis de fósforo no tratamento STDC pode ser devido ao efeito de diluição já que no primeiro plantio o STAC produziu menos que o STDC ao nivel de 100 e $200 \mathrm{mg} \mathrm{P} \mathrm{dm}^{-3}$ (contraste 2 da Tabela 3).

Os teores de Ca na alfafa foram superiores $(\mathrm{P}<0,05)$ quando utilizou-se o fosfato Gafsa associado ou não ao gesso do que com o uso da fonte solúvel em todas as doses de fósforo (Figura 32, contraste 1 da Tabela 30 e Apêndice 25). Esse resultado deve-se, provavelmente, a maior quantidade de cálcio (35\%) presente no super fosfato de Gafsa do que o superfosfato triplo $(14,5 \%)$ associado ao fato de que os tratamentos com ST produzirem mais do que aqueles que usaram o FG como fonte de fósforo (contraste 1 da Tabela 3).

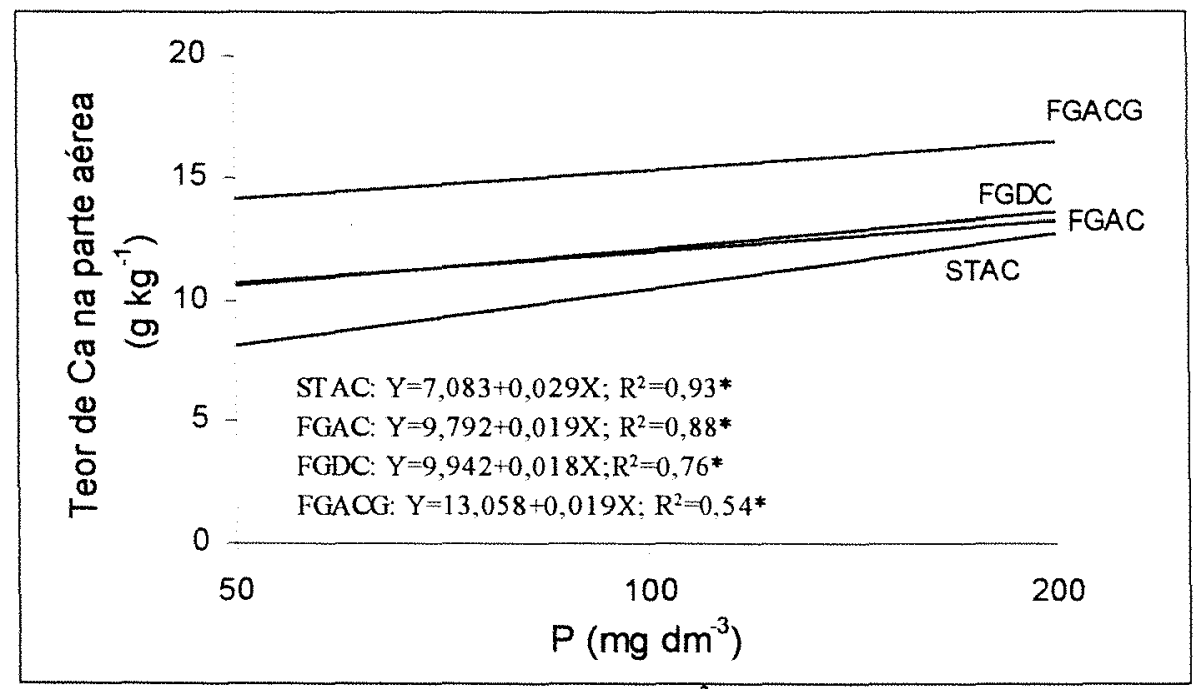

Figura 31 - Efeito dos níveis de fósforo $\left(\mathrm{mg} \mathrm{dm}^{-3}\right)$ sobre o teor de Ca na MS da parte aérea da alfafa, para os tratamentos STAC, FGAC, FGDC e FGACG, no primeiro plantio.

* significativo a $5 \%$ de probabilidade.

(STAC: superfosfato triplo aplicado antes da calagem; FGAC: Fosfato de Gafsa aplicado antes da calagem: FGDC: Fosfato de Gafsa aplicado depois da calagem; FGACG: Fosfato de Gafsa antes da calagem mais gesso).

A adição de gesso ao $\mathrm{FG}$ aumentou $(\mathrm{P}<0,05)$ a concentração de $\mathrm{Ca}$ na planta nos três níveis de $\mathrm{P}$, do primeiro plantio (Figura 32 e contraste 3 da Tabela 30). A quantidade de $\mathrm{Ca}$, proveniente da calagem ou da calagem mais gesso nos tratamentos com $\mathrm{FG}$ ou $\mathrm{FG}+\mathrm{G}$, respectivamente, foram adicionados em quantidades iguais. Uma 
explicação possivel seria a maior disponibilidade de cálcio contida no gesso, que refletiria em maior teor de cálcio no solo e consequentemente nas plantas adubadas com $\mathrm{FG}+\mathrm{G}$.

Em relação ao momento de calagem, não se obteve efeito $(\mathrm{P}>0,05)$ desse sobre a concentração de Ca na planta (Figura 32 e contrastes 2, 4 e 5 da Tabela 30). As únicas exceções foram o STDC e FGDCG, nos níveis de 50 e $100 \mathrm{mg} \mathrm{P} \mathrm{dm}^{-3}$, respectivamente, que apresentaram maior $(\mathrm{P}<0,05)$ concentração de $\mathrm{Ca}$ na planta que os tratamentos STAC e FGACG (Figura 32, contrastes 2 e 5 da Tabela 30). O melhor efeito dos tratamentos STDC e FGDCG deve-se provavelmente ao período maior de incubação do calcáreo em relação aos tratamentos, STAC e FGACG uma vez que o calcáreo foi empregado cerca de 60 dias antes nos vasos que receberam fonte de fósforo depois da calagem. Pode-se também inferir que a solubilidade da fonte de fósforo para fornecer cálcio tenha sido menor nos tratamentos onde a fonte de fósforo foi aplicada antes da calagem. Dessa maneira, menor quantidade de cálcio estaria disponivel para as plantas nos tratamentos com calagem após o uso de fósforo.

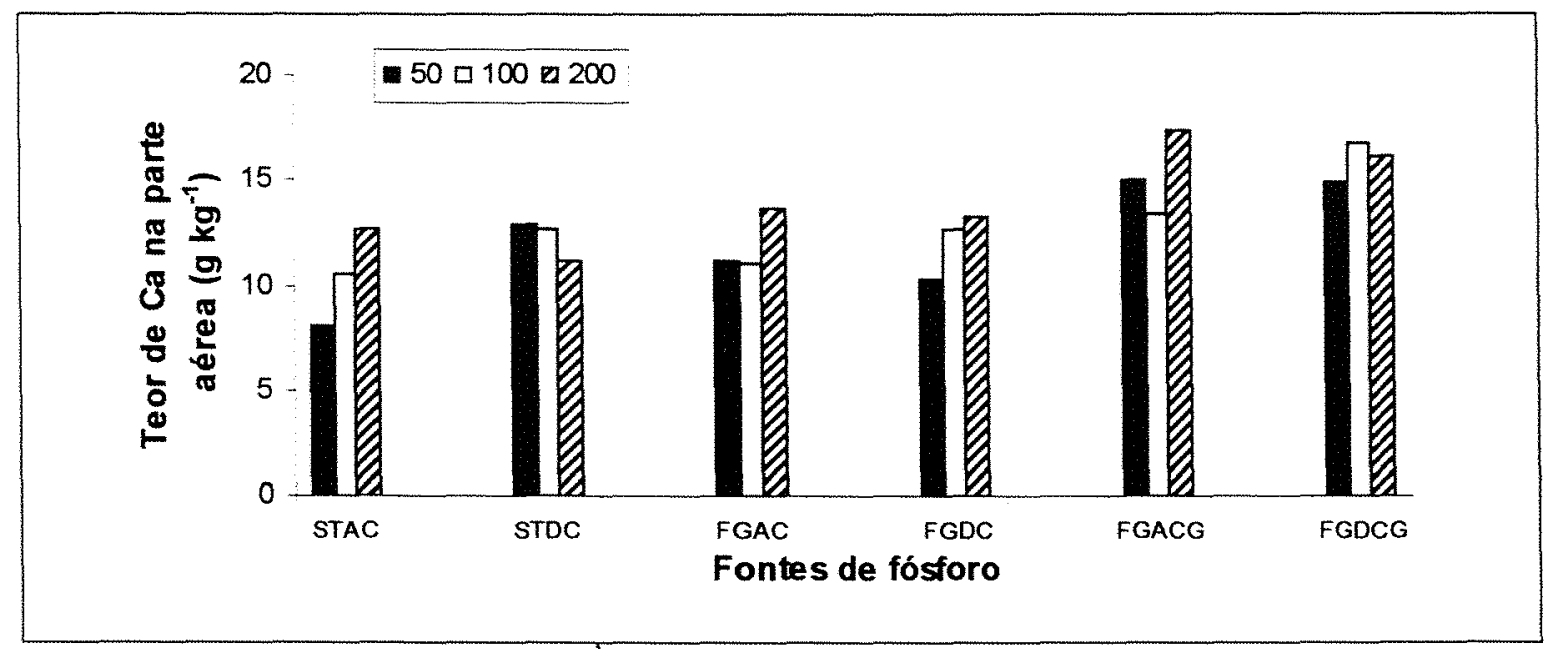

Figura 32 - Teores de $\mathrm{Ca}\left(\mathrm{g} \mathrm{kg}^{-1}\right)$ na parte aérea da alfafa em função dos tratamentos e doses de fósforo $\left(50,100 \mathrm{e} 200 \mathrm{mg} \mathrm{dm}^{-3}\right)$, no primeiro plantio.

(STAC: super triplo antes da calagem; STDC: super triplo depois da calagem; FGAC: Fosfato de Gafsa antes da calagem; FGDC: Fosfato de Gafsa depois da calagem; FGACG: Fosfato de Gafsa antes da calagem mais gesso; FGDCG: Fosfato de Gafsa depois da calagem mais gesso). 
Tabela 30 - Contrastes ortogonais para comparação do teor de Ca na MS da parte aérea da alfafa entre os tratamentos com fonte de fósforo dentro de cada dose de $\mathrm{P}\left(\mathrm{mg} \mathrm{dm}^{-3}\right)$, no primeiro plantio.

\begin{tabular}{lcccc}
\hline & & \multicolumn{3}{c}{ Valor do contraste } \\
\cline { 3 - 5 } & Non & \multicolumn{2}{c}{ Niveis de P $\left.(\mathrm{mg} \mathrm{dm})^{-3}\right)$} \\
\cline { 3 - 5 } & Contrastes & 50 & 100 & 200 \\
\hline 1 & 2STAC + 2STDC - FGAC - FGDC - FGACG - FGDCG & $-9,27^{*}$ & $-7,28^{*}$ & $-13,02^{*}$ \\
2 & STAC - STDC & $-4,88^{*}$ & $-2,12^{\text {ns }}$ & $1,47^{\text {ns }}$ \\
3 & FGAC + FGDC - FGACG - FGDCG & $-8,60^{*}$ & $-6,55^{*}$ & $-6,52^{*}$ \\
4 & FGAC - FGDC & $0,85^{\text {ns }}$ & $-1,58^{\text {ns }}$ & $0,42^{\text {ns }}$ \\
5 & FGACG - FGDCG & $0,11^{\text {ss }}$ & $-3,37^{*}$ & $1,33^{\text {ns }}$ \\
\hline
\end{tabular}

(STAC: super triplo antes da calagem; STDC: super triplo depois da calagem; FGAC: Fosfato de Gafsa antes da calagem; FGDC: Fosfato de Gafsa depois da calagem; FGACG: Fosfato de Gafsa antes da calagem mais gesso: FGDCG: Fosfato de Gafsa depois da calagem mais gesso).

* significativo a $5 \%$ de probabilidade.

${ }^{\text {ns }}$ não significativo a $5 \%$ de probabilidade.

\subsubsection{Terceiro plantio}

Para o teor de Ca na raiz não houve interação entre fontes e doses de fósforo $(\mathrm{P}>0,05)$, portanto, apenas os efeitos principais foram analisados (Apêndice 24).

O teor de cálcio na parte aérea aumentou em função das doses de fósforo para os tratamentos STAC, STDC e FGAC (Figura 33). No entanto, não se verificou efeito $(\mathrm{P}>0,05)$ dos níveis de fósforo sobre o teor de cálcio na raiz da alfafa (Figura $33 \mathrm{e}$ Apêndice 24).

A concentração média de Ca na raiz encontrada nesse trabalho, que foi de $2,09 \mathrm{~g}$ $\mathrm{kg}^{-1}$ (Apêndice 27), está próxima aos encontrados por Martins et al. (1990) e Suzuki (1991) $\left(2,7 \mathrm{e} 1,6 \mathrm{~g} \mathrm{~kg}^{-1}\right.$, respectivamente). No entanto, o teor médio de Ca presente na parte aérea da alfafa, no terceiro plantio (17,62 $\mathrm{g} \mathrm{kg}^{-1}$ - Apêndice 26) apresentou teores médios acima dos valores encontrados por Oliveira (1986), Martins et al. (1990) e Moreira (1997) que foram 14,$8 ; 12,4$ e 13,1 $\mathrm{g} \mathrm{kg}^{-1}$, respectivamente, mas dentro da faixa adequada para a alfafa $\left(10\right.$ a $\left.25 \mathrm{~g} \mathrm{~kg}^{-1}\right)$ (Werner et al., 1996).

Os teores de $\mathrm{Ca}$ na raiz apresentaram-se maiores $(\mathrm{P}<0,05)$ com utilização do FG em relação à fonte solúvel (Figura 34 e contraste 1 da Tabela 31). Para a parte aérea da planta o teor de $\mathrm{Ca}$ foi maior com o uso do FG do que com o ST para o nível de $50 \mathrm{mg} \mathrm{P}$ $\mathrm{dm}^{-3}$ (Figura 34). A explicação para esses resultados, como ocorridos no primeiro 
plantio deve-se ao superior teor de cálcio contido no fosfato de rocha do que na fonte solúvel de fósforo (Quadro 6). Além disso, o período mais longo de incubação dos tratamentos até a terceira semeadura deve ter favorecido a solubilização do FG.

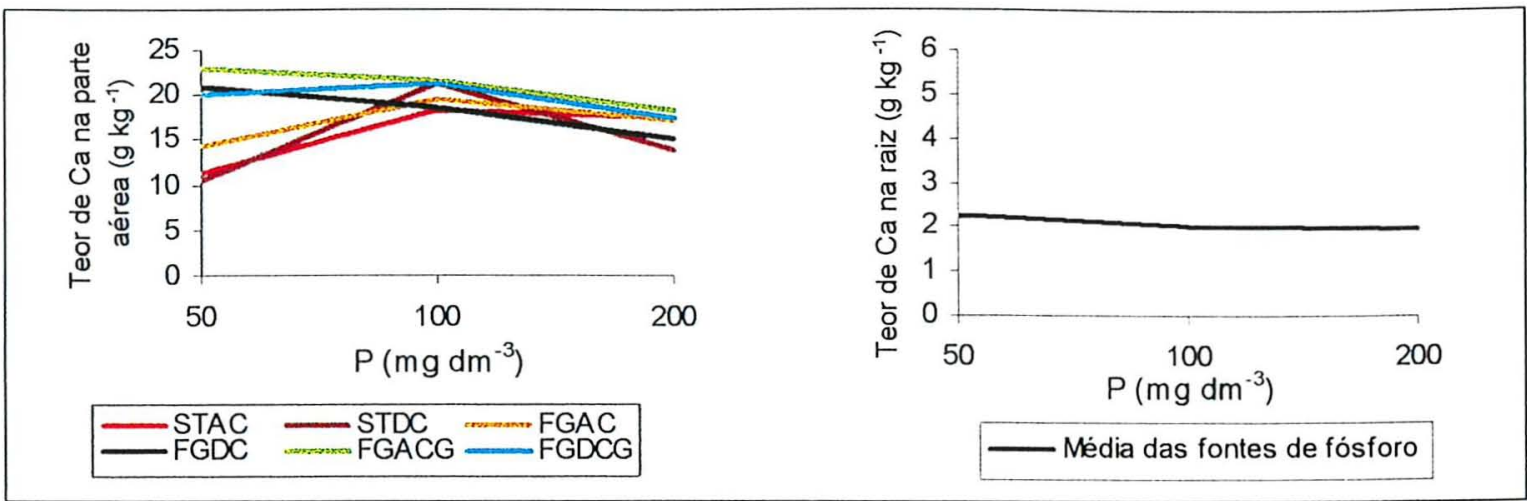

Figura 33 - Efeito das doses de $\mathrm{P}\left(\mathrm{mg} \mathrm{dm}^{-3}\right)$ sobre os teores de Ca na MS da raiz (média das fontes de fósforo) e parte aérea da alfafa (média dos níveis de fósforo), em decorrência dos diferentes tratamentos no terceiro plantio. (Fontes de fósforo: STAC: super triplo antes da calagem; STDC: super triplo depois da calagem; FGAC: Fosfato de Gafsa antes da calagem; FGDC: Fosfato de Gafsa depois da calagem; FGACG: Fosfato de Gafsa antes da calagem mais gesso; FGDCG: Fosfato de Gafsa depois da calagem mais gesso).

Os teores de Ca da alfafa dos tratamentos STAC, STDC e FGAC, praticamente, permaneceram inalterados em função dos cortes (Figura 35). Por outro lado o FGACG e o FGDCG apresentaram queda na concentração de cálcio na planta após o primeiro corte. A queda está, provavelmente, relacionada ao efeito diluição, uma vez que a produção de MS da parte aérea, em geral, aumentou com os cortes consecutivos (Tabela 7). 


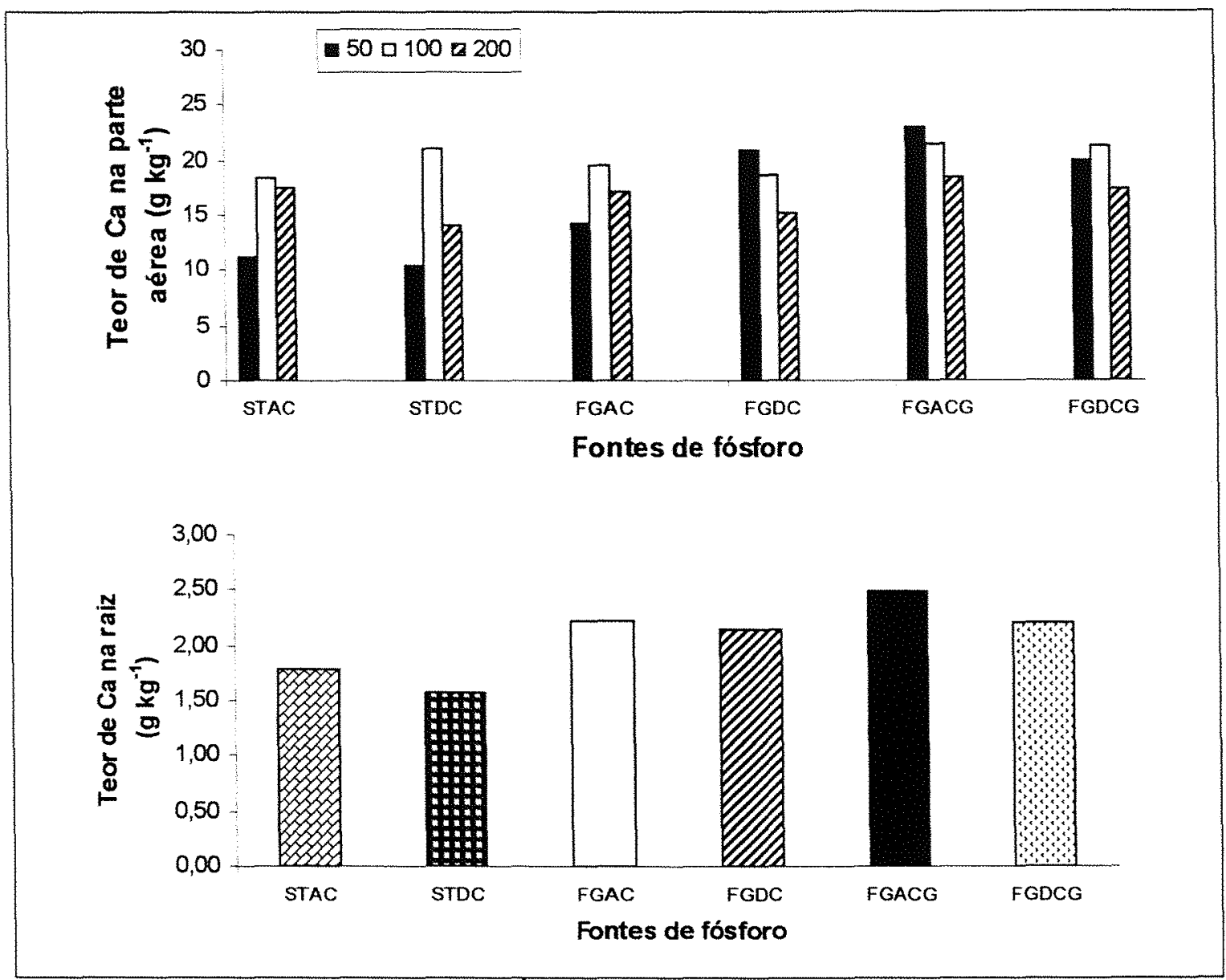

Figura 34 - Teores de $\mathrm{Ca}\left(\mathrm{g} \mathrm{kg}^{-1}\right)$ na MS da parte aérea da alfafa obtidos em decorrência dos diferentes tratamentos e doses de fósforo $(50,100$ e 200 $\mathrm{mg} \mathrm{dm}$ ) (média dos três cortes) e raiz de acordo com os tratamentos.

(STAC: super triplo antes da calagem; STDC: super triplo depois da calagem; FGAC: Fosfato de Gafsa antes da calagem; FGDC: Fosfato de Gafsa depois da calagem; FGACG: Fosfato de Gafsa antes da calagem mais gesso; FGDCG: Fosfato de Gafsa depois da calagem mais gesso).

Tabela 31 - Contrastes ortogonais para comparação do teor de Ca na MS da raiz da alfafa entre os tratamentos com fonte de fósforo referente ao terceiro plantio.

\begin{tabular}{lcc}
\hline $\mathrm{N}^{2}$ & Contrastes & Valor do contraste \\
\hline 1 & 2 STAC + 2STDC - FGAC - FGDC - FGACG - FGDCG & $-2,46^{*}$ \\
2 & STAC - STDC & $0,22^{\text {ns }}$ \\
3 & FGAC + FGDC - FGACG - FGDCG & $-0,21^{\text {ns }}$ \\
4 & FGAC - FGDC & $0,18^{\text {ns }}$ \\
5 & FGACG - FGDCG & $0,28^{\text {ns }}$ \\
\hline
\end{tabular}

(STAC: super triplo antes da calagem; STDC: super triplo depois da calagem; FGAC: Fosfato de Gafsa antes da calagem; FGDC: Fosfato de Gafsa depois da calagem: FGACG: Fosfato de Gafsa antes da calagem mais gesso; FGDCG: Fosfato de Gafsa depois da calagem mais gesso).

* significativo a $5 \%$ de probabilidade.

${ }^{n s}$ não significativo a $5 \%$ de probabilidade. 


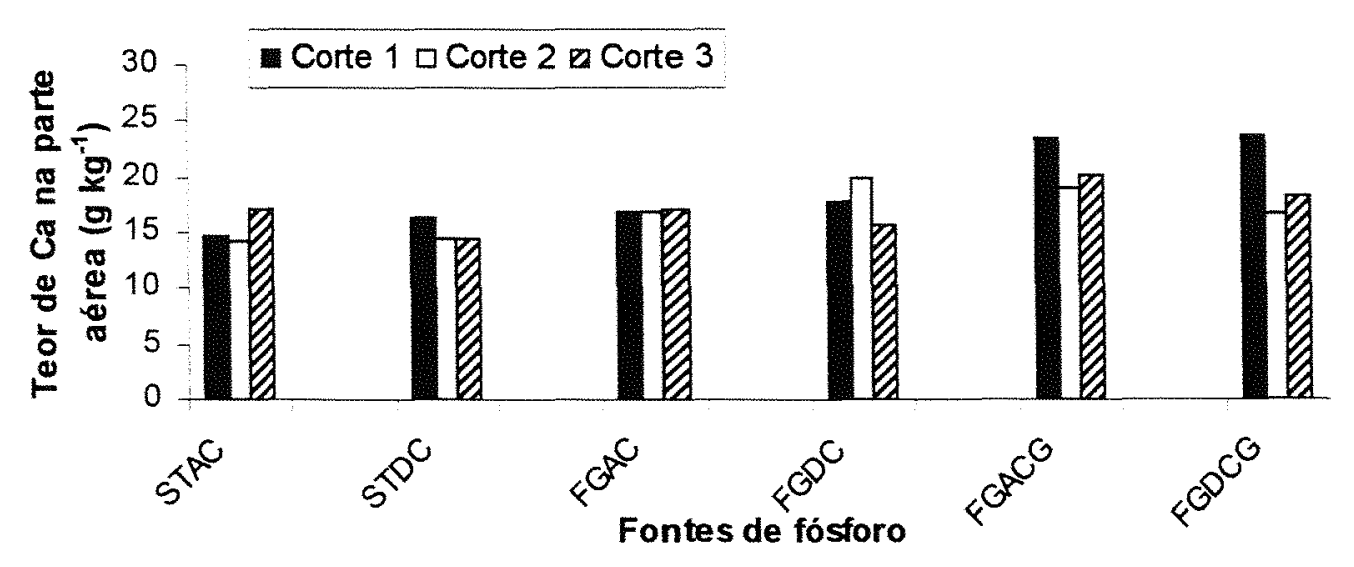

Figura 35 - Teores de $\mathrm{Ca}\left(\mathrm{g} \mathrm{kg}^{-1}\right)$ na MS da parte aérea da alfafa em respostas as épocas de corte, obtidos em decorrência dos diferentes tratamentos (médias dos três niveis de fósforo).

(STAC: super triplo antes da calagem; STDC: super triplo depois da calagem: FGAC: Fosfato de Gafsa antes da calagem; FGDC: Fosfato de Gafsa depois da calagem; FGACG: Fosfato de Gafsa antes da calagem mais gesso; FGDCG: Fosfato de Gafsa depois da calagem mais gesso).

\subsection{Teor de magnésio}

\subsubsection{Primeiro plantio}

Para o teor de $\mathrm{Mg}$ na parte aérea não houve interação entre fontes e doses de fósforo ( $\mathrm{P}>0,05$ ), portanto, apenas os efeitos principais foram analisados (Apêndice 22).

Não se obteve efeito $(\mathrm{P}>0,05)$ de fontes de fósforo sobre o teor de $\mathrm{Mg}$ na MS da parte aérea da alfafa (Apêndice 22, Figura 36 e contrastes 1, 2, 3, 4 e 5 da Tabela 32). Por outro lado, as concentrações de $\mathrm{Mg}$ na planta diminuíram $(\mathrm{P}<0,05)$ em função de doses de fósforo (Figura 37). Resultados similares foram obtidos por Fageria \& Baligar (1989). 


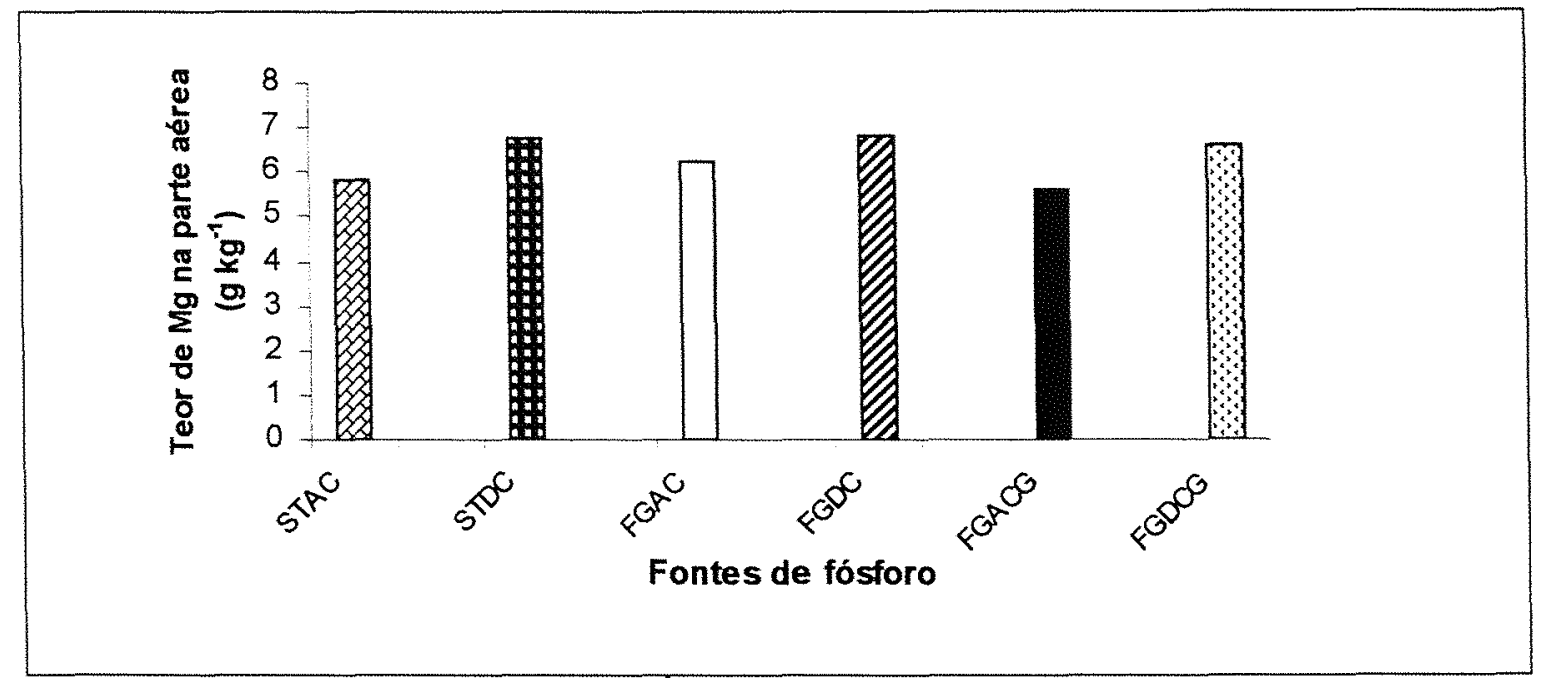

Figura 36 - Teores de $\mathrm{Mg}\left(\mathrm{g} \mathrm{kg}^{-1}\right)$ na MS da parte aérea da alfafa obtidos em decorrência dos diferentes tratamentos (médias dos três niveis de fósforo) no terceiro plantio.

(STAC: super triplo antes da calagem; STDC: super triplo depois da calagem; FGAC: Fosfato de Gafsa antes da calagem; FGDC: Fosfato de Gafsa depois da calagem; FGACG: Fosfato de Gafsa antes da calagem mais gesso; FGDCG: Fosfato de Gafsa depois da calagem mais gesso).

Tabela 32 - Contrastes ortogonais para comparação do teor de Mg na MS da parte aérea da alfafa entre os tratamentos com fonte de fósforo referentes ao primeiro plantio.

\begin{tabular}{lcc}
\hline$N^{\mathrm{a}}$ & Contrastes & Valor do contraste \\
\hline 1 & $2 \mathrm{STAC}+$ 2STDC - FGAC - FGDC - FGACG - FGDCG & $0,03^{\text {ns }}$ \\
2 & STAC - STDC & $-0,02^{\text {ns }}$ \\
3 & FGAC + FGDC - FGACG - FGDCG & $0,04^{\text {ns }}$ \\
4 & FGAC - FGDC & $-0,02^{\text {ns }}$ \\
5 & FGACG - FGDCG & $-0,03^{\text {ns }}$ \\
\hline
\end{tabular}

(STAC: super triplo antes da calagem; STDC: super triplo depois da calagem; FGAC: Fosfato de Gafsa antes da calagem; FGDC: Fosfato de Gafsa depois da calagem; FGACG: Fosfato de Gafsa antes da calagem mais gesso; FGDCG: Fosfato de Gafsa depois da calagem mais gesso).

* significativo a $5 \%$ de probabilidade.

${ }^{\text {ns }}$ não significativo a $5 \%$ de probabilidade. 


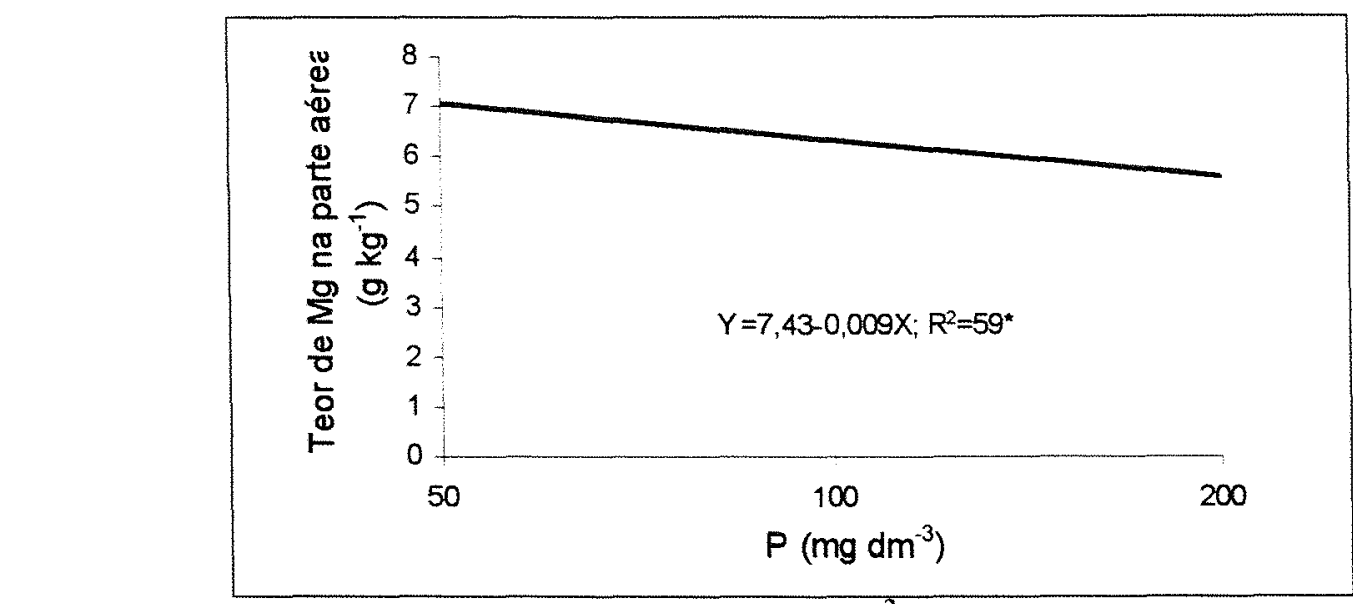

Figura 37 - Efeito dos níveis de fósforo $\left(\mathrm{mg} \mathrm{dm}^{-3}\right)$ sobre os teores de $\mathrm{Mg}$ na MS da parte aérea da alfafa referente ao primeiro plantio (média das fontes de fósforo).

* significativo a $5 \%$ de probabilidade.

(Fontes de fósforo: STAC: super triplo antes da calagem; STDC: super triplo depois da calagem; FGAC: Fosfato de Gafsa antes da calagem; FGDC: Fosfato de Gafsa depois da calagem; FGACG: Fosfato de Gafsa antes da calagem mais gesso; FGDCG: Fosfato de Gafsa depois da calagem mais gesso).

\subsubsection{Terceiro plantio}

Quando se elevou o nível de fósforo no solo de 50 para 100 ou $200 \mathrm{mg} \mathrm{P} \mathrm{dm}^{-3}$ ocorreu decréscimo no teor de $\mathrm{Mg}$ na parte áerea da alfafa para os tratamentos FGDC, FGACG e FGDCG, enquanto o tratamento FGAC não apresentou alteração no teor $\mathrm{Mg}$ na planta (Figura 38). Na raiz houve diminuição linear $(\mathrm{P}<0,05)$ no teor de $\mathrm{Mg}$ na $\mathrm{MS}$ nos tratamentos FGDC, FGACG e FGDCG (Tabela 33). Por outro lado, nos tratamentos STAC, STDC e FGAC verificou-se efeito quadrático $(\mathrm{P}<0,05)$ no teor de $\mathrm{Mg}$ da raiz (Tabela 33). A diminuição da concentração de $\mathrm{Mg}$ na $\mathrm{MS}$ em função da adição de $\mathrm{P}$, foi devida ao aumento na produção de MS e, consequentemente à diluição dos teores de $\mathrm{Mg}$ na planta. Decréscimo no teor de $\mathrm{Mg}$ na parte aérea da alfafa com altas taxas de fertilização fosfatada também foi encontrado por Markus \& Battle (1965). Entretanto, Walwolrth \& Sumner (1990) e Moreira (1997) não observaram decréscimo no teor de Mg na parte aérea da alfafa com adição de $P$, quando utilizaram o superfosfato triplo e fosfato de rocha. 

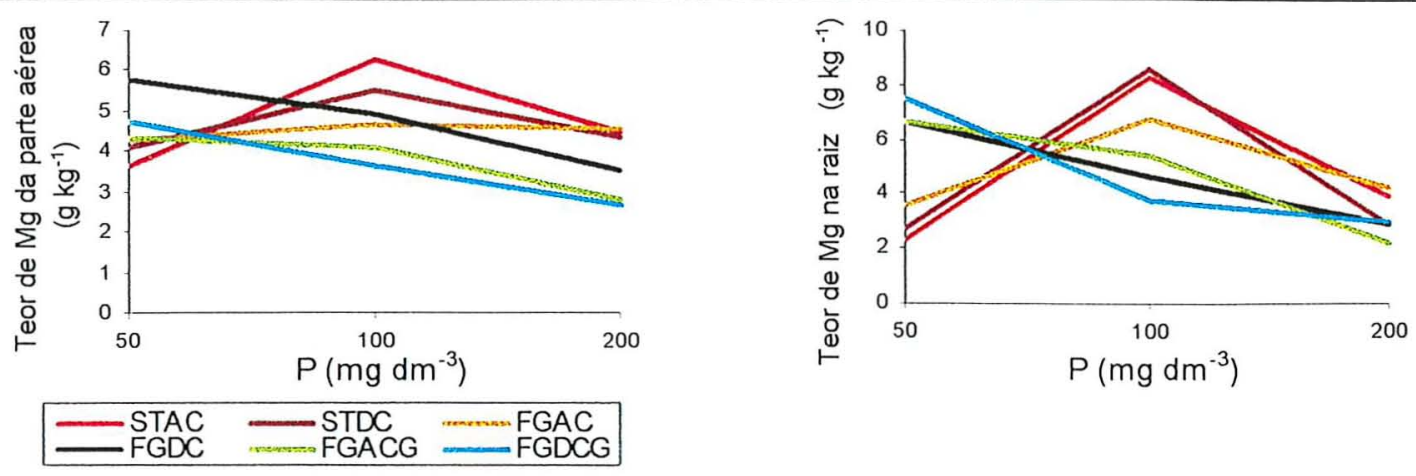

Figura 38 - Efeito das doses de fósforo $\left(\mathrm{mg} \mathrm{dm}^{-3}\right.$ ) sobre os teores de Mg na MS da parte aérea e raiz da alfafa, conforme os diferentes tratamentos, no terceiro plantio (média dos três cortes).

(STAC: super triplo antes da calagem; STDC: super triplo depois da calagem; FGAC: Fosfato de Gafsa antes da calagem; FGDC: Fosfato de Gafsa depois da calagem; FGACG: Fosfato de Gafsa antes da calagem mais gesso; FGDCG: Fosfato de Gafsa depois da calagem mais gesso).

Tabela 33 - Equações que expressam a relação entre a concentração de $\mathrm{Mg}\left(\mathrm{g} \mathrm{kg}^{-1}\right)$ na raiz das plantas em função das doses $\left(\mathrm{mg} \mathrm{dm}^{-3}\right)$ de fósforo obtida em decorrência diferentes tratamentos, no terceiro plantio.

\begin{tabular}{lll}
\hline Fontes de fósforo & Equação & $\mathrm{R}^{2}$ \\
\hline STAC & $\mathrm{Y}=-9,036+0,280 \mathrm{X}-0,0011 \mathrm{X}^{2}$ & $1,00^{*}$ \\
STDC & $\mathrm{Y}=-9,041+0,293 \mathrm{X}-0,0012 \mathrm{X}^{2}$ & $1,00^{*}$ \\
FGAC & $\mathrm{Y}=-2,497+0,151 \mathrm{X}-0,0006 \mathrm{X}^{2}$ & $1,00^{*}$ \\
FGDC & $\mathrm{Y}=7,52-0,024 \mathrm{X}$ & $0,94^{*}$ \\
FGACG & $\mathrm{Y}=8,222-0,030 \mathrm{X}$ & $0,99^{*}$ \\
FGDCG & $\mathrm{Y}=7,858-0,027 \mathrm{X}$ & $0,73^{*}$ \\
\hline
\end{tabular}

(STAC: super triplo antes da calagem; STDC: super triplo depois da calagem; FGAC: Fosfato de Gafsa antes da calagem; FGDC: Fosfato de Gafsa depois da calagem; FGACG: Fosfato de Gafsa antes da calagem mais gesso; FGDCG: Fosfato de Gafsa depois da calagem mais gesso)

* significativo a $5 \%$ de probabilidade.

As concentrações médias de $\mathrm{Mg}$ na parte aérea e na raiz da alfafa encontradas nesse trabalho (4,35 e 4,76 $\mathrm{g} \mathrm{kg}^{-1}$, respectivamente - Apêndices 26 e 27) foram menores que os encontrados por Martins et al. (1990) (3,6 e 3,5 $\mathrm{g} \mathrm{kg}^{-1}$, respectivamente), porém semelhantes ao obtido por Leach (1983) (4,60 $\left.\mathrm{g} \mathrm{kg}^{-1}\right)$ na parte aérea. Os teores de Mg da parte aérea da alfafa estão dentro da faixa considerada adequada (3 a $8 \mathrm{~g} \mathrm{~kg}^{-1}$ ), segundo Werner et al. (1996).

O teor de Mg na parte aérea foi maior quando se utilizou o ST em comparação ao FG nos níveis de 100 e $200 \mathrm{mg} \mathrm{P} \mathrm{dm}{ }^{-3}$, o mesmo ocorrendo para a raiz $(\mathrm{P}<0,05)$, no 
nível de $100 \mathrm{mg} \mathrm{P} \mathrm{dm}^{-3}$ (Figura 39 e contraste 1 da Tabela 34). A exceção foi o FGAC ao nível de $200 \mathrm{mg} \mathrm{P} \mathrm{dm}^{-3}$ onde o teor de $\mathrm{Mg}$ na MS da parte aérea da alfafa apresentase semelhante ao encintrado nos STAC e STDC (Figura 39).

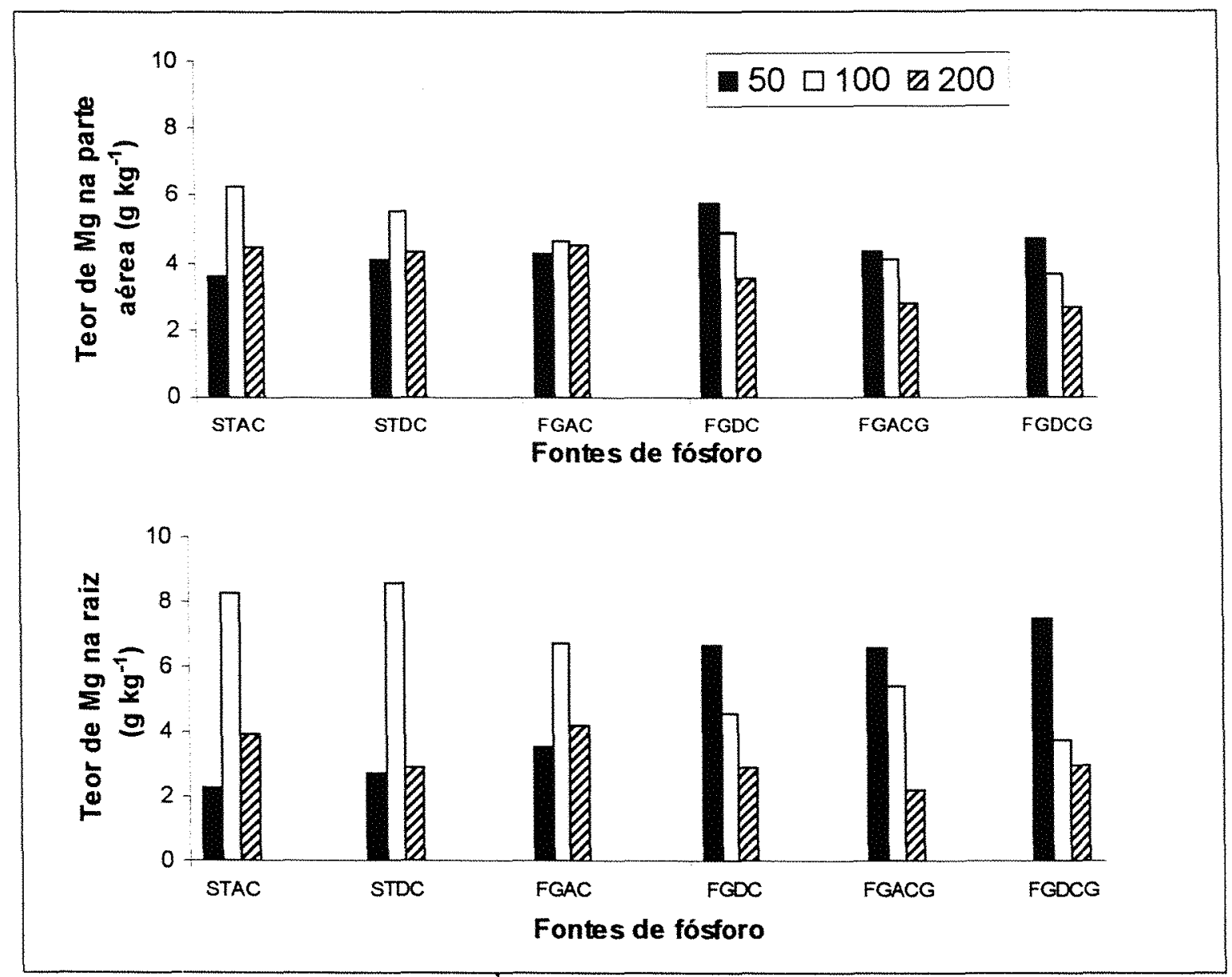

Figura 39 - Teores de $\mathrm{Mg}\left(\mathrm{g} \mathrm{kg}^{-1}\right)$ na MS da parte aérea e raiz obtidos em decorrência dos diferentes tratamentos e doses de fósforo $\left(\mathrm{mg} \mathrm{dm}^{-3}\right)$, no terceiro plantio (média dos três cortes).

(STAC: super triplo antes da calagem; STDC: super triplo depois da calagem; FGAC: Fosfato de Gafsa antes da calagem; FGDC: Fosfato de Gafsa depois da calagem; FGACG: Fosfato de Gafsa antes da calagem mais gesso; FGDCG: Fosfato de Gafsa depois da calagem mais gesso).

A adição de gesso ao $\mathrm{FG}$ resultou em menor teor de $\mathrm{Mg}$ na parte aérea da alfafa comparado ao uso do FG, nos niveis de 100 e $200 \mathrm{mg} \mathrm{P} \mathrm{dm}^{-3}$ (Figura 39), e na raiz $(\mathrm{P}<0,05)$, no nível de $200 \mathrm{mg} \mathrm{P} \mathrm{dm}^{-3}$ (Figura 39 e contraste 3 da Tabela 34). 
Tabela 34 - Contrastes ortogonais para comparação do teor de Mg na MS da raiz da alfafa entre os tratamentos com fonte de fósforo dentro de cada dose de $\mathrm{P}$, no terceiro plantio.

\begin{tabular}{lcccc} 
& & \multicolumn{3}{c}{ Valor do contraste } \\
\cline { 3 - 5 } & Contrastes & \multicolumn{3}{c}{ Niveis de P $\left(\mathrm{mg} \mathrm{dm}^{-3}\right)$} \\
\cline { 3 - 5 } & No & -30 & 100 & 200 \\
\hline 1 & $2 S T A C+2 S T D C-$ FGAC - FGDC - FGACG - FGDCG & $-3,34^{*}$ & $2,12^{*}$ & $0,51^{\text {ns }}$ \\
2 & STAC - STDC & $-0,16^{\text {ns }}$ & $-0,06^{\text {ns }}$ & $0,31^{\text {ns }}$ \\
3 & FGAC + FGDC - FGACG - FGDCG & $-0,64^{*}$ & $0,35^{\text {ns }}$ & $0,66^{*}$ \\
4 & FGAC - FGDC & $-0,62^{*}$ & $0,34^{\text {ns }}$ & $0,33^{\text {ns }}$ \\
5 & FGACG - FGDCG & $-0,13^{\text {ns }}$ & $0,37^{\text {ns }}$ & $-0,34^{\text {ns }}$ \\
\hline
\end{tabular}

(STAC: super triplo antes da calagem; STDC: super triplo depois da calagem: FGAC: Fosfato de Gafsa antes da calagem; FGDC: Fosfato de Gafsa depois da calagem; FGACG: Fosfato de Gafsa antes da calagem mais gesso; FGDCG: Fosfato de Gafsa depois da calagem mais gesso).

* significativo a $5 \%$ de probabilidade.

${ }^{\text {ns }}$ não significativo a $5 \%$ de probabilidade.

Os resultados apresentados devem-se ao efeito diluição descrito por Malavolta (1980), uma vez que o menores teores de Mg na MS apresentados nos tratamentos acima estavam relacionados com uma tendência à maior produção de MS da parte aérea (Figura 4), e superior $(\mathrm{P}<0,05)$ produção de raiz da alfafa (Figura 5 e contraste 3 da Tabela 10).

Os teores de $\mathrm{Mg}$ na parte aérea da alfafa diminuíram após o primeiro corte, apresentando teores similares para o segundo e terceiro cortes. A possível explicação para esse resultado está relacionado ao efeito diluição, uma vez que a produção de MS da parte aérea, em geral, aumentou após o primeiro corte (Tabela 7). 


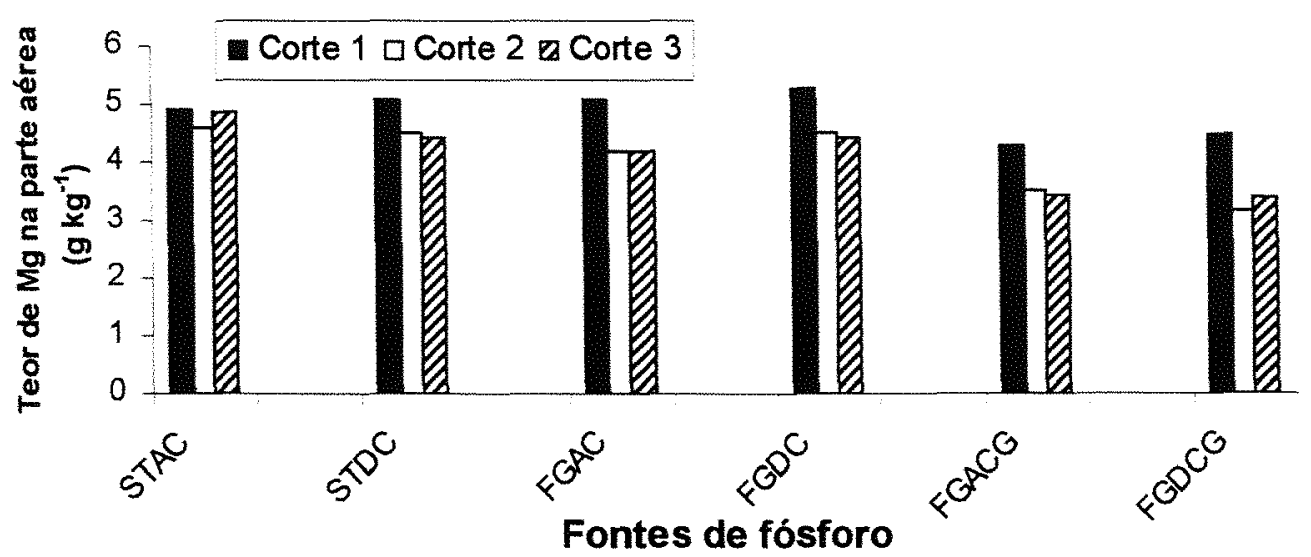

Figura 40 - Teores de $\mathrm{Mg}\left(\mathrm{g} \mathrm{kg}^{-1}\right)$ na $\mathrm{MS}$ da parte aérea da alfafa em respostas as épocas de corte, nos diferentes tratamentos, no terceiro plantio (médias dos três níveis de fósforo).

(STAC: super triplo antes da calagem; STDC: super triplo depois da calagem; FGAC: Fosfato de Gafsa antes da calagem; FGDC: Fosfato de Gafsa depois da calagem; FGACG: Fosfato de Gafsa antes da calagem mais gesso; FGDCG: Fosfato de Gafsa depois da calagem mais gesso). 


\section{CONCLUSÕES}

1 - O superfosfato triplo é uma boa fonte de fósforo para respostas iniciais de produção de MS de alfafa enquanto que o fosfato de Gafsa so é eficiente após 5 meses de incubação.

2 - A aplicação da calagem antes do superfosfato triplo aumenta a produção de alfafa por periodo curto. Após 5 meses de incubação não há diferença entre a aplicação da calagem antes ou após a adubação com ST, principalmente quando o fertilizante é misturado com o solo, em níveis de $\mathrm{pH}\left(\mathrm{CaCl}_{2}\right)$ ao redor de 5,5.

3 - O efeito do fosfato de Gafsa sobre a produção de matéria seca da alfafa não foi benéfico com o uso da calagem antes ou após a aplicação do fósforo nos níveis de $\mathrm{pH}$ ao redor de 5,5. A produção de raizes é aumentada com a fonte de fósforo na forma de fosfato de Gafsa.

4 - A eficiência do fosfato de Gafsa é aumentada devido à sua solubilização com o passar do tempo.

5-O gesso associado ao fosfato de Gafsa mostrou ser boa fonte de enxofre, melhorou o $\mathrm{pH}$ do solo e a produção do sistema radicular. A produção de matéria seca da alfafa tendeu a ser aumentada com o fornecimento de gesso.

6 - A alfafa não se estabelece em Latossolo Vermelho Amarelo Álico com níveis de fósforo de 3,0 $\mathrm{mg} \mathrm{P} \mathrm{dm}^{-3} \mathrm{em}$ resina. Pode-se inferir que níveis de fósforo acima de 30 $\mathrm{mg} \mathrm{P} \mathrm{dm}{ }^{-3}$ são suficientes, em vaso, para elevadas produções de alfafa. Níveis de 15 a 30 $\mathrm{mg} \mathrm{P} \mathrm{dm}$ proporcionam respostas para adubações fosfatadas.

7 - O fosfóro proporciona rebrota mais rápida da alfafa, bem como maior número de brotos na planta. 
8 - A adição de fósforo no solo aumenta a concentração desse elemento no solo e na alfafa.

9 - Produções muito baixas de MS podem aumentar o teor de $\mathrm{N}$ e Mg na alfafa devido ao efeito de concentração dos nutrientes.

10 - A adição de níveis crescentes de superfosfato triplo e de fosfato de Gafsa aumentam a concentração de Ca na MS da parte aérea da alfafa devido ao Ca presente nos fosfatos.

11 - Plantas de alfafa adubadas com fosfato de Gafsa apresentam maior teor de Ca na parte aérea do que plantas adubadas com superfosfato triplo emrazão do primeiro fosfato apresentar maior concentração de $\mathrm{Ca}$ em sua composição.

12 - Toxidez de Mn em alfafa é caracterizada pelo amarelecimento das bordas dos folíolos de folhas mais velhas desenvolvendo posteriormente arroxeamento, necrose e queda das folhas, bem como pontos necróticos também nas bordas das folhas. A disponibilidade de Mn no solo tende a ser maior quando o solo é autoclavado.

13 - Finalmente pode-se recomendar o uso da fonte solúvel de fósforo (200 $\mathrm{mg} \mathrm{P} \mathrm{dm}^{-3}$ ) para melhor estabelecimento inicial da alfafa aplicada depois da calagem. A essa adubação pode-se aplicar o fosfato de Gafsa misturado ao solo para garantir disponibilidade de fósforo acima de $30 \mathrm{mg} \mathrm{P} \mathrm{dm}^{-3}$. Para avaliar a economicidade do uso do fosfato de Gafsa deve-se considerar que o nível de $200 \mathrm{mg} \mathrm{P} \mathrm{dm}^{-3}$ o indice de eficiência agronômica desse fosfato esteve ao redor de $100 \%$ sem o uso do gesso e $125 \%$ com o uso do gesso. 


\section{REFERÊNCIAS BIBLIOGRÁFICAS}

ADAMS, F.; PEARSON, R.W. Crop response to lime in the southern United States and puerto Rico. In: PEARSON, R.W.; ADAMS, F. (Ed.) Soil acidity and liming. Madison: American Society of Agronomy, 1967. cap.4, p.161-206.

ANDREW, C.S. The effect of sulphur on the growth, sulphur and nitrogen concentrations, and critical sulphur concentrations of some tropical and temperate pasture legumes. Australian Journal of Agricultural Research, v.28, n.5, p.807-20, 1977.

ANDREW, C.S.; HEGARTY, M.P. Comparative responses to manganese excess of eight tropica; and four temperate pasture legume species. Australian Journal of Agricultural Research, v.20, p.687-696, 1969.

ANDREW, C.S.; JONES, R.K. The phosphorus nutrition of tropical legumes. In: ANDREWS, C.S.; KAMPRATH, E.J. (Ed.) Mineral nutrition of legumes in tropical and subtropical soils. Melbourne: CSIRO, 1978. p.295-312.

BELESKY, D.P.; FEDDERS, J.M. Residue height influences stand dynamies of alfalfa grown on a Shallow soil. Agronomy Journal, v.89, p.975-980, 1997.

BORKERT, C.M.; PAVANA, M.A.; LANTMANN, A.F. Considerações sobre o uso de gesso na agricultura. Informações Agronômicas, v.40, p. 1-3, 1987.

BRAGA, N.R.; MASCARENHAS, H.A.A.; BULISANI, E.A. et al. Eficiência agronômica de nove fosfatos em quatro cultivos consecutivos de soja. Revista Brasileira de Ciência do Solo, v.15, p.315-319, 1991. 
BRASIL, E.C.; MURAOKA, T. Comparação de extratores de fósforo em solos da Amazônia oriental. In: CONGRESSO BRASILEIRO DE CIÊNCIA DO SOLO, 25 ., Viçosa, 1995. Resumos. Viçosa: EMBRAPA, 1995. p.980-982.

CHRISTIAN, J.R. Effects of environment on the growth of alfalfa. Advances in Agronomy, v.29, p.183-227, 1977.

CHU, C.R.; MOSCHLER, W.W.; THOMAS, G.W. Rock phosphate transformations in acid soils. Soil Science Society of America Proceedings, v.26, p.476-478, 1962.

COLLINS, M.; LANG, D.J.; KELLING, K.A. Effects of phosphorus, potassium, and sulfur on alfalfa nitrogen-fixation under field conditions. Agronomy Journal, v.78, p.959-963, 1986.

COLOZZA, M.T.; SAVASTONO, S.A.L.; WERNER, J.C. et al. Efeitos da aplicação de gesso e calcário dolomítico em dois solos ácidos cultivados com soja-perene. Boletim da Indústria Animal, v.40, n. 1, p.75 -96, 1983.

CULOT, J.P.H. Nutrición mineral y fertilizatión en el ambiente de la región Pampeana. In: ARAGÓN, J.R.; AVENDAÑO, R.E.; BACON, O.G. et al. Investigación, tecnologia y producción de alfalfa. Buenos Aires: INTA, 1986. cap.4, p.81-115

DE MARCO, D.G.; LI, C.B.; RANDALL, P.J. Manganese toxicity in Trifolium balansae, T. resupinatum, T. subterraneum, Medicago murex, M. polymorpha, $M$. sativa, Lotus pedunculatus, and Ornithopus compressus: relative tolerance and critical toxicity concentrations. Australian Journal of Experimental Agriculture, v.35, p.367-374, 1995.

DOERGE, T.A.;; BOTTOMLEY, P.J.; GARDNER, E.H. Molybdenum limitations to alfalfa growth and nitrogen content on a moderately acid, high-phosphorus soil. Agronomy Journal, v.77, p.895-901, 1985.

DREVON, J.J; HARTWIG, U.A. Phosphorus deficiency increases the argon induced decline of nodule nitrogenase activity in soybean and alfalfa. Planta, v.201, p.463$469,1997$.

FAGERIA, N.K.; BALIGAR, V.C. Response of legumes and cereals to phosphorus in solution culture. Journal of Plant Nutrition, v.12, n.9, p.1005-1019, 1989. 
FICK, G. W.; HOLT, D. A.; LUGG, D. G. Environmental physiology and crop growth. In: HANSON, A.A. Alfalfa and alfalfa improvement. Madison: ASA, CSSA, SSSA, 1988. cap.5, p.163-194.

FRANCO, A.A.; DOBEREINER, J. Fixação biológica de nitrogênio. Brasilia: ABEAS, 1988. 54p.

GALLO, J.R.; HIROCE, R.; BATAGLIA, O.C. et al. Composição química inorgânica de forrageiras do Estado de São Paulo. Boletim da Indústria Animal, n.31, v.1, p.115-137, 1974.

GOEDERT, W.J.; LOBATO, E. Avaliação agronômica de fosfatos em solo de cerrado. Revista Brasileira de Ciência do Solo, v.8, p.97-102, 1984.

GOEDERT, W.J.; SOUSA, D.M.G. Uso eficiênte de fertilizantes fosfatados. In: SIMPÓSIO SOBRE FERTILIZANTES NA AGRICULTURA BRASILEIRA, Brasília, 1984. Anais. Brasília: EMBRAPA, 1984. p.206-255. (EMBRAPA DEP. Documentos, 14).

GROVE, JR.A.R.; CARLSON, G.E. Morphology and anatomy. In: HANSON, C.H. (Ed.) Alfalfa science and technology. Madison: ASA, 1972. cap.5, p. 103-122.

HANAFI, M.M.; SYERS, J.K. Agronomic and economic effectiveness of two phosphate rock materials in acid Malaysian soil. Tropical Agriculture, v.71, n.4, p.254-259, 1994.

HANAFI, M.M.; SYERS, J.K.; BOLAN, N.S. Effect of lime on the dissolution of two phosphate rocks in acid soil. Journal of the Science of Food and Agriculture, v.60, p.155-164, 1992a.

HANAFI, M.M.; SYERS, J.K.; BOLAN, N.S. Leaching effect on the dissolution of phosphate rocks in acid soils. Soil Science Society of America Journal, v.56, p.1325-1330, 1992b.

HEICHEL, G.H.; DELANEY, R.H.; CRALLE, H.T. Carbon assimilation, partitioning and utilization. In: HANSON, C.H. (Ed.) Alfalfa and alfalfa improvement. Madison: ASA, CSSA, SSSA, 1988. cap.6, p.195-222 
HEINRICHS, D.H; TORELSEN, J.E.; WARDER, F.G. Variations in chemical constituents and morphological characters within and between alfalfa populations. Canadian Journal of Plant Science, v.49, p.293-305, 1969.

HELYAR, K.R. Effects of aluminium and manganese toxicities on legume growth. In: ANDREWS, A.S.; KAMPRATH, E.J. Mineral nutrition of legumes in tropical and subtropical soils. Melbourne: CSIRO, 1978. p.207-231.

HELYAR, K.R.; ANDERSON, A.J. Responses of five pasture species to phosphorus, lime, and nitrogen on na infertile acid soil with a high phosphate sorption capacity. Australian Journal of Agricultural Research, v.21, p.677-692, 1970.

HILL, R.R.; LANYON, L.E. Phosphorus fertilizer response in experimental alfalfas selected for different phosphorus concentrations. Crop Science, v.23, p.973-976, 1983.

HONDA, C.S.; HONDA, A.M. Cultura da alfafa. Cambara: IARA, 1990. 245p.

HOWIESON, J.G.; EWING, M.A . Anual species of medicago differ greatly in their ability to nodule on acid soil. Australian Journal of Agricultural Research, v.40, p.843-850, 1989.

JAMES, D.W.; HURST, C.J.; TINDALL, T.A. Alfalfa cultivar response to phosphorus and potassium deficiency: elemental composition of the herbage. Journal of Plant Nutrition, v.18, n.11, p.2447-2464, 1995.

JONES, M.B.; QUAGLIATO, J.; FREITAS, L.M.M. Resposta de alfafa e algumas leguminosas tropicais a aplicações de nutrinetes minerais, em três solos de campo cerrado. Pesquisa Agropecuária Brasileira, v.5, p.209-214, 1970.

KABATA-PENDIAS, A.; PENDIAS, H. Trace elements in soils and plants. 3.ed. Boca Roton: CRC Press, 1985. 315p.

KELLING, K.A. Nutrient deficiencies and toxicities In: STUTEVILLE, D.L.; ERWIN, D.C. Compendium of alfalfa diseases. 2.ed. St. Paul: APS Press, 1990. cap.67, p.67-70.

KOCHHANN, R.; ANGHINONI, I.; MIELNICZUK, J. Adubação fosfatada do Rio Grande do Sul e Santa Catarina. In: OLIVEIRA, A.J.; LOURENÇO, S.; GOEDERT, 
W.J. Adubação fosfatada no Brasil. Planaltina: Embrapa,CPAC, 1982. p.29-60. (Embrapa DID. Documentos, 21).

KORNELIUS, E. Influência da calagem e da adubação fosfatada e potássica na produção de alfafa (Medicago sativa $\mathrm{L}$.) em seis solos do Rio Grande do Sul. Porto Alegre, 1972. p.126. Dissertação (M.S.) - Universidade Federal do Rio Grande do Sul.

LANYON, L.E.; GRIFFITH, W.K. Nutrition and Fertilizer Use. In: HANSON, A.A. Alfalfa and alfalfa improvement. Madison: ASA, CSSA, SSSA, 1988. cap.10, p.333-364.

LEACH, G.J. The growth of lucerne plant after cutting: the effects of cutting at different stages of maturity and at different intensities. Australian Journal of Agricultural Research, v.19, p.517-530, 1968.

LEACH, G.J. Shoot Numbers, shoot size, and yield of regrowth in three lucerne cultivars. Australian Journal of Agricultural Research, v.20, p.425-434, 1969.

LEACH, G.J. Shoot growth on lucerne plants cut at different heights. Australian Journal of Agricultural Research, v.21, p.583-691, 1970.

LEACH, G.J. The relation between lucerne shoot growth and temperature. Australian Journal of Agricultural Research, v.22, p.49-59, 1971.

LEACH, G.J. Influence of rest interval, grazing durantion and mowing on the growth, mineral content and utilization of a lucerne pasture in a subtropical environment. Journal of Agricultural Science, v.101, p.169-183, 1983.

LEE, C.; SMITH, D. Influence of soil nitrogen and potassium levels on growth and composition of lucerne grown to first flower in four temperature regimes. Journal of Agricultural Science, v.23, p.1169-1181, 1972.

LÉON, L.A.; FENSTER, W.E.; HAMMOND, L.L. Agronomic potencial of eleven phosphate rocks from Brazil, Colombia, Peru, and Venezuela. Soil Science Society of America Journal, v. 50, p.798-802, 1986.

LOBATO, E.; KORNELIUS, E.; SANZONOWICZ, C. Calagem e adubação de pastagens. Piracicaba: Potafós, 1985. 476p. 
LOMBIN, C.L.; BATES, T.E. Comparative responses of peanuts, alfalfa, and soybeans to varying rates of boron and manganese on two calcareous ontario soils. Canadian Journal of Soil Science, v. 62, n.1, 1982.

LOPES, A.S.; GUILHERME, L.R.G. Uso eficiente de fertilizantes. In: SIMPÓSIO AVANÇADO DE SOLOS E NUTRIÇÃo DE PlANTAS, 2., Piracicaba, 1989. Anais. Piracicaba: FEALQ, 1989. p.58.

MACEDO, W. Efeito de fontes e níveis de fósforo e calcário na adubação de forrageiras em solos do Rio Grande do Sul. Pesquisa Agropecuária Brasileira, v.20, n.6, p.643-657, 1985.

MACEDO, W.; GONÇALVES J.O.N.; GIRARDI-DEIRO, A.M. Melhoramento de pastagem natural com fosfatos e introdução de leguminosas em solo da fronteira oeste do Rio Grande do Sul. Revista Brasileira de Ciência do Solo, v.9, p.231-235, 1985.

MAHLER, R.L. Influence of $\mathrm{pH}$ on yield and $\mathrm{N}$ and $\mathrm{P}$ nutrition of alfalfa grown on andic Mission Silt Loam. Agronomy Journal, v.75, p.731-735, 1983.

MAILHI, S.S.; ARSHAD, M.A.; GLL, K.S.; et al. Response of alfalfa hay yield to phosphorus fertilization in two soils in central Alberta. Communications in Soil Science and Plant Analysis, v.23, n.7\&8, p.717-724, 1992.

MAlAVOlTA, E. ABC da adubação. 4.ed. São Paulo: Agronômica Ceres, 1979. $256 \mathrm{p}$.

MALAVOLTA, E. Elementos de nutrição mineral de plantas. São Paulo: Ceres, 1980. $251 \mathrm{p}$.

MALAVOLTA, E; ROMERO, J.P.; LIEM, T.H. et al. Gesso agrícola. São Paulo: ULTRAFERTIL, 1979. 32p.

MARKUS, D.K.; BATTLE, W.R. Soil and plant responses to long term fertilization of alfalfa (Medicago sativa L.). Agronomy Journal, v.57, p.613-616, 1965.

MARSCHNER, $H$. Mechanisms of manganese aquisition by roots from soils In: GRAHAM, R.D.; HANNAM, R.J.; UREN, N.C. Manganese in soils and plants. Dordrecht: Kluwer Academic, 1988. cap. 13, p.191-201. 
MARTINS, C.E.; CÓSER, A.C.; OLIVEIRA, F.T.T.; SARAIVA, O.F. Avaliação dos nutrientes limitantes ao crescimento de alfafa em solo aluvial. Revista da Sociedade Brasileira de Zootecnia, v. 19, n.4, p.333-339, 1990.

MASCARENHAS, H.A.A.; MIRANDA, M.A.C.; TANAKA, R.T. et al. Comportamento de cultivares precoces de soja em solução nutritiva contendo diferentes níveis de manganês. Pesquisa Agropecuária Brasileira, v.25, n.4, p.609$615,1990$.

MAYS, D.A.; WILKINSON, S.R.; COLE, C.V. Phosphorus nutrition of forage. In: KHASAWNEH, F.E.; SAMPLE, E.C.; KAMPRATH, E.J. The role of phosphorus in agriculture. Madison: ASA, CSSA, SSSA, 1980. cap.28, p.805-846.

MONTEIRO, A.L.G.; MORAES, A. Fisiologia e morfologia de plantas forrageiras. In: MONTEIRO, A.L.G.; MORAES, A.; CORRÊA, E.A.S. et al. Forragicultura no Paraná. Londrina: CPAF, 1996. cap.8, p.75-92.

MONTEIRO, A.L.G. Estudos morfológicos e fisiológicos da rebrota de cultivares não dormentes de alfafa (CUF 101 e Crioula) a partir do manejo de área foliar de perfilhos basilares. Piracicaba, 1989. 139p. Dissertação (Mestrado) - Escola Superior de Agricultura "Luiz de Queiroz", Universidade de São Paulo.

MOREIRA, A. Efeito de fontes e doses de fósforo na alfafa (Medicago sativa L.) e centrosema (Centrosema pubens Benth.) e avaliação de extratores. Piracicaba, 1997. 107p. Dissertação (Mestrado) - Escola Superior de Agricultura "Luiz de Queiroz", Universidade de São Paulo.

MUGWIRA, L.M.; HAQUE, I. Screening forage and browse legumes germplasm to nutrient stress I: tolerance of Medicago sativa $\mathrm{L}$. To aluminum and low phosphorus in soils and nutrient solutions. Journal of Plant Nutrition, v.16, p.17-35, 1993.

MUNNS, D.N. Soil acidity and nodulation. In: ANDREWS, C.S.; KAMPRATH, E.J. (Ed.) Mineral nutrition of legumes in tropical and subtropical soils. Melbourne: CSIRO, 1978. p.247-263.

NELSON, C.J.; SMITH, D. Growth of birsfoot trefoil and alfalfa. II. Morphological development and dry matter distribution. Crop Science, v. 8, n.1, p.21-24, 1968 
NIE, Z.N.; MACKAY, A.D.; BARKER, D.J. et al. Changes in plant population density, composition and sward structure of a hill pasture during a pastoral fallow. Grass and Forage Science, v.52, p.190-198, 1997.

NOVAIS, R.F.; NEVES, J.C.L.; BARRO, N.F. Curso de fertilidade do solo: módulo 7 - fósforo. Brasília: ABEAS, 1990. 132p.

OLIVEIRA, E.L.; MUZILLI, O.; TORNERO, M.T.T. Avaliação da eficiência agronômica de fosfatos naturais. Revista Brasileira de Ciência do Solo, v.8, p.63$67,1984$.

OLIVEIRA, P.R.D. Avaliação da produção e da qualidade de cultivares da alfafa (Medicago sativa L.). Piracicaba, 1986. 75p. Dissertação (Mestrado) - Escola de Agricultura "Luiz de Queiroz", Universidade de São Paulo.

OTSUBO, A.A. Calagem e boro em um Latossolo Vermelho Escuro cultivado com alfafa (Medicago sativa L.). Jaboticabal, 1993. 107p. Dissertação (M.S.) Faculdade de Ciências Agrárias e Veterinárias, Universidade Estadual Paulista "Julio de Mesquita Filho".

PETIT, H.V.; PESANT, A.R.; BARNETT, G.M. et al. Quality and morphological characteristics os alfalfa as affected by soil moisture, $\mathrm{pH}$ and phosphorus fertilization. Canadian Journal of Plant Science, v.72, p.147-162, 1992.

PINHEIRO, S.L.G.; LANZER, E.A.; NUERNBERG, N. Recomendações econômicas para a calagem e adubação fosfatada da alfafa no planalto catarinense. Pesquisa Agropecuária Brasileira, v.28, n.10, p.1109-1119, 1993.

RAIJ, B. van Gesso agrícola na melhoria do ambiente radicular no subsolo. São Paulo: ANDA, 1988. 88p.

RAIJ, B. van Fertilidade do solo e adubação. São Paulo: Ceres; Piracicaba: Potafos, 1991. 343p.

RAIJ, B. van; ROSAND, P.C.; LOBATO, E. Adubação fosfatada no Brasil apreciação geral, conclusões e recomendações. In: OLIVEIRA, A.J; LOURENÇO, S.; GOEDERT, W.J. Adubação fosfatada no Brasil. Planaltina: Embrapa,CPAC, 1982. p.9-28. (Embrapa DID. Documentos, 21). 
RAIJ, B. van; QUAGGIO, J.A.; SILVA, N.M. Extraction of phosphorus, potassium, calcium and magnesium from soil by ion-exchange resin procedure. Communications in Soil Science and Plant Analysis, v. 17, n.5, p.547-66, 1986.

RAMOS, M.G. Avaliação da eficiência de oito fosfatos para as culturas de trigo e soja em um Latossolo Vermelho-Escuro argiloso. Revista Brasileira de Ciência do Solo, v.6, p.38-42, 1982.

RANDO, E.M. Desenvolvimento da alfafa (Medicago sativa L.) em diferentes níveis de pH, potássio e enxofre no solo. Piracicaba, 1992. 220p. Tese (Doutorado) - Escola de Agricultura "Luiz de Queiroz", Universidade de São Paulo.

RECHCIGL, J.E.; EDMISTEN, K.L.; WOLF, D.D.; RENEAU, R.B. Response of alfalfa grown on acid soil to different chemical amendments. Agronomy Journal, v.80, p.515-518, 1988.

RHYKERD, C.L.; OVERDAHL, C.J. Nutrition and fertilizer use. In: HANSON, A.A. Alfafa science and technology. Madison: ASA, 1972. cap.20, 437-465p.

RITCHEY, K.D.; SOUZA, D.M.G.; LOBATO, E. et al. Calcium leaching to increase rooting depth in a Brazilian savannah Oxisol. Agronomy Journal, v.72, p.40-44, 1980.

ROBISON, J.S.; SYERS, J.K. A critical evaluation of the factors influencing the dissolution of Gafsa phosphate rock. Journal of Soil Science, v.41, p.597-605, 1990.

ROBSON, A.D.; LONERAGAN, J.F. Sensitivity of annual Medicago species to manganese toxicity as affected by calcium and $\mathrm{pH}$. Australian Journal of Agricultural Research, v.21, p.223-232, 1970.

ROMERO, N. A.; COMERÓN, E.A.; USTARROZ, E. Crecimiento y utilización de la alfalfa. In: HJJANO, E.H.; NAVARRO, A. La alfalfa en la Argentina. San Juan: Editar, 1995. cap.8, p.149-172.

ROMINGER, R.S.; SMITH, D.; PETERSON, L.A. Changes in elemental concentrations in alfalfa herbage at two soil fertility levels with advance in maturity. Communications in Soil and Plant Analysis, v.6, n.2, p.163-180, 1975. 
ROSAND, P.C.; SANTANA, M.B. Influência do tempo de contato e valor fertilizante de fontes fosfatadas em solos do sul da Bahia. Revista Theobroma, v.16, n.1, p.1$15,1986$.

ROSAND, P.C.; WILD, A. Direct use of low grade phosphate rock from Brazil as fertilizer. I. Effect of reaction time in soil. Plant and Soil, v.65, p.351-362, 1982.

SÁ, J.C.M.; KEPLIN, L. A.S. Alfafa: estratégia de correção do solo, adubação de manutenção, estabelecimento e manejo da cultura. Jornal da Área de Assistência Técnica da Batavo, $n^{\circ} 84,1991$

SALE, P.W.G.; COUPER, P.L.; CACHIA, P.L.; LARKIN, P.J. Tolerance to manganese toxicity among of lucerne (Medicago sativa L.). Plant and Soil, v.146, p.31-38, 1992.

SANCHEZ, P.A.; SALINAS, J.G. Low-input technology for managing oxisols and ultisols in Tropical America. Advances in Agronomy, v.34, p.279-406, 1981.

SANDERSON, M.A. Maturity and quality of alfalfa as affected by phosphorus fertility. Communications in Soil Science and Plant Analisy, v.24, p.2715-2724, 1993.

SANDERSON, M.A.; JONES, R.M. Stand dynamics and yield components of alfalfa as affected by phosphorus fertility. Agronomy Journal, v.85, p.241-246, 1993.

SANZONOWICZ, C.; LOBATO, E.; GOEDERT, W. Efeito residual da calagem e de fontes de fósforo numa pastagem estabelecida em solo de cerrado. Pesquisa Agropecuária Brasileira, v.22, n.3, p.233-243, 1987.

SARRIES, G.A.; ALVES, M.C.; OLIVEIRA, J.C.V. Sanest: Série didática GIAGRI, ${ }^{\circ}$ 6. Piracicaba: CIAGRI, 1993. 57p.

SARRUGE, J.R.; HAAG. H.P. Análises químicas em plantas. Piracicaba: ESALQ, 1974. $56 \mathrm{p}$.

SILVA, S.C.; PEDREIRA, C.G.S. Princípios de ecologia aplicados ao manejo da pastagem. In: SIMPÓSIO SOBRE ECOSSISTEMA DE PASTAGENS, 3., Jaboticabal, 1997. Anais. Jaboticabal: FUNEP, 1997. p.1-62. 
SIMAN, A.; CRADOCK, F.W., HUNDSON, A.W. The development of manganese toxicity in pasture legumes under extreme climatic conditions. Plant and Soil, v.41, p.129-140, 1974.

SINGH, D.K.; SALE, P.W.G. Defoliation frequency and the response by white clover to increasing phosphorus supply 1. Leaf dry matter yield and plant morphology responses. Australian Journal of Agricultural Research, v.48, p.111-118, 1997.

SINGH, D.K.; SALE, P.W.G. Phosphorus supply and the growth of frequently defoliated white clover (Trifolium repens L.) in dry soil. Plant and Soil, v.205, p.155-162, 1998.

SINGH, Y; WINCH, J.E. Morphological development of two cultivars under various harvesting schedules. Canadian Journal of Plant Science, v.54, p.79-87, 1974.

SKRZYNIARZ, $H$. The effect of cutting height on the aftermath regrowth of lucerne and on the morphological structure of the root crown. Herbage Abstracs, v.54, n.6, p.187, 1984.

SMITH, G.S.; EDMEADES, D.C.; UPSDELL, M. Manganese status of New Zealand pastures 1. Toxicity in ryegrass, white clover, and lucerne. New Zealand Journal of Agricultural Research, v.26, p.215-221, 1983.

SMYTH, T.J.; SANCHEZ, P.A. Effects of lime, and phosphorus apllications to an oxisol on phosphorus sorption and ion retention. Soil Science Society of America Journal, v.44, p.500-505, 1980.

SMYTH, T.J.; SANCHEZ, P.A. Phosphate rock dissolution and availability in cerrado soil as affected by phosphorus sorption capacity. Soil Science Society of America Journal, v.46, p.339-345, 1982.

SOON, Y.K. Interactions between calcium amendments and phosphate on the response of alfafa and barley growing on acid soils. Communications in Soil Science and Plant Analysis, v.19, n.7-12, p.1343-1353, 1988.

SOUSA, D.M.G.; RITCHEY, K.D. Uso de gesso no solo de cerrado. In: SEMINÁRIO SOBRE O USO DE FOSFOGESSO NA AGRICULTURA, 1., Brasília, 1985. Anais. Brasilia: EMBRAPA, 1985. p.119-144. 
SUMNER, M.E.; SHAHANDEH, H.; BOUTON, J.; HAMMEL, J. Amelioration of an acid soil profile through deep liming and application of gypsum. Soil Science Society of America Journal, v.50, p. 1254-1258, 1986.

SUZUKI, M. Effects of stand age on agronomic, morphological and chemical characteristics of alfalfa. Canadian Journal of Plant, v.71, p.445-452, 1991.

TEUBER, L.R.; BRICK, M.A. Morphology and anatomy. In: HANSON, A.A.; BARNES, D.K.; HILL, R.R. Alfalfa and alfalfa improvement. Madison: ASA, CSSA, SSSA, 1988. cap.4, p. 125-162.

VANCE, C.P.; HEICHEL, G.H.; PHILLIPS, D.A. Nodulation and symbiotic dinitrogen fixation. In: HANSON, A.A.; BARNES, D.K.; HILL, R.R. Alfalfa and alfalfa improvement. Madison: ASA, CSSA, SSSA, 1988. cap.7, p.229-254.

VOLENEC, R.Li.J.J.; JOERN, B.C.; CUNNINGHAM, S.M. Potassium and nitrogen effects on carboydrate and protein metabolism in alfalfa roots. Journal of Plant Nutrition, v.20, n.4\&5, p.511-529, 1997.

VOLENEC, R.Li.J.J.; JOERN, B.C.; CUNNINGHAM, S.M. Effects of phosphorus nutrition on carboydrate and protein metabolism in alfalfa roots. Journal of Plant Nutrition, v.21, n.3, p.459-474, 1998.

WALWORTH, J.L.; SUMNER, M.E. Alfalfa response to lime, phosphorus, potassium, magnesium, and molybdenum on acid ultisols. Fertilizer Research, v.24, p.167-172, 1990.

WERNER, J.C.; PAULINO, V.T.; CANTARELLA, H.; ANDRADE, N.O.; QUAGGIO, J.A. Forrageiras. In: RAIJ, B. van; SILVA, N.M; BATAGLIA, O.C. Recomendações de abubações e calagem. Campinas: IAC, 1996. p.263-273. (IAC. Boletim 100).

WILSON, M.A.; ELLIS, B.G. Influence of calcium solution activity and surface area on the solubility of selected rock phosphates. Soil Science, v. 138, n.5, p.354-359, 1984.

YUPANQUI, F. F. R. Nutrição fosfatada e fotossíntese no sistema simbiótico Medicago sativa - Rhizobium meliloti em solos com diferentes disponibilidades de fósforo. Viçosa, 1997. 124p. Tese (Doutorado) - Universidade Federal de Viçosa. 


\section{APÊNDICE 1}

Produção de matéria seca da parte aérea (g MS/vaso) de plantas de alfafa obtidas durante o cultivo referente a terceira semeadura.

\begin{tabular}{|c|c|c|c|c|c|c|}
\hline \multicolumn{7}{|c|}{ Fontes de fósforo } \\
\hline $\begin{array}{l}\text { Nivel de P } \\
\left(\mathrm{mg} \mathrm{dm}^{-3}\right)\end{array}$ & STAC & STDC & FGAC & FGDC & FGACG & FGDCG \\
\hline \multicolumn{7}{|c|}{ CORTE 1} \\
\hline 50 & 0,08 & 0,08 & 0,13 & 0,15 & 0,17 & 0,89 \\
\hline 100 & 0,27 & 1,69 & 2,77 & 4,14 & 3,38 & 8,15 \\
\hline 200 & 11,93 & 14,47 & 9,80 & 9,09 & 17,47 & 16,38 \\
\hline \multicolumn{7}{|c|}{ CORTE 2} \\
\hline 50 & 0,06 & 0,05 & 0,10 & 0,93 & 0,40 & 3,25 \\
\hline 100 & 0,86 & 3,36 & 7,76 & 9,53 & 9,02 & 11,03 \\
\hline 200 & 12,63 & 12,53 & 12,00 & 12,91 & 14,95 & 16,47 \\
\hline \multicolumn{7}{|c|}{ CORTE 3} \\
\hline 50 & 0,03 & 0,02 & 0,08 & 1,90 & 0,91 & 3,57 \\
\hline 100 & 1,35 & 3,79 & 7,29 & 8,58 & 8,11 & 8,00 \\
\hline 200 & 8,42 & 8,75 & 12,32 & 11,21 & 10,46 & 11,71 \\
\hline
\end{tabular}

(STAC: super triplo antes da calagem; STDC: super triplo depois da calagem; FGAC: Fosfato de Gafsa antes da calagem; FGDC: Fosfato de Gafsa depois da calagem; FGACG: Fosfato de Gafsa antes da calagem mais gesso; FGDCG: Fosfato de Gafsa depois da calagem mais gesso).

$\mathrm{CV}$ (parcelas) $=13,3 \%$.

$\mathrm{CV}$ (subparcelas) $=14,7 \%$.

\section{APÊNDICE 2}

Quadro da análise de variância dos efeitos das fontes e niveis de fósforo sobre a produção de MS da parte aérea da alfafa no primeiro plantio.

\begin{tabular}{lccc}
\hline CAUSAS DA VARIAÇÃO & GL & Q.M. & F \\
\hline Blocos & 2 & 0,65 & \\
Fontes & 5 & 15,72 & $73,24^{*}$ \\
Níveis & 2 & 22,08 & $102,85^{*}$ \\
Fontes x Níveis & 10 & 1,83 & $8,53^{*}$ \\
Residuo & 34 & 0,21 & \\
\hline Total & 53 & & \\
\hline
\end{tabular}

$\mathrm{CV}=24,6 \%$.

*significativo a $5 \%$ de probabilidade. 


\section{APÊNDICE 3}

Quadro da análise de variância dos efeitos das fontes e níveis de fósforo, nos três cortes do terceiro plantio, sobre a produção de MS da parte aérea da alfafa (transformação dos dados - raiz $(X+0))$.

\begin{tabular}{lccc}
\hline CAUSAS DA VARIAÇÃO & GL & Q.M. & F \\
\hline Blocos & 2 & 0,18 & \\
Fontes & 5 & 6,15 & $27,44^{*}$ \\
Níveis & 2 & 112,40 & $501,68^{*}$ \\
Fontes x Níveis & 10 & 1,32 & $5,90^{*}$ \\
Resíduo (A) & 34 & 0,22 & \\
\hline Parcelas & 53 & & \\
Cortes & 2 & 2,02 & $21,29^{*}$ \\
Cortes x Fontes & 10 & 0,23 & 2,40 \\
Cortes x Niveis & 4 & 1,58 & $16,64^{*}$ \\
Cortes x Fontes x Niveis & 20 & 0,23 & $2,41^{*}$ \\
Resíduo (B) & 72 & 0,09 & \\
\hline TOTAL & 161 & & \\
CV (parcelas) $=13,0 \%$ & & & \\
CV (subparcelas) $=14,7 \%$. & & & \\
*significativo a $5 \%$ de probabilidade. & & & \\
& &
\end{tabular}

\section{APÊNDICE 4}

Quadro da análise de variância dos efeitos das fontes e níveis de fósforo, no terceiro plantio, sobre a produção de MS da raiz da alfafa (transformação dos dados - raiz ( $\mathrm{X}+$ 0)).

\begin{tabular}{lccc}
\hline CAUSAS DA VARIAÇÃO & GL & Q.M. & F \\
\hline Blocos & 2 & 0,96 & \\
Fontes & 5 & 9,42 & $18,46^{*}$ \\
Níveis & 2 & 110,40 & $216,40^{*}$ \\
Fontes $x$ Níveis & 10 & 1,89 & $3,70^{*}$ \\
Resíduo & 34 & 0,51 & \\
\hline Total & 53 & & \\
\hline CV $=16,9 \%$ & &
\end{tabular}
$\mathrm{CV}=16,9 \%$.

*significativo a $5 \%$ de probabilidade. 


\section{APÊNDICE 5}

$\mathrm{pH}\left(\mathrm{CaCl}_{2}\right)$ no solo antes do plantio e depois da última colheita de alfafa, conforme as fontes e doses de fósforo.

\begin{tabular}{llcc}
\hline & & Fontes de fósforo & \\
\hline Niveis de $\mathbf{P}\left(\mathbf{m g ~ d m}^{-3}\right)$ & ST & $\mathbf{F G}$ & $\mathbf{F G} \mathbf{G}$ \\
\hline & Antes do terceiro plantio & \\
\hline 50 & 5,50 & 5,58 & 5,65 \\
100 & 5,62 & 5,67 & 5,70 \\
200 & 5,55 & 5,75 & 5,88 \\
\hline 50 & Depois do último corte & 5,90 \\
100 & 5,00 & 5,33 & 6,22 \\
200 & 5,53 & 6,05 & 6,05 \\
\hline
\end{tabular}

(ST: média do super triplo aplicados antes e após a calagem; FG: média do Fosfato de Gafsa antes e após a calagem; FG+G: média do Fosfato de Gafsa mais gesso antes e após a calagem).

$\mathrm{CV}$ (parcelas) $=1,5 \%$.

$\mathrm{CV}$ (subparcelas) $=2,6 \%$.

\section{APÊNDICE 6}

Quadro da análise de variância dos efeitos das fontes e níveis de fósforo, nos dois períodos de amostragens, sobre o teor de $\mathrm{pH}$ no solo $\left(\mathrm{CaCl}_{2}\right)$.

\begin{tabular}{lccc}
\hline CAUSAS DA VARIAÇÃO & GL & Q.M. & F \\
\hline Blocos & 2 & 0,004 & \\
Fontes & 2 & 1,08 & $72,16^{*}$ \\
Níveis & 2 & 0,47 & $31,81^{*}$ \\
Fontes x Níveis & 4 & 0,03 & 2,30 \\
Resíduo (A) & 16 & 0,02 & \\
\hline Parcelas & 26 & & \\
Períodos & 1 & 0,03 & 1,42 \\
Períodos x Fontes & 2 & 0,40 & $18,35^{*}$ \\
Períodos x Níveis & 2 & 0,22 & $9,87^{*}$ \\
Períodos x Fontes x Níveis & 4 & 0,03 & 1,33 \\
Resíduo (B) & 18 & 0,02 & \\
\hline TOTAL & 53 & & \\
\hline
\end{tabular}

$\mathrm{CV}$ (parcelas) $=1,5 \%$.

$\mathrm{CV}$ (subparcelas) $=2,6 \%$.

*significativo a $5 \%$ de probabilidade. 


\section{APÊNDICE 7}

Teor de $\mathrm{P}\left(\mathrm{mg} \mathrm{dm}^{-3}\right)$ no solo antes do terceiro plantio e após o último corte, em função das fontes e niveis de fósforo aplicado.

\begin{tabular}{lcccccc}
\hline & \multicolumn{7}{c}{ Fontes de fósforo } \\
\hline $\begin{array}{l}\text { Niveis de } \\
\left.\text { P(mg dm } \text { d }^{-3}\right)\end{array}$ & STAC & STDC & FGAC & FGDC & FGACG & FGDCG \\
\hline \multicolumn{7}{c}{ Antes do terceiro plantio } \\
\hline 50 & 9,00 & 11,00 & 10,33 & 7,67 & 8,33 & 8,00 \\
100 & 13,67 & 17,33 & 18,67 & 12,00 & 13,33 & 15,33 \\
200 & 28,33 & 32,33 & 25,00 & 20,00 & 21,67 & 23,67 \\
\hline 50 & 9,67 & 10,67 & 9,33 & 10,67 & 9,00 & 9,67 \\
100 & 13,67 & 15,67 & 22,00 & 21,00 & 14,67 & 17,33 \\
200 & 26,00 & 27,67 & 40,67 & 31,33 & 33,00 & 31,33 \\
\hline
\end{tabular}

(STAC: super triplo antes da calagem; STDC: super triplo depois da calagem; FGAC: Fosfato de Gafsa antes da calagem; FGDC: Fosfato de Gafsa depois da calagem; FGACG: Fosfato de Gafsa antes da calagem mais gesso; FGDCG: Fosfato de Gafsa depois da calagem mais gesso).

$\mathrm{CV}$ (parcelas) $=5,0 \%$.

$\mathrm{CV}$ (subparcelas) $=5,1 \%$.

\section{APÊNDICE 8}

Quadro da análise de variância dos efeitos das fontes e níveis de fósforo, nos dois periodos de amostragens, sobre o teor de $\mathrm{P}$ no solo $\left(\mathrm{mg} \mathrm{dm}^{-3}\right)$ (transformação de dados $\log (X+0))$.

\begin{tabular}{lccc}
\hline CAUSAS DA VARIAÇÃO & GL & Q.M. & F \\
\hline Blocos & 2 & 0,16 & \\
Fontes & 5 & 0,13 & $3,50^{*}$ \\
Níveis & 2 & 10,51 & $274,25^{*}$ \\
Fontes x Níveis & 10 & 0,03 & 0,79 \\
Resíduo (A) & 34 & 0,04 & \\
\hline Parcelas & 53 & & \\
Períodos & 1 & 0,63 & $31,61^{*}$ \\
Periodos x Fontes & 5 & 0,15 & $7,31^{*}$ \\
Periodos x Níveis & 2 & 0,05 & 2,65 \\
Períodos x Fontes x Niveis & 10 & 0,03 & 1,65 \\
Resíduo (B) & 36 & 0,02 & \\
\hline TOTAL & 107 & & \\
CV (parcelas) $=5,0 \%$. & & & \\
CV (subparcelas) $=5,1 \%$. & & & \\
*significativo a 5\% de probabilidade. & & &
\end{tabular}


a)

b)

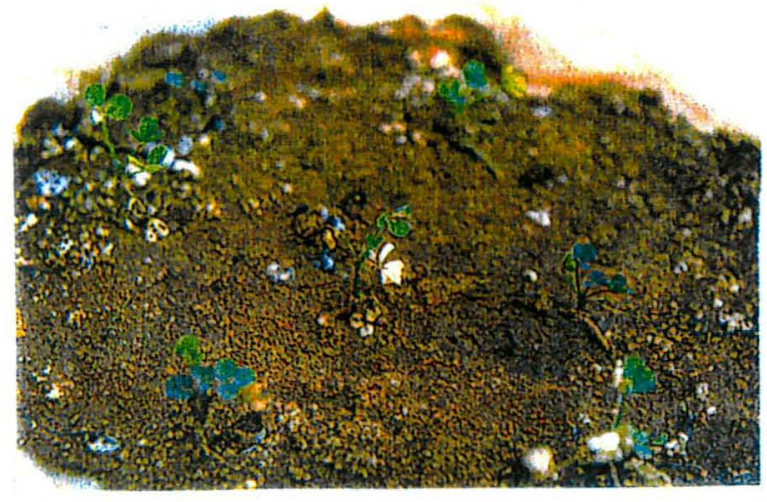

d)

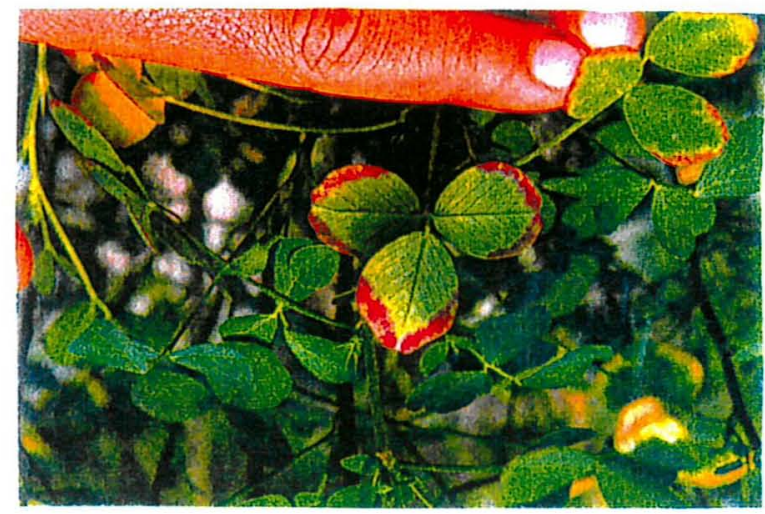

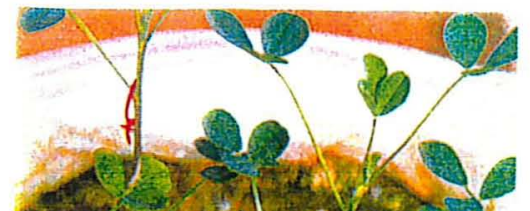

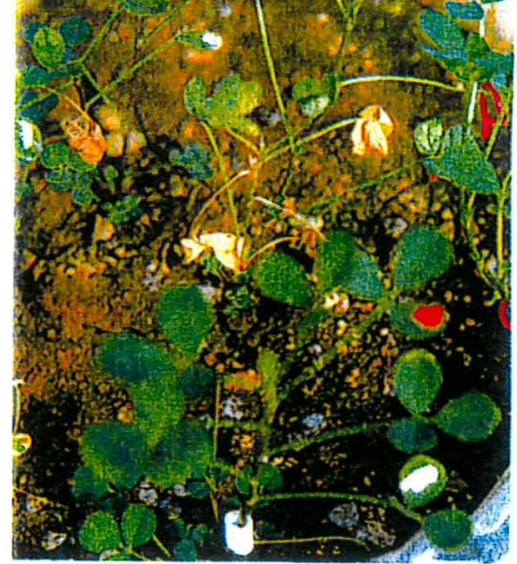

c)

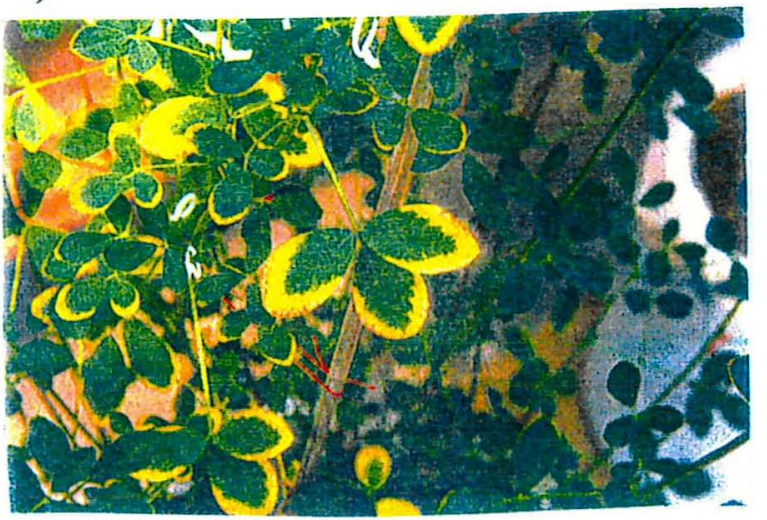

e)

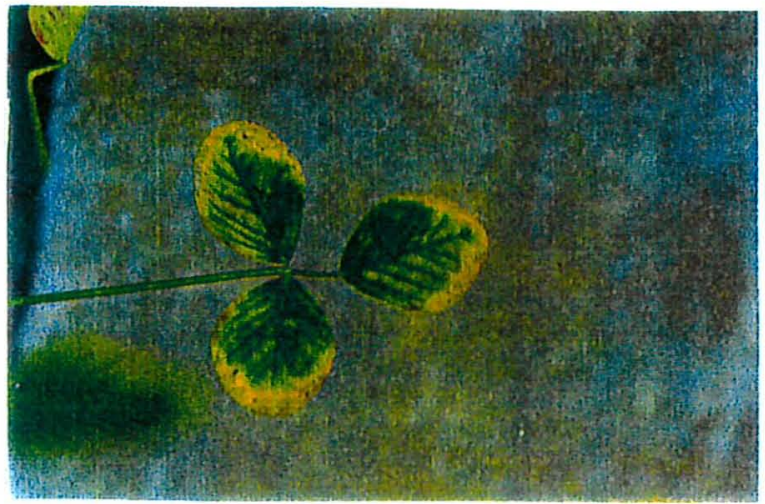

Sintomas nutricionais de plantas com, aproximadamente, 3 meses de idade: a) crescimento reduzido e morte das folhas mais velhas que apresentavam-se amareladas devido a deficiência de fósforo (superfosfato triplo aplicado antes da calagem ao nível de $100 \mathrm{mg} \mathrm{P} \mathrm{dm}^{-3}$ ) b) crescimento reduzido devido a deficiência de fósforo (testemunha); c) amarelecimento nos bordos superiores dos folíolos, seguido de necrose; d) arroxeamento intenso dos bordos inferiores dos folíolos; e) amarelecimento entre nervuras e bordos superiores dos folíolos, seguido de necrose. 


\section{APÊNDICE 10}

Esse trabalho foi realizado com o objetivo de esclarecer as possíveis causas dos sintomas visuais de toxidez de manganês observados nas plantas de alfafa durante a condução do experimento relacionado a determinação do efeito de fontes de fósforo para produção de alfafa.

Foram utilizados dois cultivares de alfafa (Crioula e Pioneer XAI - 32) e cinco doses de manganês $\left(0,5 ; 2,5 ; 5,0 ; 15,0\right.$ e $\left.30 \mathrm{mg} \mathrm{L}^{-1}\right)$, fornecido através da utilização de $\mathrm{MnSO}_{4} \mathrm{H}_{2} \mathrm{O}$. Os demais nutrientes (macro e micronutrientes) foram adicionados a partir da solução nutritiva proposta por Sarruge (1975): $1 \mathrm{~mL} \mathrm{KH}_{2} \mathrm{PO}_{4} \mathrm{M} ; 5 \mathrm{~mL} \mathrm{KNO}_{3} \mathrm{M} ; 5$ $\mathrm{mL} \mathrm{Ca}\left(\mathrm{NO}_{3}\right)_{2} \mathrm{M} ; 2 \mathrm{~mL} \mathrm{MgSO}_{4} \mathrm{M} ; 1 \mathrm{~mL}$ Fe-EDTA; $1 \mathrm{~mL}$ Micro-Mn, em cada litro de solução nutritiva. Utilizou-se de 3 repetições totalizando 30 vasos providos de tubos para drenagem e com sílica como suporte de fixação das plantas.

As mudas foram formadas em caixa com areia lavada e após 16 dias do plantio foram transplantadas (26/05/99) 15 mudas para cada vaso. Quando as plantas apresentaram um mês de idade essas foram desbastadas permanecendo 6 plantas por vaso.

Após o transplante das mudas utilizou-se a solução completa de Sarruge (1975) diluída na proporção de 1 litro de solução completa para 3 litros de água, e a cada 15 dia foi adicionado nova solução de Sarruge (1975) até completar o litro de solução utilizada em cada vaso, aumentando assim a concentração da solução a medida que as plantas cresciam. Aos 47 dias do plantio foram adicionados os tratamentos mencionados acima e a cada 15 dias procurou-se trocar a solução nutritiva dos vasos uma vez que por 15 dias somente era adicionado a solução nos vasos.

O primeiro corte realizou-se 92 dias após o plantio (10/08/99), e o segundo corte foi realizado com 31 dias de rebrota (10/09/99), sendo ambos os cortes realizados a 7,5 cm da base. 


\section{A Sintomas visuais}

\section{A.1 Primeiro periodo de crescimento}

Os primeiros sintomas de toxidez por Mn surgiram através do aparecimento de sinais de amarelecimentos nos bordos de algumas folhas (cerca de 4) mais velhas no cultivar Crioula, quando se utilizou 15 e $30 \mathrm{mg} \mathrm{Mn} \mathrm{L}^{-1}$ de solução. As plantas apresentavam esses sintomas com cerca de 14 dias após a adição dos tratamentos e tinham idade de 61 dias (Figura Ia). Os sintomas de amarelecimento nos bordos das folhas intensificaram-se com o passar do tempo. Em algumas folhas apareceram, também pontos necróticos nos bordos superiores das folhas mais velhas e, aproximadamente, 27 dias após a adição dos tratamentos com níveis de $\mathrm{Mn}$ iniciou-se arroxeamento leve nos bordos inferiores das folhas que já vinham apresentando amarelecimento dos bordos superiores. Esses arroxeamentos intensificaram-se após 39 dias da adição dos tratamentos (Figura Ib).

Para o cultivar P. XAI 32, no nível de $15 \mathrm{mg} \mathrm{Mn} \mathrm{L}^{-1}$, os sintomas foram menos intensos surgindo sinais de amarelecimento dos bordos superiores de folhas mais velhas após 20 dias da adição dos tratamentos. Para esse cultivar, nesse nível de $\mathrm{Mn}$, não se observou arroxeamento dos bordos inferiores.

No nivel de $30 \mathrm{mg} \mathrm{Mn} \mathrm{L}^{-1}$, para o cultivar P. XAI 32, o sintoma de toxidez de Mn com sinais de amarelecimento nos bordos superiores das folhas mais velhas iniciou-se, aproximadamente 17 dias após a adição dos tratamentos. Esse sintoma foi intensificando com o passar do tempo e com cerca de 28 dias após a adição dos tratamentos as folhas que vinham apresentando amarelecimento dos bordos superiores apresentaram um leve arroxeamento dos bordos inferiores que se intensificaram (Figura Ic) com o decorrer do tempo.

\section{A.2 Segundo período de crescimento}

$\mathrm{Na}$ rebrota da alfafa do cultivar Crioula, cerca de 6 dias após o primeiro corte surgiram os primeiros sintomas de toxidez por Mn como uma linha fina e esbranquiçada 
ao redor dos bordos de folhas mais velhas para os tratamentos com 15 e $30 \mathrm{mg} \mathrm{Mn} \mathrm{L}^{-1}$ de solução e, após 3 dias ocorreu certo encurvamento para baixo em algumas dessas folhas. Observou-se, também, pontos necróticos nos bordos superiores de algumas folhas mais velhas 13 dias após o primeiro corte para os tratamentos de15 e $30 \mathrm{mg} \mathrm{Mn} \mathrm{L}^{-1}$. O amarelecimento dos bordos superiores de folhas mais velhas surgiram aos 21 dias de rebrota no nível de $15 \mathrm{mg} \mathrm{Mn} \mathrm{L} \mathrm{M}^{-1}$ enquanto que, para o nível de $30 \mathrm{mg} \mathrm{Mn} \mathrm{L}^{-1}$ esse sintoma apareceu aos 17 dias de rebrota. No nivel de $30 \mathrm{mg} \mathrm{Mn} \mathrm{L}^{-1}$ algumas das folhas que tiveram amarelecimento do bordo superior apresentaram aos 21 dias de rebrota sinais de arroxeamento nos bordos inferiores que intensificaram-se com o passar do tempo.

Para o cultivar P. XAI 32, os primeiros sintomas de toxidez causado por excesso de Mn surgiram nos niveis de 15 e $30 \mathrm{mg} \mathrm{Mn} \mathrm{L}^{-1}$ de solução cerca de 7 dias após o primeiro corte. Esses sintomas apareceram, também, como linha esbranquiçada nas bordas de folhas mais velhas, sendo que algumas dessas folhas apresentaram encurvamento para baixo aos 12 e 15 dias de rebrota, nos níveis de 30 e $15 \mathrm{mg} \mathrm{Mn} \mathrm{L}^{-1}$, respectivamente. Pontos necróticos nos bordos superiores de folhas mais velhas foram observados aos 10 dias de rebrota nesses dois níveis de $\mathrm{Mn}$. O amarelecimento dos bordos superiores foram observados no cultivar P. XAI 32 após, aproximadamente, 22 dias do primeiro corte, porém não se intensificaram muito até o momento do segundo corte. Para o cultivar P. XAI 32, não se observou o arroxeamento dos bordos inferiores no segundo periodo de crescimento.

Pelas observações apresentadas percebe-se que os sintomas de toxidez de $\mathrm{Mn}$ surgiram primeiramente no cultivar Crioula comparado ao P. XAI 32. Mascarenhas et al. (1990) verificaram coincidência entre as notas de sintomologia de toxidez de Mn e produção de matéria seca para cultivares de soja, concluindo que a avaliação visual é um método seguro e prático. Entretanto, Sale et al. (1992) afirmam que a utilização de sintomas de toxidez de $\mathrm{Mn}$ em alfafa para identificação de cultivares tolerantes ao excesso de Mn não é um método eficiente. 
a)

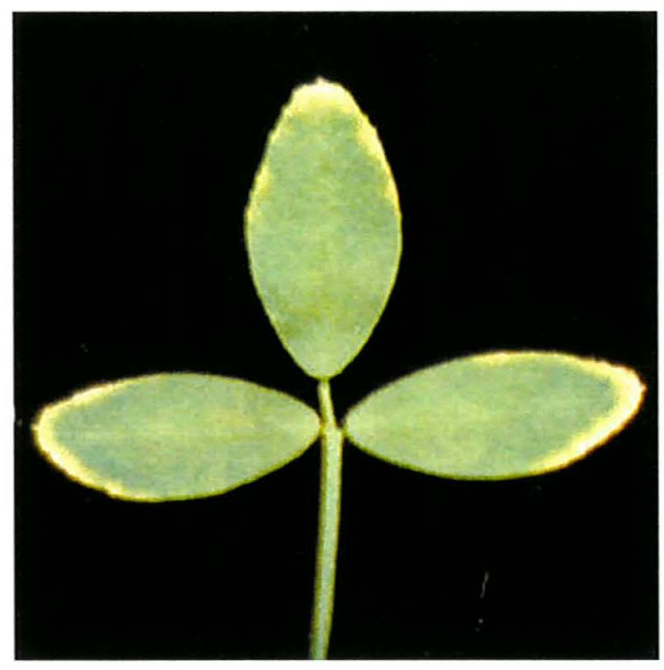

b)

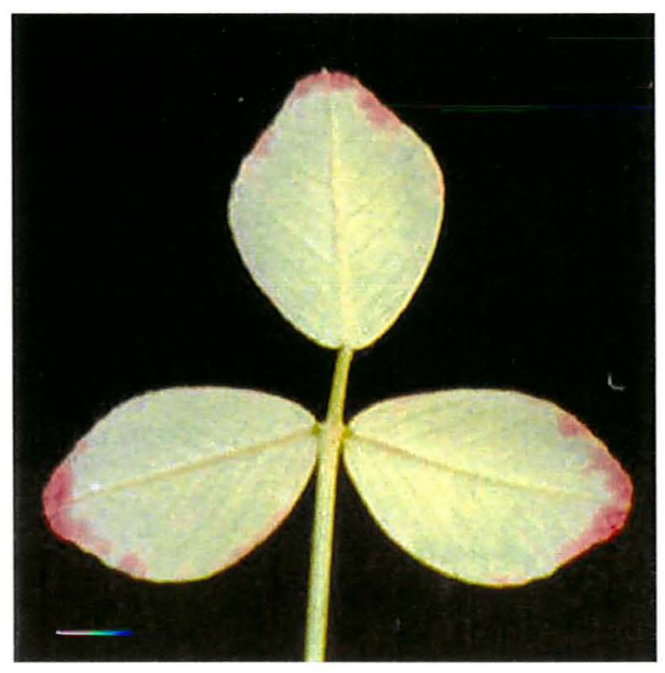

c)

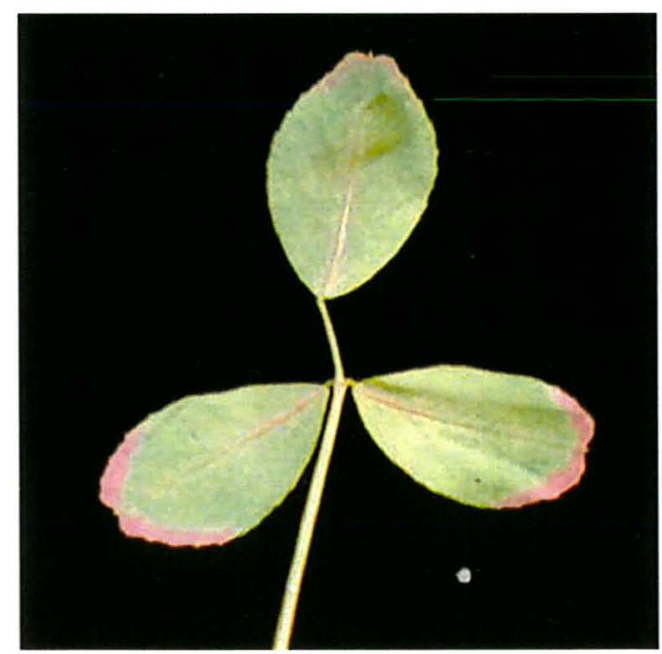

Figura I - Sintomas nutricionais: a) amarelecimento nos bordos superiores dos folíolos cv. Crioula, $30 \mathrm{mg} \mathrm{Mn} \mathrm{L}{ }^{-1}$; b) arroxeamento dos bordos inferiores dos folíolos - cv. XAI $32,30 \mathrm{mg} \mathrm{Mn} \mathrm{L}{ }^{-1}$; c) arroxeamento dos bordos inferiores dos folíolos - cv. Crioula, 30 $\mathrm{mg} \mathrm{Mn} \mathrm{L} \mathrm{M}^{-1}$. 


\section{APÊNDICE 11}

basal reral

STAC - $50 \mathrm{mg}$ de P/dm ${ }^{3}$
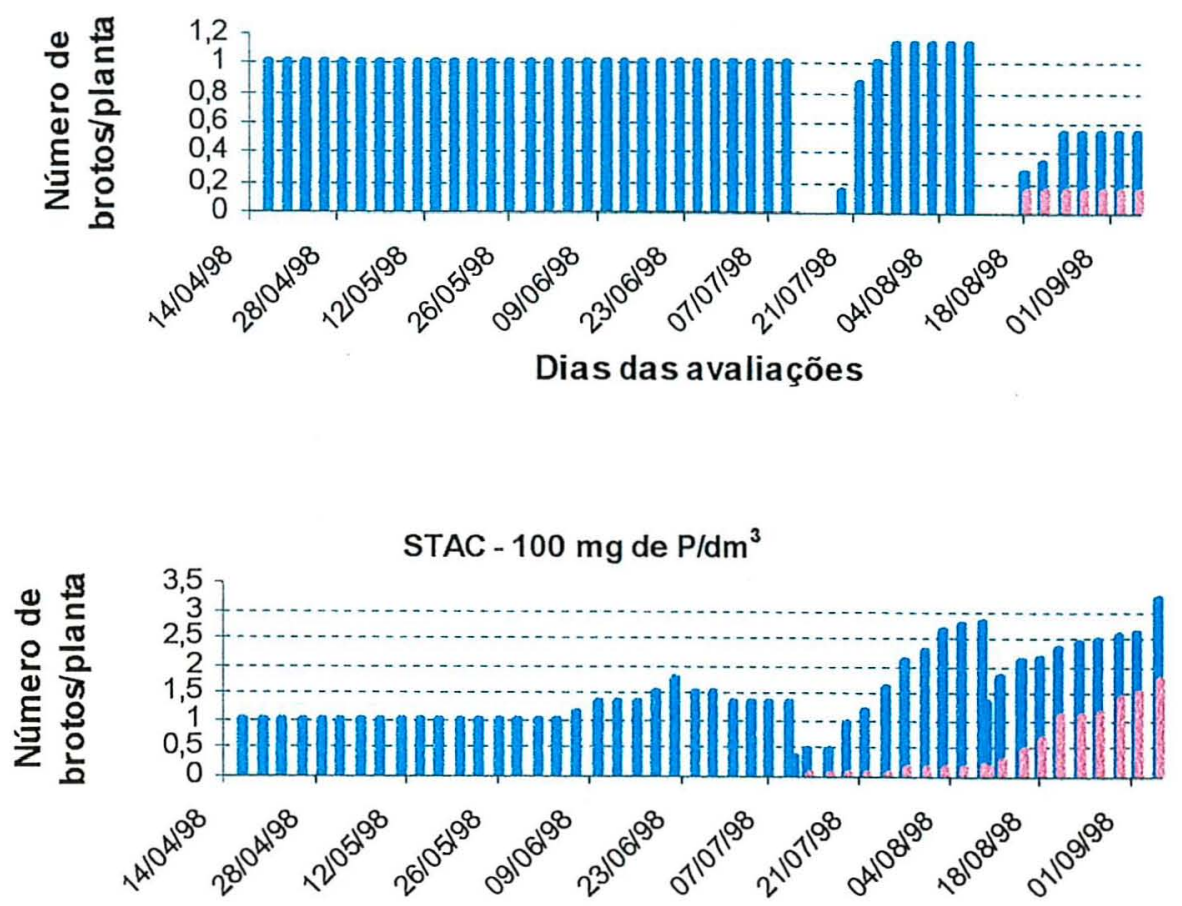

Dias da avaliações

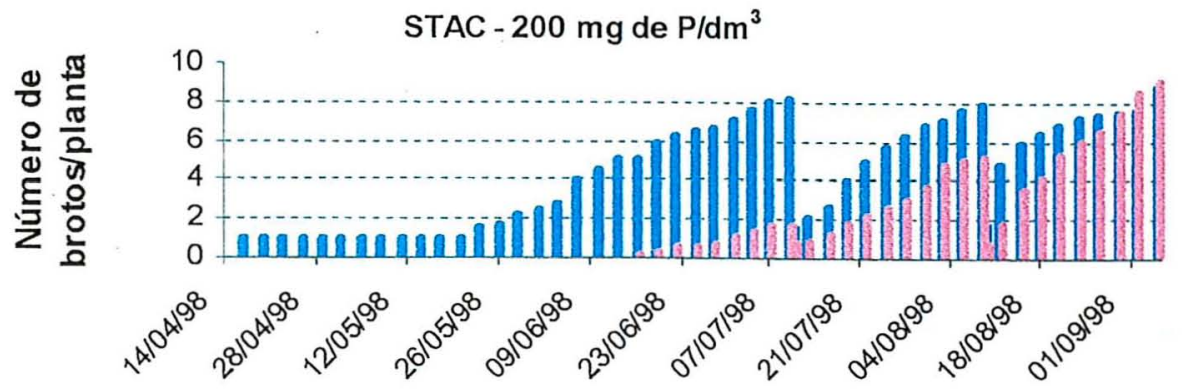

Dias da avaliações

Evolução do número de brotos basais e laterais nos níveis de 50,100 e $200 \mathrm{mg} \mathrm{P} \mathrm{dm}^{-3}$ com o uso do STAC, no terceiro plantio.

(STAC: Superfosfato triplo aplicado antes da calagem). 


\section{APÊNDICE 12}

basal 䙵 lateral

STDC - $50 \mathrm{mg}$ de P/dm ${ }^{3}$
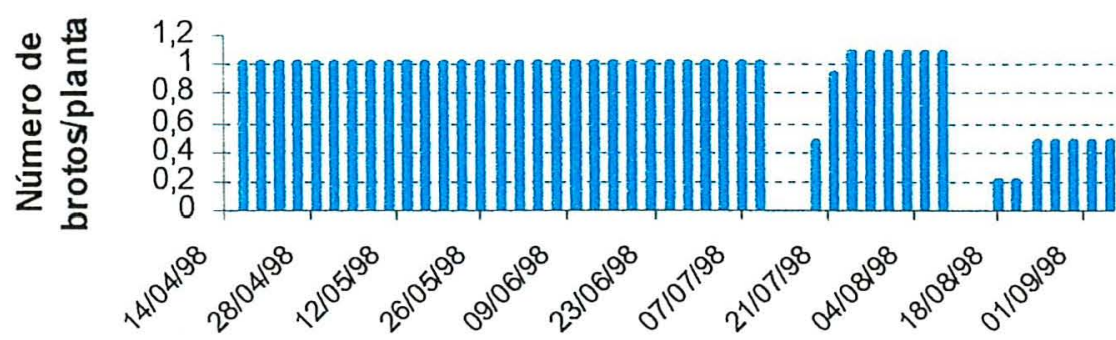

Dias das avaliações

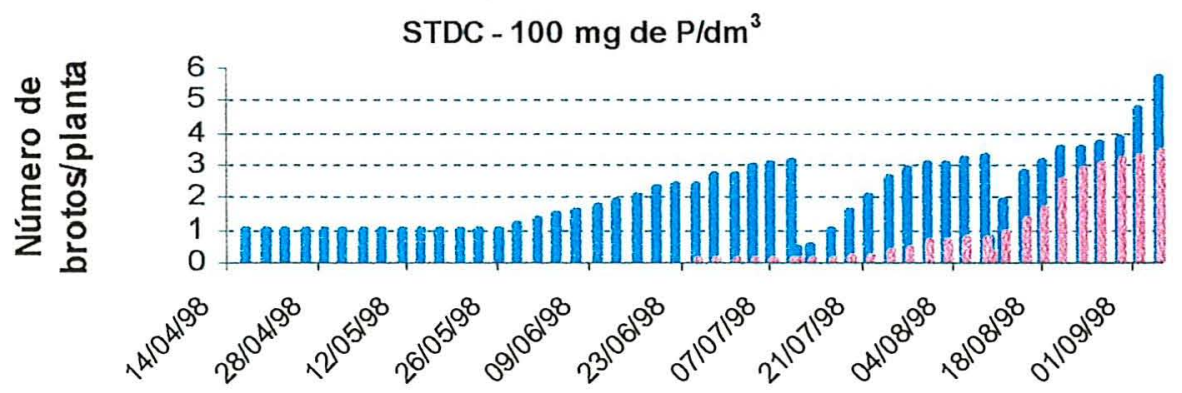

Dias da avaliações

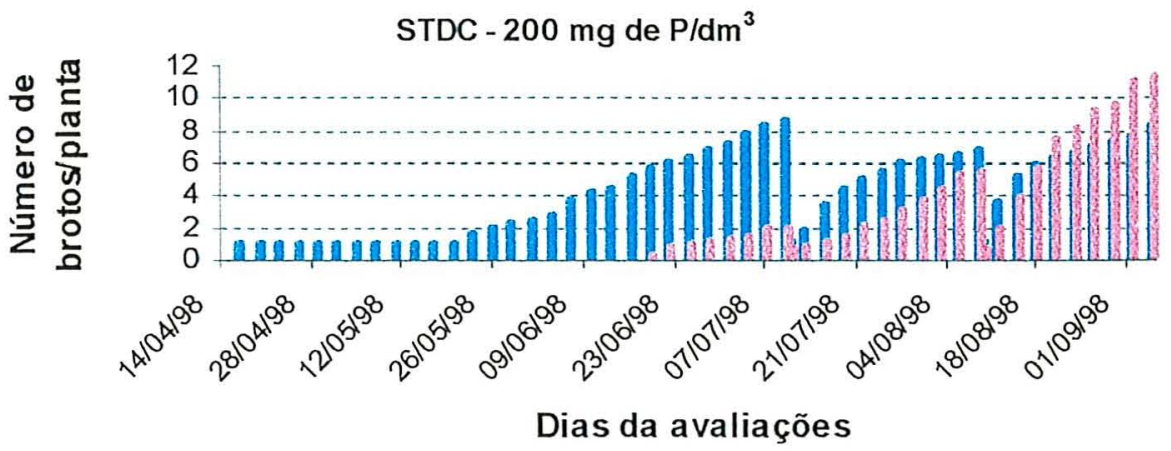

Evolução do número de brotos basais e laterais nos níveis de 50, 100 e $200 \mathrm{mg} \mathrm{P} \mathrm{dm}^{-3}$ com o uso do STDC, no terceiro plantio.

(STDC: Superfosfato triplo aplicado depois da calagem). 


\section{APÊNDICE 13}

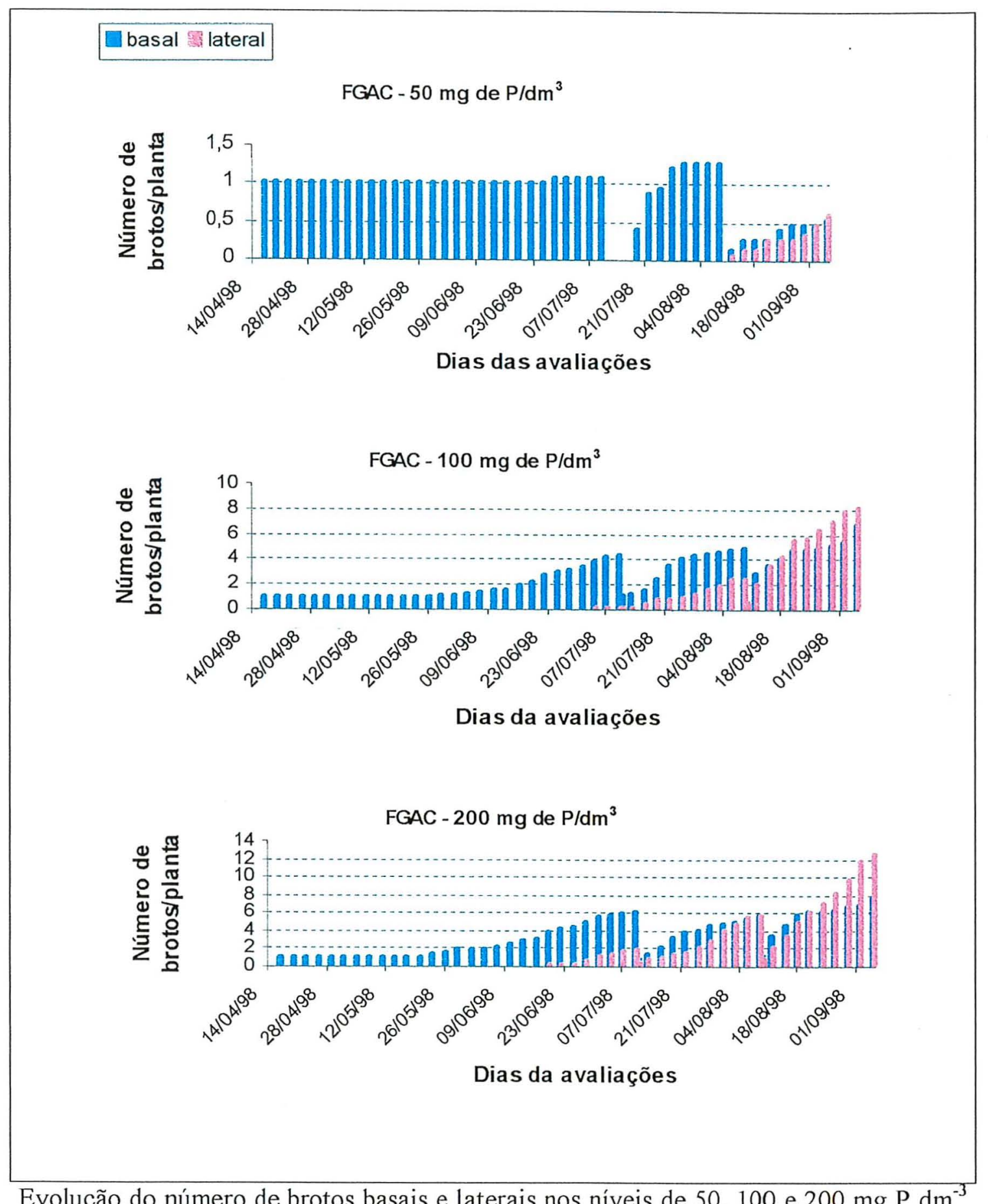

Evolução do número de brotos basais e laterais nos níveis de 50, 100 e $200 \mathrm{mg} \mathrm{P} \mathrm{dm}^{-3}$ com o uso do FGAC, no terceiro plantio.

(FGAC: Fosfato de Gafsa aplicado antes da calagem). 


\section{APÊNDICE 14}

basal 筑 lateral

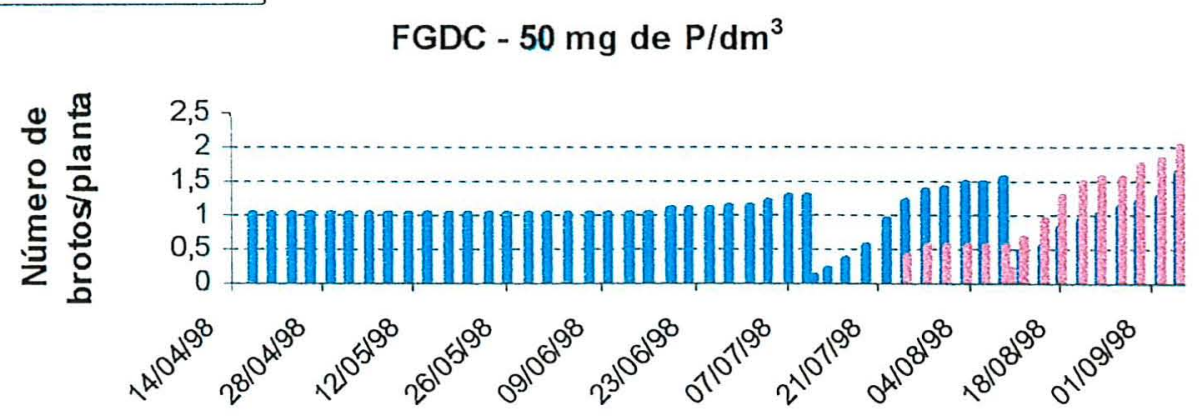

Dias das avaliações

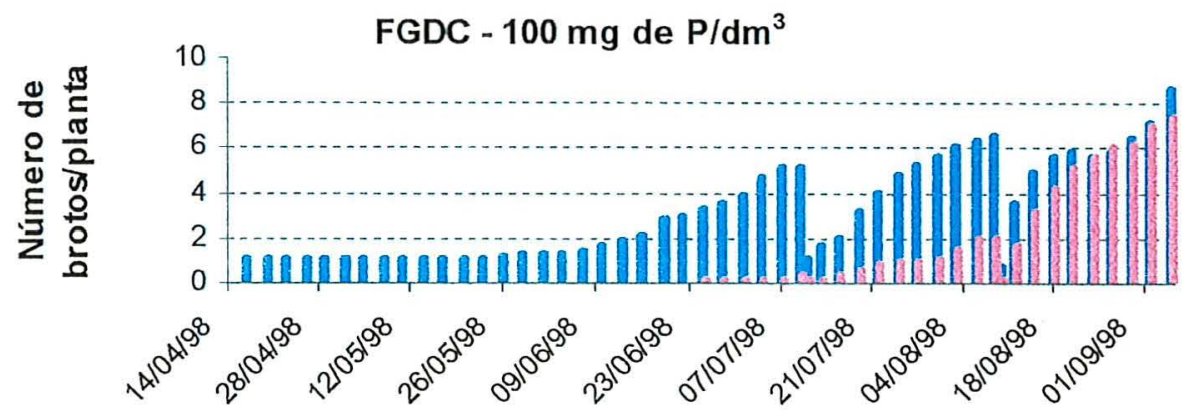

Dias das avaliações

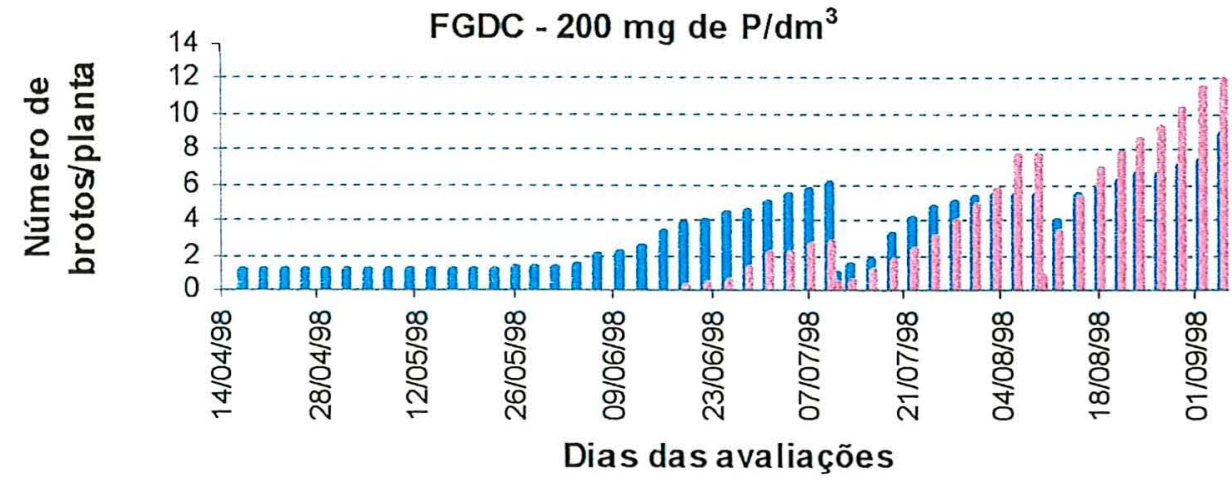

Evolução do número de brotos basais e laterais nos níveis de 50,100 e $200 \mathrm{mg} \mathrm{P} \mathrm{dm}{ }^{-3}$ com o uso do FGDC, no terceiro plantio.

(FGDC: Fosfato de Gafsa aplicado depois da calagem). 


\section{APÊNDICE 15}
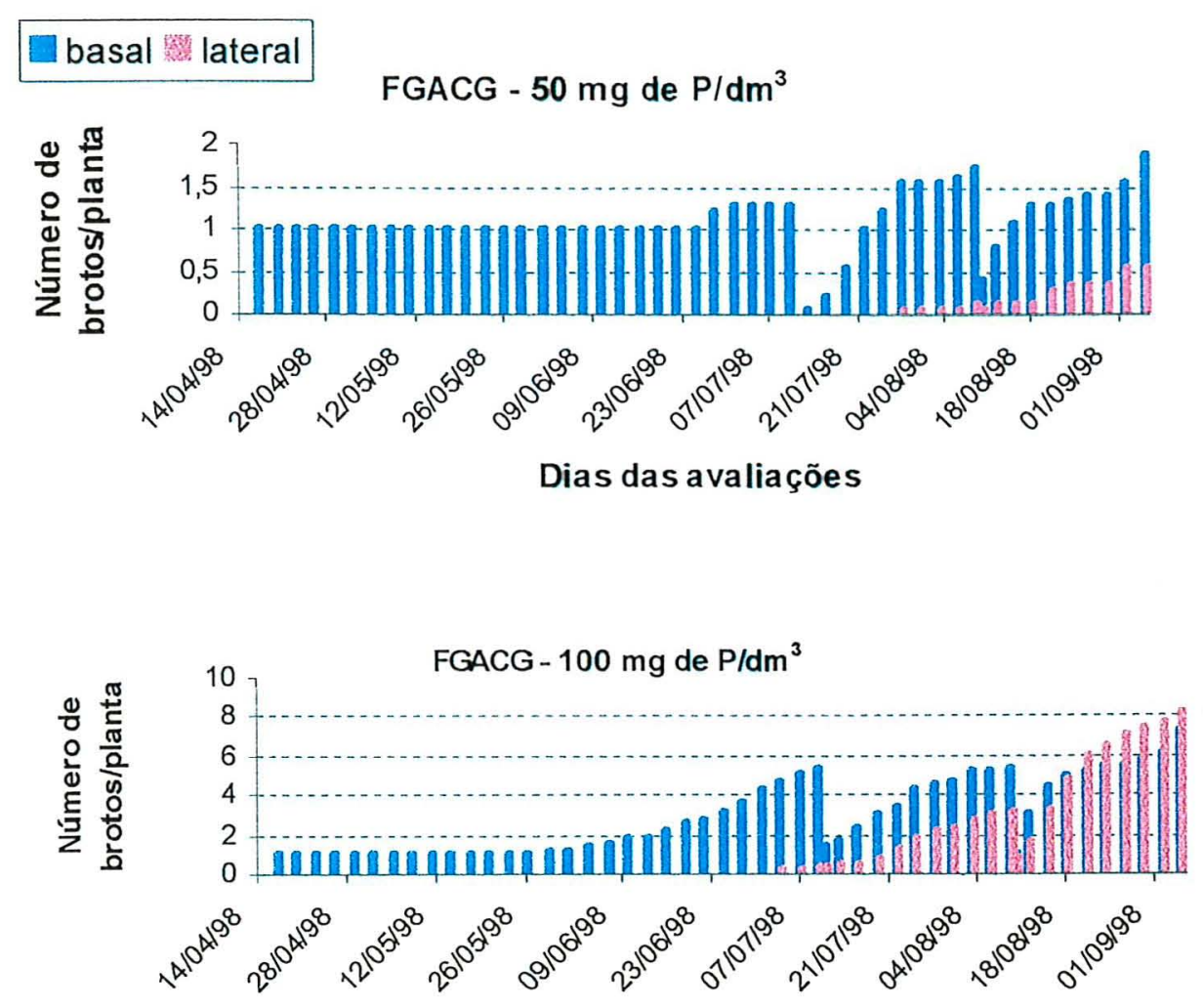

Dias das avaliações

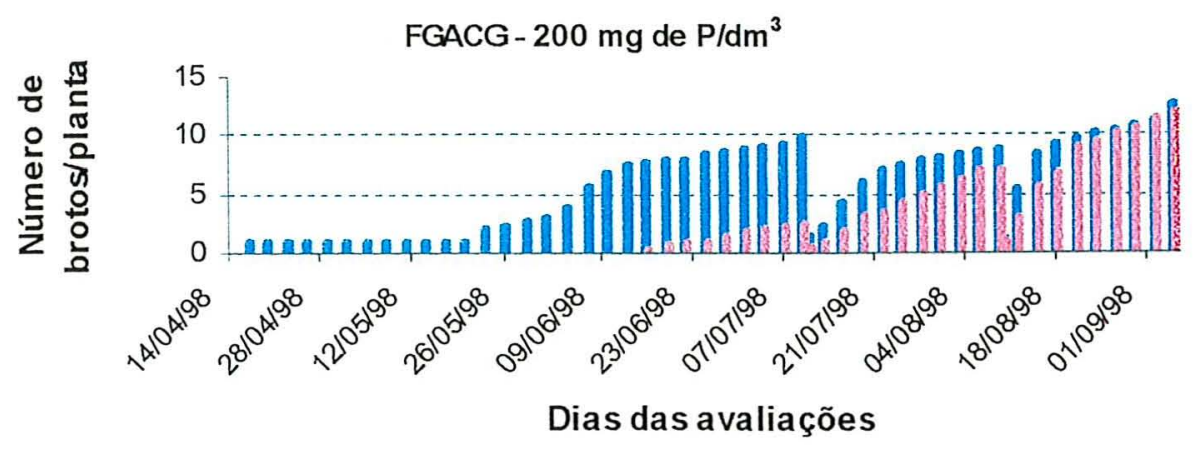

Evolução do número de brotos basais e laterais nos níveis de 50, 100 e $200 \mathrm{mg} \mathrm{P} \mathrm{dm}^{-3}$ com o uso do FGACG, no terceiro plantio.

(FGACG: Fosfato de Gafsa + gesso aplicado depois da calagem). 


\section{APÊNDICE 16}

basal 鲸 lateral

FGDCG - $50 \mathrm{mg}$ de P/dm ${ }^{3}$

$\frac{\pi}{2}$
$\frac{\pi}{2}$
$\frac{\pi}{2}$
$\frac{5}{3}$
$\frac{5}{2}$

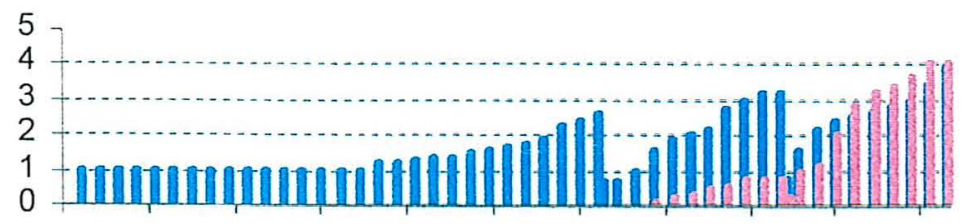

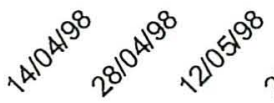

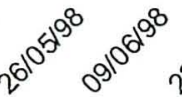

$3^{30} 0^{69^{90}}$

Dias das avaliações

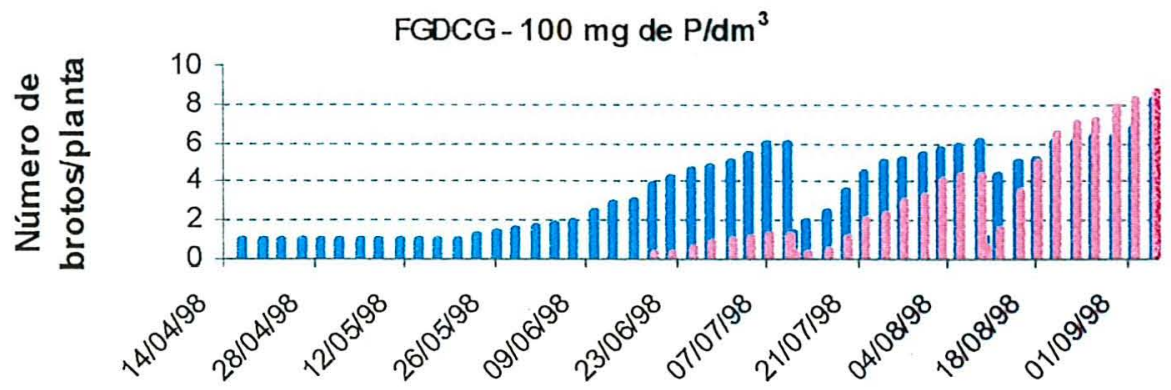

Dias da avaliações

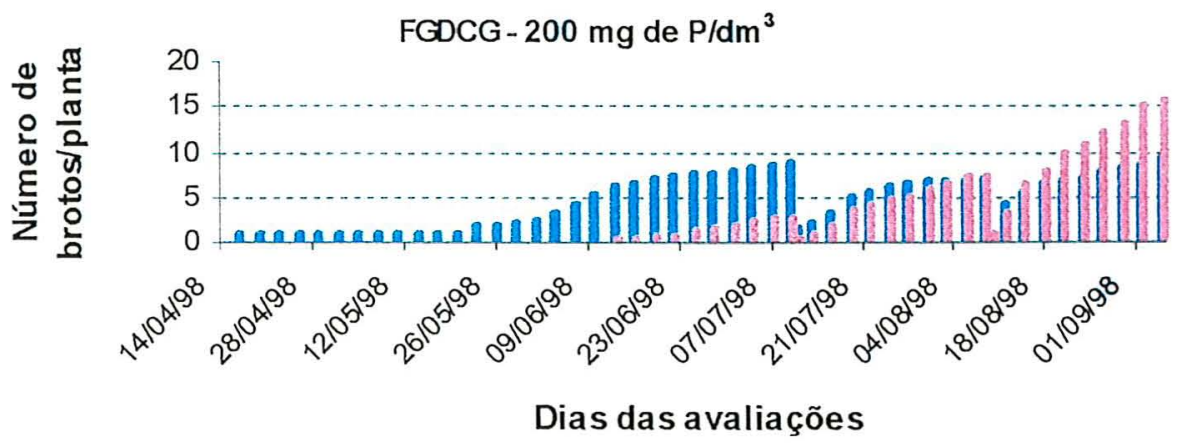

Evolução do número de brotos basais e laterais nos níveis de 50,100 e $200 \mathrm{mg} \mathrm{P} \mathrm{dm}^{-3}$ com o uso do FGDCG, no terceiro plantio.

(FGDCG: Fosfato de Gafsa + gesso aplicado depois da calagem). 


\section{APÊNDICE 17}

Número de brotos basais por planta obtidas em todas as fontes e doses de fósforo ( $\mathrm{mg}$ $\left.\mathrm{dm}^{-3}\right)$ nos três cortes realizados no terceiro plantio.

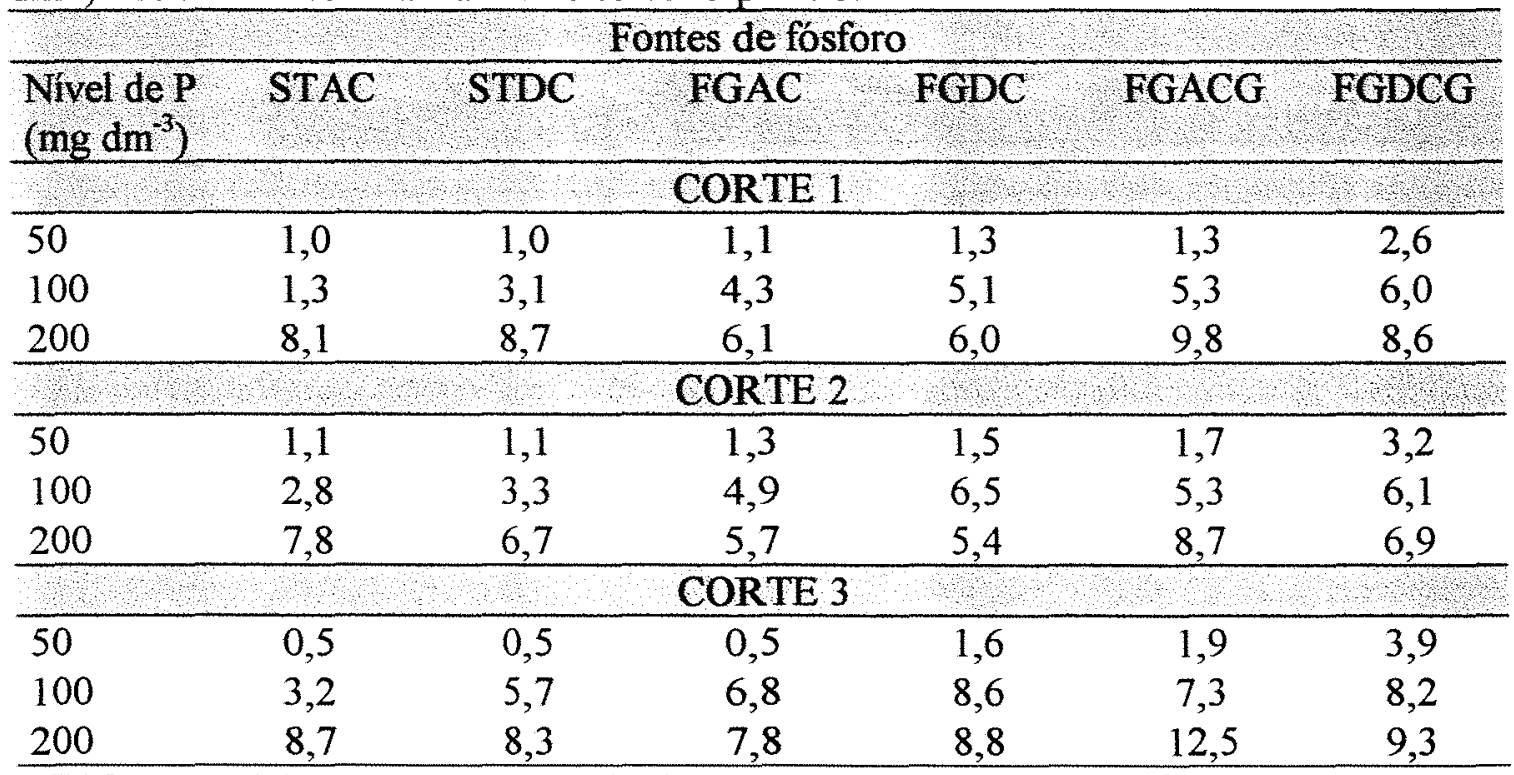

(STAC: super triplo antes da calagem; STDC: super triplo depois da calagem; FGAC: Fosfato de Gafsa antes da calagem; FGDC: Fosfato de Gafsa depois da calagem; FGACG: Fosfato de Gafsa antes da calagem mais gesso; FGDCG: Fosfato de Gafsa depois da calagem mais gesso).

$\mathrm{CV}$ (parcelas) $=11,4 \%$.

$\mathrm{CV}$ (subparcelas) $=9,0 \%$. 


\section{APÊNDICE 18}

Número de brotos laterais por planta obtidas em todas as fontes e doses de fósforo (mg $\mathrm{dm}^{-3}$ ) nos três cortes realizados no terceiro plantio.

\begin{tabular}{|c|c|c|c|c|c|c|}
\hline \multirow{2}{*}{$\begin{array}{l}\text { Nivel de P } \\
\left(\mathrm{mg} \mathrm{dm}^{-3}\right)\end{array}$} & \multicolumn{5}{|c|}{ Fontes de fósforo } & \multirow{2}{*}{ FGDCG } \\
\hline & STAC & STDC & FGAC & $\mathrm{FGDC}$ & FGACG & \\
\hline \multicolumn{7}{|c|}{ CORTE 1 } \\
\hline 50 & 0,00 & 0,00 & 0,00 & 0,00 & 0,00 & 0,00 \\
\hline 100 & 0,00 & 0,07 & 0,20 & 0,40 & 0,40 & 1,27 \\
\hline 200 & 1,67 & 2,00 & 1,80 & 2,68 & 2,47 & 2,53 \\
\hline \multicolumn{7}{|c|}{ CORTE 2} \\
\hline 50 & 0,00 & 0,00 & 0,00 & 0,53 & 0,13 & 0,73 \\
\hline 100 & 0,20 & 0,73 & 2,47 & 1,93 & 3,13 & 4,27 \\
\hline 200 & 5,13 & 5,53 & 5,60 & 7,65 & 6,93 & 7,27 \\
\hline \multicolumn{7}{|c|}{ CORTE 3} \\
\hline 50 & 0,13 & 0,00 & 0,60 & 2,00 & 0,53 & 4,07 \\
\hline 100 & 1,73 & 3,40 & 8,13 & 7,33 & 8,20 & 8,60 \\
\hline 200 & 9,07 & 11,40 & 12,40 & 11,85 & 11,80 & 15,67 \\
\hline
\end{tabular}

(STAC: super triplo antes da calagem; STDC: super triplo depois da calagem; FGAC: Fosfato de Gafsa antes da calagem; FGDC: Fosfato de Gafsa depois da calagem; FGACG: Fosfato de Gafsa antes da calagem mais gesso; FGDCG: Fosfato de Gafsa depois da calagem mais gesso).

$\mathrm{CV}$ (parcelas) $=24,6 \%$.

$\mathrm{CV}$ (subparcelas) $=20,9 \%$. 


\section{APÊNDICE 19}

Quadro da análise de variância dos efeitos das fontes e níveis de fósforo, nos três cortes do terceiro plantio, sobre o número de brotos basais por planta (transformação dos dados - raiz $(\mathrm{X}+0))$.

\begin{tabular}{lccc}
\hline EALSAS DA VARIAGÃO & GL & Q.M & F \\
\hline Blocos & 2 & 0,30 & \\
Fontes & 5 & 1,73 & $10,44^{*}$ \\
Níveis & 2 & 37,35 & $224,35^{*}$ \\
Fontes x Níveis & 10 & 0,70 & $4,18^{*}$ \\
Resíduo (A) & 34 & 0,17 & \\
\hline Parcelas & 53 & & \\
Cortes & 2 & 0,92 & $26,88^{*}$ \\
Cortes x Fontes & 10 & 0,08 & $2,31^{*}$ \\
Cortes x Niveis & 4 & 0,68 & $20,05^{*}$ \\
Cortes x Fontes x Níveis & 20 & 0,52 & 1,53 \\
Resíduo (B) & 72 & 0,03 & \\
\hline TOTAL & 161 & & \\
\hline
\end{tabular}

$\mathrm{CV}$ (parcelas) $=11,4 \%$.

CV (subparcelas) $=9,0 \%$.

*significativo a $5 \%$ de probabilidade.

\section{APÊNDICE 20}

Quadro da análise de variância dos efeitos das fontes e niveis de fósforo, nos três cortes do terceiro plantio, sobre o número de brotos laterais por planta (transformação dos dados - raiz $(X+0))$.

\begin{tabular}{lccc}
\hline CAUSAS DA VARIAÇÃO & GL & Q.M. & F \\
\hline Blocos & 2 & & \\
Fontes & 5 & 3,54 & $10,19^{*}$ \\
Níveis & 2 & 58,30 & $167,83^{*}$ \\
Fontes x Níveis & 10 & 0,41 & 1,18 \\
Resíduo (A) & 34 & 0,35 & \\
\hline Parcelas & 53 & & \\
Cortes & 2 & 34,77 & $415,80^{*}$ \\
Cortes x Fontes & 10 & 0,32 & $3,78^{*}$ \\
Cortes x Níveis & 4 & 2,21 & $26,45^{*}$ \\
Cortes x Fontes x Níveis & 20 & 0,18 & $2,17^{*}$ \\
Resíduo (B) & 72 & 0,08 & \\
\hline TOTAL & 161 & & \\
\hline CVT & & & \\
\hline
\end{tabular}

$\mathrm{CV}$ (parcelas) $=24,6 \%$.

$\mathrm{CV}$ (subparcelas) $=20,9 \%$.

*significativo a $5 \%$ de probabilidade. 


\section{APÊNDICE 21}

Coeficientes de correlação entre a produção de matéria seca da parte aérea da alfafa e o número de brotos totais (basais + laterais), em função de todas as épocas de corte.

\begin{tabular}{cccccc}
\hline & \multicolumn{5}{c}{ Fontes de fósforo } \\
\hline STAC & STDC & FGAC & FGDC & FGACG & FGDCG \\
\hline $0,92^{*}$ & $0,88^{*}$ & $0,90^{*}$ & $0,90^{*}$ & $0,86^{*}$ & $0,72^{*}$ \\
\hline
\end{tabular}

(STAC: super triplo antes da calagem; STDC: super triplo depois da calagem; FGAC: Fosfato de Gafsa antes da calagem; FGDC: Fosfato de Gafsa depois da calagem; FGACG: Fosfato de Gafsa antes da calagem mais gesso; FGDCG: Fosfato de Gafsa depois da calagem mais gesso).

* significativo a $5 \%$ de probabilidade.

\section{APÊNDICE 22}

Quadro de análise de variância dos efeitos das fontes e níveis de fósforo sobre o teor de $\mathrm{P}, \mathrm{N}, \mathrm{Ca}$ e Mg da MS da parte aérea da alfafa referente ao primeiro plantio.

\begin{tabular}{|c|c|c|c|c|c|c|c|c|c|}
\hline \multicolumn{2}{|c|}{ CAUSAS DA VARIAÇÃO } & \multicolumn{2}{|c|}{$\mathbf{P}$} & \multicolumn{2}{|c|}{$\mathrm{N}$} & \multicolumn{2}{|c|}{$\mathrm{Ca}$} & \multicolumn{2}{|c|}{$\mathrm{Mg}$} \\
\hline & GL & Q.M. & F & Q.M. & $F$ & Q.M. & F & Q.M. & $F$ \\
\hline Blocos & 2 & 0,58 & & 62,17 & & 3,57 & & 0,005 & \\
\hline Font & 5 & 0,13 & 2,05 & 91,61 & $6,24^{*}$ & 41,48 & $19,66^{*}$ & 0,002 & 1,67 \\
\hline Nive & 2 & 0,83 & $12,59 *$ & 19,98 & 1,60 & 17,88 & $8,47^{*}$ & 0,012 & $9,43^{*}$ \\
\hline Fontes $\mathrm{x}$ Níveis & 10 & 0,19 & $2,88^{*}$ & 30,41 & 2,07 & 5,97 & $2,83 *$ & 0,001 & 1,16 \\
\hline Resí & 34 & 0,07 & & 14,69 & & 2,11 & & 0,001 & \\
\hline TOTAL & 53 & & & & & & & & \\
\hline CV (\%) & & 17,8 & & 12,2 & & 11,2 & & 8.7 & \\
\hline Transformação & & & & & & & & $1 /\left(\mathrm{X}^{1 / 2}\right)$ & \\
\hline
\end{tabular}

* significativo a $5 \%$ de probabilidade. 


\section{APÊNDICE 23}

Coeficientes de correlação entre concentração de fósforo $\left(\mathrm{g} \mathrm{kg}^{-1}\right)$ na MS e a produção de matéria seca da parte aérea e raiz da alfafa, no primeiro e terceiro plantio.

\begin{tabular}{|c|c|c|c|c|c|}
\hline \multicolumn{6}{|c|}{ Fontes de fósforo } \\
\hline STAC & STDC & FGAC & FGDC & FGACG & FGDCG \\
\hline \multicolumn{6}{|c|}{$1^{\circ}$ plantio } \\
\hline$-0,46^{\mathrm{ns}}$ & $-0,004^{\mathrm{ns}}$ & $0,72^{*}$ & $0,39^{\text {ns }}$ & $0,46^{\text {ns: }}$ & $0,25^{\mathrm{ns}}$ \\
\hline \multicolumn{6}{|c|}{$3^{\circ}$ plantio } \\
\hline $0,57^{*}$ & $0,65^{*}$ & $0,71^{*}$ & $0,33^{\mathrm{ns}}$ & $0,33^{\text {ns }}$ & $0,23^{\text {ns }}$ \\
\hline \multicolumn{6}{|c|}{ Raiz $-3^{\circ}$ plantio } \\
\hline $0,45^{*}$ & $0,61^{*}$ & $0,78^{*}$ & $0,35^{\text {ns }}$ & $0,62^{*}$ & $0,27^{\text {ns }}$ \\
\hline
\end{tabular}

(STAC: super triplo antes da calagem; STDC: super triplo depois da calagem; FGAC: Fosfato de Gafsa antes da calagem; FGDC: Fosfato de Gafsa depois da calagem; FGACG: Fosfato de Gafsa antes da calagem mais gesso; FGDCG: Fosfato de Gafsa depois da calagem mais gesso).

*significativo a $5 \%$ de probabilidade.

${ }^{\text {ns }}$ não significativo a $5 \%$ de probabilidade.

\section{APÊNDICE 24}

Quadro de análise de variância dos efeitos das fontes e níveis de fósforo sobre o teor de $\mathrm{P}, \mathrm{N}, \mathrm{Ca}$ e Mg da MS da raiz da alfafa referente ao terceiro plantio.

\begin{tabular}{|c|c|c|c|c|c|c|c|c|c|}
\hline CAUSAS DA VAR & $\overline{A C ̧ A ̃ O}$ & & 5 & $\bar{N}$ & & $\mathrm{C}$ & & & $\mathrm{ig}$ \\
\hline & GL & QM. & F & Q.M. & $F$ & Q.M. & F & Q.M. & $\mathrm{F}$ \\
\hline Blocos & 2 & & & & & & & & \\
\hline Fon & 5 & 0,16 & $7,52 *$ & 67,25 & $4,45^{*}$ & 1,07 & $4,45 *$ & 0,02 & 0,29 \\
\hline Nív & 2 & 0,30 & $31,74^{*}$ & 868,55 & $57,48^{*}$ & 0,58 & 2,4 & 1,92 & $32,12^{*}$ \\
\hline Fontes $x$ Níveis & 10 & 0,03 & $2,87 *$ & 52,30 & $3,46^{*}$ & 0,16 & 0,66 & 0,61 & $10,25 *$ \\
\hline Resi & 34 & 0,01 & & 15,11 & & 0,24 & & 0,06 & \\
\hline TOTAL & 53 & & 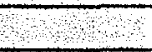 & & & & & & \\
\hline CV (\%) & & 8. & & 19,2 & & 23,5 & & 16,9 & \\
\hline Transformação & & $1 /\left(X^{1 / 2}\right.$ & & & & & & & $x+0)$ \\
\hline
\end{tabular}

* significativo a $5 \%$ de probabilidade. 


\section{APÊNDICE 25}

Teores de $\mathrm{P}, \mathrm{N}, \mathrm{Ca}$ e $\mathrm{Mg}\left(\mathrm{g} \mathrm{kg}^{-1}\right)$ na parte aérea da alfafa em função dos tratamentos e doses de fósforo referentes ao primeiro plantio.

\begin{tabular}{|c|c|c|c|c|c|c|}
\hline \multicolumn{7}{|c|}{ Fontes de fósforo } \\
\hline $\begin{array}{l}\text { Niveis de P } \\
\left(\mathrm{mg} \mathrm{dm}^{-3} \text { ) }\right.\end{array}$ & STAC & STDC & FGAC & FGDC & FGACG & FGDCG \\
\hline \multicolumn{7}{|c|}{$\mathrm{P}\left(\mathrm{g} \mathrm{kg}^{-1}\right)$} \\
\hline 50 & 1,57 & 1,38 & 0,70 & 0,95 & 1,34 & 1,23 \\
\hline 100 & 1,83 & 1,72 & 1,70 & 1,52 & 1,29 & 1,33 \\
\hline 200 & 1,48 & 1,53 & 1,83 & 1,39 & 1,63 & 1,56 \\
\hline \multicolumn{7}{|c|}{$\mathrm{N}\left(\mathrm{g} \mathrm{kg}^{-1}\right)$} \\
\hline 50 & 32,34 & 27,35 & 26,55 & 35,19 & 38,99 & 33,32 \\
\hline 100 & 28,65 & 25,76 & 33,74 & 31,45 & 36,26 & 36,31 \\
\hline 200 & 24,78 & 28,98 & 33,60 & 31,87 & 32,85 & 30,01 \\
\hline \multicolumn{7}{|c|}{$\mathrm{Ca}\left(\mathrm{g} \mathrm{kg}^{-1}\right)$} \\
\hline 50 & 8,08 & 12,97 & 11,12 & 10,27 & 15,05 & 14,93 \\
\hline 100 & 10,62 & 12,73 & 11,07 & 12,65 & 13,45 & 16,82 \\
\hline 200 & 12,62 & 11,15 & 13,72 & 13,30 & 17,43 & 16,10 \\
\hline \multicolumn{7}{|c|}{$\mathrm{Mg}\left(\mathrm{g} \mathrm{kg}^{-1}\right)$} \\
\hline 50 & 6,43 & 6,48 & 8,05 & 7,68 & 6,67 & 8,26 \\
\hline 100 & 5,25 & 6,55 & 5,29 & 6,60 & 5,05 & 6,43 \\
\hline 200 & 5,85 & 7,35 & 5,46 & 6,16 & 5,10 & 5,08 \\
\hline \multicolumn{7}{|c|}{$\begin{array}{l}\text { (STAC: super triplo antes da calagem; STDC: super triplo depois da calagem; FGAC: Fosfato de Gafsa } \\
\text { antes da calagem; FGDC: Fosfato de Gafsa depois da calagem; FGACG: Fosfato de Gafsa antes da } \\
\text { calagem mais gesso; FGDCG: Fosfato de Gafsa depois da calagem mais gesso). } \\
\mathrm{P} \rightarrow \mathrm{CV}=17,8 \% \text {. } \\
\mathrm{N} \rightarrow \mathrm{CV}=12,2 \% \text {. } \\
\mathrm{Ca} \rightarrow \mathrm{CV}=11,2 \% \text {. } \\
\mathrm{Mg} \rightarrow \mathrm{CV}=8,7 \% \text {. }\end{array}$} \\
\hline
\end{tabular}




\section{APÊNDICE 26}

Teores de $\mathrm{P}, \mathrm{N}, \mathrm{Ca}$ e $\mathrm{Mg}\left(\mathrm{g} \mathrm{kg}^{-1}\right)$ na parte aérea da alfafa em função das doses de fósforo obtidos em decorrência dos diferentes tratamentos e período de corte, no terceiro plantio".

\begin{tabular}{|c|c|c|c|c|c|c|}
\hline \multicolumn{7}{|c|}{ Fontes de fósforo } \\
\hline $\begin{array}{l}\text { Niveis de } \mathrm{P} \\
\left(\mathrm{mg} \mathrm{dm}^{-3}\right)\end{array}$ & STAC & STDC & FGAC & FGDC & FGACG & FGDCG \\
\hline \multicolumn{7}{|c|}{$\mathrm{P}\left(\mathrm{g} \mathrm{kg}^{-1}\right)$} \\
\hline \multicolumn{7}{|c|}{ CORTE 1} \\
\hline 50 & $0,43 *$ & $0,81^{*}$ & $1,03^{*}$ & $1,58^{*}$ & $1,26^{*}$ & 1,72 \\
\hline 100 & $1,70^{*}$ & $1,84^{* *}$ & 1,82 & 2,07 & 2,26 & 2,09 \\
\hline 200 & 1,89 & 1,80 & 2,09 & 2,26 & 1,64 & 1,95 \\
\hline \multicolumn{7}{|c|}{ CORTE 2} \\
\hline 50 & $0,82^{*}$ & $0,76^{*}$ & $1,05^{*}$ & 1,92 & $1,76^{* *}$ & 1,72 \\
\hline 100 & $1,55 * *$ & 1,69 & 1,98 & 2,03 & 2,03 & 1,46 \\
\hline 200 & 1,77 & 1,80 & 2,29 & 2,46 & 2,13 & 1,75 \\
\hline \multicolumn{7}{|c|}{ CORTE 3} \\
\hline 50 & $1,00^{*}$ & $0,80^{*}$ & $1,23^{*}$ & 1,23 & $0,95 * *$ & 1,34 \\
\hline 100 & 1,10 & 1,12 & 1,26 & 1,15 & 1,31 & 1,56 \\
\hline 200 & 1,29 & 1,19 & 1,54 & 1,55 & 1,56 & 1,95 \\
\hline & & & & 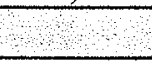 & & 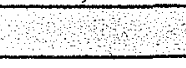 \\
\hline \multicolumn{7}{|c|}{$\mathrm{N}\left(\mathrm{g} \mathrm{kg}^{-1}\right)$} \\
\hline \multicolumn{7}{|c|}{ CORTE 1} \\
\hline 50 & $74,90^{*}$ & $60,62^{*}$ & $64,54^{*}$ & $51,66^{*}$ & $49,56^{*}$ & 39,90 \\
\hline 100 & $49,00^{*}$ & $38,92^{* *}$ & 34,07 & 32,53 & 38,13 & 29,35 \\
\hline 200 & 29,82 & 35,65 & 31,73 & 31,92 & 29,49 & 32,76 \\
\hline \multicolumn{7}{|c|}{ CORTE 2} \\
\hline 50 & $84,00^{*}$ & $68,04^{*}$ & $56,28^{*}$ & 32,76 & $44,05^{* *}$ & 31,97 \\
\hline 100 & $49,79 * *$ & 31,92 & 29,12 & 29,54 & 32,34 & 32,48 \\
\hline 200 & 32,85 & 31,08 & 31,55 & 31,31 & 32,81 & 29,91 \\
\hline \multicolumn{7}{|c|}{ CORTE 3} \\
\hline 50 & $51,80^{*}$ & $50,00^{*}$ & $50,26^{*}$ & 33,55 & $38,36^{* *}$ & 29,35 \\
\hline 100 & 33,32 & 27,95 & 30,19 & 31,27 & 28,61 & 30,75 \\
\hline 200 & 26,51 & 29,63 & 32,99 & 36,91 & 33,37 & 36,91 \\
\hline
\end{tabular}


APÊNDICE 26 - Continuação.

\begin{tabular}{|c|c|c|c|c|c|c|}
\hline 2. & & & tes de fós & & & \\
\hline $\begin{array}{l}\text { Niveis de P } \\
\left(\mathrm{mg} \mathrm{dm}^{-3}\right)\end{array}$ & STAC & STDC & FGAC & FGDC & FGACG & FGDCG \\
\hline & & & $\mathrm{a}(\mathrm{g} \mathrm{kg}$ & & & \\
\hline & 0 & & CORTE & 2 & & \\
\hline 50 & $5,85^{*}$ & $10,20^{*}$ & $12,85^{*}$ & $14,80^{*}$ & $21,25^{*}$ & 20,25 \\
\hline 100 & $18,35^{*}$ & $21,43^{* *}$ & 19,03 & 20,90 & 25,92 & 29,23 \\
\hline 200 & 19,97 & 17,82 & 18,98 & 17,90 & 23,48 & 21,65 \\
\hline & & & CORTE & & & \\
\hline 50 & $10,70^{*}$ & $10,80^{*}$ & $16,55^{*}$ & 24,62 & $23,33 * *$ & 21,95 \\
\hline 100 & $17,00^{* *}$ & 19,55 & 18,22 & 20,95 & 18,57 & 15,35 \\
\hline 200 & 15,37 & 13,27 & 15,55 & 14,12 & 15,02 & 12,55 \\
\hline & & & CORTE & & & \\
\hline 50 & $17,10^{*}$ & $10,30^{*}$ & $13,20^{*}$ & 19,83 & $24,15^{* *}$ & 17,62 \\
\hline 100 & 19,63 & 22,30 & 21,62 & 13,73 & 19,76 & 19,18 \\
\hline 200 & 17,05 & 10,87 & 16,85 & 13,50 & 16,60 & 17,70 \\
\hline 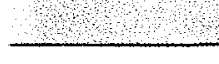 & 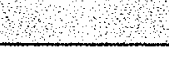 & 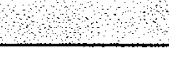 & 4 & & & \\
\hline & & & $\mathrm{Mg}(\mathrm{g} / \mathrm{kg}$ & & & \\
\hline 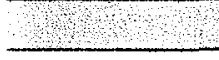 & & & CORTE & & & \\
\hline 50 & $2,34^{*}$ & $4,25^{*}$ & $4,08^{*}$ & $5,28^{*}$ & $4,55^{*}$ & 4,84 \\
\hline 100 & $6,90^{*}$ & $5,63^{* *}$ & 5,42 & 6,26 & 5,00 & 5,24 \\
\hline 200 & 5,46 & 5,49 & 5,80 & 4,29 & 3,35 & 3,31 \\
\hline & & & CORTE & & & \\
\hline 50 & $4,06^{*}$ & $3,74^{*}$ & $3,97^{*}$ & 5,41 & $4,29 * *$ & 4,71 \\
\hline 100 & $5,82 * *$ & 5,59 & 4,43 & 4,81 & 3,82 & 2,59 \\
\hline 200 & 3,92 & 4,13 & 4,20 & 3,36 & 2,45 & 2,16 \\
\hline & & & CORTE & & & \\
\hline 50 & $4,50^{*}$ & $4,34^{*}$ & $4,76^{*}$ & 6,71 & $4,22^{* *}$ & 4,61 \\
\hline 100 & 6,07 & 5,41 & 4,18 & 3,66 & 3,40 & 3,09 \\
\hline 200 & 4,04 & 3,47 & 3,59 & 2,87 & 2,63 & 2,51 \\
\hline
\end{tabular}

(STAC: super triplo antes da calagem; STDC: super triplo depois da calagem; FGAC: Fosfato de Gafsa antes da calagem; FGDC: Fosfato de Gafsa depois da calagem; FGACG: Fosfato de Gafsa antes da calagem mais gesso; FGDCG: Fosfato de Gafsa depois da calagem mais gesso).

\# Média de três repetições de cada tratamentos.

*Juntou-se as produções de MS de três repetições do tratamento para realização da análise química.

**Juntou-se as produções de MS de duas repetições do tratamento para realização da análise química. 


\section{APÊNDICE 27}

Teores de $\mathrm{P}, \mathrm{N}, \mathrm{Ca}$ e $\mathrm{Mg}\left(\mathrm{g} \mathrm{kg}^{-1}\right)$ na raiz da alfafa em função das doses de fósforo obtidos em decorrência dos diferentes tratamentos, no terceiro plantio.

\begin{tabular}{|c|c|c|c|c|c|c|}
\hline & & & tes de fó & & & 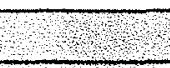 \\
\hline $\begin{array}{l}\text { Niveis de P } \\
\left(\mathrm{mg} \mathrm{dm}^{-3}\right)\end{array}$ & STAC & STDC & FGAC & FGDC & $\overline{\text { FGACG }}$ & FGDCG \\
\hline & & & $\mathrm{P}(\mathrm{g} \mathrm{kg}$ & & & 2 \\
\hline 50 & 0,48 & 0,48 & 0,46 & 0,80 & 0,68 & 0,88 \\
\hline 100 & 0,69 & 0,56 & 0,92 & 0,88 & 0,85 & 0,82 \\
\hline 200 & 0,72 & 0,57 & 1,18 & 1,27 & 0,93 & 1,25 \\
\hline & & & $\mathrm{N}(\mathrm{g} \mathrm{kg}$ & & & \\
\hline 50 & 28,98 & 31,22 & 36,26 & 28,33 & 28,56 & 15,91 \\
\hline 100 & 23,10 & 15,96 & 17,27 & 15,26 & 15,40 & 13,25 \\
\hline 200 & 15,31 & 14,47 & 15,59 & 16,29 & 15,87 & 16,75 \\
\hline & & & $\mathrm{Ca}(\mathrm{g} \mathrm{k}$ & & & \\
\hline 50 & 1,92 & 1,72 & 2,42 & 2,13 & 3,10 & 2,48 \\
\hline 100 & 1,90 & 1,65 & 2,18 & 2,12 & 2,23 & 1,95 \\
\hline 200 & 1,55 & 1,35 & 2,38 & 2,20 & 2,12 & 2,18 \\
\hline 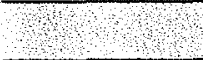 & & & $\mathrm{Mg}(\mathrm{g} \mathrm{k}$ & & & 2 \\
\hline 50 & 2,29 & 2,69 & 3,58 & 6,67 & 6,59 & 7,46 \\
\hline 100 & 8,23 & 8,59 & 6,72 & 4,60 & 5,43 & 3,74 \\
\hline 200 & 3,95 & 2,91 & 4,19 & 2,91 & 2,17 & 2,94 \\
\hline
\end{tabular}

(STAC: super triplo antes da calagem; STDC: super triplo depois da calagem; FGAC: Fosfato de Gafsa antes da calagem; FGDC: Fosfato de Gafsa depois da calagem; FGACG: Fosfato de Gafsa antes da calagem mais gesso; FGDCG: Fosfato de Gafsa depois da calagem mais gesso).

$\mathrm{P} \rightarrow \mathrm{CV}=8,3 \%$.

$\mathrm{N} \rightarrow \mathrm{CV}=19,2 \%$.

$\mathrm{Ca} \rightarrow \mathrm{CV}=23,5 \%$

$\mathrm{Mg} \rightarrow \mathrm{CV}=16,9 \%$. 